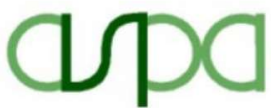

ANÀLISI I SIMULACIÓ

DE PROCESSOS AGROALIMENTARIS

\title{
Evaluation of the acid pretreatment of agroindustrial waste assisted by high-intensity ultrasound for further bioethanol production
}

\section{TESIS DOCTORAL}

Presentada por:

Tiago Carregari Polachini

Dirigida por:

Dr. Javier Telis Romero (IBILCE/UNESP - Brasil) Dr. Juan Andrés Cárcel Carrión (ASPA/UPV - España)

Universitat Politècnica de València

Departamento de Tecnología de Alimentos

Julio, 2019 
D. Juan Andrés Cárcel Carrión, Catedrático de Universidad, del Departamento de Tecnología de Alimentos de la Universitat Politècnica de València y $D$. Javier Telis Romero, Catedrático de Universidad, del Departamento de Engenharia e Tecnologia de Alimentos de la Universidade Estadual Paulista "Júlio de Mesquita Filho",

\section{HACEN CONSTAR QUE:}

El trabajo de investigación "Evaluation of the acid pretreatment of agroindustrial waste assisted by high-intensity ultrasound for further bioethanol production", que presenta D. Tiago Carregari Polachini para aspirar al doble título de Doctor en Ciencia, Tecnología y Gestión Alimentaria por parte de la Universitat Politècnica de València y Doctor en Engenharia e Ciência de Alimentos por parte de la Universidade Estadual Paulista "Júlio de Mesquita Filho", y que ha sido desarrollado bajo nuestra dirección en el Grupo de Análisis y Simulación de Procesos Agroalimentarios de la Universitat Politècnica de València y en el Instituto de Biociências, Letras e Ciências Exatas de la Universidade Estadual Paulista "Júlio de Mesquita Filho", reúne las condiciones para su aceptación como Tesis Doctoral.

Valencia, Mayo 2019

Fdo. Dr. Juan Andrés Cárcel Carrión

Fdo. Dr. Javier Telis Romero 


\section{unesp}

UNIVERSIDADE ESTADUAL PAULISTA "JÚLIO DE MESQUITA FILHO"

Câmpus de São José do Rio Preto

Tiago Carregari Polachini

Evaluation of the acid pretreatment of agroindustrial waste assisted by high-intensity ultrasound for further bioethanol production

São José do Rio Preto - SP

2019 
Tiago Carregari Polachini

Evaluation of the acid pretreatment of agroindustrial waste assisted by high-intensity ultrasound for further bioethanol production

Tese apresentada como parte dos requisitos para obtenção do título de Doutor em Engenharia e Ciência de Alimentos, junto ao Programa de PósGradução em Engenharia e Ciência de Alimentos, do Instituto de Biociências, Letras e Ciências Exatas da Universidade Estadual Paulista "Júlio de Mesquita Filho", Câmpus de São José do Rio Preto com dupla titulação em Ciencia, Tecnología y Gestión Alimentaria pela Universitat Politècnica de València.

Financiadora: CAPES (Processo número 88881.132626/2016-01)

Orientador (UNESP): Prof. Dr. Javier Telis Romero

Orientador (UPV): Prof. Dr. Juan Andrés Cárcel Carrión

Coorientador: Prof. Dr. Antonio Mulet Pons

São José do Rio Preto - SP

2019 
P762e Polachini, Tiago Carregari.

Evaluation of the acid pretreatment of agroindustrial waste assisted by high-intensity ultrasound for further bioethanol production / Tiago Carregari Polachini -- São José do Rio Preto ; Valência, 2019 $274 \mathrm{f}$. : il.

Orientador: Javier Telis Romero

Orientador: Juan Andrés Cárcel Carrión

Coorientador: Antonio Mulet Pons

Tese (doutorado com dupla titulação) - Universidade Estadual Paulista (UNESP), Instituto de Biociências, Letras e Ciências Exatas, São José do Rio Preto e Universitat Politècnica de València, Valência.

1. Engenharia de alimentos. 2. Biomassa. 3. Propriedades físicas. 4. Campos acústicos. 5. Hidrólise. 6. Cinética. I. Universidade Estadual Paulista (UNESP), Instituto de Biociências, Letras e Ciências Exatas. II. Universitat Politècnica de València. III. Título.

Ficha catalográfica elaborada pela Biblioteca do IBILCE UNESP - Câmpus de São José do Rio Preto 


\section{Tiago Carregari Polachini}

Evaluation of the acid pretreatment of agroindustrial waste assisted by high-intensity ultrasound for further bioethanol production

Tese apresentada como parte dos requisitos para obtenção do título de Doutor em Engenharia e Ciência de Alimentos, junto ao Programa de PósGradução em Engenharia e Ciência de Alimentos, do Instituto de Biociências, Letras e Ciências Exatas da Universidade Estadual Paulista "Júlio de Mesquita Filho", Câmpus de São José do Rio Preto com dupla titulação em Ciencia, Tecnología y Gestión Alimentaria pela Universitat Politècnica de València.

Financiadora: CAPES (Processo número 88881.132626/2016-01)

Comissão Examinadora

Prof. Dr. Javier Telis Romero

UNESP - São José do Rio Preto

Orientador na UNESP

Prof. Dr. Juan Andrés Cárcel Carrión UPV - Valência

Orientador na UPV

Prof. Dr. José Vicente García Pérez UPV - Valência
Prof. Dr. José Manuel Lorenzo Rodriguez

Centro Tecnolóxico de Carne - Ourense

Prof. Dr. Pedro Esteves Duarte Augusto

USP - Piracicaba

Prof. Dr. Roger Darros Barbosa

UNESP - São José do Rio Preto 


\section{ACKNOWLEDGMENTS}

This study was financed in part by the Coordenação de Aperfeiçoamento de Pessoal de Nível Superior - Brasil (CAPES) - Finance Code 001. This study was also financed by CAPES to develop part of this $\mathrm{PhD}$ thesis in Spain under the grant number 88881.132626/2016-01. Thanks to the São Paulo Research Foundation (FAPESP) (Grant number 2017/06518-2) for their financial support to develop this project.

At first, I would like to thank the Universitat Politècnica de València (UPV) and ASPA Group for hosting me during my stay in Spain and the Instituto de Biociências, Letras e Ciências Exatas (IBILCE) of the Universidade Estadual Paulista "Júlio de Mesquita Filho" (UNESP) for all what I have lived and learned there since my undergraduate course.

Moreover, a special thanks:

To my supervisor at UNESP, Prof. Javier Telis Romero, for being such a good professor and an important friend in one unique person over all of my period under his supervision. I hope to keep strengthening these bonds throughout life. In addition, thanks for making possible to get to know such kind people as my supervisor at UPV, Prof. Juan Andrés Cárcel Carrión, and Prof. Antonio Mulet Pons.

To my professors from UNESP, in special Prof. Vânia Regina Nicoletti for her professional and personal advices throughout my graduate studies.

To Prof. Juan Cárcel, my supervisor at UPV. Thanks for providing me the valuable experience to live 10 years in only one. Knowledge, friendship and unforgettable moments I will always carry with me. I hope I will be back very soon for one almuerzo. 
To Prof. Antonio Mulet, my co-supervisor, for showing me how important is to develop a good job in a healthy atmosphere. Thanks for your humbleness and for reminding us about that the simplest things are the most important.

To every one of the Group of Analysis and Simulation of Agro-food processes (ASPA) for welcoming me so well during my stay in Spain, making me feel like home. Thanks for the daily almuerzos and for the good moments we spent together. Also, an additional acknowledge to the colleagues of the Group of Microstructure and Food Chemistry (MiQuAli) for their help and friendship.

To all of my friends, who are not always physically next to me but who I can always count on to celebrate the victories and to overcome the difficulties. Life would be so empty without them.

To all of my family, in special my parents and my brother, who are the pillars of my life. They are responsible for encouraging me and for keeping me strong over my journey. My eternal gratitude to you.

To Elisa, for your love, support and for going along with me wherever we are. Thank you for beginning a family with me and for making life much more pleasant in your company. 


\section{RESUMO}

O pré-tratamento dos resíduos da agroindústria é uma das etapas mais complexas do processo de conversão da biomassa em bioetanol. Esta etapa consiste basicamente na aplicação de tratamentos físicos ou químicos à biomassa com o objetivo de hidrolizar parcialmente os carboidratos e que estes se tornem mais acessíveis para a ação subsequente de enzimas e microorganismos. Nesse sentido, o uso do ultrassom de alta intensidade tem se mostrado uma tecnologia com um potencial interessante, em combinação com métodos convencionais, para intensificar os processos de transporte de massa e energia. No presente estudo, foram caracterizados alguns resíduos agroindustriais, especificamente bagaço de mandioca, cascas de amendoim e resíduos de alcachofra como exemplos de materiais potenciais para a produção de bioetanol após pré-tratamentos ácidos com e sem a aplicação de ultrassom. Assim, os diferentes sistemas de soluções de biomassa/ácido foram caracterizados de acordo com suas propriedades termofísicas (densidade, calor específico, difusividade térmica e condutividade térmica) e comportamento reológico. Além disso, o campo acústico gerado em cada um dos diferentes sistemas foi caracterizado por um método calorimétrico, sendo estabelecidas relações entre as medidas acústicas e as propriedades termofísicas e reológicas. Posteriormente, determinou-se a cinética de liberação de açúcares redutores e totais e as mudanças estruturais produzidas nas suspensões consideradas durante os pré-tratamentos em soluções ácidas, feitos com agitação convencional ou assistidos por ultrassom. Os resultados obtidos indicaram que as suspensões com alta concentração de ácido e alto teor de sólidos apresentaram menor capacidade de transferência de calor, devido aos maiores valores de calor específico, difusividade térmica, condutividade térmica. Essas mesmas suspensões também apresentaram maiores valores de densidade e viscosidade, o que indica maior resistência ao escoamento. Isto é atribuído, não apenas à alta viscosidade, mas também ao aparecimento de um comportamento reológico não-Newtoniano, como observado a partir do ajuste do modelo de Herschel-Bulkley. Assim, em suspensões de casca de amendoim ou bagaço de mandioca com concentrações de sólidos de $8 \%$ e $6 \%$, respectivamente, foram observados considerável tensão 
residual e comportamento pseudoplástico. A temperatura também teve um efeito significativo nas propriedades termofísicas. Embora o efeito fosse menos intenso, o aumento da temperatura facilitou a transferência de calor e quantidade de movimento. Ao aumentar as concentrações de sólidos e ácido nas suspensões, também foi observada uma redução na intensidade acústica gerada durante a sonicação. O mesmo aconteceu quando as medições de temperatura foram feitas em pontos mais distantes da ponta da sonda, indicando a atenuação da energia acústica dentro das suspensões. A eficiência de conversão de energia elétrica em energia acústica foi aumentada pelo aumento da potência nominal e/ou pela redução na concentração de sólidos e ácido, enquanto que o fator de atenuação da intensidade acústica foi constante em $0,021 \mathrm{~cm}^{-1} \mathrm{em}$ todas as condições estudadas. Os dados de intensidade acústica correlacionaram-se bem com propriedades físicas previamente determinadas, apresentando altos coeficientes de correlação. Assim, na mesma potência nominal, a intensidade acústica aumentou em suspensões com baixa densidade e viscosidade. Por outro lado, maiores intensidades foram observadas nas suspensões com maior calor específico, difusividade térmica e condutividade térmica. A aplicação de ultrassom foi mais eficiente para acelerar o processo de dissolução de açúcares em meio aquoso do que o processo convencional de agitação. Além disso, o ultrassom foi eficiente para hidrolisar a biomassa sob condições de ácido e temperatura mais amenas do que as convencionalmente utilizadas, principalmente no caso de suspensões mais diluídas em sólidos. Isso pôde ser observado tanto pelos dados experimentais de produção de açúcares redutores e totais quanto pelo ajuste do modelo de Naik. Por outro lado, foram observados efeitos maiores na microestrutura da biomassa (fibras e grânulos de amido) e no comportamento reológico (maior viscosidade) das suspensões prétratadas na presença de ultrassom. O campo acústico produzido nas suspensões sofreu uma redução durante a hidrólise, possivelmente devido às referidas alterações. Assim, pode-se concluir que o ultrassom de alta intensidade é uma tecnologia interessante para intensificar os pré-tratamentos de resíduos da agroindústria para a produção de bioetanol.

Palavras-chave: Biomassa. Propriedades físicas. Campos acústicos. Hidrólise. Cinética. 


\begin{abstract}
The pre-treatment of agroindustrial wastes is one of the most complex steps of their conversion process into bioethanol. This step consists basically of applying physical or chemical treatments in biomass in order to obtain carbohydrates partially hydrolyzed and more accessible for future action of enzymes and microorganisms. In this sense, the use of high-intensity ultrasound has been shown as a technology with an interesting potential, in combination with conventional methods, to enhance the mass and energy transfer processes. In the present study, it was characterized agroindustrial residues such as cassava bagasse, peanut shells and artichoke residues as potential materials for the production of bioethanol after acid pretreatment with and without the application of ultrasound. Thus, the different biomass/acid solutions systems were characterized according to their thermophysical properties (density, specific heat, thermal diffusivity and thermal conductivity) and rheological behavior. The acoustic fields generated in these different systems during ultrasound application were also characterized by a calorimetric method. Then, the ultrasonic intensity obtained in each case was related to the termophysical and reological properties. Subsequently, the kinetics of reducing and total sugar release and the structural changes produced in the suspensions considered during the pretreatments in acid solutions with conventional agitation or assisted by ultrasound were determined. The results obtained indicated that suspensions with higher acid concentration and higher solids content showed lower heat transfer capacity, given by the higher values for specific heat, thermal diffusivity, thermal conductivity. The same suspensions presented higher values of density and viscosity, which leads to greater resistance to flow. This fact was attributed, not only to the high viscosity, but also to the appearance of non-Newtonian rheological behavior as showed by the fitting of Herschel-Bulkley model. In these cases, the suspensions containing peanut shells or cassava bagasse showed noticeable yield stress and shear-thinning behavior above solids concentration of $8 \%$ and $6 \%$, respectively. Temperature also had a significant effect on thermophysical properties. Although the effect was less intense than the other variables, the increase in temperature made easier the heat and momentum transfer. The increase of solids and acid concentration in the
\end{abstract}


suspensions produced a reduction of the acoustic intensity generated during sonication. The same fact was observed when the distance from the probe where measurements were taken increased, indicating the occurrence of attenuation of acoustic energy. The conversion yield of electrical energy into acoustic energy could be improved by increasing the nominal power and/or reducing the concentration of solids and acid, while the attenuation factor of the acoustic intensity remained constant at $0.021 \mathrm{~cm}^{-1}$ for the conditions studied. The acoustic intensity data correlated well with the physical properties previously determined, as showed the high correlation coefficients obtained. At the same acoustic power, the acoustic intensity was increased in suspensions with low density and viscosity. On the other hand, higher acoustic intensities were found for suspensions with higher specific heat, thermal diffusivity and thermal conductivity. The ultrasound application was efficient to accelerate the sugar dissolution process in aqueous medium when compared to the conventional agitation. In addition, the ultrasound was efficient for hydrolyzing the biomass under milder conditions of acid and temperature than those conventionally used, mainly in the case of the diluted suspensions in solids studied. This could be observed both by the reducing and total sugar release experimental data as well as by the fitting of the Naik model. On the other hand, greater effects were observed in the biomass microstructure (fibers and granules of starch) and in the rheological behavior (higher viscosity) of the suspensions pretreated in the presence of ultrasound. The acoustic field produced in the suspensions was reduced throughout the hydrolysis, possibly due to such changes. Thus, it can be concluded that ultrasound is an interesting technology to enhance the pre-treatments of agroindustrial waste and, later, in the processes of bioethanol production.

Keywords: Biomass. Physical properties. Acoustic fields. Hydrolysis. Kinetics. 


\section{RESUMEN}

El pre-tratamiento de los residuos de la agroindustria es una de las etapas más complejas del proceso de conversión de biomasa en bioetanol. Esta etapa consiste basicamente en aplicar tratamientos físicos o químicos a la biomasa con el objetivo de conseguir la hidrolización parcial de los carbohidratos y que ésos se vuelvan más acesibles para la posterior actuación de enzimas y microrganismos. En este sentido, el uso de ultrasonidos de alta intensidad se ha mostrado como una tecnología con un potencial interesante para, en combinación con métodos convencionales, intensificar los procesos de transporte de materia y energía. En el presente estudio se caracterizaron algunos residuos agroindustriales, concretamente el bagazo de yuca, cáscaras de cacahuetes y residuos de alcachofa, como ejemplos de materias potenciales para la producción de bioetanol después del pre-tratamiento ácido, con y sin la aplicación de ultrasonidos. Así, se caracterizaron los diferentes sistemas biomasa/soluciones ácidas de acuerdo con sus propiedades termofísicas (densidad, calor específico, difusividad térmica y conductividad térmica) y comportamiento reológico. Además, se caracterizó el campo acústico generado en cada uno de los diferentes sistemas mediante un método calorimétrico y se establecieron relaciones entre las medidas acústicas y las propiedades termofísicas y reológicas. Posteriormente, se determinaron las cinéticas de liberación de azúcares reductores y totales y los cambios estructurales producidos en las suspensiones consideradas durante los pretratamientos en disoluciones ácidas, realizados con agitación convencional o asistidos por ultrasonidos. Los resultados obtenidos indicaron que las suspensiones con alta concentración de ácido y alto contenido de sólidos presentaron una menor capacidad de transferencia de calor, debido a los valores más altos de calor específico, difusividad térmica, conductividad térmica. Estas mismas suspensiones presentaron también valores más altos de densidad y viscosidad, lo que indica una mayor resistencia al flujo. Esto se atribuye, no solo a la alta viscosidad, sino también a la aparición de un comportamiento reológico noNewtoniano, como se observó a partir del ajuste del modelo de Herschel-Bulkley. Así, en suspensiones de cáscaras de cachuetes o de bagazo de yuca con concentraciones de sólidos de $8 \%$ y $6 \%$, respectivamente, se observó una tensión 
residual considerable y un comportamiento pseudoplástico. La temperatura también presentó un efecto significativo en las propiedades termofísicas. Aunque el efecto fue menos intenso, el incremento de temperatura facilitó la transferencia de calor y de cantidad de movimiento. Al aumentar las concentraciones de sólidos y ácido en las suspensiones, también se observó una reducción de la intensidad acústica generada durante la sonicación. Lo mismo pasó al realizar las mediciones de temperatura en puntos más lejanos de la punta de la sonda, indicando la atenuación de la energía acústica en el seno de las suspensiones. La eficiencia de conversión de energía eléctrica en energía acústica se incrementó por el aumento de la potencia nominal y/o la redución en la concentración de sólidos y ácido, mientras, el factor de atenuación de la intensidad acústica se mostró constante en $0.021 \mathrm{~cm}^{-1}$ en todas las condiciones estudiadas. Los datos de intensidad acústica se relacionaron bien con las propiedades físicas previamente determinadas presentado elevados coeficientes de correlación. Así, a una misma potencia nominal, la intensidad acústica aumentó en suspensiones con baja densidad y viscosidad. Por otra parte, se observaron mayores intensidades en suspensiones con mayor calor específico, difusividad térmica y conductividad térmica. La aplicación de ultrasonidos resultó más eficiente para acelerar el proceso de disolución de azúcares en medio acuoso que al proceso de agitación convencional. Además, los ultrasonidos fueron eficientes para hidrolizar la biomasa en condiciones de ácido y temperatura más suaves que las que se utilizan convencionalmente, principalmente en el caso de las suspensiones más diluidas en sólidos. Esto se pudo observar tanto por los datos experimentales de producción de azúcares reductores y totales como a través del ajuste del modelo de Naik. Por otra parte, se observaron mayores efectos secundarios en la microestructura de la biomasa (fibras y gránulos de almidón) y en el comportamiento reológico (mayor viscosidad) de las suspensiones pretratadas en presencia de los ultrasonidos. El campo acústico producido en las suspensiones sufrió una reducción a lo largo de las hidrólisis, posiblemente debido a dichos cambios. Así, se puede concluir que los ultrasonidos son una tecnología interesante para intensificar los pre-tratamientos de residuos provenientes de la agroindustria para la producción de bioetanol. 
Palabras claves: Biomasa. Propiedades físicas. Campos acústicos. Hidrólisis. Cinética. 


\section{RESUM}

El pretractament dels residus de l'agroindústria és una de les etapes més complexes del procés de conversió de biomassa a bioetanol. Aquesta etapa consisteix bàsicament en aplicar tractaments físics o químics a la biomassa per a conseguir que els carbohidrats siguin parcialment hidrolisats i siguen més accessibles per a la posterior actuació d'enzims i microorganismes. En aquest sentit, l'ús d'ultrasons d'alta intensitat s'ha mostrat com una tecnologia amb un potencial interessant per a, en combinació amb mètodes convencionals, intensificar els processos de transport de matèria i energia. En el present estudi, es van caracteritzar residus agroindustrials com el bagàs de iuca, corfes de cacauets i residus de carxofa com a matèries potencials per a la producció de bioetanol després del pretractament àcid, amb i sense l'aplicació d'ultrasons. Així, es van caracteritzar els diferents sistemes biomassa/solucions àcides d'acord amb les seves propietats termofísiques (densitat, calor específica, difusivitat tèrmica i conductivitat tèrmica) i comportament reològic. $A$ més, es va caracteritzar el camp acústic generat en cada un dels diferents sistemes mitjançant un mètode calorimètric $\mathrm{i}$ es van establir relacions entre les mesures acústiques i les propietats termofísiques i reològiques. Posteriorment, es van determinar les cinètiques d'alliberament de sucres reductors $\mathrm{i}$ totals $\mathrm{i}$ els canvis estructurals produïts en les suspensions considerades durant els pretractaments en dissolucions àcides realitzats amb agitació convencional o assistits per ultrasons. Els resultats obtinguts van indicar que les suspensions amb alta concentració d'àcid i alt contingut de sòlids van presentar una menor capacitat de transferència de calor, donada per valors més alts per calor específica, difusivitat tèrmica, conductivitat tèrmica. Les mateixes suspensions van presentar valors més alts de densitat $\mathrm{i}$ viscositat, el que indica una major resistència al flux. Això es pot atribuir, no només a l'alta viscositat, però també a l'aparició de un comportament reològic no-newtonià, com es va observar a partir de l'ajust del model de Herschel-Bulkley. Aixi, en suspensions de corfes de cacauets o bagàs de yuca amb concentracions de sòlids de $8 \%$ i $6 \%$, respectivament, es va observar una tensió residual considerable i un comportament pseudoplàstic. La temperatura també va presentar un efecte significatiu en les propietats termofísiques. Encara que l'efecte sigui menys intens, 
l'increment de temperatura va facilitar la transferència de calor i de quantitat de moviment. En augmentar les concentracions de sòlids i àcid, també es va observar una reducció de la intensitat acústica generada en les suspensions durant la sonicació. El mateix es va passar al realitzar els mesuraments en punts més llunyans de la sonda, indicant l'atenuació d'energia acústica. L'eficiència de conversió d'energia elèctrica en energia acústica va poder ser millorada per l'augment de la potència nominal i/o redución en la concentració de sòlids i àcid, mentre el factor d'atenuació de la intensitat acústica es va mostrar constant en 0.021 $\mathrm{cm}^{-1}$ en les condicions estudiades. Les dades d'intensitat acústica es van relacionar bé amb les propietats físiques prèviament determinades amb alts coeficients de correlació. A una mateixa potència nominal, la intensitat acústica es va augmentar en suspensions amb baixa densitat i viscositat. D'altra banda, es van observar majors intensitats en suspensions amb més calor específica, difusivitat tèrmica $i$ conductivitat tèrmica. L'aplicación d'ultrasons van reultar més eficient per accelerar el procés de dissolució de sucres en medi aquós que el procés d'agitació convencional. A més, els ultrasons van ser eficients per hidrolitzar la biomassa en condicions d'àcid $i$ temperatura més suaus que els utilitzats convencionalment, principalment en el cas de les suspensions més diluïdes en sòlids. Això es va poder observar tant per les dades experimentals de producció de sucres reductors i totals com a través de la modelització amb model de Naik. D'altra banda, es van observar majors efectes secundaris en la microestructura de la biomassa (fibres i grànuls de midó) i en el comportament reològic (major viscositat) en les suspensions pretractades en presència dels ultrasons. El camp acústic produït en les suspensions va patir una reducció al llarg de les hidròlisi, possiblement a causa d'aquests canvis. Així, es pot concloure que els ultrasons són una tecnologia interessant per intensificar els pre-tractaments de residus provinents de l'agroindústria per a la producció de bioetanol.

Paraules clau: Biomassa. Propietats físiques. Camps acústics. Hidròlisi. Cinètica. 


\section{FIGURE LIST}

Figure 1.1. Biofuels classification. Source: Adapted from Nigam and Singh (2011).

Figure 1.2. Simplified flowchart of starch and cassava bagasse production. $\quad 30$

Figure 1.3. Pretreatment effect on the lignocellulose. Source: Mood et al. (2013).

Figure 4.1. Working plan.

Figure 5.1.1 Density values as a function of (a) solids concentration; (b) acid concentration and (c) absolute temperature.

Figure 5.1.2. Specific heat values as a function of (a) solids concentration; (b) acid concentration and (c) absolute temperature.

Figure 5.1.3. Thermal diffusivity values as a function of (a) solids concentration; (b) acid concentration and (c) absolute 76 temperature.

Figure 5.1.4. Thermal conductivity values as a function of (a) solids concentration; (b) acid concentration and (c) absolute 79 temperature.

Figure 5.2.1. (a) Number-based and (b) volume-based particle size distributions for powdered cassava bagasse.

96

Figure 5.2.2. Optical microscopic images at $4 x, 10 x$ and $40 x$ magnification for (a) cassava bagasse and for (b) cassava bagasse dyed with lugol at $40 x$ of magnification.

Figure 5.2.3. Distribution of the aspect ratio $\left(a_{r}\right)$ values for powdered cassava bagasse particles.

Figure 5.2.4. Rheograms of the acid suspensions containing cassava bagasse fitted to Herschel-Bulkley model. (a) $X_{A}=6 \%$ at $T=298.13 \mathrm{~K}$; (b) $X_{S}=6 \%$ at $T=298.13 \mathrm{~K}$; and (c) $X_{S}=6 \%$ and $X_{A}=6 \%$.

Figure 5.2.5. (a) Yield stress $\left(T_{0}\right)$, (b) consistency coefficient $(k)$, (c) flow behavior index $(n)$ and (d) apparent viscosity $\left(\eta_{a p p, 10 s^{-1}}\right)$ as functions of cassava bagasse concentration at different acid concentrations and temperatures.

Figure 5.2.6. (a) Yield stress $\left(T_{0}\right)$, (b) consistency coefficient $(k)$, (c) flow behavior index $(n)$ and $(d)$ apparent viscosity $\left(\eta_{a p p, 10 s^{-1}}\right)$ as 
functions of phosphoric acid concentration at different solids concentrations and temperatures.

Figure 5.2.7. (a) Yield stress $\left(I_{0}\right)$, (b) consistency coefficient ( $k$ ), (c) flow behavior index $(n)$ and $(\mathrm{d})$ apparent viscosity $\left(\eta_{a p p, 10 s^{-1}}\right)$ as functions of absolute temperature at different acid and solids 106 concentrations.

Figure 5.3.1. Zeta potential of suspensions of powdered peanut shell (PPS) at different $\mathrm{pH}$ values.

Figure 5.3.2. Particles size distribution based on (a) volume and (b) number of particles.

Figure 5.3.3. Optical microscopy of PPS at different magnifications: a) 10x; b) 40x and c, d and e) 100x.

Figure 5.3.4. Apparent viscosity (at $10 \mathrm{~s}^{-1}$ ) as function of solids content (\%) and temperature $\left({ }^{\circ} \mathrm{C}\right)$.

Figure 5.3.5. Initial yield stress (a), consistency coefficient (b) and flow behavior index (c) dependence on temperature $\left({ }^{\circ} \mathrm{C}\right)$ and solids content (\%) at $\mathrm{pH} 5.0$.

Figure 5.3.6. Relative viscosity as function of PPS concentration at $\mathrm{pH} 5.0$.

Figure 5.3.7. $\quad$ Fitted surface of density values at $\mathrm{pH} 5.0$ (left) and predicted values from the polynomial model versus the observed ones (right).

Figure 5.4.1. Set-up used for the measurements of the acoustic field produced on acid suspensions of cassava bagasse.

Figure 5.4.2. Heating rate as affected by $\mathrm{pH}$ at different (a) solids concentration $\left(P_{\mathrm{N}}=400 \mathrm{~W}\right.$ and $\left.d=1.5 \mathrm{~cm}\right)$, (b) nominal input power $\left(X_{S}=6 \%\right.$ and $\left.d=1.5 \mathrm{~cm}\right)$ and (c) distances from the sonotrode $\left(X_{\mathrm{S}}=6 \%\right.$ and $\left.P_{\mathrm{N}}=400 \mathrm{~W}\right)$.

Figure 5.4.3. Acoustic intensity $I\left(\mathrm{~W} \cdot \mathrm{cm}^{-2}\right)$ as affected by the nominal input power (a) in suspensions with different solids content $(d=1.5$ $\mathrm{cm})$ and $(\mathrm{b})$ at different distances from the sonotrode $\left(X_{S}=6 \%\right)$.

Figure 5.4.4. Acoustic intensity $I\left(\mathrm{~W} \cdot \mathrm{cm}^{-2}\right)$ as affected by solids concentration (a) under different nominal input power $(d=1.5 \mathrm{~cm})$ and $(\mathrm{b})$ at different distances from the sonotrode $\left(P_{\mathrm{N}}=400 \mathrm{~W}\right)$.

Figure 5.4.5. Acoustic intensity $I\left(\mathrm{~W} \cdot \mathrm{cm}^{-2}\right)$ as affected by the distance from the sonotrode at different (a) solids concentration $\left(P_{\mathrm{N}}=400 \mathrm{~W}\right)$ and (b) nominal input power $\left(X_{S}=6 \%\right)$; data are fitted to the 
Equation (5.4.5).

Figure 5.4.6. Yield of power conversion measured at the point of maximum cavitation $(d=1.5 \mathrm{~cm})$ as a function of (a) nominal input power and (b) solids concentration.

Figure 5.4.7. Acoustic intensity $(I)$ as a function of (a) density, (b) specific heat, (c) thermal diffusivity, (d) thermal conductivity and (e) apparent viscosity of the suspensions under different nominal 159 input power $\left(P_{\mathrm{N}}\right)$.

Figure 5.5.1. System used in ultrasonic experiments for acoustic fields measurements.

Figure 5.5.2. Representation of specific heat values fitted to Equation (5.5.8).

Figure 5.5.3. Temperature gradient along the time as a function of the biomass concentration $(X, \%)$, nominal power output of ultrasound $(U, W)$ for all $\mathrm{pH}$ values.

Figure 5.5.4. Power transmitted $(P)$ and acoustic intensity $(I)$ as function of nominal power applied $(U)$ and biomass concentration $(X)$. Properties were determined in a distance of $2 \mathrm{~cm}$ from sonotrode.

Figure 5.5.5. Power yield as function of biomass concentration $(X)$ and nominal power applied $(\mathrm{W})$.

Figure 5.6.1. Scheme of the set-up used in ultrasound-assisted experiments.

Figure 5.6.2. Geometrical characteristics (distances showed in $\mathrm{cm}$ ) of the agitation system with the corresponding shape factors.

Figure 5.6.3. Extraction kinetics with water of reducing and total sugar release from AW. Experiments carried out with conventional agitation (B5AG0).

Figure 5.6.4. Kinetics of (a) reducing sugar and (b) total sugar release fitted to Naik model for the experiments B5AG0 and B5US0.

Figure 5.6.5. Kinetics of (a) reducing sugar and (b) total sugar release fitted to Naik model for the experiments B5AG10-A and B5US10-A.

Figure 5.6.6. Kinetics of (a) reducing sugar and (b) total sugar release fitted to Naik model for the experiments B2.5AG10-A and B2.5US10A.

Figure 5.6.7. Kinetics of (a) reducing sugar and (b) total sugar release fitted to Naik model for the experiments B5AG10 and B5US10. 
Figure 5.7.1. Set-up used in the experiments under conventional agitation. 218

Figure 5.7.2. Scheme of the set-up used in the ultrasound-assisted hydrolysis.

Figure 5.7.3. Relative release of total and reducing sugar concentration over the agitation of cassava bagasse in aqueous medium.

Figure 5.7.4. Relative production of (a) reducing and (b) total sugars during the acid hydrolysis of cassava bagasse (CB) assisted by 224 conventional agitation (CA) or by ultrasound application (US).

Figure 5.7.5. Light field micrographs of cassava bagasse (stained with toluidine blue $0.1 \%$ ) before and after acid treatment under 229 conventional agitation or assisted by high-intensity ultrasound.

Figure 5.7.6. Visible (left), fluorescence (middle) and polarized light (right) micrographs at 20x of magnitude of cassava bagasse before and after acid treatments under conventional agitation or by high-intensity ultrasound. 


\section{TABLE LIST}

Table 5.1.1. Chemical composition of cassava bagasse.

Table 5.1.2. Means and standard deviations of density measurements.

Table 5.1.3. Fitting parameters ( $\pm 95 \%$ of confidence) of the empirical equations to predict density $(\rho)$, specific heat $\left(c_{p}\right)$, thermal diffusivity $(\alpha)$ and thermal conductivity $(\lambda)$ as function of cassava bagasse fraction in the slurries $\left(w_{S}\right)$, phosphoric acid in the solution $\left(w_{A}\right)$ and absolute temperature $(T / K)$.

Table 5.1.4. Means and standard deviations of specific heat measurements. 71

Table 5.1.5. Means and standard deviations of thermal diffusivity measurements.

74

Table 5.1.6. Means and standard deviations of thermal conductivity values. 78

Table 5.2.1. Chemical composition of the powdered cassava bagasse. 94

Table 5.2.2. Parameters of number-based and volume-based particle size distributions for powdered cassava bagasse.

Table 5.2.3. Fitting parameters of Herschel-Bulkley model for acid suspensions at intermediate conditions.

Table 5.2.4. Fitting parameters of an Arrhenius-type equation for apparent viscosity $\left(\eta_{a p p, 10 s^{-1}}\right)$.

Table 5.3.1. Viscosity validation using chlorobenzene as standard substance.

Table 5.3.2. Chemical composition of peanut shells.

Table 5.3.3. Fitting parameters of Herschel-Bulkley equation for some suspensions.

Table 5.3.4. Means and standard deviation of Herschel-Bulkley parameters for the runs in triplicate at 2 and $12 \%$ of solids.

Table 5.3.5. Density of acidic PPS suspensions at different temperature $\left({ }^{\circ} \mathrm{C}\right)$ and concentration of biomass (\%).

Table 5.4.1. Fitted values for $I_{0}$ and $\alpha$ at different input power and cassava bagasse concentrations.

Table 5.4.2. Fitting parameters of the Equation (5.4.6) for heating rate $(\mathrm{d} T / \mathrm{d} t)$ acoustic power $(P)$, acoustic intensity $(I)$, acoustic 
density $(D)$, acoustic power per mass of particles $\left(D_{p}\right)$ and yield of power conversion.

Table 5.4.3. Parameters of Pearson correlations between acoustic intensity and each physical property in the different nominal input power at the closest position to the sonotrode.

Table 5.5.1. Specific heat values at different solids concentration, temperature and $\mathrm{pH}$.

Table 5.5.2. Fitting parameters of different models for specific heat $\left(\mathrm{J} \cdot \mathrm{kg} \cdot \mathrm{K}^{-}\right.$ $\left.{ }^{1}\right)$.

Table 5.5.3. Fitting results and statistical validation of acoustic power $(P)$ and acoustic intensity $(I)$ by ASPPS.

Table 5.5.4. Statistical and fitting parameters to represent power yield (\%).

Table 5.6.1. Conditions of the total set of experiments.

Table 5.6.2. Kinetics parameters of adapted Naik model for the different treatments tested: extraction of soluble sugars with water (WE); hydrolysis in acid suspensions (HY) and simulation of industrial hydrolysis (IHY).

Table 5.6.3. Viscosity of the AW acid suspensions before and after HY treatments carried out with agitation (AG) or with ultrasound (US) application.

Table 5.6.4. Acoustic density measured in 5 and $2.5 \%\left(w \cdot w^{-1}\right)$ AW suspensions before and after $1 \mathrm{~h}$ of $\mathrm{HY}$ treatment.

Table 5.7.1. Fitting parameters of Naik model for the different treatments.

Table 5.7.2. Apparent viscosity for the acid suspensions before and after acid hydrolysis.

Table 5.7.3. Acoustic parameters obtained from the acoustic fields' determinations. 


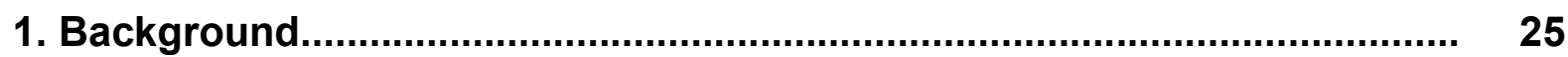

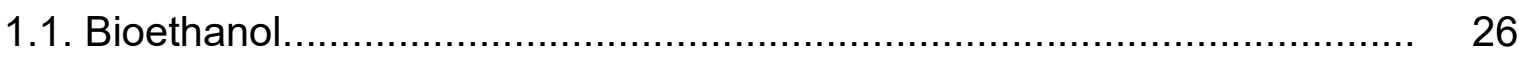

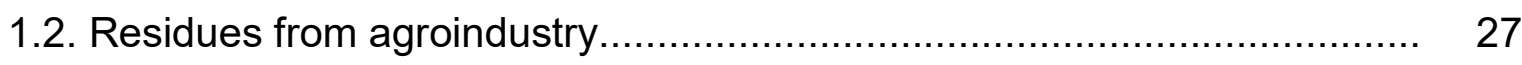

1.2.1. Chemical composition............................................................. 28

1.2.2. Cassava bagasse .................................................................. 29

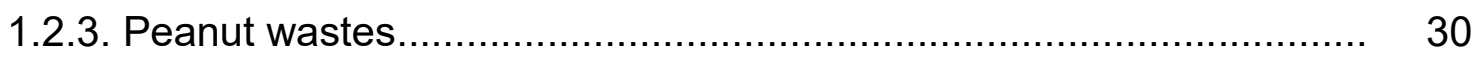

1.2.4. Artichoke wastes.................................................................... $\quad 31$

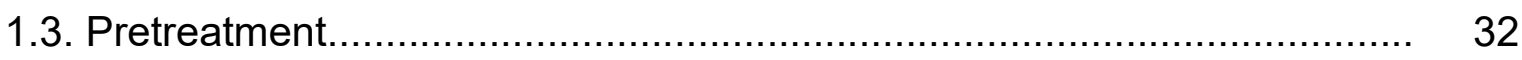

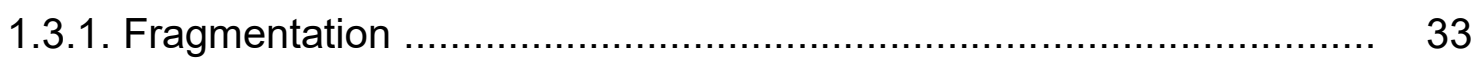

1.3.2. Steam explosion.................................................................... 33

1.3.3. Liquid hot water treatment.......................................................... 34

1.3.4 Supercritical $\mathrm{CO}_{2}$ pretreatment................................................. 34

1.3.5. Microwave irradiation................................................................... 35

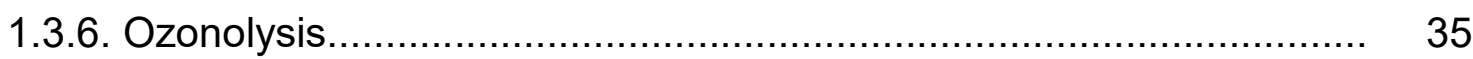

1.3.7. Alkaline pretreatment.............................................................. 35

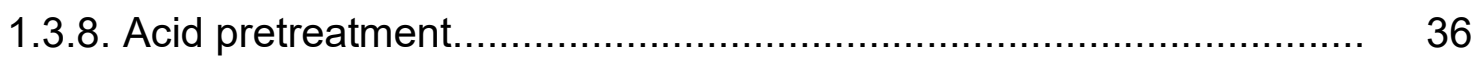

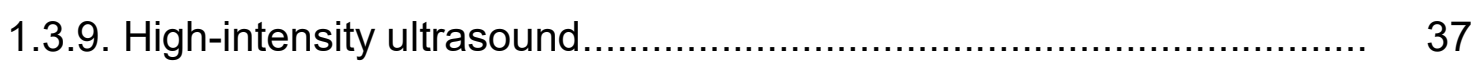

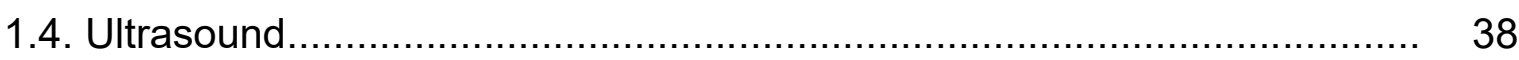

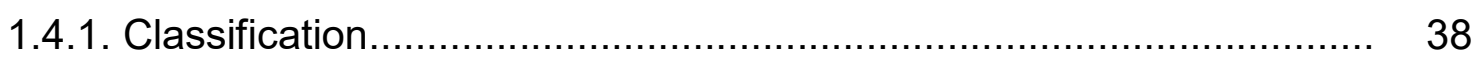

1.4.2. Actuating mechanisms............................................................ 39

1.4.3. Acoustic field characterization.................................................... 40

1.5. Ultrasound-assisted pretreatments.................................................. 42

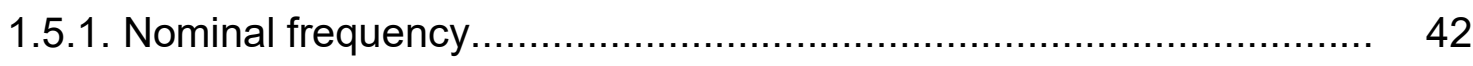

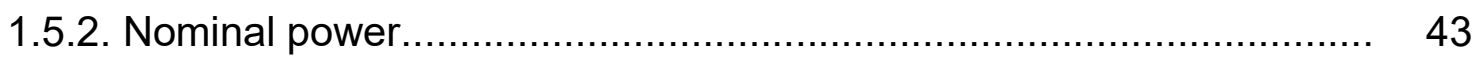

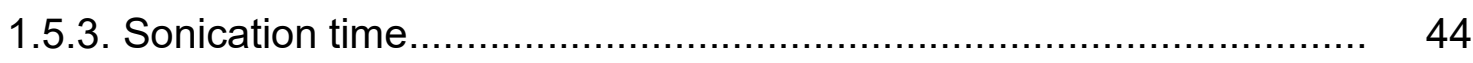

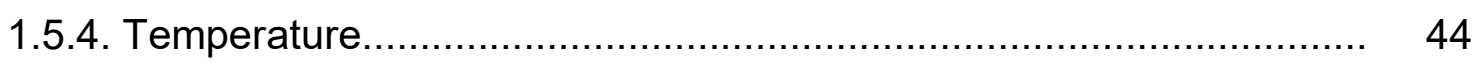

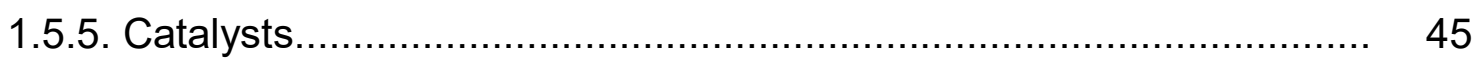

1.5.6. Suspensions properties........................................................... 46

2. Conclusion of the introduction......................................................... 48

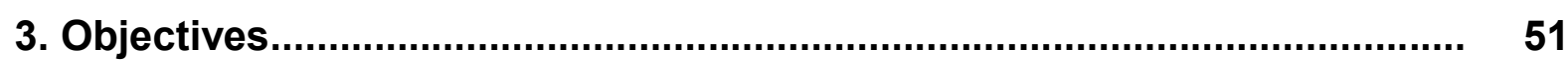

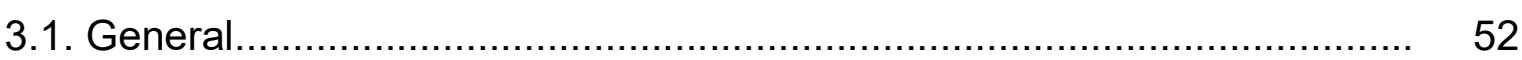




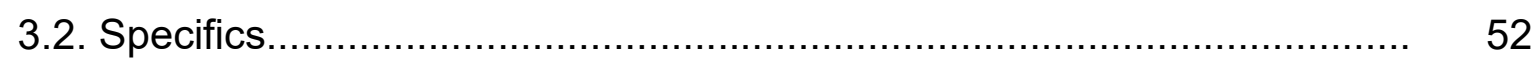

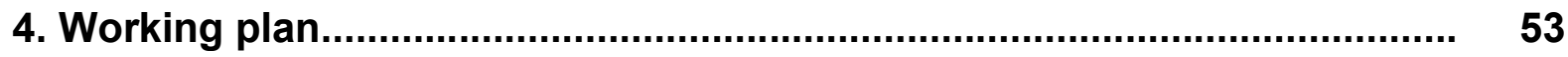

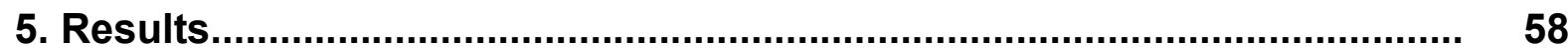

5.1. Chapter 1 - Thermophysical properties of acid suspensions of cassava 59 bagasse

5.2. Chapter 2 - Rheology of acid suspensions containing cassava bagasse. $\quad 85$

5.3. Chapter 3 - Rheology of peanut waste suspensions .......................... 114

5.4. Chapter 4 - Acoustic fields in suspensions containing cassava bagasse. 141

5.5. Chapter 5 - Acoustic fields in peanut waste suspensions...................... 165

5.6. Chapter 6 - Kinects of sugar release from artichoke waste.................... 185

5.7. Chapter 7 - Kinetics of sugar release from cassava bagasse................. 212

6. General discussion.............................................................................. 237

7. General conclusion....................................................................... 244

7.1. Thermophysical properties of cassava bagasse suspensions.................. 245

7.2. Rheological behavior of cassava bagasse suspensions.......................... 245

7.3. Rheological behavior of peanut waste suspensions............................... 246

7.4. Acoustic fields in cassava bagasse suspensions................................... 246

7.5. Acoustic fields in peanut waste suspensions....................................... 247

7.6. Kinetics of sugar release from artichoke waste................................... 247

7.7. Kinetics of sugar release from cassava bagasse ................................. 248

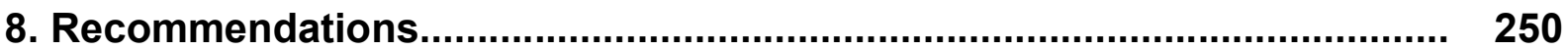

9. Scientific contributions...................................................................... 252

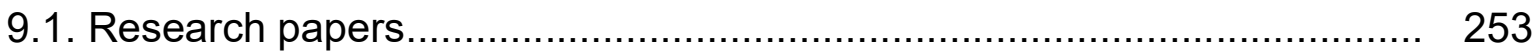

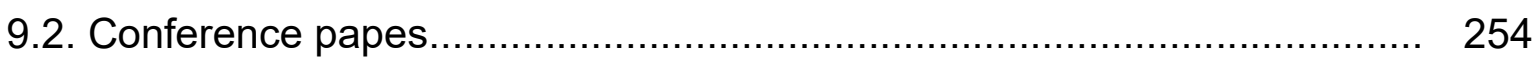

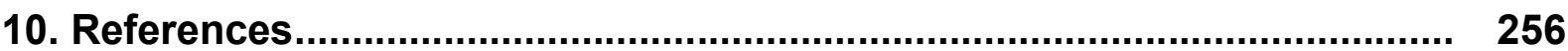


1. Background 


\subsection{Bioethanol}

The fossil fuels are responsible by the supply of approximately $80 \%$ growing energetic demand made of the world, being the majority destinated to the transport sector (Escobar et al., 2009). However, the incessant and non-sustainable use of such sources is provoking not only its exhaustion but mainly significant damages to the environment by the greenhouse gases emission (Gullison et al., 2007).

Studies have been developed looking for alternative sources in order to produce biofuels from renewable matter. In this sense, the so called biofuel has shown as one of the most important alternative to ensure the economic and environmental sustainability highlighting its high availability, the relative low cost and the no net $\mathrm{CO}_{2}$ emission when compared to fossil fuels (Singh et al., 2010). Biofuel term includes the liquid, gaseous or solid fuels obtained from biomass. Some examples of these are ethanol, methanol, charcoal, biodiesel, hydrogen and metane (Demirbas, 2008). According to Figure 1.1, these products can be classified as primary or secondary biofuels. The primary ones, as wood waste, landifill gases or pellets, are incinerated directly without any modification in order to produce heat and electricity. On the contrary, the secondary biofuels are obtained from the biomass processing by means of hydrolysis, transesterification and fermentation to produce charcoal, biogas, biodiesel or bioethanol.

Ethanol, specifically, is considered as one of the most viable biofuels to replace fossil fuels (Nigam and Singh, 2011). It can be produced by the fermentation of the sugars contained in, e. g., sugarcane, maize, potato or cassava crops (Rehman et al., 2013). These crops are rich in easily fermented carbohydrates and the obtention of bioethanol from these sources is relative easy. However, these crops are mainly used for human feeding and its use for fuel production can prevent their access for vulnerable populations.

Because of that, second generation bioethanol appeared to minimize this competition by using other alternative raw materials rich in carbohydrates such as lignocellulosic biomass. This second generation bioethanol is obtained from a biomass conversion process that consists of 4 main steps: pretreatment, hydrolysis, sugar fermentation and the resulting ethanol distillation. As the last two steps are usually applied in the fisrt generation ethanol industry, pretreatment and hydrolysis 
should be enhanced to make viable the productive chain. An efficient pretreatment of the biomass could significantly increase the hydrolysis yield, besides a sustainable use of the industrial waste.

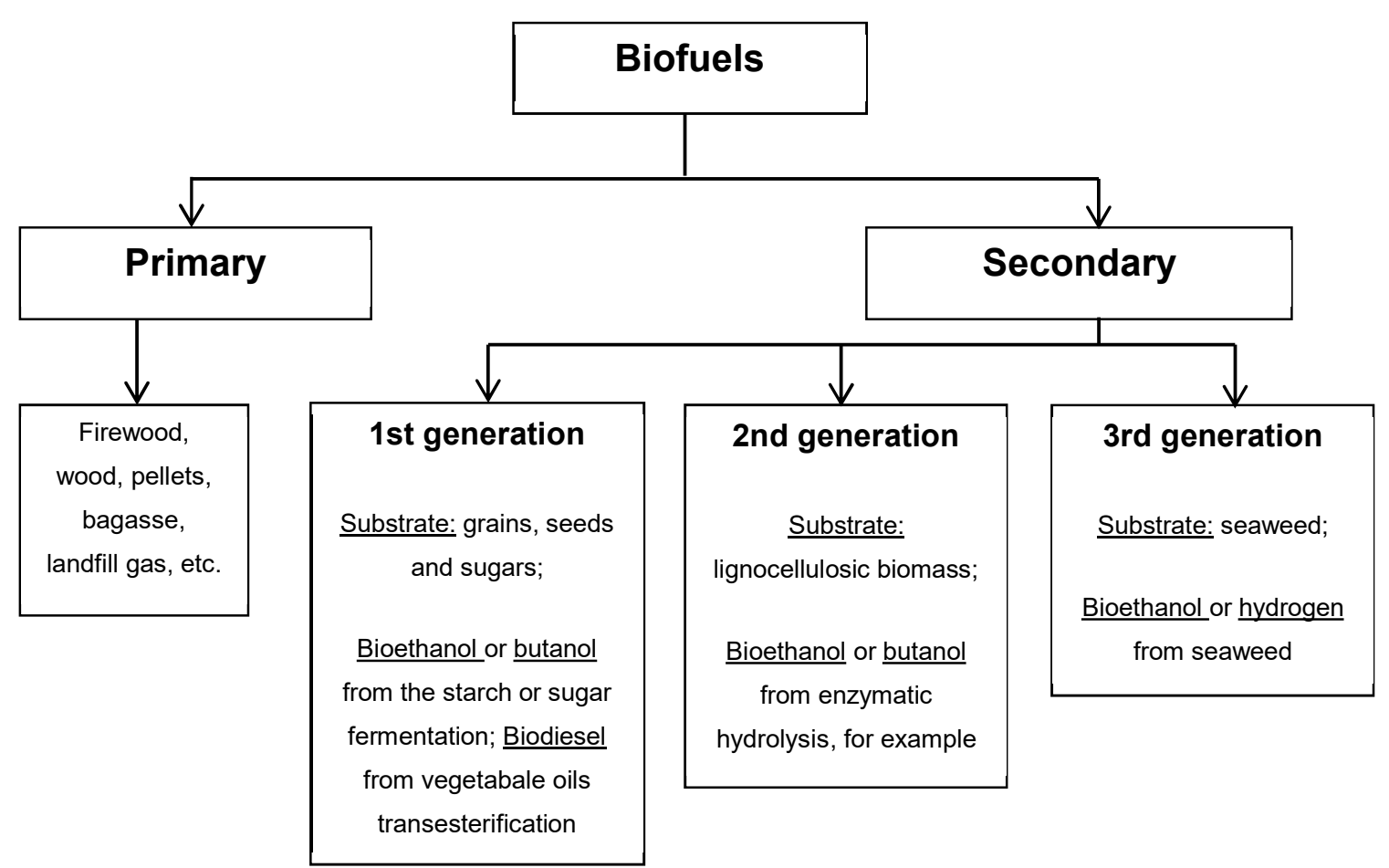

Figure 1.1. Biofuels classification. Source: Adapted from Nigam and Singh (2011).

\subsection{Residues from agroindustry}

Lignocellulosic biomass is a resource highly available and with renewable supply. In fact, the annual production of this kind of residues overcome 100,000 billions tons which leads to a high offer of raw matter at low cost (Alvira et al., 2010; Reddy and Yang, 2005). One of the main parts of this production includes the biomass left in the crop fields after harvesting while the other main part concerns the byproducts generated by the food industry. Thus, the agroindustrial sector generates biomass from the harvesting up to the most complex processing. In agriculture, there are residues such as corn stover, oat straw, barley straw, rice straw, sugarcane straw, pineapple wastes or banana flower-stalks. On the other hand, the food industry plays an important role on the production of sugarcane bagasse, cassava bagasse, tomato pomace, grape pomace, orange bagasse, coconut shells, coffee husks, soybean meal, peanut shells, rice shells and others. Despite their use as soil 
fertilizers, animal feeding and combustion as energy source (Tye et al., 2016), their compositon has aroused interest for biofuel applications.

\subsubsection{Chemical composition}

Biomass is composed by macromolecules such as cellulose, hemicellulose, lignin, and in some cases, starch. It can also present low amounts of proteins, ashes and pectin (Taiz and Zeiger, 2006). Cellulose is a polymer of linear chain composed by glucose unit, $\left(\mathrm{C}_{6} \mathrm{H}_{10} \mathrm{O}_{5}\right)_{n}$, linked among themselves through $\beta-(1,4)$ bonds. Microfibers can be obtained by inter and intramolecular hydrogen bonds, which will constitute crystalline and amorphous zones ( $\mathrm{Li}$ et al., 2010). The resulting spiral arrangement confers strength and flexibility to the material.

Hemicellulose, in turn, is a branched heteropolyssacharide that links cellulose microfiber and lignin. It is mainly composed by pentoses units (xylose, rhamnose, arabinose), hexoses (glucose, mannose, galactose), uronic acids and acetyl radicals (Gírio et al., 2010; Pandey, 2009). The linkages result in an amorhous structure with short branches that can be easily hydrolyzed into monomers of low molecular chain (Li et al., 2010). Due to the composition, only cellulose and hemicellulose can be converted into fermentable sugars from lignocellulose (Karki et al., 2011).

Diferently from the last two compounds, lignin is biopolymer not composed by carbohydrates but by complex and cross-linked linkages among aromatic chains of alcohols containing hydroxyl and methoxyl groups. It reduces the cellulose and hemicellulose accessibility to enzymes and chemicals. The specificity of the lignin bonds makes difficult its cleavage to reach and convert cellulose and hemicellulose into fermentable sugar of low molecular chain (Fara et al., 2012).

In some cases, agroindustrial residues may present certain amounts of starch entangled into the fibrous structure. This starch can be a residual fraction from a non complete use of the starchy matter during the food processing. In general, starch has a similar composition to cellulose since it is also composed by glucose monomers. However, these monomers are linked by $\alpha-(1,4)$ and $\alpha-(1,6)$ bonds responsible to form amylose with linear chain and amylopectin with branched chain, respectively. These fractions are naturally organized in a granular form, with semicrystalline structure (Singh et al., 2003). 
The way each fraction appears in the biomass depends on many factors, such as species variability, harvest season, processing conditions and storages (Kenney et al., 2013). Therefore, the performance of a particular residue should be addressed separately.

\subsubsection{Cassava bagasse}

The cassava (Manihot esculenta) is a tuber, considered as a basic food for millions of people around the world. Its cultivation is highlighted due to the easy adaptation to different climate conditions with low risks involved (Pandey et al., 2000). The result is an increasing consumption from 71 million tons in 1961 up to approximatelly 300 million tons nowadays (FAO, 2019).

Starch extraction industries are examples of industrial plants regarding the cassava processing. Besides the starch production, the processing generates great amounts of solids residues. Thus, on average a cassava starch producer is able to generate approximately 280 tons of wet bagasse ( $85 \%$ of moisture content) from 250-300 tons of cassava (Pandey et al., 2000). In this process, it is estimated that only $25 \%$ of the cassava dried matter if converted into starch. These values means that, only in Brazil, more than 2 million tons of wet cassava bagasse is wasted every year (Fiorda et al., 2013b).

This cassava bagasse, or also called cassava pulp, is a fibrous matter with low protein content which can contain $50-82 \%$ (d.b.) of residual starch after cassava processing (Carta et al., 1999; Pasquini et al., 2010). The remaining starch are related to the low yield of extraction and the difficulty of removing entangled starch (Pandey et al., 2000). As shows the flowchart of Figure 1.2, the wet residue is coldpressed and dried in a rotary drum dryer which stabilize the by-product and make easy the later processing.

The abundance of vegetable macromolecules as starch, celulose and hemicelulose makes the cassava bagasse a viable substrate for obtaining products with aggregated value. The cleavage of the glycosidic bonds of such molecules into reducing sugars has been studied with the aim of producing not only bioethanol (Escaramboni et al., 2018; Zhang et al., 2016) but also latic acid (John et al., 2006), whiskers/nanofiber of cellulose and starch nanocrystals (Pasquini et al., 2010; 
Teixeira et al., 2009), fumaric acid (Carta et al., 1999), citric acid (Prado et al., 2005), n-butanol (Lu et al., 2012), xanthan gum (Woiciechowski et al., 2004), mushroom cultivation (Beux et al., 1997), volatiles and flavors (Pandey et al., 2000) or even for increasing the fiber content in foodstuff (Fiorda et al., 2013a). Therefore, it is needed to develop an optimized process for the adequate pretreatment and to achive an efficient hydrolysis.

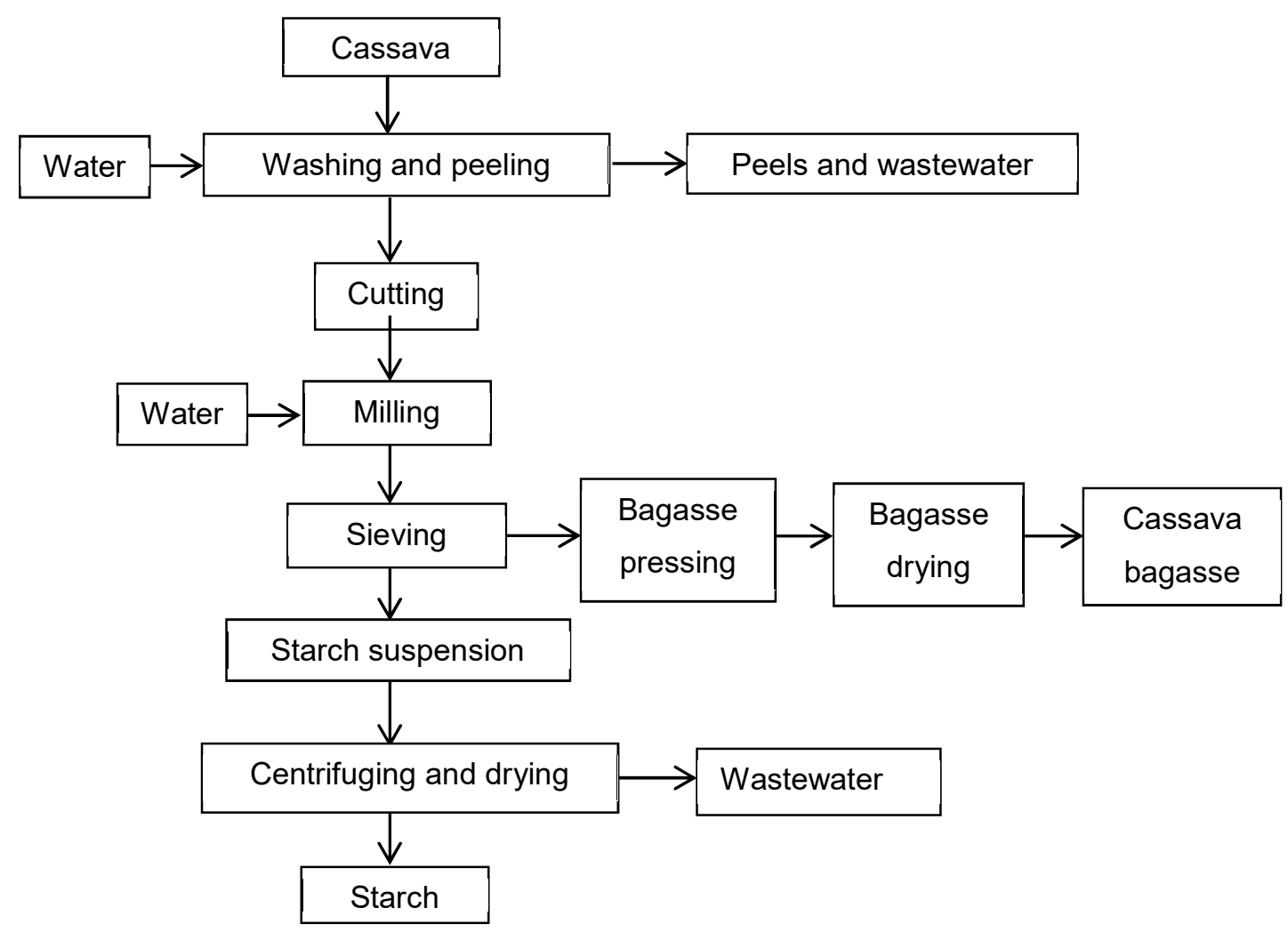

Figure 1.2. Simplified flowchart of starch and cassava bagasse production.

\subsubsection{Peanut wastes}

Brazil is a considered one of the biggest peanut producers, with an annual production around 560 thousand tons of raw peanut. The São Paulo state is responsible for $80 \%$ of the national production (IBGE, 2019) resulting in the $25 \%$ of the peanut consumed worldwide according to Associação Brasileira da Indústria de Chocolates, Amendoim e Balas - ABICAB (ABICAB, 2019). It is well appreciate as a rotative and complementary crop to the sugarcane. 
The shells represents about $25-30 \%$ of the mass of the whole peanut (Godoy et al., 1982), being the annual generation of shells estimated from the peanut processing sector of 160 thousand tons. The peanut shells are mainly composed by cellulose and hemicellulose ( $\sim 80 \%$ ) (Castro and Pereira-Jr, 2010), which reflects its potential use for releasing low molecular carbohydrates to be later fermented into bioethanol.

This residue is commonly used as fertilizer, poultry farm bedding, energy source by combustion and others. Notwithstanding, several research groups have been studying its use for feed-making, paper production (Anike et al., 2016) and biofuels obtention (Dahunsi et al., 2017; Nisamaneenate et al., 2015; Sun and Cheng, 2002). In this sense, new techniques should be evaluated for the adequate treatment of this residue in order to prepare it for bioethanol production.

\subsubsection{Artichoke wastes}

The artichoke (Cynara scolymus) is an herbaceous crop that was origanlly developed in the Mediterranean region. Artichoke has shown health-promoting activity due to their rich composition in flavonoids, anthocyanins, sesterpenes and triterpenes (Falco et al., 2015). Thus, the edible parts of the plant (heads, internal bracts and receptacle) play an important role in human nutrition.

The artichoke production reaches approximately 900,000 tons per year just in the main producer countries: Italy, Egypt, Spain and Argentina (FAO, 2017). The industrial processing of the artichoke involves the separation of outer bracts, stem and tip from pieces in order to obtain the artichoke heart. The byproducts generation concerns about $80 \%$ of the plant biomass and is wide employed for extracting bioactive compounds (Salem et al., 2015). It means that more 700,000 tons of byproducts are generated per year in the previously cited countries. Rich in cellulose, hemicellulose, fructosans and pectic polysaccharides (Femenia et al., 1998), artichoke by-products could represent an interesting source of low molecular sugars to be used for biofuel production. 


\subsection{Pretreatment}

The biomass pretreatment is the step in which the recalcitrant strucuture of the lignocellulose is broken down (Li et al., 2010). As shown in Figure 1.3, lignin involves the cellulose and hemicellulose molecules to avoid their exposure and partial depolymerization (Alvira et al., 2010; Rehman et al., 2013). After adequate pretreatment, the macromolecules become more accesible to chemicals and physical agentes for further hydrolysis (Balat, 2011).
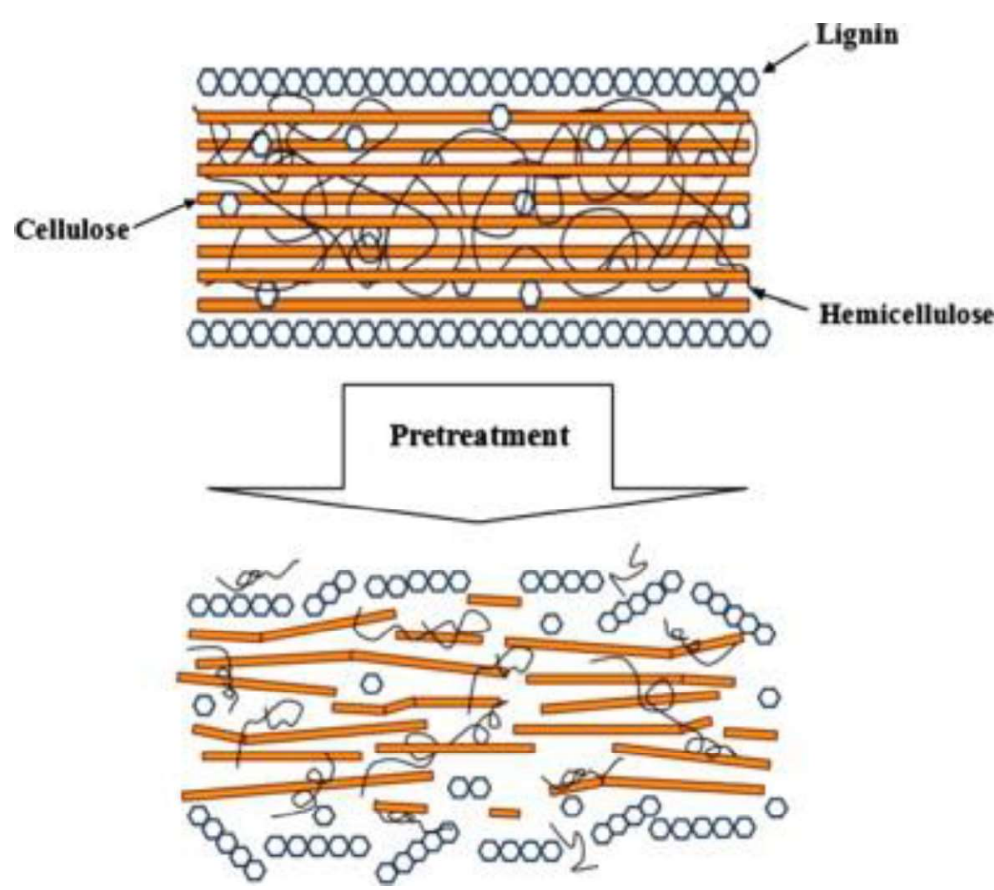

Figure 1.3. Pretreatment effect on the lignocellulose. Source: Mood et al. (2013).

The pretreatment is considered as one of the most onerous steps regarding the bioethanol production. However, alternative technologies can be applied to optimize the pretreatments by improving the efficiency and reducing costs (Mosier et al., 2005). They can be classified according to the chemical, physical or combined method. (McMillan, 1994). In this classification, water and steam are not considered as chemical agent (Mosier et al., 2005). 


\subsubsection{Fragmentation}

The fragmentation, or milling process, is one first pretreatment applied for reducing the particle size of coarser biomass. The aim is to make easier the raw material handling and to increase the particle surface area (Harmsen et al., 2010). Although it is reported that the milling process is able to depolymerize and reduce the cellulose crystallinity index (Sun and Cheng, 2002), Chang et al. (1997) reported the absence of significant effects when particle size is lower than $0.4 \mathrm{~mm}$.

Particle size reduction can be carried out by using knife, disc, ball or hammer mills. Ball mill has proven to be more effective in reducing cellulose crystallinity. On the other hand, hammer mill showed better performance on the cellulose hydrolysis when compared to disc mills (Zhu et al., 2009). In general, the efficieny of each method must be evaluated specifically for each specific kind of biomass (Schell and Harwood, 1994).

\subsubsection{Steam explosion}

Steam explosion aims to promote a fast biomass heating through the application of high-pressurized steam without chemicals addition (Agbor et al., 2011). It is an eco-friendly process with low implantation cost, in which different kind of biomass could be employed (Duque et al., 2016). The biomass remains in contact with water steam for a certain period to be, then, subjected to a fast and explosive decompression (McMillan, 1994). This explosive action on the fibers leads to their hydrolysis or also called autolysis (Chandra et al., 2007).

The explosion occurs by the use of saturated steam under high pressure (0.74.8 Mpa) and high temperatures $\left(160-240^{\circ} \mathrm{C}\right)$. The pressures is kept for seconds to minutes to hydrolyze hemicellulose as a consequence of the decompression and/or acetic acid formation by the acetyl groups existing in hemicellulose (Agbor et al., 2011). Studies related that a better yield can be attained by adding catalyst as $\mathrm{H}_{2} \mathrm{SO}_{4}, \mathrm{CO}_{2}, \mathrm{NaOH}$ or $\mathrm{SO}_{2}$ (Alvira et al., 2010; Huang et al., 2015; Sun and Cheng, 2002). 


\subsubsection{Liquid hot water treatment}

The liquid hot water treatment has been used in pilot plant to pretreat lignocellulosic biomass (Bacovsky et al., 2013). It can be also called solvolysis, hydrothermolysis or aqueous fractionation. The process is similar to the steam explosion method, but using liquid water (Agbor et al., 2011). To carry out this method, low solid concentrations $(\sim 8 \%)$ and high temperature $\left(\sim 200{ }^{\circ} \mathrm{C}\right)$ are employed. The temperature range of processing can vary depending on the desired effects (Wyman et al., 2005). The hot water acts on the hemiacetal linkages and liberates acids, which make easier the breakage of the ether linkages. A limiting factor is the resulting saccharides can be degradated into microbial inhibitor agentes such as furfural and 5-hydroxymethyl-furfural (Palmqvist and Hahn-Hägerdal, 2000). Despite the low cost technology, the treatment with liquid hot water demands high volume of water and the resulting sugar concentration is consequently reduced (Bobleter, 1994).

\subsubsection{Supercritical $\mathrm{CO}_{2}$ pretreatment}

Supercritical $\mathrm{CO}_{2}$ pretreatment is quite similar to steam explosion pretreatment by the fact of the use of changes of pressure. Carbon dioxide $\left(\mathrm{CO}_{2}\right)$ is found in the supercritical state when subjected to critical pressure above $7.4 \mathrm{MPa}$ and temperature higher than $31^{\circ} \mathrm{C}$ (Alinia et al., 2010). In these conditions, the fluid presents a density close to liquids and diffusivity and viscosity close to gases. The $\mathrm{CO}_{2}$ molecules have adequate size to penetrate into the microscopic pores of the lignocellulosic biomass. When $\mathrm{CO}_{2}$ comes in contact with water content, it generates carbonic acid for catalyzing biomass hydrolysis (Mood et al., 2013). The process does not generate large amount residues since carbonic acid shows low corrosivity and $\mathrm{CO}_{2}$ is easily removed when the system is depressurized (Schacht et al., 2008). Zheng et al. (1995) state that, besides the $\mathrm{CO}_{2}$ abundace, the technology is relatively cheap, non-inflammable, non-toxic and environmentally safe. 


\subsubsection{Microwave irradiation}

The microwave heating involves thermal and non-thermal effects (Alvira et al., 2010), being more advantageous than conventional heating. While the conventional heating is based on the heat transfer on the particles surface, the microwave irradiation generates heat by the interaction between the electromagnetic field and the material ( $\mathrm{Hu}$ and Wen, 2008). When the dielectric polarization occurs, the molecules collisions leads to partial breakdown of cellulose structure and hemicellulose and lignin removal (Gabhane et al., 2011).

This type of irradiation can be applied on biomass immersed in solutions with diluted chemical reagents. Studies identified that alkaline ones, specifically sodium hydroxide, are more viable to be used together with microwave (Zhu et al., 2005; Zhu et al., 2006).

\subsubsection{Ozonolysis}

Ozonolysis used ozone gas $\left(\mathrm{O}_{3}\right)$ for mainly breaking up the lignin linkages and affecting hemicellulose structure by oxidation reactions (Sun and Cheng, 2002). Although Sun and Cheng (2002) and Kumar et al. (2009) did not observed significant effect on cellulose, Balat (2011) stated that ozone can increase its biodegradability.

In this method, most of the experiments are carried out in hydrated fixed bed. These conditions promote higher effectiveness when compared to the experiments in aqueous suspensions containing or not acetic acid (Vidal and Molinier, 1988).

Among the advantages, there are water solubility, high availability, high oxidizing capacity, easy-handling at room conditions and absence of degradation compounds after the treatment (García-Cubero et al., 2009; Mood et al., 2013). The main disadvantage is related to the ozone cost production, since it is necessary large amounts to treat lignocellulosic biomass (Sun and Cheng, 2002).

\subsubsection{Alkaline pretreatment}

The use of alkaline agentes is focused on solubilizing lignin and increasing cellulose digestibility (Alvira et al., 2010). Calcium hydroxide (or lime), sodium hydroxide, potassium hydroxide and ammonia hydroxide are able to effectively 
reduce the lignin content in plant residues (Chandra et al., 2007; Taherzadeh and Karimi, 2008). Although the lignin removal can lead to an increase in the cellulose crystallinity, the increase in the active sites for enzyme adsorption improve the cellulose accessibility (Kim and Holtzapple, 2006).

The alkaline pretreatment can span from seconds to days, according to the required intensity. Kumar et al. (2009) reported lower sugar degradation when using alcaline methods instead acids, but the production of inhibiting compounds is worth of investigation to optimize the pretreatment conditions. The simultaneous addition of oxidant catalysts as $\mathrm{O}_{2}$ and $\mathrm{H}_{2} \mathrm{O}_{2}$ has shown as an alternative to reduce furfural and 5-hydroximethyl-furfural formation (Saha and Cotta, 2006).

\subsubsection{Acid pretreatment}

The usage of acids for modifying lignocellulosic structure is one of the most applied pretreatments due to its effectiveness and low costs. The mechanisms is focused on hemicellulose solubilization into sugar monomers (arabnose, galactose, glucose, mannose and xylose) and oligomers with possible cellulose degradation (Sun and Cheng, 2005). Diluted or concentrated acid can be employed, however high concentrations solutions can raise difficulties on the further fermentation process by the probable formation of inhibiting compounds. Moreover, concentrated solutions can lead to equipment corrosion and acid recovery is impaired (Wyman et al., 2005).

The acid pretreatment appeared as a favorable method for industrial scale, being applicable for different kind of biomass (Alvira et al., 2010). It can be performed at high temperatures $\left(\sim 180^{\circ} \mathrm{C}\right)$ for short periodos or under low temperatures with longer duration to avoid sugar degradation (Saha and Cotta, 2006). The acids most commonly used are the sulfuric acid, hydrochloric acid, phosphoric acid and nitric acid (Lenihan et al., 2010). Thus, hydrochloric acid and sulfuric acid are applied in concentrations between $1-10 \%$ at temperatures in the range of $100-150{ }^{\circ} \mathrm{C}$. In this conditions, the hexoses release becomes less effective due to monosaccharides degradation (Wingren et al., 2003). Phosphoric acids, on the other hand, is reported to be advantageous for pretreating and hydrolyzing both lignocellulosic and starchy feedstock (Fontana et al., 2001). By being less severe, phosphoric acid has high conversion efficiency with lower formation of furfural and acetic acid (Gámez et al., 
2004; Romero et al., 2007). Gámez et al. (2006) recommend the hydrolyzate neutralization with sodium hydroxide in order to produce sodium phosphate, nutrient for the microbial growth during alcoholic fermentation (Martínez et al., 2012).

\subsubsection{High-intensity ultrasound}

The treatment with ultrasound application is based on the energy application in the form of sound waves. This waves can provide enough energy to breakdown the hydrogen bonds in the lignocellulosic material, besides physicochemical effects on the treated medium (Bochek, 2003). In addition to its capacity for promoting cellulose and hemicellulose hydrolysis into fermentable sugars, the sonication process is also able to enhance the further fermetable process (Rehman et al., 2013; Sulaiman et al., 2011).

Sonochemical effects can alter the morphology of biomass particles suspended in the fluid, promote the microfragmentation, defibrillation, increase of surface area, lignin-carbohydrate bond breakdown, lignin aromatic ring opening by the rupture of carbon-carbon bonds, formation of radicals by the rupture of the carbon-hydrogen bonds and the consequent depolymerization of lignocellulose when in contact with $\mathrm{H}_{3} \mathrm{O}^{+}$and $\mathrm{OH}^{-}$ions (García et al., 2011; Gonçalves and Schuchardt, 2002; Iskalieva et al., 2012; Li et al., 2012; Shewale and Pandit, 2009).

Several studies have evidenced the ultrasound efficacy when treating different types of biomass such as corn bran (Ebringerová and Hromádková, 2002), wheat straw (Sun and Tomkinson, 2002), rice hulls (Yu et al., 2009), palm empty fruit bunch (Yunus et al., 2010), sugarcane bagasse (Velmurugan and Muthukumar, 2011), tea processing waste (Germec et al., 2016), sorghum bagasse (Goshadrou et al., 2011), banana flower-stalk (Villa-Vélez et al., 2015) and others.

The magnitude of the pretreatment with ultrasound is dependent on many factors. The intensity of the acoustic field is one of the most important ones, being influenced by the reactor configuration, exposure time to ultrasound, working temperature, frequency, power, amplitude, transducer efficiency, kind of suspensions and biomass properties (Gogate et al., 2011; Rehman et al., 2013). Such variables are taken into account specifically in the next sections. 


\subsection{Ultrasound}

Ultrasound are mechanical waves with frequency above the human hearing limit (> 16-20 kHz) (Carlin, 1972). When applied with enough power, it produces a series of effect that can affect a process, a product or a chemical reaction (Cárcel, 2003). Unlike the electromagnetical waves, the acoustic waves need a material to be propagated being no possible their application in vaccum conditions.

A basic system to apply ultrasound includes a source of energy and a transducer. This last is the responsible for converting a specific type of energy into acoustic energy. They are different kind of transducers such as piezoelectric, magneto-estrictive or fluid operated which produce acoustic energy from electric, magnetic or fluid energy, respectively (Gallego-Juárez, 1999; Kuttruff, 1988; Mason and Lorimer, 2002). Nowadays, the most used transducers are piezolelectric due to their simplicity and efficiency. They are based in the changes of shape that a changing polarity electric field produces in piezoelectric materials. Thus, the electric energy is converted into acoustic energy at a given frequency and intensity (Recuero, 1995).

\subsubsection{Classification}

Ultrasound can be classified as low-intensity or high-intensity ultrasound according to the frequency and intensity applied. The use of low-intensity ultrasound, or signal ultrasound, was firstly developed in the fields of metallurgy, medicine and food technology. Its operation is based on the alterations that sound waves suffer through the medium propagation. Sound parameters as velocity, attenuation, absorption or spectrum frequency are used to monitor process and products (Povey, 1997). In these types of applications, ultrasound operates at intensities lower than 1 $\mathrm{W} \cdot \mathrm{cm}^{-2}$ and frequencies higher than $100 \mathrm{kHz}$ in order to avoid alterations in the material. This fact contributes for using low-intensity ultrasound for fast, accurate, simple, instantaneous and non-destructive analyses of products with low costs involved (Bermúdez-Aguirre et al., 2011; McClements and Gunasekaran, 1997).

Studies have demonstrate the potential use of ultrasound for analyzing the composition of meat products (Benedito et al., 2001), degragation in milk packing 
(Elvira et al., 2006), alcohol and sugar content in beverages (Krause et al., 2011), moisture content in honey (Camara and Laux, 2010), frying oil deterioration (Benedito et al., 2002b), semi-crystalline structure in fatty products (Coupland, 2004), chesse mechanical properties (Cho and Irudayaraj, 2003), variation on the particle size of food emulsion (Gan et al., 2006), foreign bodies (Benedito et al., 2002a) and others.

On the other hand, high-intensity ultrasound (or power ultrasound) is used to affect a specific process or a product. It operates at intensities higher than $1 \mathrm{~W} \cdot \mathrm{cm}^{-2}$ and frequencies below $100 \mathrm{kHz}$. Ultrasound have been used to enhance process like the cleaning (Marangopoulos et al., 1995), drying (García-Pérez et al., 2011), filtration (Kobayashi et al., 1999), emulsification (Gaikwad and Pandit, 2008), homogenization (Gavahian et al., 2018), microorganisms and enzyme inactivation (Huang et al., 2017), bioactive compounds and oil extraction (Azmir et al., 2013; Tian et al., 2013), osmotic dehydration (Amami et al., 2017), grains hydration (Patero and Augusto, 2015), lignocellulosic biomass degradation (Rehman et al., 2013), etc. The way how ultrasound provides the sonochemical effects is explained by different mechanisms, including cavitation, heating and microjets formation.

\subsubsection{Actuating mechanisms}

Cavitation is one of the most studied mechanisms involved in the highintensity ultrasound application in liquid media. It occurs in the treated medium due to the molecular displacement produced by the generation of successive zones of high and low pressure. If the power is high enough, vaccum is created during the decompression cycle and overcome the attractive forces that keep molecules together. This phenomenon cause bubbles appearance, usually called cavitation bubbles (Mason and Cordemans, 1996). The collapse and disruption of such bubble release great amounts of energy, being able to reach punctual temperature (hot spots) of $4000 \mathrm{~K}$ and pressures of $100 \mathrm{MPa}$. In contrast, these hot points lasts approximately $0.1 \mu \mathrm{s}$ and the cooling rate is about $10^{10} \mathrm{~K} / \mathrm{s}$ (Mason and Cordemans, 1996). The collision strength among these bubble is able to breakdown the linkages of polymeric materials, besides the enhacament of the energy and mass transfer in the liquid-solid interface by the limit layer disruption (Mason and Cordemans, 1996). 
Microagitation at interfaces is other of the main actuating mechanism of ultrasound (Liang, 1993). When the ultrasonic wave finds an obstacle, they interact according to the wave length, frequency and material size. If the obstacle is bigger than the wave length, almost all the waves are reflected and diffraction may occur. If the opposite, the object will move together with the wave and the acoustic wave will provoke agitation in areas of difficult access (Carlin, 1972).

The fluid heating also occurs during ultrasound application as a consequence of the viscous resistance to the vibration of the medium molecules (Mason and Lorimer, 2002). This property can be used for measuring the actual acoustic intensity produced by the acoustic field (Liang, 1993). The rise in the medium temperature depends on the thermophysical properties of the propagating medium, the acoustic frequency and the acoustic power applied. Althoug it represents few increments in the beginning of the process, it is important to take this fact in account when developing process under controlled temperature (Mason and Lorimer, 2002).

\subsubsection{Acoustic field characterization}

The combination of the mechanisms involved and their magnitude determine the intensity of the sonochemical effects in a given process. These alterations are dependent on the actual energy that is absorbed by the medium when irradiated by ultrasound. Thus, not all the electrical input energy provided to the transducer is transformed into mechanical energy and not all the mechanical energy is converted into acoustic energy. The yield of power conversion is related to the equipment design as well as the physical properties of the treated medium (Raso et al., 1999).

Because of that, the actual acoustic fields produced in a specific process must be characterized to quantify the efectiveness of the ultrasonic treatment. As the frequency generally does not oscillate more than 5-10\% from the nominal frequency, the main focus is for determining the actual acoustic intensity. However, the difficulties for comparing and reproducing those measurements should be addressed when studying different methods (Raso et al., 1999).

Amont the the most used techniques to characterize the acoustic field produced in a system, there are the calorimetric methods and the use of hydrophones due to their reproducibility and repeatability. The calorimetric method 
correlated the heat generation from the molecular resistance to the movement during compression and decompression cycle as the ultrasound acts (Margulis and Margulis, 2003; Margulis and Maximenko, 1991). For this, the temperature rise is measured over the first seconds of ultrasound application assuming as adiabatic the system. Then, the acoustic power can be calculated by the Equation (1.1):

$U=\rho V c_{p}\left(\frac{d T}{d t}\right)$

where $U$ is the actual acoustic power (W), $\rho$ is the medium density $\left(\mathrm{kg} \cdot \mathrm{m}^{-3}\right), V$ is the treated volume $\left(\mathrm{m}^{3}\right), c_{p}$ is the specific heat of the medium $\left(\mathrm{J} \cdot \mathrm{kg}^{-1} \cdot{ }^{\circ} \mathrm{C}^{-1}\right)$ and $d T \cdot d t^{-1}$ is the rate of temperature increase $\left({ }^{\circ} \mathrm{C} \cdot \mathrm{s}^{-1}\right)$ produced by the sonication. This method shows a high accuracy aroung 7\% (Berlan and Mason, 1996) and repeatibility of 5\% (Raso et al., 1999). However, the measurements provided are not as faster as the measurements provide by hydrophones.

In this sense, hydrophones are simple equipment used for measuring acoustic pressure. They operate opposite as a transducer, receiving a mechanical stimulus and converting it into an electrical signal (Hodnett and Zeqiri, 1997). This electrical signal is related with the acoustic preassure produced by the acoustic field. The acoustic pressure values in a specific point could be correlated with acoustic intensity by the following Equation (1.2):

$I=\frac{U}{A}=\frac{P^{2}}{2 \rho c}$

where $I$ is the acoustic intensity $\left(\mathrm{W} \cdot \mathrm{m}^{-2}\right)$, also given by the relation between $U(\mathrm{~W})$ and the emitter surface area $A\left(\mathrm{~m}^{2}\right), P$ is the acoustic pressure $\left(\mathrm{Pa}\right.$, or $\left.\mathrm{N} \cdot \mathrm{m}^{-2}\right)$ and $c$ is the sound velocity when propagated in a given medium $\left(\mathrm{m} \cdot \mathrm{s}^{-1}\right)$.

The hydrophones provide very local measurement. Thus, a high variation in the acoustic pressure can be registered in the same system which permits localize high and low acoustic preassures zones in the system. Therefore, they provide an accurate measurement of the acostic field, allowing to detect stationary fields and 
how they can be affected by the temperature and liquid height, for example (Hodnett and Zeqiri, 1997). On the contrary, hydrophones are sensitive to some chemicals such as acids, this avoiding their use to characterize acoustic fields in acid conditions.

However, both hydrophones and the calorimetric methods are considered simple and reliable techniques for measuring acoustic fields, besides presenting good correlation between their measurements (Cárcel et al., 2007a; Cárcel et al., 2007b).

\subsection{Ultrasound-assisted pretreatments}

The application of ultrasound as pretreament can enhace heat and mass transfer process. The collapse of cavitation microbubbles releases an important amount of energy in the form of chocking waves. It can induce the increase of the local temperature and pressure that cause the fluid flow in the sense of wave propagation, the appeareance of an intense microturbulence, the generation of free radicals, the enhancing of mixing process, the mass transfer in the solid-liquid interface or, even, the erosion and degradation of solid residues (García et al., 2011; Gogate and Pandit, 2008; Li et al., 2012; Mason, 1999; Rehman et al., 2013).

Some processing variables can be adjusted to enhance the sonochemical effects of ultrasonic assisted pretreatment on the lignocellulose integrity. They can be related to both equipment design and processing conditions. Concerning the equipment design, the use of probe-type system showed to be more advantageous when treating lignocellulosic materials when compared to ultrasonic baths (Chisti, 2003) due to the ability to produce intenser fields. On the other hand, operations conditions such as frequency, power, processing time, applied temperature and catalyst concentration can be changed in order to contribute for achieving good results. These operation parameters are better described in the next sections:

\subsubsection{Nominal frequency}

The frequency of sound wave classifies ultrasound according to its application. It is defined as the number of vibrations, or complete cycles, per unit of time. Gogate 
et al. (2011) suggest a range of frenquecy between 10-100 kHZ for processes aiming to produce intense physical effects such as polymer disruption or degradation. Because of that, the applied frequency should be taken into account in pretreatments that involves microrganisms and enzymes, which require severe conditions. In this sense, Gadhe et al. (2006) observed that the application of high frequencies ( 610 $\mathrm{kHz}$ ) leads to more superficial effects on the lignocellulosic estructures when compared to lower frequencies. Although frequency variations in the proposed range of $10-100 \mathrm{kHz}$ does not present a clear alteration in the cavitation effects, some studies evaluated the use of multiple and double frequency methods in order to increase the interaction among the cavitation bubbles and consequently the secondary cavitation (Gogate et al., 2011; Gogate et al., 2003; Servant et al., 2003).

\subsubsection{Nominal power}

The amplitude of a sound wave is the height of peak wave and represents the amount of energy to be transported. Consequently, the nominal power represents the energy transferred per unit of time. The application of high input power is directly related with the achiving of the desired ultrasonic effects. Thus, the higher acoustic intensity applied, the greater number of cavitation bubbles, the larger bubbles life cycle and the implosion pressure and therefore, the higher degradation on the cellulosic matter (Aimin et al., 2005; Chen et al., 2011; Yang et al., 2009; Yunus et al., 2010). Moerover, the increase in the applied power could permit the shorten of the processing time (Imai et al., 2004).

However, an excess of power applied could negatively affect the sonication process. The increased number of cavitation bubbles can produce that most of them are located in the sonotrode tip, raising difficulties on the energy transfer towards the medium (Gogate et al., 2011). In addition, extending the ultrasound-assisted pretreatment at any power applied can be not viable. Besides the high energetic demand, sugar release can be not improved above certain conditions (MontalboLomboy et al., 2010). Thus, power and treatment duration should be optimized in order to obtain the desired results. 


\subsubsection{Sonication time}

Increasing the duration of ultrasound-assisted pretreatments contributes for deslignifying biomass and releasing sugar (Rehman et al., 2013). However, after a specific time, studies revealed no influence on the biomass digestion (Huang et al., 2011; Montalbo-Lomboy et al., 2010; Nikolić et al., 2010; Sun and Tomkinson, 2002). Thus, the determination of the kinetics of sugar production is worth of investigation for optimizing the time of processing and energy.

On the other hand, the processing duration can affect the pretreatment efficiency, depending on the system used or the raw material composition. Starchy biomass, for example, generally requires shorter periods of sonication (in the range of seconds) in comparison with purely lignocellulosic biomass (range of minutes) (Khanal et al., 2007; Montalbo-Lomboy et al., 2010; Nikolić et al., 2010). Both starch and cellulose present molecules more and less organized with crystalline and amorphous regions, respectively being the amorphous zones more easily to access by the pretreatment (Huang et al., 2007).

Catalyst-assisted processes are also influenced by the sonication time. The processing duration increases the contact time between catalyst and suspended solids. Although studies did not evidenced an improvement after 25 minutes of sonication (Sun et al., 2002), other authors related an increase in the xylan and xylose production after extending sonication over 45-60 minutes (Yang et al., 2009; Yunus et al., 2010).

\subsubsection{Temperature}

In general, the intensity of cavitation produced by the sonication is not affected when temperature ranges from 20 to $60{ }^{\circ} \mathrm{C}$. Above this limit, the collapse of the cavitation bubbles can be less severe during the compression cycles (Rehman et al., 2013) and, therefore, its effects. Even though some researches reported the intensification of the hydrolysis by increasing temperature, this influence may be attributed to the enhancement of enzymatic rates, type of biomass and equipament operation conditions (Nikolić et al., 2010). In acid or alkaline medium, the use of high temperatures implies higher reaction rate by their enhanced chemical action. The 
application of ultrasound provides similar effects, but they are more noticeable when low or moderate temperatures are considered (Rehman et al., 2013).

Additionally, one of the main mechanisms attributed to the application of ultrasound in liquid media, like biomass aqueous suspension, is the heating due the friction produced by ultrasonic vibration. For this reason, the temperature of ultrasound-assisted process should be controlled to avoid over-heating which would cause enzyme and microrganisms inactivation. Thus, for example, in the absence of controlled conditions, treating cassava biomass suspensions with an acoustic density of $8.5 \mathrm{~W} \cdot \mathrm{mL}^{-1}$ could rise the temperature up to $60^{\circ} \mathrm{C}$ with only 30 seconds of sonication (Nitayavardhana et al., 2010). Lower acoustic densities around $3 \mathrm{~W} \cdot \mathrm{mL}^{-1}$ was able to rise the temperature of suspensions containing soy flakes in $8{ }^{\circ} \mathrm{C}$ after 120 seconds of ultrasound application (Karki et al., 2010). These difference in the temperature increase are consequence of the different rates of energy transfer per mass of fluid (Montalbo-Lomboy et al., 2010).

\subsubsection{Catalysts}

The use of catalystic agentes is an alternative for optimizing time and energy during pretreatments. Among the compounds that can enhance lignocellulose pretreatment, there are organic solvents, ionic liquids, acids, alkalis and enzymes.

Thus, organic solvents have been studied with the aim of assisting the lignin removal from biomass. Sonication combined with organic solvent such as ethanol and methanol, have demonstrated effectivess on solubilizing ether linkages from both lignin and hemicellulose. Different solvent mixtures can be used for improving the access to the biomass, but costs and toxicity should be addressed (Sun et al., 2002; Zhao et al., 2009).

The application of ionic liquids is other potential alternative. It consist of the use of fluids entirely composed by ions that can digest cellulose and reduce its crystallinity for further hydrolysis (Dadi et al., 2007; Tadesse and Luque, 2011). Different type of biomass can be treated by ionic liquid at room temperature to be then enzymatically hydrolyzed in the same medium (Yang et al., 2010). On the other hand, the rise in temperature could reduce glucose release (Ninomiya et al., 2012). 
Regarding the use of diluted acids, they have high efficiency in the conversion process of lignocellulose. Although the use of inorganic acids have been widely studied, few researches have been carried out combining with ultrasound application (Rehman et al., 2013). Yang et al. (2009) demonstrated that ultrasound reduced 95\% the required time for release the same amounts of xylans when compared to conventional treatment. In general, diluted acid hydrolysis required high temperature but long treatments. In this sense, the acid concentration and the biomass type should be taken into account when studying a specific application (Sun and Cheng, 2002).

Alkaline pretreatments also have important effects on cellulose digestibility and lignin solubilization when combined with ultrasound (Carvalheiro et al., 2008) saving time and reagents (Zhang et al., 2008). The increase of treatment temperature could also accelerate the conversion rate into sugar by the improvement in the mixing process and making easy the access to the ether linkage by the catalyst. Velmurugan and Muthukumar (2012), for example, found that the optimal conditions for the ultrasound-assisted alkaline pretreatment of sugarcane bagasse were $400 \mathrm{~W}$ of input power in suspesions with $4 \%$ of solids, $3 \%$ of $\mathrm{NaOH}$ over $47 \mathrm{~min}$ at $70^{\circ} \mathrm{C}$.

As the chemical pretreatment could be enhanced by ultrasound, enzymatic ones may be also positively affected by sonication. However, the acoustic treatment should be not too severe to avoid undesirable effects on the enzymatic activity (Chisti, 2003). Cellulases, for example, are able to digest lignocellulosic biomass by the consecutive adsorption and desorption of the enzymes to the particles surface area (Mansfield et al., 1999). The micro-agitation caused by ultrasound facilitate the contact in the enzyme-substrate interface by enhancing mass transfer and removing hydrolysis products from the active sites (Easson et al., 2011).

\subsubsection{Suspensions properties}

Many of the parameters related to the raw material can influence the acoustic intensity applied and, so, the magnitude of ultrasound effects on the solid material. The physical properties of the treating material interfere in the acoustic waves affecting the cavitation intensity and providing different effects in distinct systems 
(Boistier-Marquis et al., 1999). Thus, to form the cavitation bubbles, during decompression phase, it must overcome the liquid cohesive forces. Viscous liquids tend to present higher cohesive forces, raising difficulties to the cavitation occurrence. Decreasing the surface tension by the tensoactive agents may facilitate the cavitation, but it also decrease the intensity of the bubbles collapse. Volatile liquids present high vapor pressure and, although it is beneficial for occurring cavitation, the produced gas can reduce the bubbles shockwave. Suspensions with higher density tend to present lower attenuation and to absorb higher acoustic power for a same treated volume. Analogously, suspensions with higher specific heat capacity showed higher temperature increases over time and, so, higher acoustic intensity (Boistier-Marquis et al., 1999; Gogate et al., 2011; Polachini et al., 2017). Therefore, the knowledge of the medium properties is useful not only for estimating the resulting cavitation magnitude but also for the correct development and design of the processes and equipment (pumps, agitators, decanters, heat exchanger, pressure loss and others) involved in the bioethanol industry (Polachini et al., 2016).

In order to increase the environmental viability of the process, it is recommended the use of cheap and non-toxic liquid media such as water, diluted acids or diluted bases (Rehman et al., 2013). Sonication in purely aqueous medium is able to produce $\mathrm{H}_{3} \mathrm{O}^{+}$and $\mathrm{OH}^{-}$ions that can act as oxidizing agents over the biomass, mainly at the high temperature and high local pressures as found during cavitation bubbles collapse (García et al., 2012).

Regarding the economic aspects, it is suggested to use concentrated suspensions instead diluted ones. However, the high solids loading in suspension results in higher viscosity, which reduce particles mobility and heat and mass transfer is impaired. Thus, it is necessary to evaluate an optimal concentration that concerns good cavitating activity with reasonable energy transfer (Gogate et al., 2011). Moreover, the size of the suspended particles can also influence the pretreatment based on the same solids concentration but energy expenses for reducing particles size should be addressed (Rehman et al., 2013). 
2. Conclusion of the introduction 
The reuse of agroindustrial wastes has two main goals, to reduce the amount of residues and their environmental impact and at the same time, to obtain raw matter for new processes or directly products with high aggregated value. Production of boethanol, or second generation ethanol, is one of these products that can be obtained through the adequate processing of lignocellulosic and/or starchy waste. In addition to the sustainable destination of the residues, bioethanol industry contributes for using biofuels in opposition to the non-renewable sources as fossil oil.

In order to improve the biofuel production, many factors should be taken into account. Some issues are related to the composition, availabillitiy, accessibility and costs associated to the raw material, while other aspects are focused on the development and study of their pretreatment and hydrolysis conditions.

The fibrous and starchy residue from cassava processing is a result from the starch extraction industries. This bagasse presents high contents of residual starch, entangled in the fibrous matter. Its specific composition, together with its high availability, makes the cassava bagasse an interesting product for acting as substrate in the bioethanol industry. Other examples of interesting raw matterials to this end are the peanut shells, by-product of peanut industry, or the artichoke waste resulting of the artichoke industrialization process.

Among the technologies applied to the pretreatment and conversion of agroindustry residues into fermentable sugars, the ultrasound irradiation has shown good results when combined with conventional methods. Ultrasound is able to enhance reactions through the intensification of mass and energy transport. The mechanisms involved during sonication are not completely elucidated, but many effects has been attributed to cavitation, microagitation and heating. These phenomena are the main responsible to alter the composition and structure of the raw material. The magnitude of such effects is the result of the combination of the thermophysical properties of the medium and the operating conditions. Physical properties of the medium provide important information for the correct design of bioreactors, agitators, pumps and momentum, heat and mass transfer processes. Moreover, their knowledge could allow the understanding of the sonochemical effects produced in different material when irradiated under the same conditions. In this sense, the characterization of the actual acoustic energy introduced in each different 
system is worth to be studied using adequate techniques such as calorimetric methods. 
3. Objectives 


\subsection{General}

The general objective of this thesis was the characterization and quantification of the process variable influence in the acid pretreatment of agroindustrial residues with the assistance of high-intensity ultrasound for enhancing further bioethanol production.

\subsection{Specifics}

In order to attain the general objetictive, it was intended specifically:

1. To characterize different agroindustrial residues according to chemical and physical aspects;

2. To determine and evaluate the physical properties of different acid/aqueous suspensions used as pretreament of biomass for bioethanol production, including rheological behavior, density, specific heat, thermal diffusivity and thermal conductivity;

3. To determine and to evaluate the acoustic fields generated by ultrasound irradiation in different acid/aqueous suspensions considered;

4. To model and to quantify the kinetics of acid hydrolysis of agroindustrial residues assisted by high-intensity ultrasound in comparison with conventional agitation; 
4. Working plan 
In this section is described the working plan (Figure 4.1) followed in the present thesis. It was elaborated to achieve the objectives previously established. It consists of 7 main chapters that address the acid pretreatments of some agroindustrial wastes assisted by high-intensity ultrasound. Each chapter addresses different steps and requirements for developing the biomass treatment in order to provide useful information for bioethanol industry. The specific matherials and methods used are widely described in each chapter.

In Chapter 1, it was studied the effect of solids concentration $(0,2,4,6,8$ and $\left.10 \% w \cdot w^{-1}\right)$, acid concentration $\left(0,2,4,6,8\right.$ and $\left.10 \% w \cdot w^{-1}\right)$ and temperature $(5,15$, 25,35 and $45^{\circ} \mathrm{C}$ ) on the thermophysical properties of acid suspensions containing cassava bagasse. Thus, a total of 36 suspensions were characterized at different temperatures by the determination of density, by using a density meter; specific heat capacity, by differential scanning calorimetry; thermal diffusivity, by using a diffusivity cell; and thermal conductivity by their correlation. Each determination was carried out in triplicate. The average values were fitted to empirical models as functions of the significant variables $(p<0.05)$. The influence of the significant parameter on each property was discussed.

Secondly, in the Chapter 2, the rheology of acid suspensions of cassava bagasse was addressed. For this, the acid suspensions studied in the Chapter 1 at different solid concetration, acid concentration and temperature were considered. These cassava bagasse suspensions were previously characterized according to its chemical composition, morphology and particle size distribution. After, flow curves, from shear rate of 0.01 up to $260.5 \mathrm{~s}^{-1}$, were obtained in a rotation rheometer at controlled temperature. Data about shear stress versus shear rate were fitted to the Herschel-Bulkley model. Regarding the studied variables (solids concentration in suspension, acid concentration in the solutions and temperature), their influence on the yield stress, consistency coefficient and flow index behavior were discussed and fitted to some proposed models such as Arrhenius-type equations.

The Chapter 3 concerns the rheological properties of acid suspensions containing powdered peanut shells, an abundant agroindustrial waste in Brazil from the peanut processing. Peanut waste was characterized according to the morphology, particle size distribution, fractions of cellulose, hemicellulose and lignin 
in lignocellulose. Acid solutions at different $\mathrm{pH}(3,4,5,6$ and 7) were added to powdered peanut sheel in order to obtain different acid suspensions with different solids concentration $\left(0,2,4,6,8,10\right.$ and $\left.12 \% w \cdot w^{-1}\right)$. These suspensions were analyzed in a rotational rheometer at $1,10,20,30,40,50$ and $60{ }^{\circ} \mathrm{C}$ in a range of shear rate from 0.01 up to $260.5 \mathrm{~s}^{-1}$. Flow curves were fitted to the models of Newton, Bingham, Power Law and Herschel-Bulkley and the rheological parameters were expressed by exponential functions that relate simultaneously the significant variables $(p<0.05)$. Zeta potential of the acid suspensions was determined to evaluate the particles interaction at the different $\mathrm{pH}$. Density of the same acid suspensions was also determined with a density meter in at the same studied temperatures and empirical models were fitted.

Chapter 4 was focused on studying the different acoustic field generated in acid suspensions containing cassava bagasse. This step was carried out following a calorimetric method and the acoustic field was measured in suspensions of 2, 4, 6, 8 and $10 \% \mathrm{w} \cdot \mathrm{w}^{-1}$ of cassa bagasse. These suspensions were obtained by dispersing the biomass in solution with phosphoric acid concentration of $0,2,4,6,8$ and $10 \%$ $w \cdot w^{-1}$. Sonication occurred by applying 160, 240, 320, 360 and $400 \mathrm{~W}$ using a probe type ultrasonic processor (UP400S, Hielscher, Germany). The temperature increase was monitored at $1.5,2.5,3.5,4.5$ and $5.5 \mathrm{~cm}$ from the sonotrode tip. From the measurements, acoustic parameters such as acoustic power, acoustic intensity, acoustic density and attenuation were determined and modeled. Moreover, they were correlated with the physical properties previously reported in the Chapter 1 and 2.

In the Chapter 5, acoustic fields were adressed in acid suspensions of powdered peanut shells, also using a calorimetric method. The acoustic power and acoustic intensity were studied for the suspensions with different solids concentration $\left(4,6,8\right.$ and $\left.10 \% \mathrm{w} \cdot \mathrm{w}^{-1}\right)$, at different $\mathrm{pH}$ values $(3,4,5,6$ and 7$)$. The nominal input power of the ultrasonic equipment (UP400S, Hielscher, Germany) was established in different levels: $80,120,160,200,240,280$ and $320 \mathrm{~W}$. It was done to evaluate the effect of the the nominal input power on the acoustic power as well as for calculating the conversion efficiency. To make possible this study, data of specific heat capacity of the acid suspensions were experimentally determined. Empirical models were used to fit the experimental data to the significant variables $(p<0.05)$. 
Finally, the kinetics of sugar release during the pretreatment of some agroindustry residues (cassava bagasse and artichoke) in acid solutions wer evaluated in Chapter 6 and 7. Initially, Chapter 6 consisted of evaluating the kinetics of sugar release from artichoke waste, an abundant residue in Spain. The process of sugar dissolution in aqueous solution and actual hydrolysis in acid medium was differentiated. Both processes were addressed with ultrasound application and compared to a conventional agitation process. Moreover an industrial approach was studied. For this, suspensions with $5 \% \mathrm{w} \cdot \mathrm{w}^{-1}$ of biomass were used in aqueous suspensions for dissolution experiments, and in $10 \% \mathrm{w} \cdot \mathrm{w}^{-1}$ of phosphoric acid for hydrolysis experiments. Kinetics of both total and reducing sugar production were obtained and modeled to Naik model. The effect of decreasing biomass to $2.5 \% \mathrm{~W} \cdot \mathrm{w}^{-}$ 1 on the acid hydrolysis was also taken into account. The characterization of the rheological and acoustic behavior of the different suspensions considered was also carried out both at the beginning and at the end of the experiments. These rheological and acoustic properties were related with the kinetics of sugar release obtained in the different conditions tested.

Lastly, Chapter 7 concerns the sugar release from cassava bagasse. Dissolution was also studied separately from the actual hydrolysis. Suspensions with $5 \% \mathrm{w} \cdot \mathrm{w}^{-1}$ of biomass were treated by ultrasound and by conventional agitation. Kinetics of total and reducing sugar release was determined and modeled to Naik model. Similarly as done in Chapter 6, variations caused by each process in the rheological properties and acoustic fields were evaluated. Moreover, structural modifications on both fibrous matter and starch granules were analyzed by light, polarized light and fluorescende microscopy. 


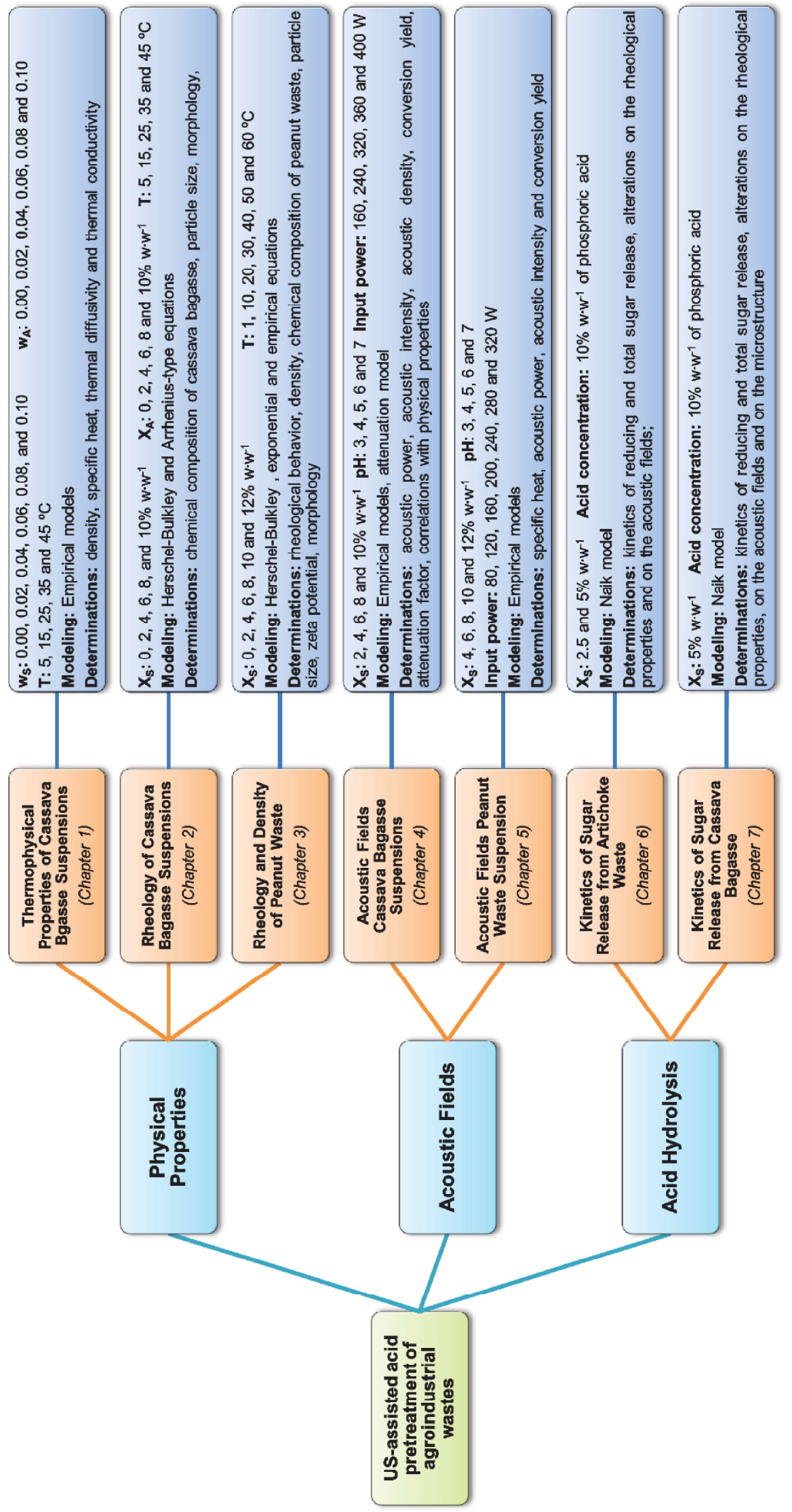

Figure 4.1. Working plan. 
5. Results 
5.1. CHAPTER 1

Thermophysical Properties of Acid Suspensions of

Cassava Bagasse 
Thermophysical Properties of Dilute Acid Slurries of Cassava Bagasse as a Function of Biomass Loading, Acid Concentration and Temperature

Tiago Carregari Polachini ${ }^{1,2}$; Antonio Mulet ${ }^{2}$; Juan A. Cárcel ${ }^{2}$; Javier Telis-Romero ${ }^{1}$

${ }^{1}$ Food Engineering and Technology Department, São Paulo State University (Unesp), Institute of Biosciences, Humanities and Exact Sciences (Ibilce), Campus São José do Rio Preto, Cristóvão Colombo Street 2265, São José do Rio Preto, São Paulo State, 15054000, Brazil.

${ }^{2}$ Grupo de Análisis y Simulación de Procesos Agroalimentarios, Departamento de Tecnología de Alimentos, Universitat Politècnica de València (UPV), Camino de Vera, $s / n$, Valencia, 46071, Spain. 
Abstract: For the design of equipment and processes optimization, the thermophysical properties of the raw materials are a must. This is the case of cassava bagasse acid conversion. So, this work was aimed at determining and modeling density, specific heat, thermal diffusivity and thermal conductivity of acid slurries of cassava bagasse with different mass fractions of cassava bagasse $(0.00$ to 0.10 ) and phosphoric acid ( 0.00 to 0.10$)$ at temperatures from 278.13 to $318.13 \mathrm{~K}$. Results obtained show that density varied from 986.5 to $1029.3 \mathrm{~kg} \cdot \mathrm{m}^{-3}$, specific heat from 3830.0 to $4142.6 \mathrm{~J} \cdot \mathrm{kg}^{-1} \cdot \mathrm{K}^{-1}$, thermal diffusivity from $0.9624 \times 10^{-7}$ to $1.5249 \times 10^{-7}$ $\mathrm{m}^{2} \cdot \mathrm{s}^{-1}$ and thermal conductivity from 0.3825 to $0.6212 \mathrm{~W} \cdot \mathrm{m}^{-1} \cdot \mathrm{K}^{-1}$. While density increased with increasing solids and acid content at decreasing temperature, the thermal properties decreased at higher solids and acid content and increased when heating the slurries. The values were well-fitted to polynomial models with good accuracy $\left(R^{2}>0.921\right.$ and $\left.M R E<1.75 \%\right)$, allowing the application of the models to obtain reliable and ready-to-use data for cassava bagasse processing. Thus, reported data can be used for designing momentum, heat and mass transfer processes for bioethanol production from cassava bagasse.

Keywords: pretreatment, bioethanol, specific heat, density, thermal conductivity, thermal diffusivity. 


\subsubsection{Introduction}

The exhaustion and environmental damages of fossil fuels has driven to the search of new processes to make viable the biofuels production from renewable sources. Second generation ethanol (or bioethanol) is a clear example of this biofuel, which is commonly obtained by previous hydrolysis of agroindustry residues.

In a general way, these processes involve the dispersion of a material in an alkaline or acid medium at specific temperature to proceed with a pretreatments to breakdown the recalcitrant structure of the biomass for further conversion into bioethanol ( $\mathrm{Li}$ et al., 2010). Concerning the acid treatments, it has been widely applied due to its high efficiency and low costs (Sun and Cheng, 2005). Despite it can be used concentrate, the employment of dilute acid solutions is interesting since it reduces the production of inhibiting compounds, avoids equipment corrosion, makes easier the acid recovery and is able to treat different kinds of biomass (Alvira et al., 2010; Wyman et al., 2005).

Specifically, phosphoric acid has been used for treating both lignocellulosic and starchy materials (Ramón et al., 2015; Werle et al., 2013), besides presenting less formation of furfural and acetic acid during hydrolysis (Fontana et al., 2001; Martínez et al., 2012). The resulting sodium phosphate from phosphoric acid neutralization with sodium hydroxide can also be used as nutrient for microorganisms during the alcoholic fermentation step (Gámez et al., 2006).

It is interesting to consider phosphoric acid to hydrolyze residues from starch extraction industry such as cassava (Manihot esculenta) bagasse. This renewable resource has been also studied as raw material for bioethanol production thanks to its high residual starch contents, which can vary from 30 to $85 \mathrm{~g}$ of starch $100 \mathrm{~g}^{-1}$ of dried matter (Carta et al., 1999; Pasquini et al., 2010; Sánchez et al., 2017). With an approximate annual generation of 2 million tons of wet cassava bagasse estimated in Brazil, cassava bagasse generation also tends to increase with the growing consumption of cassava (FAO, 2017; Fiorda et al., 2013).

The mixture of cassava bagasse in acid solution is submitted to a series of unit operations to reach the conditions for pretreatment, hydrolyses, fermentation and distillation. These processes should be correctly designed to avoid over- and underestimation of energy expenses (Polachini et al., 2016a). The knowledge of 
thermophysical properties is an essential step to optimize the process and equipment development involved in the bioethanol industry. They are fundamental data to provide an adequate choice of equipment, such as pumps, mixers, pipes, bioreactors and heat exchanger, as well as their operating conditions.

Whereas density of slurries is useful for designing transport operations, specific heat capacity, thermal conductivity and thermal diffusivity play an important role on the design of heat transfer processes. In addition to the basic information for flow design, the knowledge of density is necessary to predict processes involving heat, momentum and mass transfer. On the other hand, thermal properties in heterogeneous systems are of great value to the literature in order to design and control the process parameters (Rodríguez and González, 2003). According to Samaniuk et al. (2012), much of the costs involved in the biomass pretreatment is related to the necessary energy to warm up and cool down the biomass flows.

The scarcity of such data makes necessary its experimental determination to establish how these properties change in front a variation on solids content, acid concentration and temperature. Modeling these properties is a must for process design and optimization.

\subsubsection{Materials and Methods}

\subsubsection{Samples preparation and characterization}

The wet cassava bagasse was provided by a starch extraction industry in northwest of São Paulo state, Brazil. This residue was transported in plastic bags to be dried in a convective tray dryer at $323.13 \mathrm{~K}$ for 24 hours. The dried waste was then milled using a knife mill M4FH1C (PHD, Piracicaba, Brazil) and then sieved to obtain a powdered cassava bagasse with particle size less than $147 \mu \mathrm{m}$ by using a mesh 100 Tyler sieve.

Acid slurries were prepared using phosphoric acid 85\% (Purity $>99.95 \%$, Dinâmica, Diadema, São Paulo) to obtain different mass fraction concentration in distilled water ( $w_{A}=0.00 ; 0.02 ; 0.04 ; 0.06 ; 0.08$ and 0.10 ). This solution was added to cassava bagasse to obtain mass fractions in the final suspension of $w_{S}=0.00 ; 0.02$; $0.04 ; 0.06 ; 0.08$ and 0.10 . It resulted in 36 different slurries to perform the experiments. 
Chemical composition of cassava bagasse is presented in Table 5.1.1. It was determined in four replicates according to the protein content by micro-Kjeldahl method, fats by Soxhlet extraction, ashes by muffle incineration and moisture in an oven, following the procedures described by AOAC (2005). Additionally, starch content was determined by the chemical method proposed by McCready et al. (1950), total fibers content based on the values of neutral detergent fiber (NDF) as described by Van Soest et al. (1991) and total sugars by difference. Also based on Van Soest et al. (1991) method, the content of cellulose, hemicellulose and lignin were determined for cassava bagasse.

Table 5.1.1. Chemical composition of cassava bagasse.

\begin{tabular}{|c|c|}
\hline \multicolumn{2}{|l|}{ General composition } \\
\hline Moisture ( $\mathrm{g}$ of water $100 \mathrm{~g}^{-1}$ of raw matter) & $4.98 \pm 0.16$ \\
\hline Protein ( $\mathrm{g}$ of protein $100 \mathrm{~g}^{-1}$ of dried matter) & $1.35 \pm 0.04$ \\
\hline Fats ( $\mathrm{g}$ of fats $100 \mathrm{~g}^{-1}$ of dried matter) & $0.30 \pm 0.01$ \\
\hline Ashes ( $\mathrm{g}$ of ashes $100 \mathrm{~g}^{-1}$ of dried matter) & $1.03 \pm 0.04$ \\
\hline Total sugars ( $\mathrm{g}$ of total sugars $100 \mathrm{~g}^{-1}$ of dried matter) & $0.85 \pm 0.04$ \\
\hline Starch ( $\mathrm{g}$ of starch $100 \mathrm{~g}^{-1}$ of dried matter) & $85.93 \pm 0.48$ \\
\hline Fibers ( $\mathrm{g}$ of fibers $100 \mathrm{~g}^{-1}$ of dried matter) & $10.53 \pm 0.47$ \\
\hline \multicolumn{2}{|l|}{ Fibers composition* } \\
\hline Cellulose ( $\mathrm{g}$ of cellulose $100 \mathrm{~g}^{-1}$ of fiber) & $52.79 \pm 0.13$ \\
\hline Hemicellulose ( $\mathrm{g}$ of hemicellulose $100 \mathrm{~g}^{-1}$ of fiber) & $36.82 \pm 1.27$ \\
\hline Lignin ( $\mathrm{g}$ of lignin $100 \mathrm{~g}^{-1}$ of fiber) & $10.39 \pm 0.49$ \\
\hline
\end{tabular}

\subsubsection{Density $(\rho)$ determination}

Density $\left(\rho / \mathrm{kg} \cdot \mathrm{m}^{-3}\right)$ of the different acid slurries containing cassava bagasse were measured in a density meter DMA 4500M (Anton Paar, Austria), using approximately $2 \mathrm{~mL}$ of sample. Measurements were taken after establishing temperatures in triplicate over the temperature range of $278.13-318.13 \mathrm{~K}$ in $10 \mathrm{~K}$ degree intervals in the own equipment. Calibration was carried out with air and deionized water, previously to each experiment.

\subsubsection{Specific heat $\left(c_{p}\right)$ determination}

Slurries samples of approximately $10 \mathrm{mg}$ were added into aluminum pans (ref 0219-0062, Perkin Elmer, USA) through a micro syringe of $25 \mu \mathrm{L}$ (Agilent, Santa 
Clara, USA). The aluminum pans were hermetically sealed to support an internal pressure up to $206.8 \mathrm{kPa}$.

Analyses were carried out in triplicate in a differential scanning calorimeter DSC 8000 (Perkin Elmer, Shelton, USA), using the ASTM E-1269-05 method (ASTM-E1269, 2005). Before each assay, the heating rate was calibrated with standard sapphire disks at heat flow of $20 \mathrm{~K} \cdot \mathrm{min}^{-1}$ (Archer, 1993). Indium (melting point $429.75 \mathrm{~K}, \Delta H_{f}=28.45 \mathrm{~J} \cdot \mathrm{g}^{-1}$ ) was used for temperature calibration. Nitrogen (99.5\% purity) was used as purge gas at approximately $50 \mathrm{~mL} \cdot \mathrm{min}^{-1}$.

The scanning program was: isothermal at $278.13 \mathrm{~K}$ for $4 \mathrm{~min}$, followed by heating up at $20 \mathrm{~K} \cdot \mathrm{min}^{-1}$ up to $318.13 \mathrm{~K}$, then kept isothermal for $4 \mathrm{~min}$. Data at the temperatures of $278.13,288.13,298.13,308.13$ and $318.13 \mathrm{~K}$ were analyzed by PYRIS 10.1 software (Perkin Elmer, Shelton, USA). The results were used to compute $c_{p}$, the specific heat of the slurry $\left(\mathrm{J} \cdot \mathrm{kg}^{-1} \cdot \mathrm{K}^{-1}\right)$, according to Equation (5.1.1), where $c_{P_{S T}}$ is the specific heat of the standard sapphire disk $\left(\mathrm{J} \cdot \mathrm{kg}^{-1} \cdot \mathrm{K}^{-1}\right), D_{S}$ is the vertical displacement between sample and empty pan thermal curves $(\mathrm{mW}), D_{S T}$ is the vertical displacement between sapphire disks and empty pans thermal curves in the same temperature $(\mathrm{mW}), M_{S}$ the sample mass $(\mathrm{kg})$ and $M_{S T}$ is the sapphire disk mass $(\mathrm{kg})$.

$c_{P}=c_{P_{S T}} \frac{D_{S} M_{S T}}{D_{S T} M_{S}}$

\subsubsection{Thermal diffusivity $(\alpha)$ determination}

Thermal diffusivity measurements were conducted in triplicate using a similar apparatus as used by Minin et al. (2009). It was based on a cylindrical metallic cell $\left(24.75 \cdot 10^{-3} \mathrm{~m}\right.$ of internal radius $R$ and $248.5 \cdot 10^{-3} \mathrm{~m}$ of length) with nylon caps of similar thermal diffusivity of the samples $\left(1.09 \cdot 10^{-7} \mathrm{~m}^{2} \cdot \mathrm{s}^{-1}\right)$. Two type $\mathrm{T}$ thermocouples were fixed in the center and on the cell surface and, then, immersed into a stirred thermostatic bath (MK70, MLW, Dresden, Germany). The bath was maintained at constant heating rate and stirred and the temperature was recorded in the center of the cell. 
The calculations of thermal diffusivity were based on the solution of the heat conservation equation for transient system, one-dimensional radial and constant heat flow (Minim et al., 2009). The solution expressed by Equation (5.1.2) considered $T_{R}=T$ for $t>0$ and $r=R$ and $\left.\left(\frac{d T}{d r}\right)\right|_{r=0}=0$ for $t>0$ :

$\alpha=\frac{A R^{2}}{4\left(T_{R}-T_{0}\right)}$

where $\left(T_{R}-T_{0}\right)$ is the temperature difference between the surface and the center of the cell $(\mathrm{K}), A$ is the constant heating rate $\left(\mathrm{K} \cdot \mathrm{s}^{-1}\right)$ and $\alpha$ the thermal diffusivity $\left(\mathrm{m}^{2} \cdot \mathrm{s}^{-1}\right)$. The values of $\alpha$ were calculated for the mean temperatures $\left(\left(T_{R}+T_{0}\right) / 2\right)$ of 278.13 , $288.13,298.13,308.13$ and $318.13 \mathrm{~K}$.

\subsubsection{Thermal conductivity $(\lambda)$ determination}

By the definition of thermal diffusivity, the thermal conductivity values could be obtained by Equation (5.1.3) (Minim et al., 2009):

$\lambda=\alpha \rho c_{p}$

where $\lambda$ is the thermal conductivity $\left(\mathrm{W} \cdot \mathrm{m}^{-1} \cdot \mathrm{K}^{-1}\right), \alpha$ the thermal diffusivity $\left(\mathrm{m}^{2} \cdot \mathrm{s}^{-1}\right), \rho$ the density $\left(\mathrm{kg} \cdot \mathrm{m}^{-3}\right)$ and $c_{p}$ the specific heat $\left(\mathrm{J} \cdot \mathrm{kg}^{-1} \cdot \mathrm{K}^{-1}\right)$. For the calculations, the mean experimental value of each thermophysical property was used.

\subsubsection{Mathematical modeling}

The means and standard deviations of the triplicate experimental values of each property were calculated for the 36 different slurries at the temperatures of $278.13,288.13,298.13,308.13$ and $318.13 \mathrm{~K}$. Means were submitted to estimated effects analysis through STATISTICA 10 (StatSoft Inc., Tulsa, USA). It was analyzed the significance of the linear and quadratic terms of cassava bagasse mass fraction $\left(w_{S}\right)$, mass fraction of phosphoric acid in solution $\left(w_{A}\right)$ and absolute temperature $(T / K)$, besides the linear interaction among them. The significant variables $(p<0.05)$ 
were used to fit the data and provide a predictive equation for each property of the slurries based. The generic Equation (5.1.4) shows the variables and the corresponding empirical parameters $\left(z_{0}\right.$ to $z_{9}$ ), which were obtained from the fitting procedure. The accuracy of the resulting models was evaluated by the determination coefficient $\left(R^{2}\right)$ and the percentage of mean relative error (MRE). The software OriginPro 8.0 (OriginLab Corporation, Northampton, USA) was used to plot the graphs for each variable.

$$
\rho, c_{p}, \alpha, \lambda=z_{0}+z_{1} w_{S}+z_{2} w_{S}^{2}+z_{3} w_{A}+z_{4} w_{A}^{2}+z_{5} T+z_{6} T^{2}+z_{7} w_{S} w_{A}+z_{8} w_{S} T+z_{9} w_{A} T
$$

\subsubsection{Results and discussion}

\subsubsection{Density $(\rho)$}

The mean densities of the slurries were measured for the range of temperature, solids and acid concentration considered. Table 5.1.2 presents such results, which varied from 986.5 up to $1029.3 \mathrm{~kg} \cdot \mathrm{m}^{-3}$. These data are in close agreement with the ones published in literature for acid slurries containing different biomass (Polachini et al., 2016b; Villa-Vélez et al., 2017).

In general, solids content affected density values more intensely than temperature and acid concentration. Taking into account the influence of each variable on the response, a significant linear effect of temperature, acid and biomass concentration was observed. Additionally, quadratic effect of temperature and solids fraction on density was also significant. These terms were employed to fit experimental values and to obtain the Equation (5.1.5) presented in Table 5.1.3.

Figure 5.1.1 represents the data as a function of the studied parameters. It showed a non-linear variation of density when the solids content was changed, being in accordance to the statement of Rahman (1995) for different food fluids. This variation is positive as the solids in suspension increase, probably due to the higher specific mass of the starchy material when compared to the liquid. Cardoso et al. (2013) reported density values between 1368.9 and $1616.8 \mathrm{~kg} \cdot \mathrm{m}^{-3}$ for sorghum and soybean bagasse. After analyzing density of sugarcane bagasse and empty fruit brunch particles, similar data were also observed in the study of Mantilla et al. (2014). 
An increase of slurries densities was also found by increasing acid content. As the phosphoric acid density is close to $1868 \mathrm{~kg} \cdot \mathrm{m}^{-3}$ (Dean, 1999), it results in a positive contribution to the resulting slurry density. In the same way as solids, the increase on acid concentration inserts compounds of higher specific mass in a same volume of sample.

Table 5.1.2.. Means and standard deviations of density measurements.

\begin{tabular}{|c|c|c|c|c|c|c|}
\hline \multirow{3}{*}{$w_{S}$} & \multirow{3}{*}{$w_{A}$} & \multicolumn{5}{|c|}{$\begin{array}{l}\text { Density } \\
\rho / \mathrm{kg} \cdot \mathrm{m}^{-3}\end{array}$} \\
\hline & & & & $\mathrm{T} / \mathrm{K}$ & & \\
\hline & & 278.13 & 288.13 & 298.13 & 308.13 & 318.13 \\
\hline \multirow{6}{*}{0.00} & 0.00 & $993.4 \pm 1.3$ & $993.7 \pm 2.1$ & $991.2 \pm 2.2$ & $989.8 \pm 1.1$ & $986.5 \pm 2.3$ \\
\hline & 0.02 & $995.4 \pm 0.2$ & $994.9 \pm 0.7$ & $993.3 \pm 1.0$ & $991.8 \pm 1.2$ & $989.1 \pm 3.5$ \\
\hline & 0.04 & $997.1 \pm 0.7$ & $996.3 \pm 0.8$ & $995.5 \pm 0.6$ & $993.4 \pm 1.5$ & $990.8 \pm 0.8$ \\
\hline & 0.06 & $998.9 \pm 0.6$ & $998.3 \pm 1.5$ & $997.2 \pm 1.4$ & $995.1 \pm 1.5$ & $992.4 \pm 2.1$ \\
\hline & 0.08 & $1000.8 \pm 1.4$ & $999.3 \pm 2.2$ & $998.9 \pm 1.3$ & $996.5 \pm 0.8$ & 994. \\
\hline & 0.10 & $1002.0 \pm 0.3$ & $1001.8 \pm 0.8$ & $1000.5 \pm 0.8$ & $998.6 \pm 0.9$ & 996. \\
\hline \multirow{6}{*}{0.02} & 0.00 & $997.1 \pm 3.4$ & $996.8 \pm 0.9$ & $995.4 \pm 0.8$ & \pm 1.5 & 2.2 \\
\hline & 0.02 & 1.1 & 997 & $996.6 \pm 2.8$ & 994. & 3.3 \\
\hline & 0.04 & 1000.2 & 1000. & $999.0 \pm 0.8$ & 997.4 & 0.5 \\
\hline & 0.06 & 1002. & 1001 & $1000.0 \pm 1.8$ & 998.1 & 2.8 \\
\hline & 0.08 & & 100 & $1002.6 \pm 0.6$ & 2.1 & \\
\hline & 0.10 & 0.3 & 2.2 & $1003.1 \pm 1.5$ & 1.5 & 2.7 \\
\hline \multirow{6}{*}{0.04} & 0 & & & $999.8 \pm 2.5$ & 2.0 & \\
\hline & 0.02 & & 100 & $1001.1 \pm 1.5$ & \pm 1.2 & \\
\hline & 0.04 & \pm 1.2 & \pm 1.2 & $1003.4 \pm 1.2$ & $1001.1 \pm 4.3$ & \pm 2.7 \\
\hline & 0.06 & \pm 2.6 & \pm 4.7 & $1005.4 \pm 2.3$ & $1002.9 \pm 2.3$ & \pm 0.3 \\
\hline & 0.08 & & \pm 2.0 & $1006.6 \pm 0.7$ & \pm 1.1 & \pm 2.4 \\
\hline & 0.10 & 2.7 & & $1008.5 \pm 2.6$ & 0.9 & 2.5 \\
\hline \multirow{6}{*}{0.06} & & \pm 0.9 & \pm 2.4 & $1004.9 \pm 0.9$ & \pm 2.4 & \pm 0.3 \\
\hline & 0.02 & \pm 2.5 & $1008.5 \pm 0.5$ & $1006.9 \pm 0.8$ & \pm 0.5 & 1002 \\
\hline & 0.04 & $0.1 \pm 0.7$ & $1009.8 \pm 1.0$ & $1008.5 \pm 1.0$ & \pm 1.0 & $.8 \pm 0.8$ \\
\hline & 0.06 & $0 \pm 0.9$ & $9 \pm 1.1$ & $1010.2 \pm 1.2$ & $3 \pm 0.8$ & $1005.3 \pm 0.7$ \\
\hline & 0.08 & \pm 1.0 & $2 \pm 2.3$ & $1011.0 \pm 1.9$ & $4 \pm 2.8$ & $1007.6 \pm 5.9$ \\
\hline & 0.10 & $5 \pm 2.0$ & $9 \pm 1.8$ & $1013.2 \pm 2.4$ & $1011.8 \pm 0.4$ & $1009.2 \pm 1.2$ \\
\hline \multirow{6}{*}{0.08} & 0.00 & \pm 0.9 & $1012.2 \pm 1.7$ & $1011.4 \pm 0.7$ & $1009.9 \pm 2.7$ & $1006.2 \pm 0.3$ \\
\hline & 0.02 & $1014.0 \pm 1.7$ & $1014.6 \pm 1.5$ & $1012.4 \pm 2.5$ & $1010.5 \pm 1.5$ & $1008.6 \pm 4.1$ \\
\hline & 0.04 & $1017.6 \pm 1.8$ & $1015.6 \pm 1.3$ & $1014.5 \pm 4.1$ & $1012.2 \pm 1.1$ & $1009.7 \pm 0.7$ \\
\hline & 0.06 & $1017.4 \pm 1.8$ & $1017.7 \pm 2.3$ & $1016.5 \pm 2.5$ & $1014.5 \pm 0.8$ & $1011.5 \pm 0.2$ \\
\hline & 0.08 & $1020.2 \pm 0.3$ & $1019.9 \pm 0.8$ & $1017.9 \pm 1.4$ & $1016.5 \pm 2.2$ & $1012.7 \pm 0.7$ \\
\hline & 0.10 & $1021.5 \pm 1.3$ & $1021.1 \pm 4.2$ & $1019.6 \pm 0.2$ & $1018.4 \pm 0.8$ & $1014.4 \pm 3.5$ \\
\hline \multirow{6}{*}{0.10} & 0.00 & $1020.2 \pm 2.3$ & $1019.2 \pm 4.9$ & $1018.7 \pm 2.5$ & $1016.7 \pm 4.3$ & $1013.6 \pm 1.6$ \\
\hline & 0.02 & $1022.2 \pm 1.7$ & $1021.7 \pm 3.1$ & $1020.4 \pm 2.1$ & $1018.1 \pm 2.2$ & $1015.7 \pm 1.0$ \\
\hline & 0.04 & $1023.8 \pm 2.9$ & $1023.4 \pm 2.3$ & $1022.2 \pm 1.4$ & $1020.1 \pm 1.2$ & $1017.5 \pm 2.2$ \\
\hline & 0.06 & $1025.5 \pm 1.0$ & $1025.0 \pm 1.1$ & $1024.2 \pm 1.5$ & $1021.1 \pm 1.4$ & $1019.2 \pm 1.4$ \\
\hline & 0.08 & $1026.8 \pm 2.7$ & $1026.6 \pm 0.7$ & $1025.3 \pm 1.8$ & $1023.6 \pm 2.6$ & $1020.8 \pm 1.7$ \\
\hline & 0.10 & $1029.0 \pm 1.5$ & $1029.3 \pm 1.6$ & $1027.2 \pm 1.3$ & $1025.3 \pm 2.9$ & $1022.4 \pm 0.6$ \\
\hline
\end{tabular}


The influence of temperature is related to the degree of molecular interaction. When heated, intermolecular bonds such as hydrogen bonds are weakened and the molecules gain kinetic energy (Kruse and Dahmen, 2015). It resulted in a slight increase on the volume and, consequently, a decrease on the final density.

Table 5.1.3. Fitting parameters ( $\pm 95 \%$ of confidence) of the empirical equations to predict density $(\rho)$, specific heat $\left(c_{p}\right)$, thermal diffusivity $(\alpha)$ and thermal conductivity $(\lambda)$ as function of cassava bagasse fraction in the slurries $\left(w_{S}\right)$, phosphoric acid in the solution $\left(W_{A}\right)$ and absolute temperature $(T / K)$.

\begin{tabular}{ccccc}
\hline \multirow{2}{*}{ Parameter } & $\rho / \mathrm{kg} \cdot \mathrm{m}^{-3}$ & $c_{p} / \mathrm{J} \cdot \mathrm{kg}^{-1} \cdot \mathrm{K}^{-1}$ & $\alpha \cdot 10^{7} / \mathrm{m}^{2} \cdot \mathrm{s}^{-1}$ & $\lambda / \mathrm{W} \cdot \mathrm{m}^{-1} \cdot \mathrm{K}^{-1}$ \\
& Eq. $(5.1 .5)$ & Eq. $(5.1 .6)$ & Eq. $(5.1 .7)$ & Eq. $(5.1 .8)$ \\
\hline$z_{0}$ & $701.49 \pm 30.43$ & $3886.60 \pm 143.16$ & $1.0477 \pm 0.0192$ & $0.4392 \pm 0.0136$ \\
$z_{1}$ & $145.01 \pm 5.98$ & $-756.34 \pm 398.70$ & $-0.5230 \pm 0.0943$ & $-0.2729 \pm 0.0666$ \\
$z_{2}$ & $1219.29+57.50$ & $-16917.76 \pm 3827.10$ & $-31.4530 \pm 0.9048$ & $-13.8121 \pm 0.6397$ \\
$z_{3}$ & $87.19 \pm 1.68$ & $2948.06 \pm 2390.27$ & $-1.4561 \pm 0.0943$ & $-0.5087 \pm 0.01869$ \\
$z_{4}$ & - & $-6058.23 \pm 3827.10$ & $1.4153 \pm 0.9048$ & - \\
$z_{5}$ & $2.107 \pm 0.205$ & $0.767 \pm 0.478$ & $0.0015 \pm 0.0001$ & $0.0006 \pm 0.0001$ \\
$z_{6}$ & $-0.004 \pm 0.0003$ & - & - & - \\
$z_{7}$ & - & - & - & - \\
$z_{8}$ & - & - & - & - \\
$z_{9}$ & - & $-8.46 \pm 7.906$ & - & 0.995 \\
$R^{2}$ & 0.998 & 0.921 & 0.998 & $1.75 \%$ \\
$M R E$ & $0.04 \%$ & $0.47 \%$ & $0.59 \%$ & \\
\hline
\end{tabular}




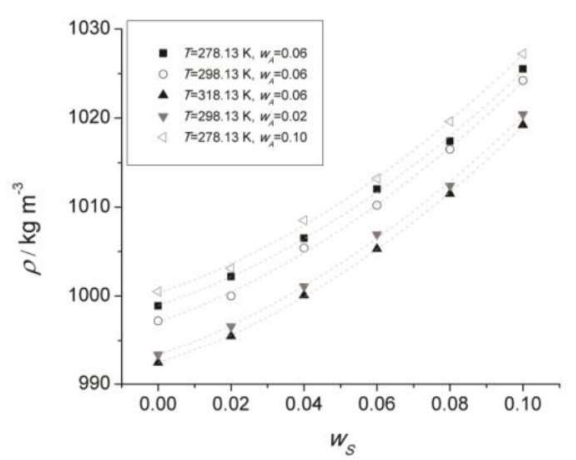

(a)

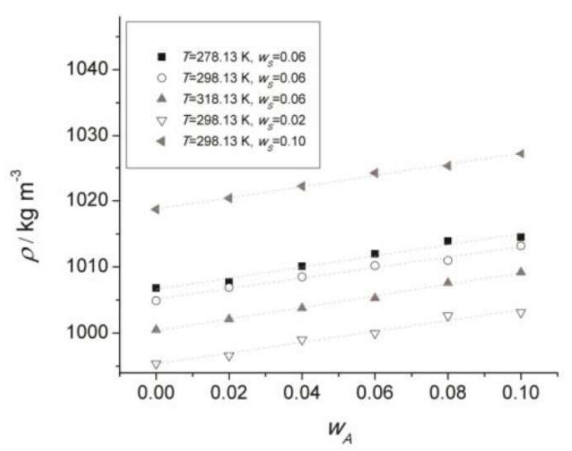

(b)

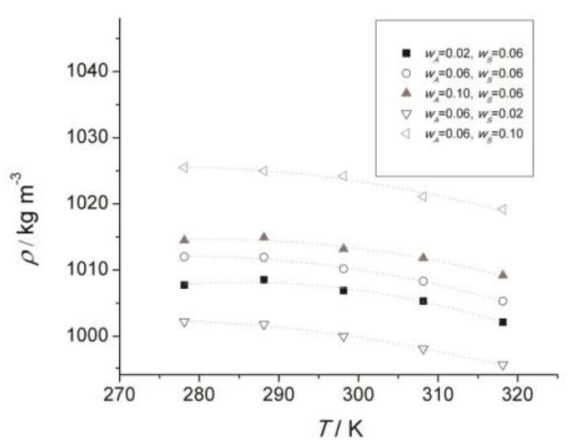

(c)

Figure 5.1.1. Density values as a function of (a) solids concentration; (b) acid concentration and (c) absolute temperature.

\subsubsection{Specific heat $\left(c_{p}\right)$}

The experimental mean values of measured specific heat varied from 3830.0 to $4142.6 \mathrm{~J} \cdot \mathrm{kg}^{-1} \cdot \mathrm{K}^{-1}$, as shown in Table 5.1.4. These results are in agreement with the data reported for acidified suspensions containing powdered peanut shells and banana flower-stalk (Polachini et al., 2017; Villa-Vélez et al., 2017), which were also determined by differential scanning calorimetry. 
Table 5.1.4. Means and standard deviations of specific heat measurements.

\begin{tabular}{|c|c|c|c|c|c|c|}
\hline \multirow{3}{*}{$w_{s}$} & \multirow{3}{*}{$w_{A}$} & \multicolumn{5}{|c|}{$\begin{array}{l}\text { Specific heat } \\
c_{p} / \mathrm{J} \cdot \mathrm{kg}^{-1} \cdot \mathrm{K}^{-1}\end{array}$} \\
\hline & & & & & & \\
\hline & & 278.13 & 288.13 & 298.13 & 308.13 & 318.13 \\
\hline \multirow{6}{*}{0.00} & 0.00 & $4085.5 \pm 11.6$ & $4104.4 \pm 11.0$ & $4086.9 \pm 16.6$ & $4112.4 \pm 11.2$ & $4108.3 \pm 14.2$ \\
\hline & 0.02 & $4127.6 \pm 6.4$ & $4127.8 \pm 9.5$ & $4108.5 \pm 12.5$ & $4110.8 \pm 8.9$ & $4111.5 \pm 4.1$ \\
\hline & 0.04 & $4139.1 \pm 8.7$ & $4106.5 \pm 12.3$ & $4103.3 \pm 5.4$ & $4132.7 \pm 5.1$ & $4140.4 \pm 9.1$ \\
\hline & 0.06 & $4096.4 \pm 4.1$ & $4133.7 \pm 4.2$ & $4135.3 \pm 5.5$ & $4125.9 \pm 5.7$ & $4130.6 \pm 2.0$ \\
\hline & 0.08 & $4142.6 \pm 5.6$ & $4138.9 \pm 10.8$ & $4141.8 \pm 4.0$ & $4130.1 \pm 12.7$ & $4091.7 \pm 6.0$ \\
\hline & 0.10 & $4104.1 \pm 7.1$ & $4100.2 \pm 5.8$ & $4101.4 \pm 5.7$ & $4107.8 \pm 4.0$ & $4122.0 \pm 11.9$ \\
\hline \multirow{6}{*}{0.02} & 0.00 & $4102.9 \pm 6.1$ & $4076.1 \pm 2.9$ & $4103.4 \pm 1.1$ & $4119.8 \pm 8.9$ & $4107.6 \pm 8.9$ \\
\hline & 0.02 & $4078.7 \pm 2.3$ & $4114.6 \pm 8.7$ & $4103.7 \pm 8.9$ & $4104.2 \pm 8.1$ & $4115.4 \pm 22.0$ \\
\hline & 0.04 & $4008.8 \pm 5.8$ & $4095.7 \pm 7.5$ & $4089.6 \pm 8.7$ & $4117.3 \pm 11.3$ & $4103.3 \pm 13.9$ \\
\hline & 0.06 & $4088.4 \pm 9.8$ & $4068.3 \pm 5.8$ & $4095.5 \pm 11.1$ & $4121.2 \pm 13.2$ & $4096.4 \pm 10.9$ \\
\hline & 0.08 & $4089.0 \pm 9.4$ & $4089.5 \pm 8.2$ & $4099.4 \pm 8.3$ & $4112.7 \pm 9.1$ & $4075.6 \pm 5.4$ \\
\hline & 0.10 & $4062.5 \pm 5.0$ & $4057.1 \pm 8.8$ & $4019.6 \pm 12.2$ & $4021.9 \pm 4.5$ & $4117.8 \pm 8.5$ \\
\hline \multirow{6}{*}{0.04} & 0.00 & $4072.5 \pm 22.6$ & $4005.9 \pm 2.1$ & $4007.8 \pm 2.7$ & $4080.6 \pm 2.4$ & $4087.3 \pm 4.1$ \\
\hline & 0.02 & $4072.5 \pm 9.3$ & $4050.5 \pm 5.6$ & $4075.3 \pm 9.7$ & $4078.5 \pm 14.4$ & $4062.3 \pm 13.2$ \\
\hline & 0.04 & $4029.7 \pm 4.4$ & $4074.4 \pm 12.5$ & $4072.6 \pm 5.8$ & $4003.5 \pm 3.0$ & $4091.1 \pm 2.0$ \\
\hline & 0.06 & $3992.5 \pm 3.0$ & $4065.2 \pm 5.4$ & $4078.8 \pm 8.1$ & $4069.7 \pm 2.7$ & $4001.6 \pm 3.3$ \\
\hline & 0.08 & $4062.2 \pm 2.0$ & $4068.5 \pm 14.8$ & $4064.9 \pm 3.2$ & $4073.1 \pm 4.1$ & $4074.3 \pm 1.6$ \\
\hline & 0.10 & $4056.3 \pm 8.8$ & $4048.1 \pm 11.0$ & $4052.7 \pm 8.0$ & $4061.7 \pm 9.4$ & $4053.6 \pm 5.7$ \\
\hline \multirow{6}{*}{0.06} & 0.00 & $3986.0 \pm 6.1$ & $3987.3 \pm 9.2$ & $4023.2 \pm 11.2$ & $4030.1 \pm 11.4$ & $4042.4 \pm 4.1$ \\
\hline & 0.02 & $4031.9 \pm 16.6$ & $3967.5 \pm 8.7$ & $4023.5 \pm 5.5$ & $4026.8 \pm 6.8$ & $4039.0 \pm 9.1$ \\
\hline & 0.04 & $4020.1 \pm 4.6$ & $3964.8 \pm 4.0$ & $4021.0 \pm 6.1$ & $4030.4 \pm 6.8$ & $4032.5 \pm 2.0$ \\
\hline & 0.06 & $4023.5 \pm 2.7$ & $4017.6 \pm 6.1$ & $3961.5 \pm 3.9$ & $4022.8 \pm 9.4$ & $4028.7 \pm 6.7$ \\
\hline & 0.08 & $4011.5 \pm 5.9$ & $4016.4 \pm 16.1$ & $3896.6 \pm 15.2$ & $4017.9 \pm 6.1$ & $4025.4 \pm 5.3$ \\
\hline & 0.10 & $3997.5 \pm 14.2$ & $3993.4 \pm 2.6$ & $3995.6 \pm 5.2$ & $3998.6 \pm 3.4$ & $4014.0 \pm 6.0$ \\
\hline \multirow{6}{*}{0.08} & 0.00 & $3976.6 \pm 1.6$ & $3919.9 \pm 7.2$ & $3976.9 \pm 3.1$ & $3980.4 \pm 5.4$ & $3992.2 \pm 19.5$ \\
\hline & 0.02 & $3967.8 \pm 11.8$ & $3980.9 \pm 4.7$ & $3901.8 \pm 9.3$ & $3980.6 \pm 14.9$ & $3991.2 \pm 4.4$ \\
\hline & 0.04 & $3965.1 \pm 14.4$ & $3975.9 \pm 15.1$ & $3980.8 \pm 11.4$ & $3977.9 \pm 17.1$ & $3936.9 \pm 11.8$ \\
\hline & 0.06 & $3959.6 \pm 16.9$ & $3937.9 \pm 6.4$ & $3963.7 \pm 6.1$ & $3967.0 \pm 8.8$ & $3971.2 \pm 11.0$ \\
\hline & 0.08 & $3962.6 \pm 8.3$ & $3964.3 \pm 6.6$ & $3966.7 \pm 10.9$ & $3958.5 \pm 8.3$ & $3892.6 \pm 13.0$ \\
\hline & 0.10 & $3945.1 \pm 5.3$ & $3918.3 \pm 9.4$ & $3857.6 \pm 6.3$ & $3878.4 \pm 6.5$ & $3864.7 \pm 13.3$ \\
\hline \multirow{6}{*}{0.10} & 0.00 & $3851.1 \pm 6.6$ & $3846.0 \pm 10.2$ & $3873.5 \pm 2.5$ & $3877.2 \pm 2.4$ & $3862.4 \pm 7.4$ \\
\hline & 0.02 & $3849.7 \pm 8.7$ & $3849.2 \pm 5.0$ & $3886.9 \pm 5.7$ & $3859.8 \pm 11.7$ & $3860.1 \pm 2.4$ \\
\hline & 0.04 & $3870.1 \pm 2.7$ & $3876.2 \pm 10.9$ & $3849.4 \pm 8.3$ & $3887.9 \pm 11.3$ & $3892.7 \pm 7.8$ \\
\hline & 0.06 & $3863.4 \pm 9.3$ & $3866.8 \pm 5.9$ & $3895.1 \pm 6.2$ & $3895.0 \pm 15.4$ & $3901.0 \pm 8.1$ \\
\hline & 0.08 & $3866.9 \pm 11.5$ & $3830.0 \pm 4.3$ & $3860.9 \pm 9.1$ & $3860.7 \pm 8.4$ & $3865.0 \pm 5.4$ \\
\hline & 0.10 & $3845.4 \pm 4.5$ & $3857.8 \pm 11.1$ & $3871.8 \pm 4.0$ & $3849.5 \pm 3.8$ & $3878.1 \pm 5.5$ \\
\hline
\end{tabular}


The evaluation of the variables effects on the specific heat of cassava bagasse slurries showed higher effect of biomass concentration, followed by acid content and temperature. The significant terms of each variable were used to obtain the Equation (5.1.6) with the fitting parameters showed in Table 5.1.3.

Figure 5.1.2 presents the corresponding regression, in which could be seen the higher influence of solids concentration in front of acid content and temperature. Increasing biomass loading implied decreasing specific heat, indicating the lower heat capacity of cassava bagasse compared to the dispersant. It is mainly related to the presence of carbohydrates such as starch and fibers, which have specific heat approximately three times lower than water (Choi and Okos, 1986). Reported data of specific heat for different biomass in the range $1300-2000 \mathrm{~J} \cdot \mathrm{kg}^{-1} \cdot \mathrm{K}^{-1}$ also indicates the decrease on specific heat after solids addition (Dupont et al., 2014; Williams et al., 2017). In the specific case of cassava, Njie et al. (1998) reinforced this trend by determining specific heat of cassava at different moisture content and temperature. Values from 1636 to $3275 \mathrm{~J} \cdot \mathrm{kg}^{-1} \cdot \mathrm{K}^{-1}$ where observed for the lowest moisture content and temperature ( $10 \mathrm{~g}$ of water per $100 \mathrm{~g}$ of wet cassava at $309.13 \mathrm{~K}$ ) and for the highest moisture content and temperature $(68 \mathrm{~g}$ of water per $100 \mathrm{~g}$ of wet cassava at $324.13 \mathrm{~K}$ ), respectively. The addition of a specific solute in solution promotes a breakdown of the hydrogen bonds existing in the liquid medium (electrostriction effect), leading to a decrease in the specific heat values. The liquid medium bonds the biomass particles according to the particle composition and molecules conformation, which makes important the determination specifically for the case of cassava bagasse.

Among others, Dupont et al. (2014), Bitra et al. (2010) or Guo et al. (2013) reported a linear dependence on temperature of the specific heat of distinct sources of biomass. This is in accordance to the results obtained in this study, which also observed a slight positive dependence on temperature of the specific heat of cassava bagasse slurries. In the same way, the phosphoric acid content demonstrated a significant negative effect on $c_{p}$. At higher temperatures, the specific heat decreased as the $\mathrm{H}_{3} \mathrm{PO}_{4}$ concentration in the dispersant increased maybe due to the low heat capacity of phosphoric acid $\left(\sim 1500 \mathrm{~J} \cdot \mathrm{kg}^{-1} \cdot \mathrm{K}^{-1}\right.$ at $\left.298.13 \mathrm{~K}\right)$ (Dean, 1999) and to the electrostriction effect. 


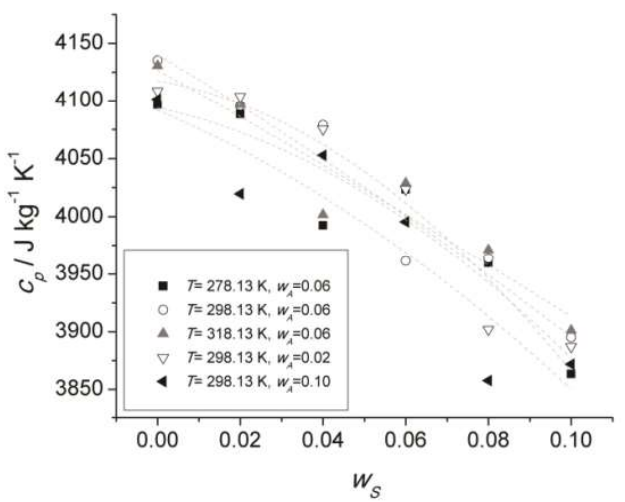

(a)

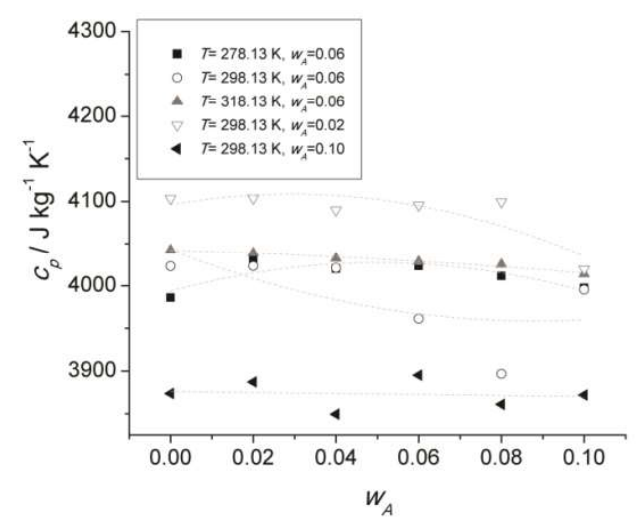

(b)

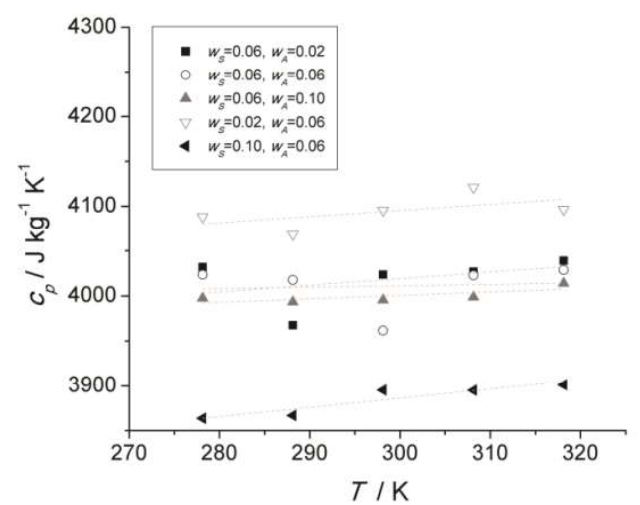

(c)

Figure 5.1.2. Specific heat values as a function of (a) solids concentration; (b) acid concentration and (c) absolute temperature.

\subsubsection{Thermal diffusivity ( $\alpha)$}

The effective thermal diffusivity values of cassava bagasse are presented in Table 5.1 .5 , ranging between $0.9624 \cdot 10^{-7}$ and $1.5249 \cdot 10^{-7} \mathrm{~m}^{2} \cdot \mathrm{s}^{-1}$ on the conditions 
tested. The experimental data are close to the ones published for fruit juices (Cabral et al., 2007; Minim et al., 2009).

Table 5.1.5. Means and standard deviations of thermal diffusivity measurements.

\begin{tabular}{|c|c|c|c|c|c|c|}
\hline \multirow{3}{*}{$w_{S}$} & & \multicolumn{5}{|c|}{$\begin{array}{c}\text { Thermal diffusivity } \\
\alpha \cdot 10^{7} / \mathrm{m}^{2} \cdot \mathrm{s}^{-1}\end{array}$} \\
\hline & & & & & & \\
\hline & & 278.13 & & 298.13 & & \\
\hline \multirow{6}{*}{0.00} & 0.00 & $1.4702 \pm 0.0115$ & $1.4635 \pm 0.0098$ & $1.4950 \pm 0.0228$ & $1.5023 \pm 0.0145$ & 1.5249 \\
\hline & 0.02 & $4327 \pm 0.0060$ & $4517 \pm 0.0123$ & $1.4650 \pm 0.0172$ & $1.4839 \pm 0.074$ & $1.5149 \pm$ \\
\hline & 0.04 & $1.4090 \pm 0.0121$ & $1.4251 \pm 0.0096$ & $1.4382 \pm 0.0055$ & $1.4438 \pm 0.0129$ & \\
\hline & 0.06 & $1.3796 \pm 0.0116$ & $1.3871 \pm 0.0066$ & $1.4023 \pm 0.0042$ & $1.4182 \pm 0.0126$ & $1.4317 \pm 0.0033$ \\
\hline & 0.08 & $1.3525 \pm 0.0075$ & $1.3822 \pm 0.0209$ & $1.3910 \pm 0.0063$ & $1.4042 \pm 0.0089$ & $1.4232 \pm 0.0014$ \\
\hline & 0.10 & $1.3341 \pm 0.0091$ & $1.3486 \pm 0.0037$ & $1.3658 \pm 0.0043$ & 1.3799 & 1.3993 \\
\hline \multirow{6}{*}{0.02} & 0.00 & & & $20 \pm 0.0098$ & 1.485 & \\
\hline & 0.02 & & & $12 \pm 0.0161$ & & \\
\hline & 0.04 & & & $1.4167 \pm 0.0038$ & & \\
\hline & 0.06 & $1.3567 \pm 0.0030$ & $1.3754 \pm 0.0087$ & $1.3887 \pm 0.0183$ & $1.4074 \pm$ & $1.4375 \pm 0.0095$ \\
\hline & 0.08 & $1.3346 \pm 0.0043$ & $1.3506 \pm 0.0095$ & $1.3638 \pm 0.0047$ & 1.3698 & 1.390 \\
\hline & 0.10 & $1.3070 \pm 0.0165$ & 1.3149 & $1.3301 \pm 0.0048$ & 1.3460 & 0109 \\
\hline \multirow{6}{*}{0.04} & 0.00 & & & $57 \pm 0.0094$ & & \\
\hline & 0.02 & & & $9 \pm 0.0$ & & \\
\hline & 0.04 & & & $37 \pm 0.0119$ & & \\
\hline & 0.06 & & & $1.3279 \pm 0.0011$ & & \\
\hline & 0.08 & $1.2859 \pm 0.0061$ & $1.2995 \pm$ & $1.3107 \pm 0.0013$ & $1.3306 \pm$ & 1.347 \\
\hline & 0.10 & $1.2575 \pm 0.0127$ & 1.26 & $1 \pm 0.01$ & & \\
\hline \multirow{6}{*}{0.06} & 0.00 & & & $2 \pm 0.0125$ & 1.36 & $\overline{1.3 \xi}$ \\
\hline & 0.02 & & & $30 \pm 0.0024$ & & \\
\hline & 0.04 & 1.26 & & $42 \pm 0.0042$ & & \\
\hline & 0.06 & & 1.24 & $9 \pm 0.0003$ & & \\
\hline & 0.08 & $1.2145 \pm 0.0030$ & & $1.2334 \pm 0.0152$ & 1.26 & \\
\hline & 0.10 & $1.1895 \pm 0.0087$ & & $1.2187 \pm 0.0192$ & 1.23 & \pm 0.0092 \\
\hline \multirow{6}{*}{0.08} & 0.00 & $1.2227 \pm 0.0055$ & 1.239 & $1.2539 \pm 0.0021$ & $1.2598 \pm 0.0109$ & $1.2856 \pm 0.0010$ \\
\hline & 0.02 & & & $41 \pm 0.0149$ & 1.24 & \\
\hline & 0.04 & 1.16 & & $9 \pm 0.0229$ & 1.21 & 1.23 \\
\hline & 0.06 & & & $1.1706 \pm 0.0135$ & & \\
\hline & 0.08 & $1.1156 \pm 0.0016$ & $1.1300 \pm 0.0054$ & $1.1469 \pm 0.0052$ & $1.1626 \pm 0.0143$ & $1.1790 \pm 0.0030$ \\
\hline & 0.10 & $1.0909 \pm 0.0111$ & $1.0949 \pm 0.0090$ & $1.1212 \pm 0.0002$ & $1.1325 \pm 0.0003$ & $1.1390 \pm 0.0026$ \\
\hline \multirow{6}{*}{0.10} & 0.00 & $1.0906 \pm 0.0092$ & $1.1022 \pm 0.0089$ & $1.1205 \pm 0.0014$ & $1.1349 \pm 0.0088$ & $1.1550 \pm 0.0078$ \\
\hline & 0.02 & & & $1.0923 \pm 0.0092$ & & \\
\hline & 0.04 & $1.0364 \pm 0.0033$ & $1.0501 \pm 0.0090$ & $1.0687 \pm 0.0024$ & $1.0848 \pm 0.0020$ & $1.0964 \pm 0.0092$ \\
\hline & 0.06 & $1.0145 \pm 0.0048$ & $1.0289 \pm 0.0092$ & $1.0423 \pm 0.0016$ & $1.0579 \pm 0.0064$ & $1.0778 \pm 0.0053$ \\
\hline & 0.08 & $0.9907 \pm 0.0102$ & $1.0053 \pm 0.0029$ & $1.0184 \pm 0.0068$ & $1.0284 \pm 0.0019$ & $1.0485 \pm 0.0015$ \\
\hline & 0.10 & $0.9624 \pm 0.0060$ & $0.9767 \pm 0.0065$ & $0.9922 \pm 0.0056$ & $1.0091 \pm 0.0102$ & $1.0268 \pm 0.0031$ \\
\hline
\end{tabular}

It is known that thermal diffusivity is a relation between the facility of heat conduction, given by thermal conductivity $(\lambda)$, and the energy storage capacity, given 
by the volumetric heat capacity $\left(\rho c_{p}\right)$. Among those parameters, thermal conductivity of the slurries is the one that can be affected by the size and porosity of the suspended particles. The high porosity of particles could promote an increase on its permeability. However, despite the improvement on mass transfer, the heat transfer inside the particles is impaired. In order to reduce the porosity effect on the thermal properties of the resulting slurries, this study intended to work with small particle size which also contributed to maintain its homogeneity during the determinations.

Among the whole studied terms for each variable, the quadratic terms of temperature and all interactions did not significantly affect thermal diffusivity. As occurred for the previous properties, thermal diffusivity was more affected by biomass loading than by acid concentration and temperature. As stated by Singh (1982), temperature and water content are determinant factors to promote changes on thermal diffusivity of food products as small changes on food composition seem to have a small influence on this property. The Equation (5.1.7) presented in Table 5.1.3 expressed this property with great accuracy and low mean relative error.

As shown in Figure 5.1.3 thermal diffusivity values decreased with increasing cassava bagasse concentration. It can be linked to the low intrinsic thermal properties of the solids in suspension. The study of Choi and Okos (1986) presents the predictive equations for thermal diffusivity of the individual compounds of foodstuff, such as carbohydrates and fibers, as a function of temperature. Using the predicted thermal diffusivity value for carbohydrates (or even fibers) at $293.13 \mathrm{~K}$, it could be seen that they represent almost the half of water thermal diffusivity at the same temperature. Although these equations are useful for estimate food properties, they do not take into account the interactions between the compounds as experimental measurements. Some works looked for obtaining experimental thermal diffusivity of lignocellulosic materials to optimize the biomass pyrolysis (Jalan and Srivastava, 1999; Koufopanos et al., 1991; Williams et al., 2017). However, these studies reported different results due to the material heterogeneity such as porosity and anisotropic properties.

Slurries with increasing acid content in the dispersant medium showed an analogous effect like the solids increase, although less pronounced. The decrease of thermal diffusivity with increasing phosphoric acid concentration is a response to its 
low thermal conductivity caused by the disorganization of the hydrogen bonds of the liquid by adding both acid and biomass. Mixtures of acid/water tended to present lower values as the medium became more acidified (Turnbull, 1971).

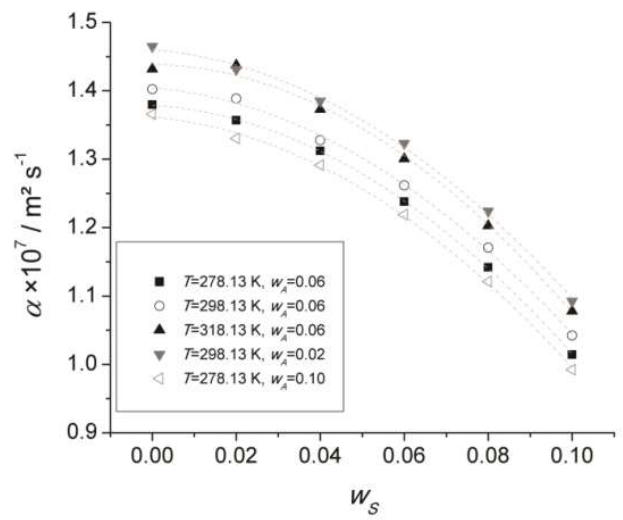

(a)

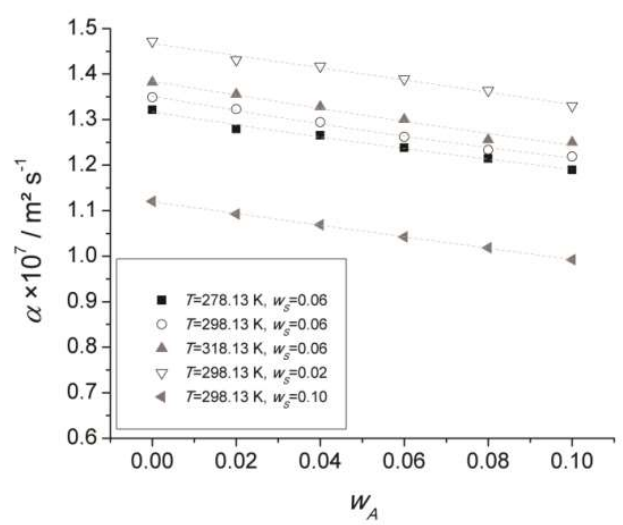

(b)

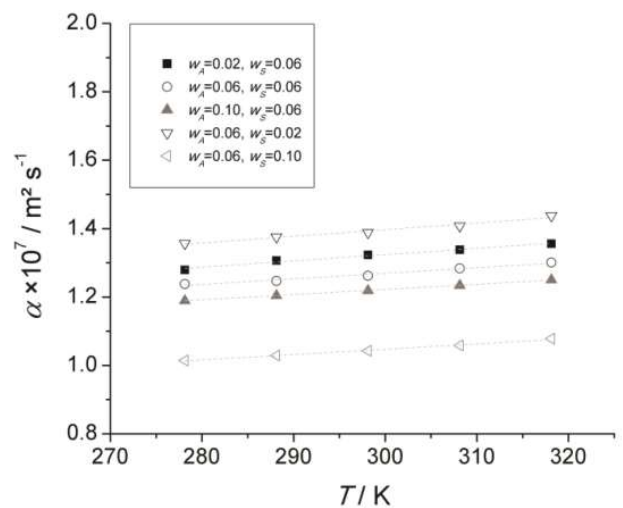

(c)

Figure 5.1.3. Thermal diffusivity values as a function of (a) solids concentration; (b) acid concentration and (c) absolute temperature. 
Heating the suspension induced a slight increase in thermal diffusivity. It is a consequence of a decrease in density and, consequently, in volumetric heat capacity $\left(\rho c_{p}\right)$ of the suspension in front an increase on temperature, even though the specific heat shows a little decrease with increasing temperature. This behavior is reinforced by the decrease on predicted values of volumetric heat capacity (from 3934.43 to $4111.48 \mathrm{~kJ} \cdot \mathrm{m}^{-3} \cdot \mathrm{K}^{-1}$ ) and, likely, a increase on thermal conductivity at the same conditions.

\subsubsection{Thermal conductivity $(\lambda)$}

Thermal conductivity $(\lambda)$ was also determined from the values of thermal diffusivity, specific heat and density for the different suspensions. The calculated values varied from (0.3808 up to 0.6180$) \mathrm{W} \cdot \mathrm{m}^{-1} \cdot \mathrm{K}^{-1}$ in the range of solids and acid concentration and temperature. Means and standard deviations of the triplicates are displayed in Table 5.1.6.

As the thermal conductivity was determined from the thermal diffusivity data, it is expected to be affected by the contribution of the significant variables affecting the latter. The non-linear regression resulted in Equation (5.1.8) with the fitting parameters contained in Table 5.1.3.

The Figure 5.1.4 shows that thermal conductivity $(\lambda)$ values follow the same trend as thermal diffusivity $(\alpha)$ values, as seen as they are functions of each other. The effective heat conduction is dependent on the dispersed and dispersant properties. The increase in biomass content resulted in lower thermal conductivity of the slurries. It was probably due to the low heat conduction capacity of the starchy residues, which was observed by Maroulis et al. (1990) for starch granules. As phosphoric acid and starchy materials also present a low heat conduction capacity (Turnbull, 1971), the increase of these compounds in suspensions contributed to the reduction on thermal conductivity of the resulting slurry. In other words, dilute slurries would result in more intense heat exchanges during biomass hydrolysis at high temperatures as a consequence of the increase on thermal conductivity. 
Table 5.1.6. Means and standard deviations of thermal conductivity values.

\begin{tabular}{|c|c|c|c|c|c|c|}
\hline \multirow{3}{*}{$w_{S}$} & \multirow{3}{*}{$w_{A}$} & \multicolumn{5}{|c|}{$\begin{array}{c}\text { Thermal conductivity } \\
\lambda / \mathrm{W} \cdot \mathrm{m}^{-1} \cdot \mathrm{K}^{-1}\end{array}$} \\
\hline & & & & $T / \mathrm{K}$ & & \\
\hline & & 278.13 & 288.13 & 298.13 & 308.13 & 318.13 \\
\hline \multirow{6}{*}{0.00} & 0.00 & $0.5967 \pm 0.0071$ & $0.5969 \pm 0.0069$ & $0.6056 \pm 0.0130$ & $0.6115 \pm 0.0083$ & $0.6180 \pm 0.0130$ \\
\hline & 0.02 & $0.5886 \pm 0.0035$ & $0.5962 \pm 0.0068$ & $0.5979 \pm 0.0095$ & $0.6050 \pm 0.0051$ & $0.6161 \pm 0.0056$ \\
\hline & 0.04 & $0.5815 \pm 0.0066$ & $0.5831 \pm 0.0062$ & $0.5875 \pm 0.0034$ & $0.5927 \pm 0.0069$ & $0.6008 \pm 0.0069$ \\
\hline & 0.06 & $0.5645 \pm 0.0056$ & $0.5724 \pm 0.0042$ & $0.5783 \pm 0.0033$ & $0.5823 \pm 0.0069$ & $0.5869 \pm 0.0029$ \\
\hline & 0.08 & $0.5607 \pm 0.0046$ & $0.5717 \pm 0.0114$ & $0.5755 \pm 0.0039$ & $0.5779 \pm 0.0059$ & $0.5788 \pm 0.0019$ \\
\hline & 0.10 & $0.5486 \pm 0.0048$ & $0.5540 \pm 0.0027$ & $0.5604 \pm 0.0030$ & $0.5660 \pm 0.0028$ & $0.5748 \pm 0.0096$ \\
\hline \multirow{6}{*}{0.02} & 0.00 & $0.5956 \pm 0.0045$ & $0.5912 \pm 0.0030$ & $0.6013 \pm 0.0047$ & $0.6078 \pm 0.0091$ & $0.6070 \pm 0.0080$ \\
\hline & 0.02 & $0.5724 \pm 0.0039$ & $0.5843 \pm 0.0071$ & $0.5853 \pm 0.0095$ & $0.5907 \pm 0.0059$ & $0.5975 \pm 0.0111$ \\
\hline & 0.04 & $0.5500 \pm 0.0036$ & $0.5712 \pm 0.0036$ & $0.5788 \pm 0.0032$ & $0.5849 \pm 0.0048$ & $0.5897 \pm 0.0036$ \\
\hline & 0.06 & $0.5559 \pm 0.0028$ & $0.5606 \pm 0.0053$ & $0.5687 \pm 0.0100$ & $0.5789 \pm 0.0058$ & $0.5862 \pm 0.0071$ \\
\hline & 0.08 & $0.5478 \pm 0.0035$ & $0.5540 \pm 0.0059$ & $0.5605 \pm 0.0034$ & $0.5638 \pm 0.0037$ & $0.5653 \pm 0.0034$ \\
\hline & 0.10 & $0.5340 \pm 0.0075$ & $0.5362 \pm 0.0037$ & $0.5363 \pm 0.0043$ & $0.5423 \pm 0.0026$ & $0.5597 \pm 0.0072$ \\
\hline \multirow{6}{*}{0.04} & 0.00 & $0.5649 \pm 0.0070$ & $0.5682 \pm 0.0025$ & $0.5713 \pm 0.0056$ & $0.5901 \pm 0.0062$ & $0.5876 \pm 0.0047$ \\
\hline & 0.02 & $0.5577 \pm 0.0061$ & $0.5609 \pm 0.0065$ & $0.5650 \pm 0.0068$ & $0.5709 \pm 0.0083$ & $0.5743 \pm 0.0082$ \\
\hline & 0.04 & $0.5382 \pm 0.0065$ & $0.5498 \pm 0.0078$ & $0.5552 \pm 0.0063$ & $0.5481 \pm 0.0108$ & $0.5655 \pm 0.0019$ \\
\hline & 0.06 & $0.5273 \pm 0.0062$ & $0.5419 \pm 0.0119$ & $0.5446 \pm 0.0028$ & $0.5484 \pm 0.0018$ & $0.5494 \pm 0.0048$ \\
\hline & 0.08 & $0.5267 \pm 0.0030$ & $0.5329 \pm 0.0063$ & $0.5363 \pm 0.0013$ & $0.5445 \pm 0.0031$ & $0.5500 \pm 0.0059$ \\
\hline & 0.10 & $0.5152 \pm 0.0077$ & $0.5185 \pm 0.0022$ & $0.5277 \pm 0.0072$ & $0.5340 \pm 0.0067$ & $0.5332 \pm 0.0021$ \\
\hline \multirow{6}{*}{0.06} & 0.00 & $0.5303 \pm 0.0024$ & $0.5302 \pm 0.0031$ & $0.5455 \pm 0.0071$ & $0.5526 \pm 0.0074$ & $0.5589 \pm 0.0020$ \\
\hline & 0.02 & $0.5197 \pm 0.0035$ & $0.5229 \pm 0.0022$ & $0.5360 \pm 0.0021$ & $0.5416 \pm 0.0021$ & $0.5487 \pm 0.0032$ \\
\hline & 0.04 & $0.5140 \pm 0.0018$ & $0.5127 \pm 0.0023$ & $0.5248 \pm 0.0030$ & $0.5316 \pm 0.0032$ & $0.5377 \pm 0.0028$ \\
\hline & 0.06 & $0.5041 \pm 0.0027$ & $0.5069 \pm 0.0020$ & $0.5050 \pm 0.0012$ & $0.5206 \pm 0.0029$ & $0.5267 \pm 0.0024$ \\
\hline & 0.08 & $0.4940 \pm 0.0024$ & $0.4997 \pm 0.0075$ & $0.4859 \pm 0.0088$ & $0.5116 \pm 0.0074$ & $0.5094 \pm 0.0085$ \\
\hline & 0.10 & $0.4824 \pm 0.0062$ & $0.4882 \pm 0.0040$ & $0.4934 \pm 0.0096$ & $0.4991 \pm 0.0018$ & $0.5064 \pm 0.0051$ \\
\hline \multirow{6}{*}{0.08} & 0.00 & $0.4926 \pm 0.0028$ & $0.4916 \pm 0.0046$ & $0.5043 \pm 0.0016$ & $0.5064 \pm 0.0064$ & $0.5164 \pm 0.0031$ \\
\hline & 0.02 & $0.4810 \pm 0.0054$ & $0.4892 \pm 0.0042$ & $0.4835 \pm 0.0082$ & $0.4995 \pm 0.0050$ & $0.5010 \pm 0.0065$ \\
\hline & 0.04 & $0.4714 \pm 0.0082$ & $0.4779 \pm 0.0041$ & $0.4834 \pm 0.0126$ & $0.4889 \pm 0.0047$ & $0.4893 \pm 0.0030$ \\
\hline & 0.06 & $0.4600 \pm 0.0083$ & $0.4606 \pm 0.0052$ & $0.4716 \pm 0.0073$ & $0.4759 \pm 0.0016$ & $0.4831 \pm 0.0021$ \\
\hline & 0.08 & $0.4510 \pm 0.0017$ & $0.4569 \pm 0.0033$ & $0.4631 \pm 0.0040$ & $0.4678 \pm 0.0078$ & $0.4648 \pm 0.0031$ \\
\hline & 0.10 & $0.4396 \pm 0.0056$ & $0.4381 \pm 0.0065$ & $0.4410 \pm 0.0009$ & $0.4473 \pm 0.0012$ & $0.4465 \pm 0.0041$ \\
\hline \multirow{6}{*}{0.10} & 0.00 & $0.4285 \pm 0.0053$ & $0.4320 \pm 0.0067$ & $0.4421 \pm 0.0019$ & $0.4474 \pm 0.0056$ & $0.4522 \pm 0.0046$ \\
\hline & 0.02 & $0.4194 \pm 0.0045$ & $0.4237 \pm 0.0069$ & $0.4332 \pm 0.0052$ & $0.4352 \pm 0.0059$ & $0.4426 \pm 0.0028$ \\
\hline & 0.04 & $0.4106 \pm 0.0027$ & $0.4166 \pm 0.0057$ & $0.4205 \pm 0.0024$ & $0.4303 \pm 0.0025$ & $0.4343 \pm 0.0054$ \\
\hline & 0.06 & $0.4019 \pm 0.0033$ & $0.4078 \pm 0.0047$ & $0.4158 \pm 0.0019$ & $0.4207 \pm 0.0048$ & $0.4285 \pm 0.0036$ \\
\hline & 0.08 & $0.3934 \pm 0.0063$ & $0.3953 \pm 0.0018$ & $0.4031 \pm 0.0043$ & $0.4064 \pm 0.0026$ & $0.4137 \pm 0.0018$ \\
\hline & 0.10 & $0.3808 \pm 0.0034$ & $0.3878 \pm 0.0043$ & $0.3946 \pm 0.0031$ & $0.3983 \pm 0.0055$ & $0.4071 \pm 0.0021$ \\
\hline
\end{tabular}




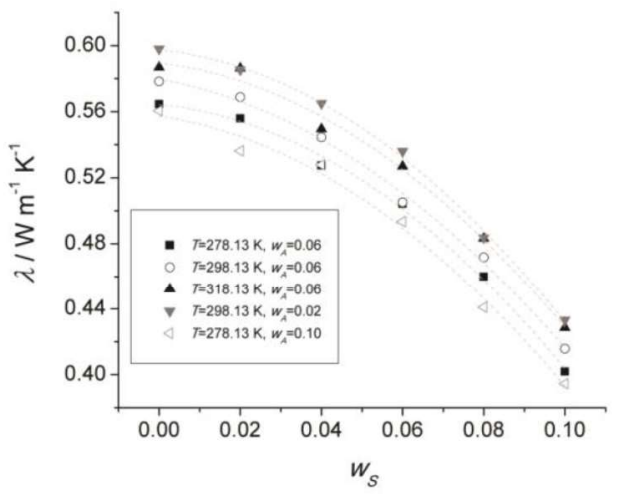

(a)

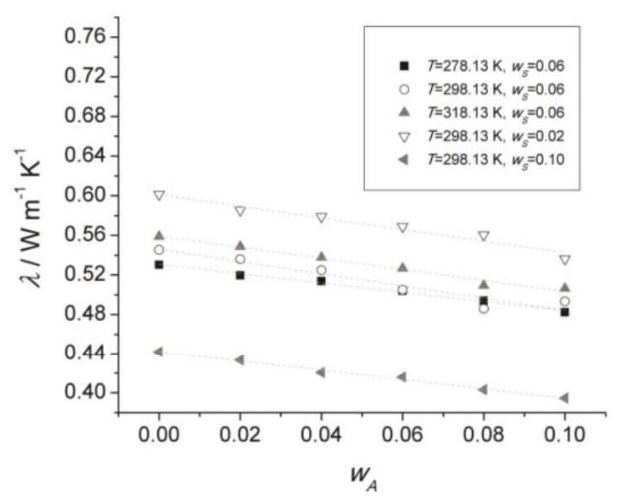

(b)

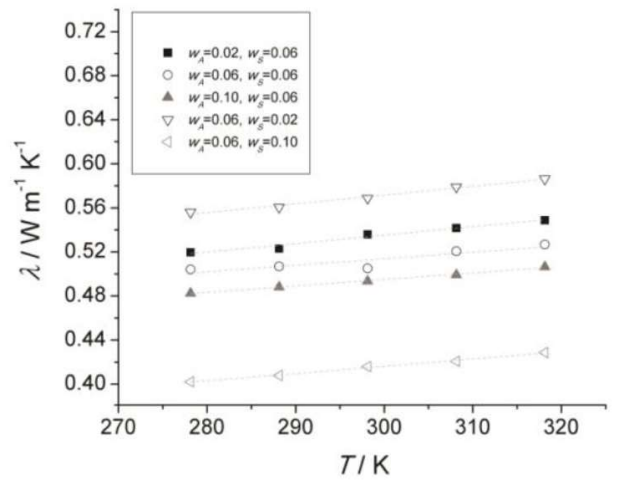

(c)

Figure 5.1.4. Thermal conductivity values as a function of (a) solids concentration; (b) acid concentration and (c) absolute temperature.

\subsubsection{Conclusions}

This work was focused on the determination and fitting to empirical models of thermophysical properties of acid slurries containing cassava bagasse in order to 
provide information for an efficient design of pretreatment processes. Thermophysical properties such as density, specific heat, thermal diffusivity and thermal conductivity of the different suspensions were obtained in a range of temperature ( 278.13 to $318.13 \mathrm{~K}$ ), phosphoric acid mass fraction ( 0 to 0.10 ) and solids mass fraction ( 0.00 to 0.10$)$. In general, the experimental values were fitted to polynomial models with high determination coefficients $\left(R^{2}>0.92\right)$ and low mean relative error $(M R E<1.75 \%)$.

Specifically, density increased with increasing solids and acid content and decreasing temperature. Specific heat, thermal diffusivity and thermal conductivity followed similar trend, decreasing with the increase of solids content. This is linked to the decrease of heat conduction on dilute slurries. On the other hand, a temperature increase provided a slight increment on specific heat, thermal diffusivity and thermal conductivity.

Results of this study indicated that, besides the hydrolysable potential of cassava bagasse, the acid pretreatments/hydrolysis can be correctly developed in order to optimize its conversion. Reported data also bring information to reduce costs and save energy by applying better conditions according to the momentum, heat and mass transfer properties.

\subsubsection{Acknowledgments}

Authors acknowledge the São Paulo Research Foundation - FAPESP (Grant 2017/06518-2) and Coordination for the Improvement of Higher Level Personnel CAPES (Grant 88881.132626/2016-01) for financial support.

\subsubsection{References}

Alvira, P., Tomás-Pejó, E., Ballesteros, M., Negro, M.J., (2010). Pretreatment technologies for an efficient bioethanol production process based on enzymatic hydrolysis: A review. Bioresource Technology 101(13), 4851-4861.

AOAC, (2005). Official Methods of Analysis, 16 ed. Association of Official Analytical Chemists, Washington, D. C.

Archer, D.G., (1993). Thermodynamic Properties of Synthetic Sapphire (a-Al2O3), Standard Reference Material 720 and the Effect of Temperature-Scale 
Differences on Thermodynamic Properties. Journal of Physical and Chemical Reference Data 22(6), 1441-1453.

ASTM-E1269, (2005). Standart test method for determining specific heat capacity by differentail scanning calorimetry. ASTM Internacional, West Conshohocken.

Bitra, V.S.P., Banu, S., Ramakrishna, P., Narender, G., Womac, A.R., (2010). Moisture dependent thermal properties of peanut pods, kernels, and shells. Biosystems Engineering 106(4), 503-512.

Cabral, R.A.F., Orrego-Alzate, C.E., Gabas, A.L., Telis-Romero, J., (2007). Rheological and thermophysical properties of blackberry juice. Food Science and Technology (Campinas) 27, 589-595.

Cardoso, C.R., Oliveira, T.J.P., Santana Junior, J.A., Ataíde, C.H., (2013). Physical characterization of sweet sorghum bagasse, tobacco residue, soy hull and fiber sorghum bagasse particles: Density, particle size and shape distributions. Powder Technology 245, 105-114.

Carta, F.S., Soccol, C.R., Ramos, L.P., Fontana, J.D., (1999). Production of fumaric acid by fermentation of enzymatic hydrolysates derived from cassava bagasse. Bioresource Technology 68(1), 23-28.

Choi, Y., Okos, M.R., (1986). Effects of temperature and composition on the thermal properties of foods, in: Lemauguer, M., Jelen, M. (Eds.), Food Engineering and Process Aplications. Elsevier Applied Science Publishers, London, pp. 93-101.

Dean, J.A., (1999). Lange's Handbook of Chemistry (15 ed). McGraw-Hill, Inc., New York.

Dupont, C., Chiriac, R., Gauthier, G., Toche, F., (2014). Heat capacity measurements of various biomass types and pyrolysis residues. Fuel 115, 644-651.

FAO, (2019). Official data of cassava production. Food and Agriculture Organization of the United Nations.

Fiorda, F.A., Soares-Jr, M.S.S., Silva, F.A., Souto, L.R.F., Grossmann, M.V.E., (2013). Farinha de bagaço de mandioca: aproveitamento de subproduto e comparação com fécula de mandioca. Pesquisa Agropecuária Tropical 43(4), 408-416.

Fontana, J.D., Passos, M., Baron, M., Mendes, S.V., Ramos, L.P., (2001). Cassava Starch Maltodextrinization/Monomerization through Thermopressurized 
Aqueous Phosphoric Acid Hydrolysis, in: Davison, B.H., McMillan, J., Finkelstein, M. (Eds.), Twenty-Second Symposium on Biotechnology for Fuels and Chemicals. Humana Press, Totowa, NJ, pp. 469-478.

Gámez, S., González-Cabriales, J.J., Ramírez, J.A., Garrote, G., Vázquez, M., (2006). Study of the hydrolysis of sugar cane bagasse using phosphoric acid. Journal of Food Engineering 74(1), 78-88.

Guo, W., Lim, C.J., Bi, X., Sokhansanj, S., Melin, S., (2013). Determination of effective thermal conductivity and specific heat capacity of wood pellets. Fuel 103, 347-355.

Jalan, R.K., Srivastava, V.K., (1999). Studies on pyrolysis of a single biomass cylindrical pellet-kinetic and heat transfer effects. Energy Conversion and Management 40(5), 467-494.

Koufopanos, C.A., Papayannakos, N., Maschio, G., Lucchesi, A., (1991). Modelling of the pyrolysis of biomass particles. Studies on kinetics, thermal and heat transfer effects. The Canadian Journal of Chemical Engineering 69(4), 907-915.

Kruse, A., Dahmen, N., (2015). Water - A magic solvent for biomass conversion. The Journal of Supercritical Fluids 96, 36-45.

Li, C., Knierim, B., Manisseri, C., Arora, R., Scheller, H.V., Auer, M., Vogel, K.P., Simmons, B.A., Singh, S., (2010). Comparison of dilute acid and ionic liquid pretreatment of switchgrass: Biomass recalcitrance, delignification and enzymatic saccharification. Bioresource Technology 101(13), 4900-4906.

Mantilla, S.V., Gauthier-Maradei, P., Gil, P.A., Cárdenas, S.T., (2014). Comparative study of bio-oil production from sugarcane bagasse and palm empty fruit bunch: Yield optimization and bio-oil characterization. Journal of Analytical and Applied Pyrolysis 108, 284-294.

Maroulis, Z.B., Drouzas, A.E., Saravacos, G.D., (1990). Modeling of thermal conductivity of granular starches. Journal of Food Engineering 11(4), 255-271.

Martínez, M.L., Sánchez, S., Bravo, V., (2012). Production of xylitol and ethanol by Hansenula polymorpha from hydrolysates of sunflower stalks with phosphoric acid. Industrial Crops and Products 40(0), 160-166.

McCready, R.M., Guggolz, J., Silviera, V., Owens, H.S., (1950). Determination of starch and amylose in vegetables. Analytical Chemistry 22(9), 1156-1158. 
Minim, L.A., Telis, V.R.N., Minim, V.P.R., Alcantara, L.A.P., Telis-Romero, J., (2009). Thermophysical Properties of Lemon Juice as Affected by Temperature and Water Content. Journal of Chemical \& Engineering Data 54(8), 2269-2272.

Njie, D.N., Rumsey, T.R., Singh, R.P., (1998). Thermal properties of cassava, yam and platain. Journal of Food Engineering 37(1), 63-76.

Pasquini, D., Teixeira, E.M., Curvelo, A.A.S., Belgacem, M.N., Dufresne, A., (2010). Extraction of cellulose whiskers from cassava bagasse and their applications as reinforcing agent in natural rubber. Industrial Crops and Products 32(3), 486490.

Polachini, T.C., Betiol, L.F.L., Bastos, M.G., Telis, V.R.N., Souza, A.C., TelisRomero, J., (2016a). Density, thermal expansion coefficient, and rheological behaviour of meat extract under different temperatures and solids concentrations. The Canadian Journal of Chemical Engineering 94(5), 988-994.

Polachini, T.C., Carvalho, G.R., Telis-Romero, J., (2017). Determination of acoustic fields in acidic suspensions of peanut shell during pretreatment with highintensity ultrasound. Brazilian Journal of Chemical Engineering 34(2), 385-394.

Polachini, T.C., Sato, A.C.K., Cunha, R.L., Telis-Romero, J., (2016b). Density and rheology of acid suspensions of peanut waste in different conditions: An engineering basis for bioethanol production. Powder Technology 294, 168-176.

Rahman, M.S., (1995). Handbook of Food Properties. CRC Press, Boca Raton.

Ramón, A.P., Taschetto, L., Lunelli, F., Mezadri, E.T., Souza, M., Foletto, E.L., Jahn, S.L., Kuhn, R.C., Mazutti, M.A., (2015). Ultrasound-assisted acid and enzymatic hydrolysis of yam (Dioscorea sp.) for the production of fermentable sugars. Biocatalysis and Agricultural Biotechnology 4(1), 98-102.

Rodríguez, P., González, G., (2003). Photoacoustic measurements of thermal diffusivity of amylose, amylopectin and starch. Journal of Food Engineering 58(3), 205-209.

Samaniuk, J.R., Scott, C.T., Root, T.W., Klingenberg, D.J., (2012). Rheological modification of corn stover biomass at high solids concentrations. Journal of Rheology 56(3), 649-665. 
Sánchez, A.S., Silva, Y.L., Kalid, R.A., Cohim, E., Torres, E.A., (2017). Waste biorefineries for the cassava starch industry: New trends and review of alternatives. Renewable and Sustainable Energy Reviews 73, 1265-1275.

Singh, R.P., (1982). Thermal diffusivity in food processing. Food Technology 36(2), 87-91.

Sun, Y., Cheng, J.J., (2005). Dilute acid pretreatment of rye straw and bermudagrass for ethanol production. Bioresource Technology 96(14), 1599-1606.

Turnbull, A.G., (1971). Thermal conductivity of phosphoric acid-water mixtures at 25. deg. Journal of Chemical \& Engineering Data 16(1), 79-83.

Van Soest, P.J., Robertson, J.B., Lewis, B.A., (1991). Methods for Dietary Fiber, Neutral Detergent Fiber, and Nonstarch Polysaccharides in Relation to Animal Nutrition. Journal of Dairy Science 74(10), 3583-3597.

Villa-Vélez, H.A., Cornelio, M.L., Corrêa, J.L.G., Telis-Romero, J., (2017). Identification of acoustic fields in aqueous biomass solutions of banana waste pretreated by power ultrasound. Biomass Conversion and Biorefinery, 1-10.

Werle, L.B., Garcia, J.C., Kuhn, R.C., Schwaab, M., Foletto, E.L., Cancelier, A., Jahn, S.L., Mazutti, M.A., (2013). Ultrasound-assisted acid hydrolysis of palm leaves (Roystonea oleracea) for production of fermentable sugars. Industrial Crops and Products 45(0), 128-132.

Williams, C.L., Westover, T.L., Petkovic, L.M., Matthews, A.C., Stevens, D.M., Nelson, K.R., (2017). Determining Thermal Transport Properties for Softwoods Under Pyrolysis Conditions. ACS Sustainable Chemistry \& Engineering 5(1), 1019-1025.

Wyman, C.E., Dale, B.E., Elander, R.T., Holtzapple, M., Ladisch, M.R., Lee, Y.Y., (2005). Coordinated development of leading biomass pretreatment technologies. Bioresource Technology 96(18), 1959-1966. 
5.2. CHAPTER 2

Rheology of Acid Suspensions Containing Cassava Bagasse 
Powder Technology, 2019, v. 354, p.271-280.

Rheology of Acid Suspensions Containing Cassava Bagasse: Effect of Biomass Loading, Acid Content and Temperature

Tiago Carregari Polachini ${ }^{1,2}$; Antonio Mulet ${ }^{2}$; Juan A. Cárcel ${ }^{2}$; Javier Telis-Romero ${ }^{1}$

${ }^{1}$ Food Engineering and Technology Department, São Paulo State University (Unesp), Institute of Biosciences, Humanities and Exact Sciences (lbilce), Campus São José do Rio Preto, Cristóvão Colombo Street 2265, São José do Rio Preto, São Paulo State, 15054000, Brazil.

${ }^{2}$ Grupo de Análisis y Simulación de Procesos Agroalimentarios, Departamento de Tecnología de Alimentos, Universitat Politècnica de València (UPV), Camino de Vera, s/n, Valencia, 46071, Spain. 


\begin{abstract}
Understanding the rheological behavior of acid suspensions of cassava bagasse provides essential information for the design of conversion processes. This study was aimed at rheological characterization of cassava bagasse suspension according to its composition, morphology and particle size. Suspension with different cassava bagasse concentrations $\left(0-10 \% \mathrm{w} \cdot \mathrm{w}^{-1}\right)$, phosphoric acid content $(0-10 \%$ $\mathrm{W} \cdot \mathrm{w}^{-1}$ ) at temperatures between 278.13 and $318.13 \mathrm{~K}$ were submitted to steady-state flow over a wide range of shear rates $\left(1-265 \mathrm{~s}^{-1}\right)$. The biomass particles, with aspect ratio close to 2 , had considerable residual starch $(\sim 50 \% \mathrm{db})$, low lignin content and adequate particle size $(<200 \mu \mathrm{m})$ for the conversion process. Flow curves were wellfitted to the Herschel-Bulkley model, presenting a Newtonian domain at low solids and acid content and a non-Newtonian behavior with noticeable yield stress and $n<1$ at above $6 \%$ of cassava bagasse. Resistance to flow increased as the solids loading and acid content increased and shear-thinning behavior appeared under the following conditions: above $6 \%$ of cassava bagasse at any acid content. Temperature dependence could be expressed as a function of an Arrhenius-type equation with good accuracy of fit.
\end{abstract}

Keywords: lignocellulose, residual starch, apparent viscosity, Herschel-Bulkley model, shear-thinning, Arrhenius-type equation. 


\subsubsection{Introduction}

The widespread and non-sustainable use of fossil fuels is contributing to their exhaustion, besides damaging the environment by the emission of greenhouse gases. Developing and optimizing the second generation ethanol process has become increasingly interesting for producing biofuels from renewable sources. The adequate processing of biomass into bioethanol implies not only a reduction in $\mathrm{CO}_{2}$ emissions throughout the fuel production chain but also an eco-friendly destination of the residues from agro-industrial processes.

Such wastes are generally composed of macromolecules of cellulose, hemicellulose and lignin. Some of them can also present certain amounts of starch, protein, pectin and ash depending on the product, species, harvest conditions, processing and storage (Kenney et al., 2013). The variability in its composition reinforces the importance of specifically evaluating the performance of each potential biomass for a given process.

Cassava (Manihot esculenta) is one of the main raw materials used in the starch extraction industry, where cassava bagasse appears as a valuable and abundant byproduct. Currently, in Brazil alone, approximately 2 million tons of wet bagasse per year are generated (FAO, 2019, Fiorda et al., 2013). The differential for cassava bagasse in relation to other residues is associated with its high residual starch content which is a consequence of the low yield of cassava starch extraction (Pandey et al., 2000), which can range from approximately 30 up to $85 \%$ (db) according to the literature (Pasquini et al., 2010; Sánchez et al., 2017).

Due to its specific chemical composition, cassava bagasse is a potential raw material for bioethanol production. However, well designed pretreatment and hydrolysis needs to be carried out to access the entangled starch and the complex structure of cellulose and hemicellulose. The conversion efficiency of these main macromolecules into small chain carbohydrates must be characterized by high sugar production with low formation of sugar degradation compounds. This can be attained by pretreating the biomass under mild temperatures, using less aggressive acids and under easy-mixing conditions. Phosphoric acid, for example, is able to hydrolyze both lignocellulosic and starchy biomass with reduced sugar degradation (Gámez et al., 2006); Lenihan et al., 2010). Its use at low temperatures can also prevent the starchy 
suspension from gelatinizing, which would decrease the mass transfer and the yield of cold hydrolysis of starch granules.

In addition to the technological issues, the process efficiency is highly dependent on the correct design of equipment and unit operations. The properties of the raw material are the fundamental information needed to optimize the industrial process. Properties, such as the rheological ones, allow an adequate choice of pumps, accessories, mixers, bioreactors and pipes (Polachini et al., 2016b). However, the study of the properties demands more efforts for the case of heterogeneous aqueous systems which may be influenced by the different amounts of insoluble (biomass particles) and soluble (acid) compounds. While particles can have different sizes and aspect ratios, the presence of an acid can affect how the particles interact with each other during the flow (Pääkkö et al., 2007; Stickel et al., 2009).

Consequently, the way of each of the factors listed above influences the rheological behavior of dilute acid suspensions of cassava bagasse needs to be investigated.

Steady-flow curves provide useful data not only for the rheological modelling but also for evaluating the transition between Newtonian and non-Newtonian behavior. Modifications in the suspension compositions may turn Newtonian fluids into viscoplastic fluids with significant initial stress to start the flow, pseudoplastic (or shear-thinning) or dilatant (or shear-thickening) fluids in the presence or absence of yield stress. On the one hand, the shear-thinning fluids show decreasing apparent viscosity as the shear rate is increased. On the other hand, the apparent viscosity of the shear-thickening ones tends to increase with increasing shear rate. Distinct systems may need different sources of energy to attain similar pretreatment conditions, even more so when they include non-conventional techniques such as high-intensity ultrasound.

Therefore, this study focused on determining and modelling the rheological behavior of different acid suspensions containing previously-characterized cassava bagasse. 


\subsubsection{Materials and Methods}

\subsubsection{Cassava bagasse and suspension preparation}

Coarsely particulate, dried cassava bagasse was kindly provided by TechnoAmido (São Pedro do Turvo, Brazil). These coarse particles were ground using an M4FH1C knife mill (PHD, Piracicaba, Brazil) at $1750 \mathrm{rpm}$ and then the powdered bagasse was standardized using a sieve (Tyler mesh 100) in order to obtain particles smaller than $0.147 \mathrm{~mm}$.

Dilute acid suspensions were prepared varying the phosphoric acid (85\% solution; purity $>99.95 \%$ ), (Dinâmica, Diadema, São Paulo), content in distilled water at the following concentrations: $0,2,4,6,8$ and $10 \%$ (g of acid per $100 \mathrm{~g}$ of solvent). These solutions were added to cassava bagasse to obtain suspensions with final solids concentrations of $0,2,4,6,8$ and $10 \%$ (g of cassava bagasse per $100 \mathrm{~g}$ of suspension). Combining the 6 acid solutions with the 6 cassava bagasse concentrations resulted in a total of 36 samples to be analyzed.

\subsubsection{Cassava bagasse characterization}

\subsection{Chemical composition}

The cassava bagasse was characterized according to its chemical composition, in triplicate, by determining the protein content by the micro-Kjeldahl method, fat content by Soxhlet extraction, ash content by muffle incineration and moisture content in an oven according to AOAC (2005). Among the carbohydrates, starch content was quantified in a similar way to that described by Paul et al. (2017), total fiber content was quantified by the method proposed by Van Soest et al. (1991) and total soluble sugars was found by difference. Moreover, the fractions of cellulose, hemicellulose and lignin in the lignocellulose were determined based on the values of insoluble fibers in acid (ADF) and neutral detergent (NDF).

\subsection{Particle size}

Particle size of the powdered cassava bagasse was determined in triplicate by laser diffraction (LD) using a MAM 5005 Mastersizer (Malvern Panalytical , Malvern, UK). Distilled water was used as the dispersing medium for the measurements. In this technique, the particles scatter light at an angle of diffraction which is considered 
inversely proportional to their size. The particle size distribution is initially measured based on volume, expressing the volume percentage of particles in continuous size intervals. Making use of these values, the number-based distribution can be determined by the equivalent sphere assumption.

The diameter of the samples was represented as the volume weighted mean diameter $\left(D_{4,3}\right)$, also known as the De Brouckere mean diameter, defined by Equation (5.2.1), and surface weighted mean diameter $\left(D_{3,2}\right)$ or the so-called Sauter mean diameter, defined by Equation (5.2.2). The De Brouckere mean diameter assumes spherical particles of the same volume as the actual particles, while the Sauter mean diameter is defined as the diameter of the sphere with the same surface area as the particle (Castagnini et al., 2015). Polydispersity (width of distribution) was also evaluated according to span value, given in Equation (5.2.3). All of them were calculated with respect to the volume-based and number-based distributions.

$$
\begin{aligned}
& D_{4,3}=\frac{\sum n_{i} \cdot d_{i}^{4}}{\sum n_{i} \cdot d_{i}^{3}} \\
& D_{3,2}=\frac{\sum n_{i} \cdot d_{i}^{3}}{\sum n_{i} \cdot d_{i}^{2}} \\
& \text { span }=\frac{D_{0,9}-D_{0,1}}{D_{0,5}}
\end{aligned}
$$

where, $n_{i}$ is the number of particles with $d_{i}$ diameter $(\mu \mathrm{m}), D_{0,1}, D_{0,5}$ and $D_{0,9}$ are additional parameters given by the instrument which represent the maximum particle diameter below which $10 \%, 50 \%$ and $90 \%$ of the sample exists, respectively.

\subsection{Particles morphology}

The morphology of cassava bagasse particles was evaluated using a BX43 optical microscope (Olympus, Tokyo, Japan) with coupled camera at 4x, 10x and 40x magnitude. Samples were dispersed in distilled water for glass slide preparation and images were acquired from different areas on the microscope slides. In order to identify and to show the presence of residual starch, the bagasse was marked with lugol solution. 
Besides the visual analyses, particles were also characterized according to the aspect ratio $\left(a_{r}\right)$ given by the relation between length $(L)$ and width $(w)$. Measurements of such characteristic dimensions were done for 100 particles in the different fields of view using the cellSens software version 1.18 (Olympus, Tokyo, Japan).

\subsubsection{Rheological measurements}

Rheological measurements were carried out in triplicate using an AR-G2 rotational rheometer (TA Instruments, New Castle, USA) with the SPC (Starch Pasting Cell) geometry. Approximately $28 \mathrm{~mL}$ of each sample were inserted into the equipment and shear rate ramps were set from 1 to $265 \mathrm{~s}^{-1}$ in steady flow with 10 points per logarithm interval. The rheological experiments were conducted at five different temperatures: $278.13,288.13,298.13,308.13$ and $318.13 \mathrm{~K}$, using a controlled temperature bath and a new sample for each assay. Data of shear stress were obtained from Universal Analysis 2000 data acquisition system version 4.7 (TA Instruments, New Castle, USA).

\subsubsection{Modelling}

The means of the triplicate experimental values of the shear stress obtained at each fixed shear rate were calculated for the 36 samples at the temperatures of $278.13,288.13,298.13,308.13$ and $318.13 \mathrm{~K}$. Average data of shear stress were plotted against shear rate to obtain the corresponding rheograms. The Newton (Equation 5.2.4), Bingham (Equation 5.2.5), Power Law (Equation 5.2.6) and Herschel-Bulkley (Equation 5.2.7) models were used to analyze the rheological behavior:

$$
\begin{aligned}
& \tau=\mu \dot{\gamma} \\
& \tau=\tau_{0}+\eta_{B} \dot{\gamma} \\
& \tau=k \dot{\gamma}^{n} \\
& \tau=\tau_{0}+k \dot{\gamma}^{n}
\end{aligned}
$$


In these equations, $T(\mathrm{~Pa})$ is shear stress, $\dot{\gamma}\left(\mathrm{s}^{-1}\right)$ is shear rate, $\mu$ (Pa-s) is the Newtonian viscosity, $T_{0}(\mathrm{~Pa})$ is the yield stress, $\eta_{B}(\mathrm{~Pa} \cdot \mathrm{s})$ is the plastic viscosity, $k$ $\left(\mathrm{Pa} \cdot \mathrm{s}^{n}\right)$ is the consistency coefficient and $n$ (dimensionless) is the flow behavior index. Fluids with flow behavior index below 1 correspond to shear-thinning fluids while values above 1 indicate shear-thickening behavior. The apparent viscosity $\eta_{a p p}$ (Pa.s) at a fixed shear rate can be determined from the values of $\mu$ after equalizing the shear stress of a non-Newtonian model to the Newton model [16]. The OriginPro 8.0 software (OriginLab Corporation, Northampton, USA) was used to plot the graphs and to carry out the non-linear regressions.

The parameters from the Herschel-Bulkley model were submitted to estimated effects analysis using the STATISTICA 10 software (StatSoft Inc., Tulsa, USA) in order to study the influence of the variables on the rheological parameters. The significance of the linear and quadratic terms of cassava bagasse concentration $\left(X_{S}\right.$, $\left.\% \mathrm{w} \cdot \mathrm{w}^{-1}\right)$, phosphoric acid content $\left(X_{A}, \% \mathrm{w} \cdot \mathrm{w}^{-1}\right)$ and absolute temperature $(T, \mathrm{~K})$ were analyzed as well as the possible linear interaction among them. The significant variables $(p<0.05)$ were used to fit the data and provide a predictive equation for each parameter. The accuracy of fit was evaluated through the adjusted determination coefficient $\left(R_{a d j}^{2}\right)$, which is a modification of the conventional determination coefficient $R^{2}$ to take into account the number of parameters of the fitted model, and by the root mean square error (RMSE), given respectively by Equation (5.2.8) and Equation (5.2.9):

$$
\begin{gathered}
R_{a d j}^{2}=1-\frac{(m-1)}{(m-p-1)}\left(1-R^{2}\right) \\
R M S E=\sqrt{\frac{\sum_{m=1}^{m}\left(\hat{y}_{m}-y_{m}\right)^{2}}{m}}
\end{gathered}
$$

where $m$ is the number of experimental data, $p$ the number of parameters in the model, $R^{2}$ is the determination coefficient, $\hat{y}_{m}$ the predicted data and $y_{m}$ the experimental data. 
The effect of temperature on the apparent viscosity of the suspensions was modelled by an Arrhenius-type equation (Equation 5.2.10):

$$
\eta_{a p p, 10 s^{-1}}=A_{0} \exp \left(\frac{E_{a}}{R T}\right)
$$

where $A_{0}$ is the pre-exponential factor $(\mathrm{Pa} \cdot \mathrm{s}), E_{a}$ is the activation energy $\left(\mathrm{J} \cdot \mathrm{mol}^{-1}\right)$ and $R$ is the universal gas constant $\left(8.314 \mathrm{~J} \cdot \mathrm{mol}^{-1} \cdot \mathrm{K}^{-1}\right)$.

\subsubsection{Results and discussion}

\subsubsection{Chemical characterization}

Cassava bagasse samples were chemically characterized (Table 5.2.1). The samples have considerable amounts of residual starch around $50 \%$ (d.b.). This agrees with results reported by other authors of residual starch in cassava bagasse ranging from $30 \%$ up to $85 \%$ (db) (Pandey et al., 2000; Pasquini et al., 2010). Starch is a polymer with great capacity for releasing fermentable matter. After being hydrolyzed, it can be used as substrate for many applications, including for second generation ethanol production.

Table 5.2.1. Chemical composition of the powdered cassava bagasse.

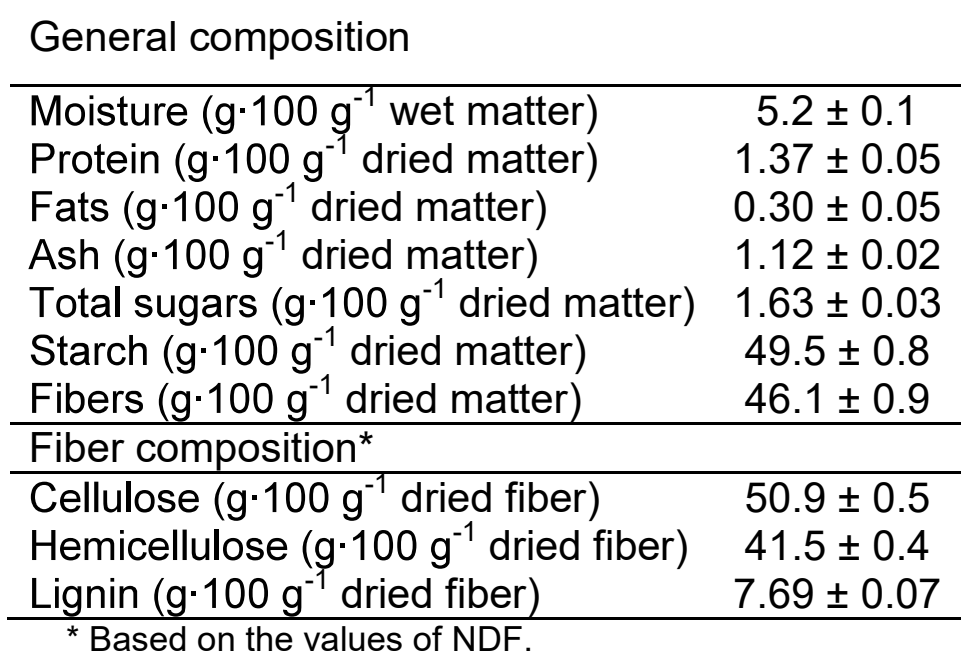

Similarly as reported by Polachini et al. (2016a) and Silva et al. (2015), the cassava bagasse also showed low fat, ash and protein content. As a consequence of 
the low concentration of high-value nutrients, cassava bagasse is not often used for animal feed. Consequently, the higher carbohydrate content makes it advantageous for microbial conversion when compared to other residues (Pandey et al., 2000).

Fibers represented $46.1 \%$ of the bagasse, approximately $92 \%$ being cellulose and hemicellulose. In addition to the capacity for releasing sugar from starch, low molecular weight carbohydrates can also be obtained in large amounts from the fibrous matter. Lu et al. (2012) showed the high production of glucose and lower amounts of xylose and arabinose from the hydrolysis of starch and lignocellulose from cassava bagasse. On the other hand, it is known that the presence of lignin makes the hydrolyzation of cellulose and hemicellulose difficult. Thus, the low content of lignin observed in cassava bagasse fibers ( $\approx 8 \%)$ offers advantages in contrast with other residues such as sugarcane bagasse, rice straw, corn stover and wheat straw, which all showed 14-23\% lignin by dry weight (Volynets et al., 2017).

\subsubsection{Particles size determination}

Particle size distribution of powdered cassava bagasse was determined based on the volume percentage of particles and also based on the number percentage of equivalent spheres. Figure 5.2.1 shows the particle distribution, where a monomodal distribution can be seen for both cases.

Table 5.2.2 presents the average values of the different diameters as well as the span values obtained from the volume-based and number-based distributions. According to the $D_{0,9}$ from the number-based distribution, powdered cassava bagasse presented the majority $(90 \%)$ of particles with particle size smaller than 6.1 $\mu \mathrm{m}$. However, probably, the presence of a few bigger particles (fibers and agglomerates) resulted in a volume weighted mean diameter $\left(D_{4,3}\right)$ of approximately $120 \mu \mathrm{m}$

Concerning the volume-based distribution, the average volume-weighted mean diameter $\left(D_{4,3}\right)$ was $175 \mu \mathrm{m}$. On the other hand, the values for surfaceweighted mean diameter $D_{3,2}(\sim 60 \mu \mathrm{m})$ were much lower than $D_{4,3}$ probably due to the presence of longer, thinner particles instead of more rounded ones (Polachini et al., 2016b). According to Glaser (2015), $D_{3,2}$ is an efficient parameter for evaluating hydrolysis performance of non-homogeneous substrates. The same author also 
stated that biomass with particle size below $200 \mu \mathrm{m}$ is more accessible to cellulases for further conversion. Consequently, cassava bagasse is an adequate substrate for cellulases since all the mean diameters obtained were lower than this value. A slightly higher span value of 1.935 was a consequence of the varied particle sizes, which can be seen in Figure 5.2.1. Moreover, $10 \%$ of the volume occupied by the particles $\left(D_{0,1}\right)$ is attributed to particles smaller than $40 \mu \mathrm{m}$ and $90 \%$ of the volume occupied $\left(D_{0,9}\right)$ corresponds to particles smaller than $340 \mu \mathrm{m}$. Thus, it can be assumed that that $80 \%$ of the occupied volume is linked to particles with mean diameter between $40 \mu \mathrm{m}$ and $340 \mu \mathrm{m}$. This observation reinforced the difference between the two distributions, which means that more small particles are necessary to occupy the same volume as bigger ones.
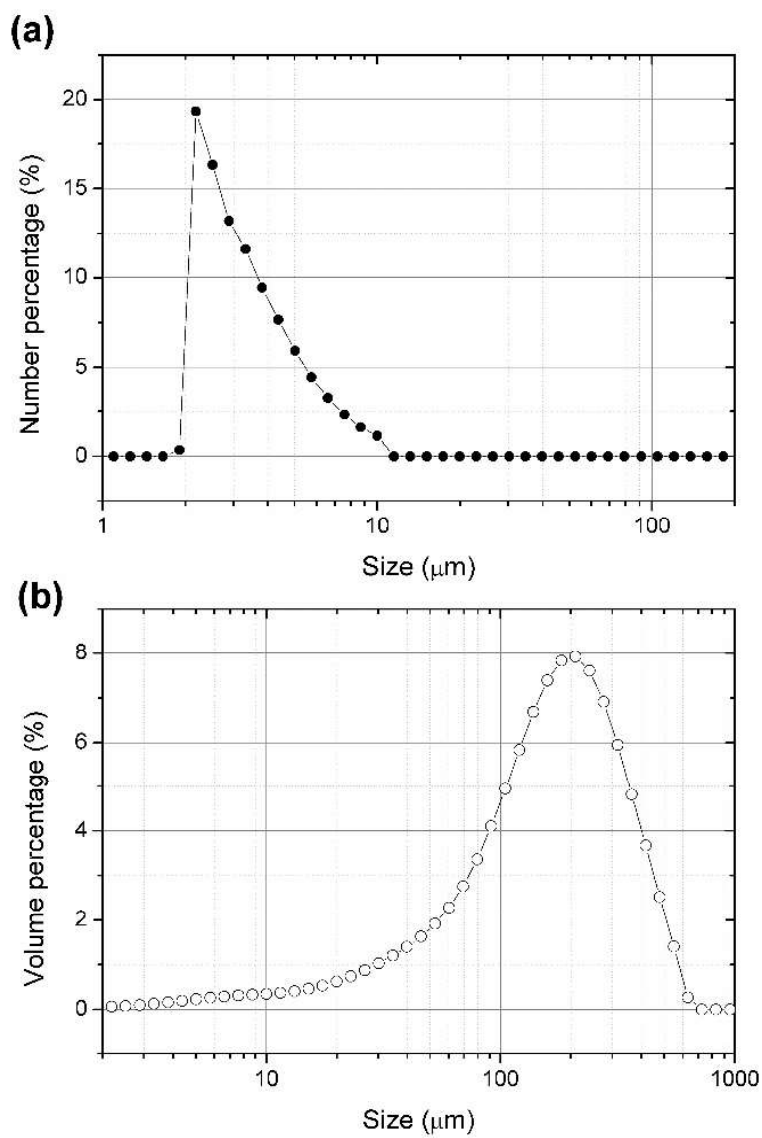

Figure 5.2.1. (a) Number-based and (b) volume-based particle size distributions for powdered cassava bagasse. 
Table 5.2.2. Parameters of number-based and volume-based particle size distributions for powdered cassava bagasse.

\begin{tabular}{lcc}
\hline \multirow{2}{*}{ Parameters } & \multicolumn{2}{c}{ Average values } \\
& Number based & Volume based \\
\hline$D_{0,1}(\mu \mathrm{m})$ & 2.1 & 39.3 \\
$D_{0,5}(\mu \mathrm{m})$ & 2.9 & 155.5 \\
$D_{0,9}(\mu \mathrm{m})$ & 6.1 & 340.1 \\
De Brouckere mean diameter $-D_{4,3}(\mu \mathrm{m})$ & 119.7 & 175.5 \\
Sauter mean diameter $-D_{3,2}(\mu \mathrm{m})$ & 53.4 & 66.3 \\
Span & 1.401 & 1.935 \\
\hline
\end{tabular}

\subsubsection{Morphological characteristics}

Optical microscopy analyses were carried out for cassava bagasse at different magnifications. Figure 5.2.2 shows particles with varied morphologies such as round, rectangular and elongated shapes. They are typical of cellulosic residues, with irregular form and the possible presence of microfibers. Similar structures have been reported in the literature for peanut shells (Polachini et al., 2016b), sugarcane bagasse (Chandel et al., 2014) and even cassava bagasse (Travalini et al., 2017). In addition to the cellulosic particles, there were also starch granules (black arrows in Figure 5.2.2a). Figure 5.2.2b shows the cassava bagasse marked with lugol, where the bluish-purple structure indicated starch with iodine. It could be seen that some starch was in the form of granules dispersed or entangled in the fibrous network, which was also observed by Versino et al. (2015) and Odoch et al. (2017) using scanning electronic microscopy of cassava bagasse. Another fraction seemed to be solubilized as amylose and amylopectin, probably as a result of a partial starch gelatinization and leaching during the cassava processing. The bluish areas also reflect the difficulty in recovering all the cassava starch during its extraction process. 
(a)

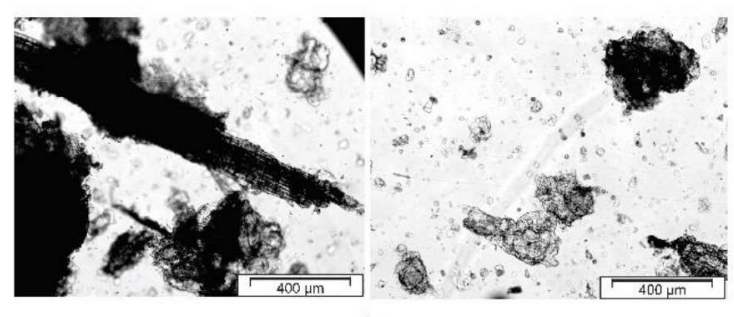

$4 \mathrm{x}$

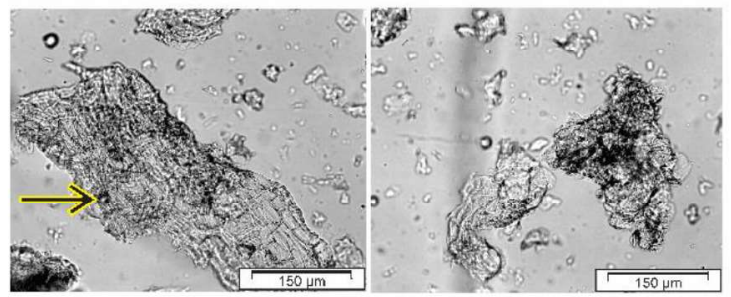

$10 \mathrm{x}$

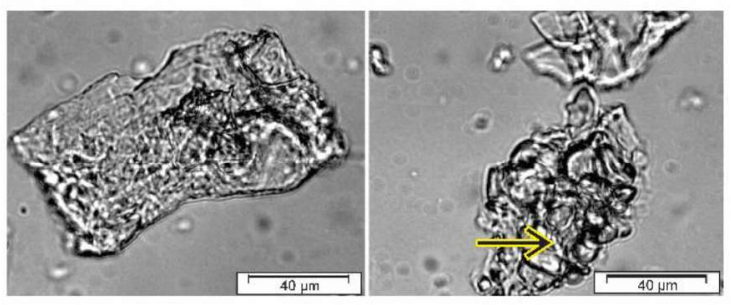

$40 \mathrm{x}$ (b)
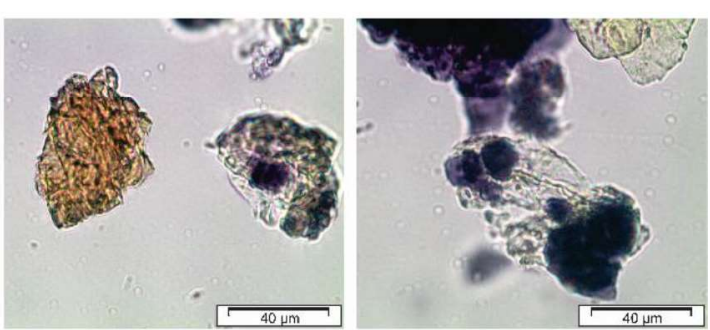

a.
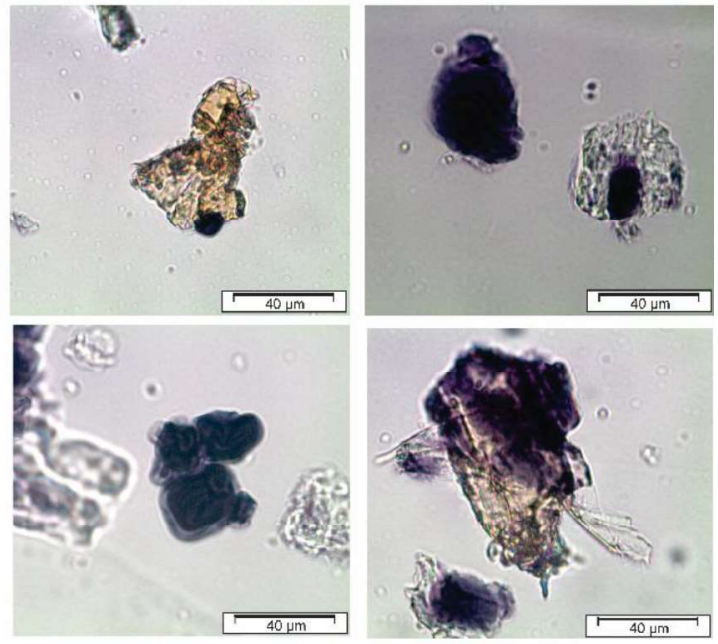

Figure 5.2.2. Optical microscopic images at $4 x, 10 x$ and $40 x$ magnification for (a) cassava bagasse and for (b) cassava bagasse dyed with lugol at $40 \mathrm{x}$ of magnification.

The aspect ratio $\left(a_{r}\right)$ of the samples was also determined from the microscopic images. Mean aspect ratio of the sample was found to be 1.98 , being the distribution of the aspect ratio shown in the histogram in Figure 5.2.3. More than $60 \%$ of the particles analyzed had aspect ratios in the range between 1 and 2.5, which is similar to the mean values and the data reported for other agro-industrial residues (El-Sayed and Mostafa, 2014). The presence of starch granules in relatively spherical form leads to a high concentration of particles with an aspect ratio near to 1 . 


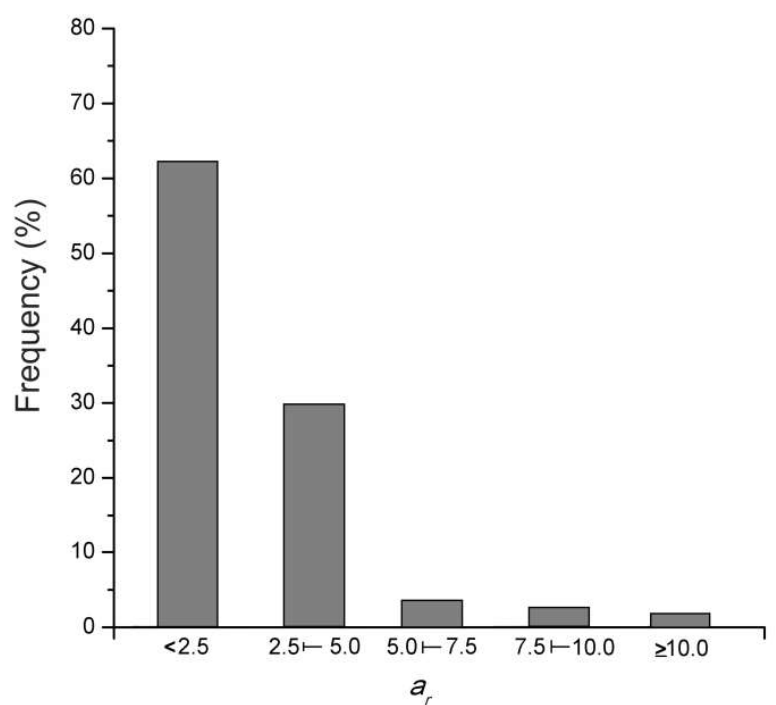

Figure 5.2.3. Distribution of the aspect ratio $\left(a_{r}\right)$ values for powdered cassava bagasse particles.

\subsubsection{Flow behavior}

The mean shear stress was calculated in all samples for each fixed shear rate at the different temperatures. The values obtained were in the range from $0.001 \mathrm{~Pa}$ to $8.181 \mathrm{~Pa}$ at $1.01 \mathrm{~s}^{-1}$ and from 0.184 $\mathrm{Pa}$ to $604.91 \mathrm{~Pa}$ at $263.34 \mathrm{~s}^{-1}$. In general, as shown in Figure 5.2.4, shear stresses increased with the increase of cassava bagasse and acid content and the lowering of temperature. Certain non-linearity could be visually noticed in the rheograms for the more concentrated suspensions at the lower temperatures (Figure 5.2.4).

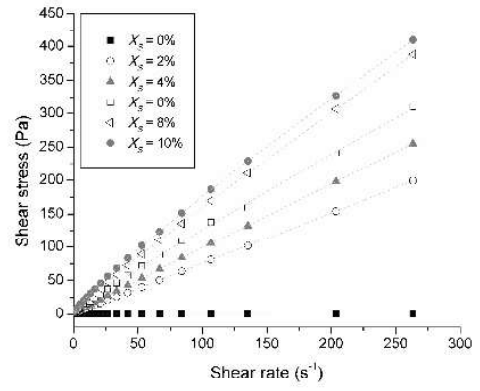

(a)

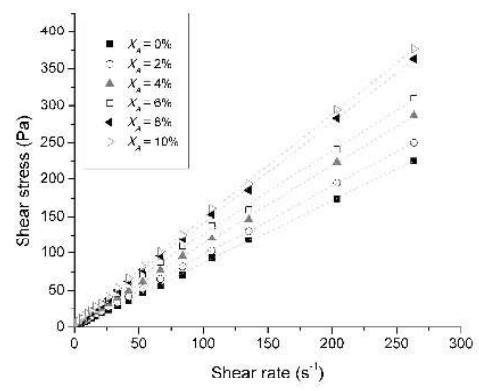

(b)

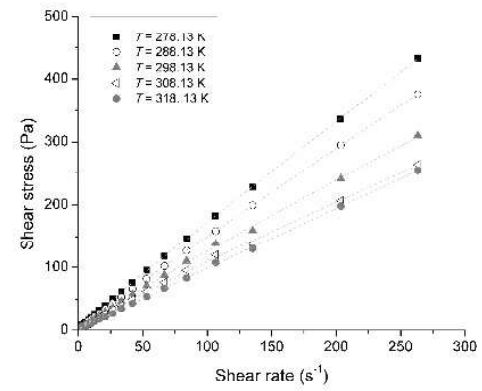

(c)

Figure 5.2.4. Rheograms of the acid suspensions containing cassava bagasse fitted to Herschel-Bulkley model. (a) $X_{A}=6 \%$ at $T=298.13 \mathrm{~K}$; (b) $X_{S}=6 \%$ at $T=298.13 \mathrm{~K}$; and (c) $X_{S}=6 \%$ and $X_{A}=6 \%$. 
The rheograms were fitted to the Herschel-Bulkley model in order to estimate and to evaluate the rheological parameters, the presence of yield stress and shearthinning or shear-thickening behavior. Figure 5.2.4 also shows some fitted data as a function of solids concentration, acid content and temperature. In Table 5.2.3, some fitting parameters for acid suspensions at intermediate concentration of solids, acid content and temperatures are shown.

Although all data were well-fitted to Herschel-Bulkley model $\left(R^{2}>0.998\right)$, not all fitting parameters presented large values or physical meaning. For example, acid solutions and suspensions with solids content up to $4 \%$ showed relatively low yield stresses $\left(\tau_{0}\right)$ and flow behavior index $(n)$ very close to 1 . In these conditions, the Herschel-Bulkley model turns into the Newton model and the consistency coefficient can be considered as Newtonian viscosity. Coussot (2005) assumed that the interactions between biomass particles are negligible in suspensions with low concentration of solids $(<4 \%)$, with Newtonian-like behavior of the dispersant medium predominating.

Table 5.2.3. Fitting parameters of Herschel-Bulkley model for acid suspensions at intermediate conditions.

\begin{tabular}{|c|c|c|c|c|c|c|c|c|c|c|}
\hline \multirow{4}{*}{$\begin{array}{l}\text { Temperature } \\
\text { (K) }\end{array}$} & \multirow{4}{*}{ Parameters } & \multicolumn{9}{|c|}{ Cassava bagasse concentration, $X_{S}$} \\
\hline & & \multicolumn{3}{|c|}{$2 \%$} & \multicolumn{3}{|c|}{$6 \%$} & \multicolumn{3}{|c|}{$10 \%$} \\
\hline & & \multicolumn{9}{|c|}{$\left[\mathrm{H}_{3} \mathrm{PO}_{4}\right], X_{A}$} \\
\hline & & $2 \%$ & $6 \%$ & $10 \%$ & $2 \%$ & $6 \%$ & $10 \%$ & $2 \%$ & $6 \%$ & $10 \%$ \\
\hline \multirow{4}{*}{278.13} & $T_{0}$ & 0.2944 & 0.7862 & 1.1915 & 0.9188 & 1.6739 & 2.5462 & 2.2481 & 2.7290 & 3.2157 \\
\hline & $k$ & 0.3730 & 0.8157 & 1.2886 & 1.7530 & 2.0878 & 2.2757 & 4.1297 & 4.6276 & 4.9354 \\
\hline & $n$ & 1.0033 & 1.0049 & 0.9999 & 0.9687 & 0.9559 & 0.9621 & 0.8889 & 0.8762 & 0.8509 \\
\hline & $R_{a d j}^{2}$ & 0.9999 & 0.9999 & 0.9999 & 0.9999 & 0.9999 & 0.9998 & 0.9999 & 0.9999 & 0.9999 \\
\hline \multirow{4}{*}{298.13} & $T_{0}$ & 0.2399 & 0.7788 & 1.1225 & 0.6610 & 0.7291 & 2.4177 & 1.1702 & 1.6657 & 2.1652 \\
\hline & $k$ & 0.2965 & 0.7291 & 1.2204 & 1.0540 & 1.7695 & 1.6891 & 2.5929 & 3.0772 & 3.4120 \\
\hline & $n$ & 0.9990 & 1.0058 & 0.9966 & 0.9809 & 0.9253 & 0.9686 & 0.8878 & 0.8767 & 0.8512 \\
\hline & $R_{a d j}^{2}$ & 0.9999 & 0.9999 & 0.9999 & 0.9999 & 0.9994 & 0.9998 & 0.9999 & 0.9999 & 0.9999 \\
\hline \multirow{4}{*}{318.13} & $T_{0}$ & 0.2376 & 0.6803 & 1.1625 & 0.4719 & 1.4434 & 1.7694 & 0.7119 & 1.2045 & 1.6431 \\
\hline & $k$ & 0.2469 & 0.7073 & 1.1595 & 0.7370 & 1.0349 & 1.6120 & 1.7670 & 2.1613 & 2.6310 \\
\hline & $n$ & 1.0019 & 0.9989 & 0.9988 & 0.9809 & 0.9864 & 0.9405 & 0.8938 & 0.8701 & 0.8531 \\
\hline & $R_{a d j}^{2}$ & 0.9999 & 0.9999 & 0.9999 & 0.9999 & 0.9998 & 0.9987 & 0.9999 & 0.9999 & 0.9999 \\
\hline
\end{tabular}


When the solids content and the phosphoric content was 6\%, non-Newtonian behavior was more marked. It was noticed that the yield stress $\left(T_{0}\right)$ increased and the values of the flow behavior index $(n)$ decreased when acid or solids concentrations were higher. At the lower temperature with the highest acid and solids concentration the highest $T_{0}$ value (3.21) and the lowest $n(0.85)$ were found. These values are in accordance with previous studies for both lignocellulosic and starchy materials, which fitted the Herschel-Bulkley model to suspensions containing corn stover, peanut shells and amaranth starch (Gozzo et al., 2009; Polachini et al., 2016; Viamajala et al., 2009) with similar trends. As reported in the literature, suspensions containing biomass generally present shear-thinning behavior with significant yield stress when approximately $5 \%$ of solids is attained (Stickel et al., 2009).

The maximum value observed for yield stress was approximately $3.22 \mathrm{~Pa}$, indicating that the most concentrated suspensions tested in this work were still able to be mixed by traditional stirred tanks instead of specialized reactors. Roche et al. (2009) stated that suspensions with yield stress up to $10 \mathrm{~Pa}$ behave as pourable liquids, instead of paste-like characteristics with complex transport properties. These conditions promote the acid-particle interactions since the catalyst is more adequately and uniformly distributed in the dispersant when compared to concentrated materials (Viamajala et al., 2009). In this context, the energy required for moving the materials increases with increasing solids content. The consistency coefficient can increase up to approximately 20 times (from 0.25 to $4.96 \mathrm{~Pa} \cdot \mathrm{s}^{n}$ ) when the solids concentration varies from $2 \%$ to $10 \%$ (5 times).

In addition to the visible effect of the variables on rheological parameters, an analysis of the estimated effects was carried out to evaluate its significance $(p<0.05)$. In general, yield stress $\left(\tau_{0}\right)$ and consistency coefficient $(k)$ were linearly affected by all variables. Additionally, significant quadratic effects were observed for temperature and biomass concentration, besides the linear interaction $X_{S} T$ and $X_{S} X_{A}$, on both $T_{0}$ and $k$. On the other hand, flow behavior index $(n)$ was linearly affected by the biomass and acid contents and by the linear interaction between them. Solids content also had a quadratic effect on $n$, with no significant influence of temperature.

Apparent viscosity $\left(\eta_{a p p, 10 s^{-1}}\right)$ was calculated at specific shear rate of $10 \mathrm{~s}^{-1}$, which is considered adequate for a mixing and stirring process (Steffe, 1996; 
Viamajala et al., 2009). It ranged from $7.07 \times 10^{-4} \mathrm{~Pa} \cdot \mathrm{s}$ for the pure water at $318.13 \mathrm{~K}$ up to $3.82 \mathrm{~Pa} \cdot \mathrm{s}$ for the most solid and acid concentrated suspension at $278.13 \mathrm{~K}$. These values were linearly influenced by all variables with an additional quadratic effect of temperature. The linear interactions $X_{S} T$ and $X_{S} X_{A}$ were also significant, similar to $T_{0}$ and $k$.

In this way, non-linear regression can be done for each rheological parameter as a simultaneous function of the significant variables. Equation (5.2.11), Equation (5.2.12), Equation (5.2.13) and Equation (5.2.14) that follow were well-fitted to yield stress, consistency coefficient, flow behavior index and apparent viscosity. They had the fitted determination coefficient $\left(R_{a d j}^{2}\right)$ equal to 0.8596, 0.9744, 0.9392 and 0.9677 , and the root mean square error equal to $0.28 \mathrm{~Pa}, 0.19 \mathrm{~Pa} \cdot \mathrm{s}^{\mathrm{n}}, 0.01 \mathrm{~Pa} \mathrm{~s}$ and 0.17 Pa.s, respectively:

$$
\begin{gathered}
\begin{aligned}
\tau_{0}=25.48-0.177 T+0.00031 T^{2} & +1.2648 X_{S}-0.00471 X_{S}^{2} \\
+ & 0.06515 X_{A}-0.00371 X_{S} T+0.00834 X_{S} X_{A}
\end{aligned} \\
\begin{aligned}
k=25.49-0.179 T+0.00031 T^{2}+ & 1.8991 X_{S}-0.01222 X_{S}^{2} \\
+ & 0.05198 X_{A}-0.00591 X_{S} T+0.00756 X_{S} X_{A}
\end{aligned} \\
n=0.9987+0.006588 X_{S}-0.001617 X_{S}^{2}+0.000187 X_{A}-0.000553 X_{S} X_{A} \\
\eta_{a p p, 10 s^{-1}}=24.09-0.16795 T+0.00029 T^{2} \\
+1.70511 X_{S}+0.066 X_{A}-0.00497 X_{S} T+0.00296 X_{S} X_{A}
\end{gathered}
$$

In any acid solutions and acid suspensions with solids concentration lower than $6 \%\left(w \cdot w^{-1}\right)$, yield stress values can be disregarded $\left(T_{0} \approx 0\right)$, the flow behavior index can be approximated to unity $(n \approx 1)$ and both $k$ and $\eta_{a p p, 10 s^{-1}}$ can be considered as for the Newtonian viscosity.

\subsection{Solids concentration}

The effect of solids concentration on the rheological parameters was also evaluated. Figure 5.2.5 shows the yield stress, consistency coefficient and flow behavior index as functions of cassava bagasse concentration. These graphs are in accordance with the previous analyses of variance, presenting the linear and quadratic effect of biomass on all rheological parameters. 

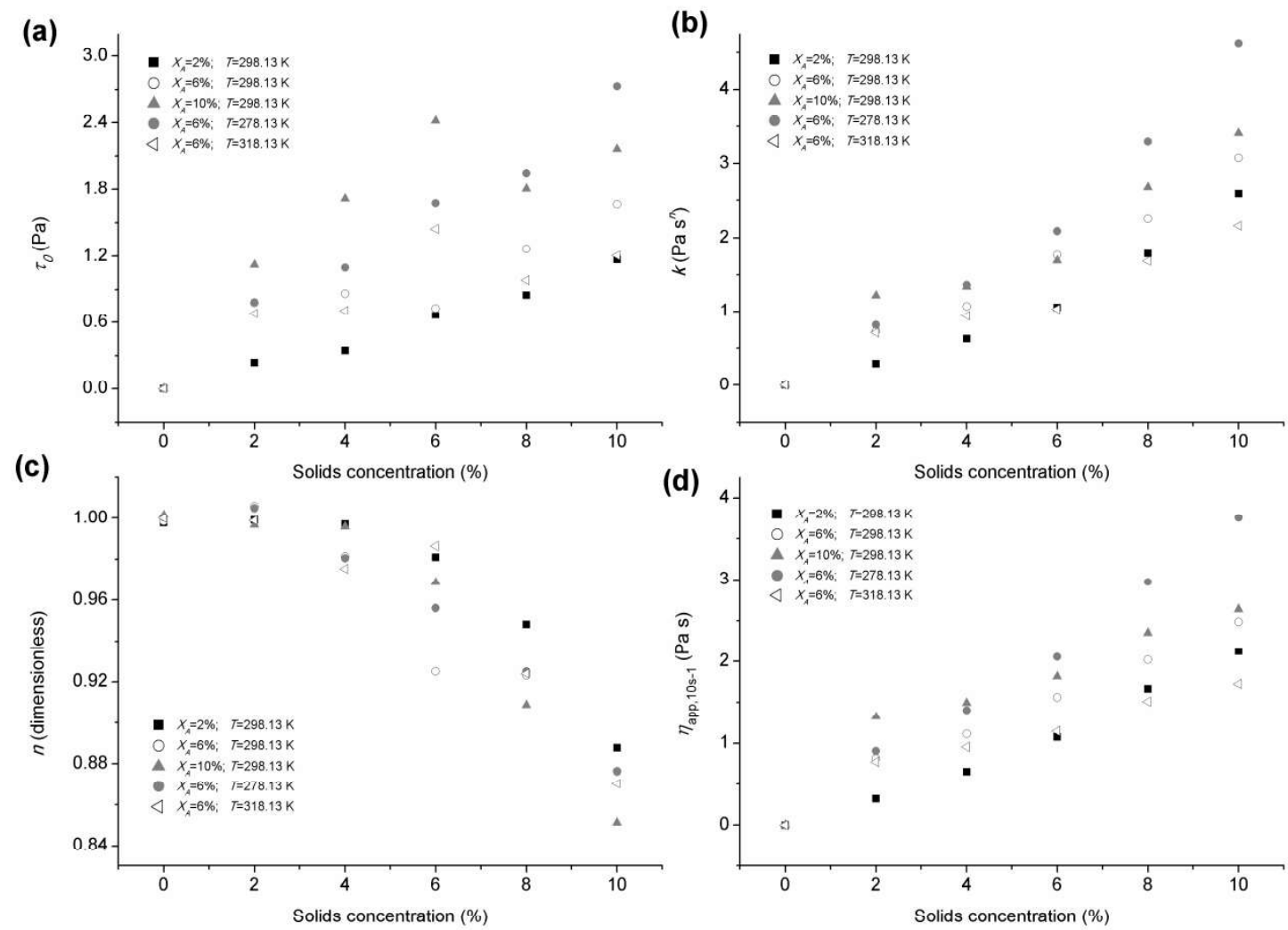

Figure 5.2.5. (a) Yield stress $\left(\tau_{0}\right)$, (b) consistency coefficient $(k)$, (c) flow behavior index $(n)$ and (d) apparent viscosity $\left(\eta_{a p p, 10 s^{-1}}\right)$ as functions of cassava bagasse concentration at different acid concentrations and temperatures.

The values of yield stress increased as the solids concentration increased. Although authors correlate yield stress with solids concentration by a power relation (Stickel et al., 2009), Laera et al. (2007) states that a linear tendency can be assumed in the case of diluted suspensions. The yield stress information is useful since it corresponds to the initial energy needed to move biomass suspensions. The way yield stress behaves as solids concentration changes can provide important information about the increase in power requirements when particle settling occurs before the mixer starts moving (Stickel, 2009).

A similar trend was also observed for the consistency coefficient and for apparent viscosity. Higher values were obtained with increasing biomass content probably due to more particle-particle interaction during the flow as a consequence of 
the number of particles and the reduction of dispersant as it is absorbed causing the particles to swell (Volynets et al., 2017). In addition, mechanical energy is also dissipated by the dispersant when it flows around the particles when they appear in slightly higher concentrations (Chen et al., 2018).

The flow behavior index had a non-linear decrease as the solids concentration increased. The drop in the $n$ values reflects the decrease in apparent viscosity as the shear rate increased. Polachini et al. (2016b) related the shear-thinning behavior to the increasing number of collisions among the particles in high loaded suspensions and a consequent deviation from Newtonian properties. Moreover, the breakdown of the aggregate as the shear rate increases can promote the release of interstitial dispersant and particles alignment, providing easy-flow characteristics and the reduction in apparent viscosity values.

\subsubsection{Phosphoric acid content}

The acidification of the medium also had significant influence on the rheological parameters. Figure 5.2.6 shows the effect of $\mathrm{H}_{3} \mathrm{PO}_{4}$ concentration on rheological behavior for different acid suspensions. While the yield stress, consistency coefficient and apparent viscosity increased linearly with increasing acid concentration, the flow behavior index seemed to present a slight less pronounced linear decrease as acid content was increased.

The apparent viscosity of the acid solutions increased linearly with increasing acid content. Furthermore, Pääkkö et al. (2007) stated that the negative charges of hemicellulose can be neutralized by the $\mathrm{H}+$ ions. This might reduce electrostatic repulsion among the particles, which leads to an increase in the interfibrillar action and, consequently, in the suspension viscosity. Also, this increase in the particleparticle interaction seemed to slighty enhance the shear-thinning behavior in the higher loaded samples. This could be due to higher particle aggregation and the consequent release of the water trapped within the aggregates at higher shear rates. 
(a)

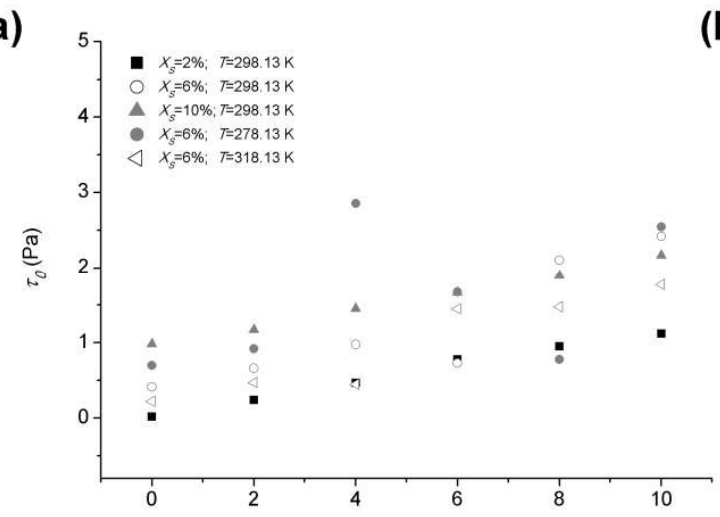

(c)

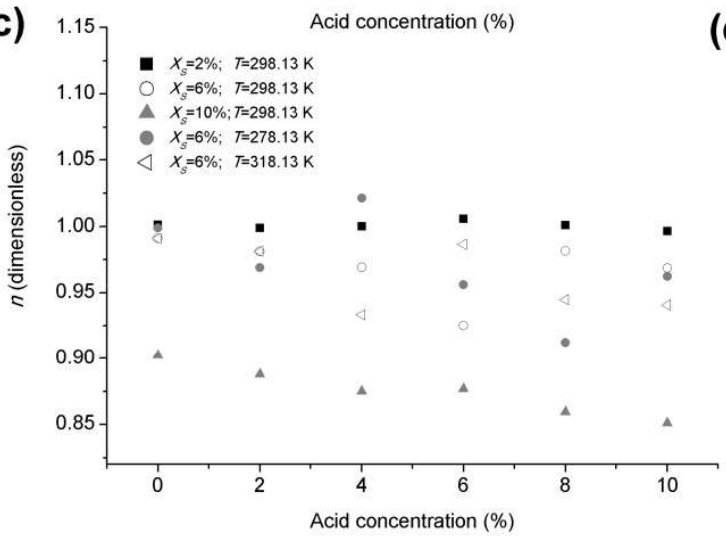

(b)

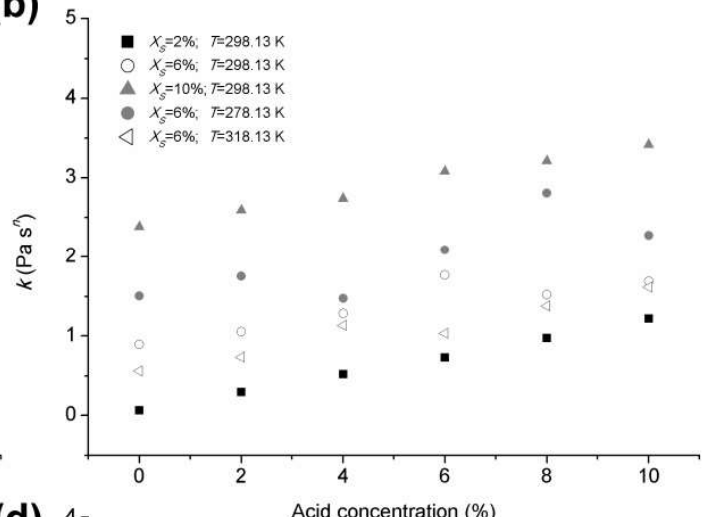

(d)

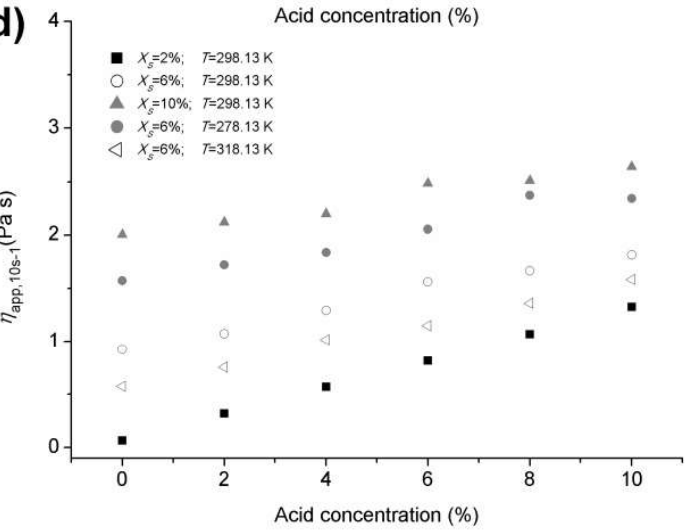

Figure 5.2.6. (a) Yield stress $\left(T_{0}\right)$, (b) consistency coefficient $(k)$, (c) flow behavior index $(n)$ and (d) apparent viscosity $\left(\eta_{a p p, 10^{-1}}\right)$ as functions of phosphoric acid concentration at different solids concentrations and temperatures.

\subsection{Temperature dependence}

Temperature had significant influence on yield stress, consistency coefficient and apparent viscosity but no effect on the flow behavior index. The values of $T_{0}, k$ and $\eta_{a p p, 1 s^{-1}}$ tended to decrease significantly as the temperature increased (Figure 5.2.7). The resistance to flow decreased as a consequence of the increase in the degree of molecular thermodynamic movement with increasing temperature. Increasing the temperature keeps the particles away from each other which reduces both viscosity and the specific mass of liquid materials. A similar trend was observed for microalgae slurries and peanut shell suspensions over similar temperature ranges (Chen et al., 2018; Polachini et al., 2016b). 

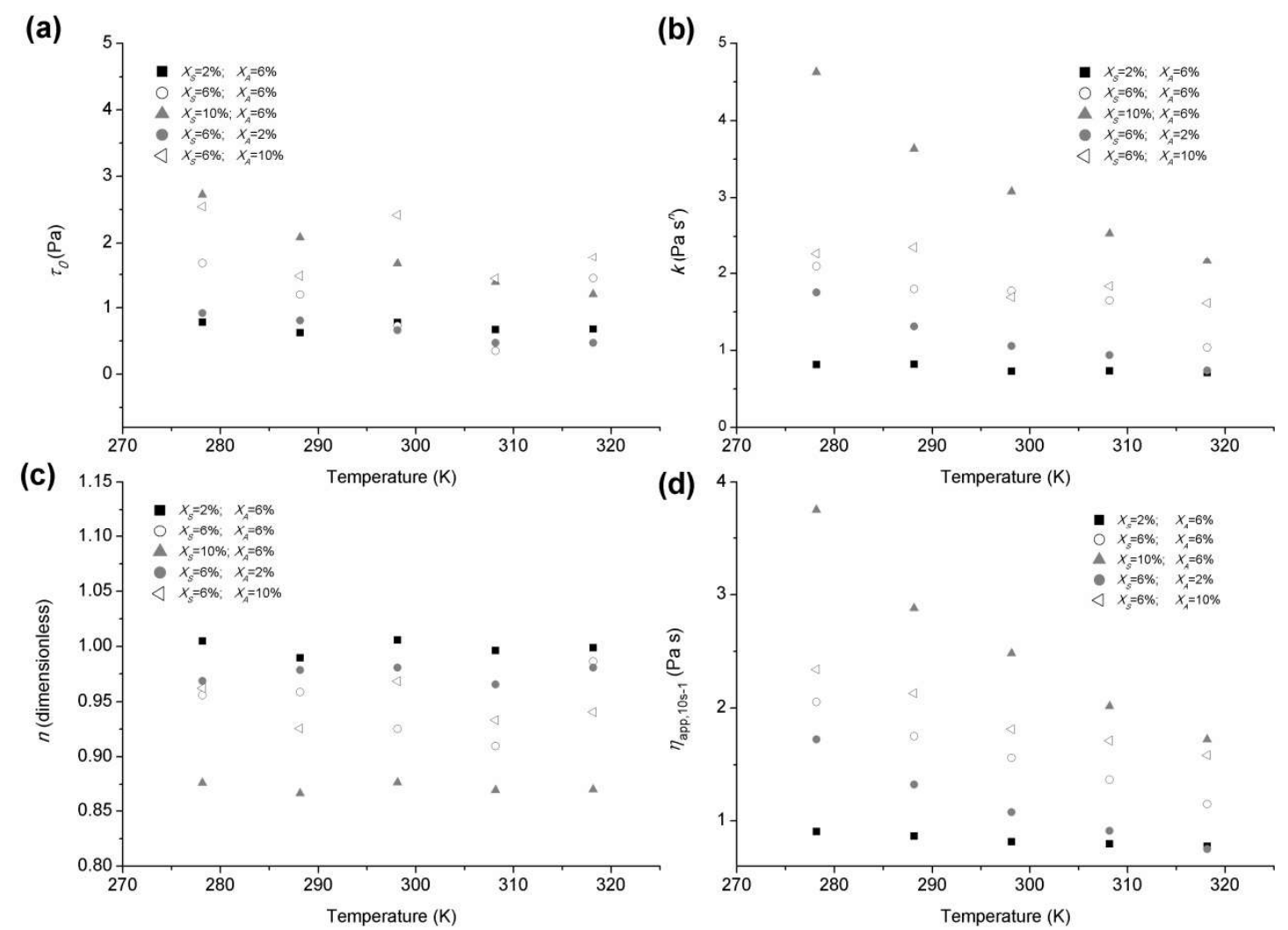

Figure 5.2.7. (a) Yield stress ( $\left.T_{0}\right)$, (b) consistency coefficient $(k)$, (c) flow behavior index $(n)$ and $(\mathrm{d})$ apparent viscosity $\left(\eta_{a p p, 10^{-1}}\right)$ as functions of absolute temperature at different acid and solids concentrations.

Although the analyses of variance showed quadratic influence of temperature on $\tau_{0}, k$ and $\eta_{a p p, 10 s^{-1}}$, the literature usually correlates the effect of temperature on rheological parameters by an Arrhenius-type equation. Thus, the activation energy of the Arrhenius equation reflects the temperature dependence of each sample. In other words, suspensions with higher $E_{a}$ have more pronounced variation in viscosity for the same temperature change when compared to the ones with lower $E_{a}$.

The fitting parameters of an Arrhenius-type equation are shown in Table 5.2.4. The goodness of fit was measured by $R_{a d j}^{2}$, achieving values greater than 0.8603 for all samples. Ségalen et al. (2015) demonstrated that slurries such as sludge follow an Arrhenius-type behavior when they are fully broken, i. e., when non-hydrodynamic forces can be neglected by applying enough shear rate. It means that the 
suspensions at the studied conditions in our work presented liquid-like characteristics, its transport being easier when compared to solid-like fluids.

Table 5.2.4. Fitting parameters of an Arrhenius-type equation for apparent viscosity ( $\left.\eta_{a p p, 10 s^{-1}}\right)$.

\begin{tabular}{cccccccc}
\hline $\begin{array}{c}\text { Cassava } \\
\text { bagasse } \\
\begin{array}{c}\text { concentration, } \\
X_{S}(\%)\end{array}\end{array}$ & Parameters & 0 & 2 & 4 & 6 & 8 & 10 \\
\hline 0 & $A_{o}(\mathrm{~Pa} \cdot \mathrm{s})$ & $9.82 \times 10^{-7}$ & $9.26 \times 10^{-7}$ & $1.03 \times 10^{-6}$ & $1.02 \times 10^{-6}$ & $2.52 \times 10^{-6}$ & $1.49 \times 10^{-6}$ \\
& $E_{a}\left(\mathrm{~kJ} \cdot \mathrm{mol}^{-1}\right)$ & 17.22 & 17.36 & 17.24 & 17.26 & 15.10 & 16.40 \\
& $R_{a d j}^{2}$ & 0.9925 & 0.9919 & 0.9766 & 0.9793 & 0.9544 & 0.9953 \\
& $A_{o}(\mathrm{~Pa} \cdot \mathrm{s})$ & $1.41 \times 10^{-4}$ & $4.34 \times 10^{-4}$ & 0.0240 & 0.0582 & 0.1326 & 0.0472 \\
4 & $E_{a}\left(\mathrm{~kJ} \cdot \mathrm{mol}^{-1}\right)$ & 19.76 & 17.92 & 8.99 & 7.35 & 5.72 & 8.54 \\
& $R_{a d j}^{2}$ & 0.9995 & 0.8604 & 0.9858 & 0.9909 & 0.9651 & 0.9538 \\
& $A_{0}(\mathrm{~Pa} \cdot \mathrm{s})$ & $6.08 \times 10^{-4}$ & 0.0023 & 0.0142 & 0.0256 & 0.0213 & 0.0916 \\
6 & $E_{a}\left(\mathrm{~kJ} \cdot \mathrm{mol}^{-1}\right)$ & 18.16 & 15.31 & 11.23 & 10.14 & 10.86 & 7.49 \\
& $R_{a d j}^{2}$ & 0.9993 & 0.9953 & 0.9954 & 0.9907 & 0.9835 & 0.9758 \\
& $A_{0}(\mathrm{~Pa} \cdot \mathrm{s})$ & $1.01 \times 10^{-3}$ & 0.0026 & 0.0066 & 0.0130 & 0.0223 & 0.0342 \\
8 & $E_{a}\left(\mathrm{~kJ} \cdot \mathrm{mol}^{-1}\right)$ & 17.98 & 16.02 & 13.97 & 12.51 & 11.40 & 10.52 \\
& $R_{a d j}^{2}$ & 0.9995 & 0.9970 & 0.9982 & 0.9840 & 0.9958 & 0.9961 \\
& $A_{0}(\mathrm{~Pa} \cdot \mathrm{s})$ & $1.50 \times 10^{-3}$ & 0.0029 & 0.0061 & 0.0075 & 0.0121 & 0.0236 \\
& $E_{a}\left(\mathrm{~kJ} \cdot \mathrm{mol}{ }^{-1}\right)$ & 17.84 & 16.38 & 14.66 & 14.35 & 13.27 & 11.74 \\
& $R_{a d j}^{2}$ & 0.9999 & 0.9964 & 0.9950 & 0.9916 & 0.9978 & 0.9951 \\
\hline
\end{tabular}

The flow activation energy of the acid solutions $\left(X_{S}=0 \%\right)$ resulted in higher values than the ones for acid suspensions, even presenting a slight decrease with increasing acid concentration. These values are in close agreement with the range established for pure water (13 up to $16 \mathrm{~kJ} \cdot \mathrm{mol}^{-1}$ ) (Ouerfelli et al., 2012), as it was the major component. These values indicated that the dispersants had their apparent viscosity more strongly affected by temperature in relation to the suspensions. Krokida et al. (2001) stated that the addition of non-soluble solids, such as fibers, in the suspensions implies lower $E_{a}$ when compared to water.

The addition of biomass particles to an acidified medium can increase the number of hydrogen bonds related to, e. g. the carboxyl groups in the hemicellulose and hydroxyl groups in the amylose and amylopectin. The higher sensitivity of apparent viscosity with increasing solids content can be linked to the structural 
changes of the aggregates as a consequence of the buildup or breakdown of the hydrogen bonding and hydrophobic interactions when temperature is altered (Alves et al., 2010). Analogously, it could be seen that $E_{a}$ of the suspensions tend to decrease as the acid concentration increased, probably due to the neutralization of the carboxyl and hydroxyl groups by the $\mathrm{H}^{+}$ions.

In the aqueous suspensions $\left(X_{A}=0 \%\right)$, the activation energy tended to decrease when the solids content increased. The absence of hydrogen ions may raise difficulties in establishing hydrogen bonds among the molecules, leading to charge repulsion by the particles. In addition, the high number of small particles in powdered cassava bagasse could act like a dispersant to facilitate the flow of coarser particles. This phenomenon, observed by Farris (1968), could explain the reduced required flow energy as the suspensions become more concentrated.

\subsubsection{Conclusions}

The high content of residual starch ( $49 \%)$ and cellulose and hemicellulose (total of $\sim 43 \%$ ) in the dried bagasse highlighted the need for an adequately designed conversion process not only for converting entangled and dispersed residual starch but also the fermentable matter of lignocellulose. In order to provide important information for the design of equipment and plant operations, rheological behavior of different acid suspensions was studied as a function of solids concentration (0-10\% $\left.w \cdot w^{-1}\right)$, phosphoric acid in the solution $\left(0-10 \% w \cdot w^{-1}\right)$ and temperature (278.13$318.13 \mathrm{~K}$ ). Samples with less than $6 \%$ of solids presented Newtonian behavior while the more concentrated ones $(\geq 6 \%)$ behaved as non-Newtonian fluids with noticeable yield stress $\left(0 \mathrm{~Pa}<T_{0}<3.22 \mathrm{~Pa}\right)$ and shear-thinning characteristics $(0.85<n<1)$.

Resistance to the flow $\left(\tau_{0}, k\right.$ and $\left.\eta_{a p p, 10 s^{-1}}\right)$ was increased by increasing cassava bagasse loading, acid content and decreasing temperature. Flow behavior index $(n)$ decreased as the biomass and acid concentration increased but no effect of temperature was noticeable. For the range of variables considered, polynomial models could be fitted to provide ready-to-use information. Under the studied conditions, suspensions showed liquid-like properties. These facilitate the mass transport and the access of enzymes when compared to high concentrated pastes. Additionally, in these conditions, hydrolysis and further additional treatments can be 
enhanced since these conditions allow more efficient propagation of ultrasound in conversion processes assisted by non-conventional technologies.

\subsubsection{Acknowledgment}

The authors would like to thank Prof. Rosiane Lopes Cunha and Prof. Ana Carla Kawazoe Sato from University of Campinas (UNICAMP) for their support with particle size analyses. The authors also acknowledge the São Paulo Research Foundation - FAPESP (Grant number 2017/06518-2) and the Coordination for the Improvement of Higher Education Personnel - CAPES (Grant number 88881.132626/2016-01) for their financial support.

\subsubsection{References}

Alves, V.D., Freitas, F., Costa, N., Carvalheira, M., Oliveira, R., Gonçalves, M.P., Reis, M.A.M., (2010). Effect of temperature on the dynamic and steady-shear rheology of a new microbial extracellular polysaccharide produced from glycerol byproduct. Carbohydrate Polymers 79(4), 981-988.

AOAC, (2005). Official Methods of Analysis, 16 ed. Association of Official Analytical Chemists, Washington, D. C.

Castagnini, J.M., Betoret, N., Betoret, E., Fito, P., (2015). Vacuum impregnation and air drying temperature effect on individual anthocyanins and antiradical capacity of blueberry juice included into an apple matrix. LWT - Food Science and Technology 64(2), 1289-1296.

Chandel, A.K., Antunes, F.A., Anjos, V., Bell, M.J., Rodrigues, L.N., Polikarpov, I., de Azevedo, E.R., Bernardinelli, O.D., Rosa, C.A., Pagnocca, F.C., da Silva, S.S., (2014). Multi-scale structural and chemical analysis of sugarcane bagasse in the process of sequential acid-base pretreatment and ethanol production by Scheffersomyces shehatae and Saccharomyces cerevisiae. Biotechnology for Biofuels 7(1), 63.

Chen, H., Fu, Q., Liao, Q., Zhang, H., Huang, Y., Xia, A., Zhu, X., (2018). Rheological properties of microalgae slurry for application in hydrothermal pretreatment systems. Bioresource Technology 249, 599-604. 
Coussot, P., (2005). Rheometry of Pastes, Suspensions and Granular Materials Application in Industry and Environment. John Wiley \& Sons, Hoboken, New Jersey.

El-Sayed, S.A., Mostafa, M.E., (2014). Analysis of Grain Size Statistic and Particle Size Distribution of Biomass Powders. Waste and Biomass Valorization 5(6), 1005-1018.

FAO, (2019). Official data of cassava production. Food and Agriculture Organization of the United Nations.

Farris, R.J., (1968). Prediction of the Viscosity of Multimodal Suspensions from Unimodal Viscosity Data. Transactions of The Society of Rheology (1957-1977) 12(2), 281-301.

Fiorda, F.A., Soares-Jr, M.S.S., Silva, F.A., Souto, L.R.F., Grossmann, M.V.E., (2013). Farinha de bagaço de mandioca: aproveitamento de subproduto e comparação com fécula de mandioca. Pesquisa Agropecuária Tropical 43(4), 408-416.

Gámez, S., González-Cabriales, J.J., Ramírez, J.A., Garrote, G., Vázquez, M., (2006). Study of the hydrolysis of sugar cane bagasse using phosphoric acid. Journal of Food Engineering 74(1), 78-88.

Glaser, R., (2015). Enzyme-based lignocellulose hydrolyzation-Sauter mean diameter of raw materials as a basis for cellulase performance characterization and yield prediction. Journal of Biotechnology 214, 9-16.

Gozzo, A.M., Cunha, R.L., Menegalli, F.C., (2009). Extensional and shear viscosity of acidified amaranth starch-sodium caseinate suspensions. Food Science and Technology (Campinas) 29, 587-596.

Kenney, K.L., Smith, W.A., Gresham, G.L., Westover, T.L., (2013). Understanding biomass feedstock variability. Biofuels 4(1), 111-127.

Krokida, M.K., Maroulis, Z.B., Saravacos, G.D., (2001). Rheological Properties of Fluid Fruit and Vegetable Purree Products: Compilation of Literature Data. International Journal of Food Properties 4(2), 179-200.

Laera, G., Giordano, C., Pollice, A., Saturno, D., Mininni, G., (2007). Membrane bioreactor sludge rheology at different solid retention times. Water Research 41(18), 4197-4203. 
Lenihan, P., Orozco, A., O’Neill, E., Ahmad, M.N.M., Rooney, D.W., Walker, G.M., (2010). Dilute acid hydrolysis of lignocellulosic biomass. Chemical Engineering Journal 156(2), 395-403.

Lu, C., Zhao, J., Yang, S.-T., Wei, D., (2012). Fed-batch fermentation for n-butanol production from cassava bagasse hydrolysate in a fibrous bed bioreactor with continuous gas stripping. Bioresource Technology 104, 380-387.

Odoch, M., Buys, E.M., Taylor, J.R.N., (2017). Mechanism of cassava tuber cell wall weakening by dilute sodium hydroxide steeping. Food Chemistry 228, 338-347.

Ouerfelli, N., Barhoumi, Z., Iulian, O., (2012). Viscosity Arrhenius Activation Energy and Derived Partial Molar Properties in 1,4-Dioxane + Water Binary Mixtures from 293.15 to $323.15 \mathrm{~K}$. Journal of Solution Chemistry 41(3), 458-474.

Pääkkö, M., Ankerfors, M., Kosonen, H., Nykänen, A., Ahola, S., Österberg, M., Ruokolainen, J., Laine, J., Larsson, P.T., Ikkala, O., Lindström, T., (2007). Enzymatic Hydrolysis Combined with Mechanical Shearing and High-Pressure Homogenization for Nanoscale Cellulose Fibrils and Strong Gels. Biomacromolecules 8(6), 1934-1941.

Pandey, A., Soccol, C.R., Nigam, P., Soccol, V.T., Vandenberghe, L.P.S., Mohan, R., (2000). Biotechnological potential of agro-industrial residues. II: cassava bagasse. Bioresource Technology 74(1), 81-87.

Pasquini, D., Teixeira, E.M., Curvelo, A.A.S., Belgacem, M.N., Dufresne, A., (2010). Extraction of cellulose whiskers from cassava bagasse and their applications as reinforcing agent in natural rubber. Industrial Crops and Products 32(3), 486490.

Paul, S., Das, M.K., Baishya, P., Ramteke, A., Farooq, M., Baroowa, B., Sunkar, R., Gogoi, N., (2017). Effect of high temperature on yield associated parameters and vascular bundle development in five potato cultivars. Scientia Horticulturae $225,134-140$.

Polachini, T.C., Betiol, L.F.L., Lopes-Filho, J.F., Telis-Romero, J., (2016a). Water adsorption isotherms and thermodynamic properties of cassava bagasse. Thermochimica Acta 632, 79-85. 
Polachini, T.C., Sato, A.C.K., Cunha, R.L., Telis-Romero, J., (2016b). Density and rheology of acid suspensions of peanut waste in different conditions: An engineering basis for bioethanol production. Powder Technology 294, 168-176.

Roche, C.M., Dibble, C.J., Knutsen, J.S., Stickel, J.J., Liberatore, M.W., (2009). Particle concentration and yield stress of biomass slurries during enzymatic hydrolysis at high-solids loadings. Biotechnology and Bioengineering 104(2), 290-300.

Sánchez, A.S., Silva, Y.L., Kalid, R.A., Cohim, E., Torres, E.A., (2017). Waste biorefineries for the cassava starch industry: New trends and review of alternatives. Renewable and Sustainable Energy Reviews 73, 1265-1275.

Ségalen, C., Dieudé-Fauvel, E., Clément, J., Baudez, J.C., (2015). Relationship between electrical and rheological properties of sewage sludge - Impact of temperature. Water Research 73, 1-8.

Silva, E.C., Cereda, M.P., Colman, T.A.D., Demiate, I.M., Schnitzler, E., (2015). Characterisation of cassava bagasse in different granulometries from two starch processing plants. The Journal of Microbiology, Biotechnology and Food Sciences 5(2), 99-102.

Steffe, J.F., (1996). Rheological Methods in Food Process Engineering (2 ed). Freeman Press, East Lansing.

Stickel, J.J., Knutsen, J.S., Liberatore, M.W., Luu, W., Bousfield, D.W., Klingenberg, D.J., Scott, C.T., Root, T.W., Ehrhardt, M.R., Monz, T.O., (2009). Rheology measurements of a biomass slurry: an inter-laboratory study. Rheologica Acta 48(9), 1005-1015.

Travalini, A.P., Prestes, E., Pinheiro, L.A., Demiate, I.M., (2017). Extraction and Characterization of Nanocrystalline Cellulose from Cassava Bagasse. Journal of Polymers and the Environment.

Van Soest, P.J., Robertson, J.B., Lewis, B.A., (1991). Methods for Dietary Fiber, Neutral Detergent Fiber, and Nonstarch Polysaccharides in Relation to Animal Nutrition. Journal of Dairy Science 74(10), 3583-3597. 
Versino, F., López, O.V., García, M.A., (2015). Sustainable use of cassava (Manihot esculenta) roots as raw material for biocomposites development. Industrial Crops and Products 65, 79-89.

Viamajala, S., McMillan, J.D., Schell, D.J., Elander, R.T., (2009). Rheology of corn stover slurries at high solids concentrations - Effects of saccharification and particle size. Bioresource Technology 100(2), 925-934.

Volynets, B., Ein-Mozaffari, F., Dahman, Y., (2017). Biomass processing into ethanol: pretreatment, enzymatic hydrolysis, fermentation, rheology, and mixing. Green Processing and Synthesis 6(1), 1-22. 
5.3. CHAPTER 3 Rheology of Peanut Waste Suspensions 


\section{Density and Rheology of Acid Suspensions of Peanut Waste in Different Conditions: an Engineering Basis for Bioethanol Production}

Tiago Carregari Polachini ${ }^{1 *}$; Ana Carla Kawazoe Sato ${ }^{2}$; Rosiane Lopes da Cunha ${ }^{2}$ and Javier Telis-Romero ${ }^{1}$

${ }^{1}$ Food Engineering and Technology Department, State University of São Paulo, São José do Rio Preto, São Paulo, 15054000, Brazil.

${ }^{2}$ School of Food Engineering, Department of Food Engineering , University of Campinas (UNICAMP), Campinas, São Paulo, 13083-862, Brazil. 
Abstract: The current world-wide energetic situation implies in researches about new resources and technologies capable of producing biofuels, such as the peanut processing residues. To design operations associated to bioethanol processing, understanding material properties, as density and rheology, is necessary. In this study, peanut shells were firstly chemically characterized, showing $37.1 \%$ cellulose, $33.4 \%$ hemicellulose and $15.0 \%$ lignin. Aqueous acid suspensions of powdered peanut shell were prepared and their physical properties were determined. Rheological parameters and density could be correlated with solid content and temperature by exponential and quadratic equations, respectively, while $\mathrm{pH}$ did not present significant effect on these parameters. Dilute suspensions showed Newtonian behavior, but at concentration above $8 \%(\mathrm{w} / \mathrm{w})$ of solids, a non-Newtonian behavior was observed, showing yield stress and shear thinning. By evaluating the relative viscosity behavior with increasing solids concentration, Farris effect was also evidenced in suspensions above $8 \%$ of solids due to the presence of fine particles. Such result indicates the possibility of processing peanut shells for biofuel production in solids concentration higher than $10 \%$, without a significant influence on viscosity. Keywords: rheological parameter, peanut shell, physical properties, shear thinning, suspension, bioethanol. 


\subsubsection{Introduction}

Nowadays, with the high exploitation of fossil fuels, one of the biggest environmental worries is the fuel supply (Verlmurugan and Muthukumar, 2011). It has influenced many studies to bring new technologies and renewable sources to produce energy, mainly from lignocellulosic materials. Biomass is the more suitable and available source able to produce biofuels, as bioethanol and biodiesel in a short time (Hamelinck et al, 2005; Sun and Cheng, 2002).

Agro-industrial residues, wood and some urban residues are the examples of biomass, with a dry matter composed of cellulose, hemicellulose and lignin. Agroindustrial wastes are interesting biomass source due to its low cost and abundance in agriculture producing countries as Brazil (Castro and Pereira-Jr, 2010).

Currently in Brazil, peanut processing can generate more than 90 thousand tons of waste, considering the average shell/grain ratio of $30 \%$ (Godoy et al., 1982) and an annual production, around of 320.000 tons in 2014 (IBGE, 2014). Thus, its polymeric composition of fermentable material is attractive to develop new treatments and processes. The peanut shells, currently used as fertilizers and fodder in poultry farms, could be used as raw material in bioethanol conversion/preparation processing after physical, chemical, biological or even combined pretreatments.

The major step of bioethanol production consists into the breakdown of hemicellulose and the crystalline structure from the cellulose for sugars release, which will be fermented into ethanol and later distilled. All these steps generally occur in stirred bioreactors using acid medium (Araki and Kuga, 2001; Esteghlalian et al., 1997; Wijaya et al., 2014).

A correct understanding of the material properties, as density and rheology, is necessary to design cost-effective treatments processes (Riedlberger and WeusterBotz, 2012) during fermentation and handling agro-industrial residues. Rheology is also used to understand the product's structural behavior (Steffe, 1996), besides its importance on designing pipes and process equipment.

Rheological/structural behavior depends on a number of factors, including chemical composition, particle size and shape, surface effects and/or additives presence. These factors are generally heterogeneous in biomass suspensions, once particles vary in terms of composition, size and shape (Stickel et al., 2009). The flow 
characteristics of suspensions can be defined either by the continuous or dispersed phase, or even by the influence of one in another (Ferguson and Kemblowski, 1991). Considering that the combination of these facts makes unique the properties of each suspension, the need of published physical properties data of such systems is emphasized.

So, this study intended to characterize and evaluate the rheological behavior and density of acid suspensions of peanut shell powder in different conditions of biomass concentration, temperature and $\mathrm{pH}$.

\subsubsection{Materials and Methods}

\subsubsection{Peanut shell preparation}

Cleaned and dried peanut (Arachis hypogaea L.) shells were obtained from Agro-industrial Cooperative - COPLANA (Jaboticabal, São Paulo, Brazil). Using a knife mill MA380 (Marconi, Piracicaba, Brazil), the shells were milled and separated by Tyler sieves (mesh 12 and 24) to obtain a particle size distribution between 1397 and $701 \mu \mathrm{m}$.

\subsubsection{Chemical characterization}

Analysis of moisture, dry matter, cellulose, hemicelullose, lignin and total sugars were done aiming the characterization of the peanut shell. Moisture and dry matter were determined by a vacuum oven, according to AOAC 926.12 method (AOAC, 1997).

Cellulose, hemicellulose and lignin content were determined using a method on reflux extraction with neutral detergent or acid detergent solutions for 90 min (Van Soest, 1963; Van Soest and Wine, 1967). Filtrate was washed with hot distilled water and ethanol, then oven-dried until constant weight. The percentage of each washing represents the neutral detergent fibers (NDF) and acid detergent fibers (ADF). To determinate the lignin amount, sulfuric acid $(72 \% \mathrm{w} / \mathrm{w})$ was added to the samples under magnetic stirring at $20{ }^{\circ} \mathrm{C}$ every hour, during $3 \mathrm{~h}$. After washing with hot distilled water until a sulfuric acid concentration of $3 \%(\mathrm{w} / \mathrm{w})$, the filtration residue (lignin) was dried and weighed. The difference between NDF and ADF indicates the 
hemicellulose content, and subtracting the lignin percentage from ADF results in the cellulose content.

Total sugars content was determined from the acid hydrolyzed samples of NDF and ADF, by high-performance liquid chromatography (HPLC) according to the AOAC 982.14 method (AOAC, 1997). Hydrolyzed sample was centrifuged at $1850 \times \mathrm{g}$ for $2 \mathrm{~min}$ at $20^{\circ} \mathrm{C}$. After removing the supernatant, sugars were extracted into $50 \%$ ethanol, passed through a Sep-Pak $\circledast$ C18 cartridge (Waters Associates, Milford, MA, USA) and then filtered through a $0.45 \mathrm{~mm}$ nylon disc. Separation and quantification were carried out on a ubondapak- $\mathrm{NH}_{2}$ column $(30 \mathrm{~cm} \times 3.9 \mathrm{~mm}$ i.d., Waters, Milford, MA, USA) and a refractive index (IR) detector, using $\mathrm{CH}_{3} \mathrm{CN}$ and $\mathrm{H}_{2} \mathrm{O}(80: 20 \mathrm{v}$ :v) as mobile phase. Concentrations were calculated based on prepared external standards.

\subsubsection{Zeta (ろ) Potential}

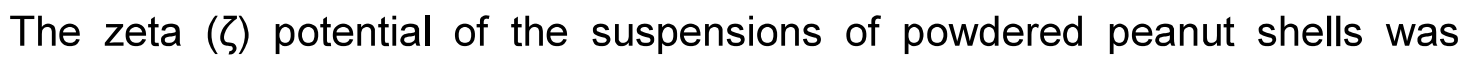
determined using a Zetasizer Nano ZS equipment (Malvern Instruments, Worcestershire, UK). Suspensions containing $0.01 \%(\mathrm{w} / \mathrm{w})$ of powdered peanut shells were previously prepared at different $\mathrm{pH}(3.0,4.0,5.0,6.0$ and 7.0) using $0.05 \%(\mathrm{w} / \mathrm{w}) \mathrm{H}_{2} \mathrm{SO}_{4}$ solutions. Each sample was transferred to the cuvettes for zeta potential measurements, which were done in triplicate.

\subsubsection{Particles size distribution}

Particle size distribution of the peanut powder, separated by Tyler sieves mesh 12 and 24, was evaluated by laser diffraction (LD) using a Mastersizer S model MAM 5005 (Malvern Instruments Ltd., UK), with distilled water as dispersing medium. Each sample was evaluated in 6 replicates. Diameter of samples was represented as the volume weighted mean diameter $\left(D_{4,3}\right)$, defined by Equation (5.3.1) and surface weighted mean diameter $\left(D_{3,2}\right)$, defined by Equation (5.3.2). Polydispersity was evaluated according to span value, given in Equation (5.3.3).

$$
D_{4,3}=\frac{\sum n_{i} \cdot d_{i}^{4}}{\sum n_{i} \cdot d_{i}^{3}}
$$


$D_{3,2}=\frac{\sum n_{i} \cdot d_{i}^{3}}{\sum n_{i} \cdot d_{i}^{2}}$

$\operatorname{span}=\frac{D_{9,0}-D_{1,0}}{D_{5,0}}$

where, $n_{i}$ is the number of particles with $d_{i}$ diameter, $D_{1,0}, D_{5,0}$ and $D_{9,0}$ are diameters at $10 \%, 50 \%$ and $90 \%$ cumulative volume, respectively.

\subsubsection{Optical microscopy (OM)}

Particle morphology was analyzed through optical microscopy (OM). Using microscope slides and glass cover slips, particles were observed at 10, 40 and 100x magnification using a Carl Zeiss Model Axio Scope A.1 (Zeiss, Germany). Images were also evaluated using the public domain software Image $\mathrm{J} v 1.36 \mathrm{~b}$. The pixelscale values were converted into microns by a scaling factor and the group of particles present in the captured images were measured. The length $(L)$ and the width $(w)$ were the dimensions determined for the fibers, and the aspect ratio $\left(a_{r}\right)$ was calculated by $a_{r}=L / W$.

\subsubsection{Rheological measurements}

Suspensions were prepared with different solids content: 0, 2; 4; 6; 8; 10 and $12 \%(w / w)$ using an analytical balance (model AUX220, Shimadzu, Japan). Solutions with varying $\mathrm{pH}(3.0 ; 4.0 ; 5.0 ; 6.0$ and 7.0$)$ were used for dispersing the suspensions. These solutions were prepared and stabilized for 3 days with distilled water and diluted sulfuric acid $\left(\mathrm{H}_{2} \mathrm{SO}_{4}\right)$ at $0.05 \%$. The suspensions were prepared and inserted immediately into the equipment.

Rheological measurements were done in an AR-G2 rheometer (TA Instruments, USA) with SPC (Starch Pasting Cell) geometry to avoid the particles sedimentation. Samples of approximately $28 \mathrm{~cm}^{3}$ were required in each run and shear rate ramps were set from 0 to $260.5 \mathrm{~s}^{-1}$ in steady flow. Sample temperature (1, $10,20,30,40,50$ and $60^{\circ} \mathrm{C}$ ) was controlled by the equipment bath. Shear stress data were extracted by data acquisition system Universal Analysis 2000 version 4.7 (TA Instruments, USA). 
Table 5.3.1. Viscosity validation using chlorobenzene as standard substance.

\begin{tabular}{cccccc}
\hline \multirow{2}{*}{$\begin{array}{c}\text { Standard } \\
\text { substance }\end{array}$} & Temperature & \multicolumn{2}{c}{${\text { Viscosity }(\mathrm{cP})^{*}}^{*}$} & $\begin{array}{c}\text { Confidence } \\
\text { Interval (95\%) }\end{array}$ & $p_{\text {value }}$ \\
\cline { 2 - 6 } & ${ }^{\circ} \mathrm{C}$ & Literature $^{\mathrm{a}}$ & Experimental $^{\mathrm{b}}$ & & \\
\hline Chlorobenzene & 0 & 1.058 & $1.056 \pm 0.0104$ & $(1.049 ; 1.063)$ & 0.596 \\
$\mathrm{C}_{6} \mathrm{H}_{5} \mathrm{Cl}$ & 25 & 0.753 & $0.751 \pm 0.0071$ & $(0.746 ; 0.755)$ & 0.377 \\
& 50 & 0.575 & $0.578 \pm 0.0060$ & $(0.574 ; 0.582)$ & 0.087 \\
\hline
\end{tabular}

${ }^{a}$ Data from Lide (1993).

${ }^{\mathrm{b}}$ Mean \pm standard deviation for eleven experimental data.

Chlorobenzene was the standard substance in calibration. The measurements in Table 5.3.1 did not present significant difference $\left(p_{\text {value }}>0.050\right)$ with the ones published in literature (Lide, 1993), indicating that the equipment is properly calibrated.

\subsubsection{Density analysis}

Density $\left(\rho, \mathrm{kg} / \mathrm{m}^{3}\right)$ was determined for the same suspensions used in rheological determination. Analyses were carried out in a volumetric standard picnometer DIN ISSO 3507 (Brand, Wertheim, Germany), equipped with a lid and a graduated thermometer with sensibility of $0.1^{\circ} \mathrm{C}$. Sample temperature was changed and stabilized using a thermostatic bath MA-159 (Marconi, São Paulo, Brazil). For each measurement, the picnometer was calibrated with distilled water according to the procedures described in ASTM-D1480 (ASTM, 1989).

Experimental measurements were done in triplicate, using a $50 \mathrm{~mL}$ picnometer and an analytical balance with $0.0001 \mathrm{~g}$ of precision (model AUX220, Shimadzu, Japan).

\subsubsection{Data modeling}

Rheograms were plotted, obtaining shear stress as function of shear rate. Rheological behavior was evaluated using flow models with 1 to 3 parameters (Equations (5.3.4)-(5.3.7)) and their adjusted correlation coefficient $\left(R^{2}\right)$. Newton (1 parameter), Bingham and Power Law (2 parameters) and Herschel-Bulkley model (3 parameters) are represented by Equation (5.3.4)-( 5.3.7), respectively; whereas $T$ $(\mathrm{Pa})$ is shear stress $(\mathrm{Pa}), \dot{\gamma}(1 / \mathrm{s})$ is shear rate, $k\left(\mathrm{~Pa} . \mathrm{s}^{n}\right)$ is the consistency coefficient, 
$n$ (dimensionless) is the flow behavior index, $T_{0}(\mathrm{~Pa})$ is the initial yield stress to start the flow, $\mu$ (Pa.s) is Newtonian viscosity, $\eta_{B}$ (Pa.s) is plastic viscosity and $\eta_{a p p}$ (Pa.s) is apparent viscosity at a fixed shear rate (Holdsworth, 1993; Steffe, 1996).

$$
\begin{aligned}
& \tau=\mu \dot{\gamma} \\
& \tau=\tau_{0}+\eta_{B} \dot{\gamma} \\
& \eta_{a p p}=\frac{\tau_{0}}{\dot{\gamma}}+\eta_{B} \\
& \tau=k \dot{\gamma}^{n} \\
& \eta_{a p p}=k \dot{\gamma}^{n-1} \\
& \tau=\tau_{0}+k \dot{\gamma}^{n} \\
& \eta_{a p p}=\frac{\tau_{0}}{\dot{\gamma}}+k \dot{\gamma}^{n-1}
\end{aligned}
$$

A usual manner to correlate the rheological parameters with solid content and temperature was proposed by Rao (1986). The author recommends exponential equations to fit data, due to their good representativeness. The following exponential models (Equation (5.3.8) and (5.3.9)) have the adjusted parameters $A, B, C$ and $D$, and $X_{S}$ as the solid content $(\% \mathrm{~m} / \mathrm{m}), T$ as the temperature $\left({ }^{\circ} \mathrm{C}\right)$ and $R$ as the gas universal constant $(8.314 \mathrm{~J} / \mathrm{mol} \mathrm{K})$.

$$
\begin{aligned}
& \mu, \eta_{a p p}, k, n=A+B \exp \left(\frac{C}{R(T+273.15)}\right) X_{S}^{D} \\
& \mu, \eta_{a p p}, k, n=A \exp \left(B X_{S}+C X_{S}^{2}+\frac{D}{R(T+273.15)}\right)
\end{aligned}
$$

For suspensions, is common to use the values of relative viscosity $\left(\eta_{\text {rell }}\right)$ as function of the volume fraction of solids, which is given by a relation between the suspension $\left(\eta_{s}\right)$ and dispersant $\left(\eta_{d}\right)$ viscosity (Santana et al., 2012). 
In the case of density, data were fitted to polynomial models of second degree simultaneously for concentration of solids and temperature.

\subsubsection{Results and discussion}

\subsubsection{Chemical characterization}

The chemical composition of peanut shell is displayed in Table 5.3.2. The obtained composition of dry matter resembles to other studied lignocellulosic materials, as almonds shells, sugarcane bagasse and rice straw (Mood et al., 2013), and even for some results presented by Castro \& Pereira-Jr (2010) for peanut shells. Total sugars indicate the maximum potential of conversion from lignocellulose compounds such as cellulose and hemicellulose.

Table 5.3.2. Chemical composition of peanut shells.

\begin{tabular}{|c|c|}
\hline Chemical composition & Results $^{* * *}$ \\
\hline Moisture $\left(w \cdot w^{-1}, w\right.$. b. $)$ & $11.0 \pm 0.1$ \\
\hline Dry matter $\left(w \cdot w^{-1}, w . b.\right)$ & $89.0 \pm 0.1$ \\
\hline Cellulose $^{*}\left(w \cdot w^{-1}\right.$, d.b. $)$ & $37.1 \pm 1.0$ \\
\hline Hemicellulose $e^{*}\left(w \cdot w^{-1}\right.$, d.b. $)$ & $33.4 \pm 0.6$ \\
\hline $\operatorname{Lignin}^{*}\left(w \cdot w^{-1}\right.$, d.b. $)$ & $15.0 \pm 0.3$ \\
\hline Total sugars ${ }^{* *}\left(g \cdot L^{-1}\right)$ & $65.1 \pm 1.6$ \\
\hline
\end{tabular}

\subsubsection{Zeta Potential}

Zeta potential or surface charge of materials is strongly influenced by $\mathrm{pH}$, since it determines the degree of protonation of functional groups in the material surface (Lin et al., 2006). Figure 5.3.1 shows zeta potential of peanut shells as a function of $\mathrm{pH}$. 


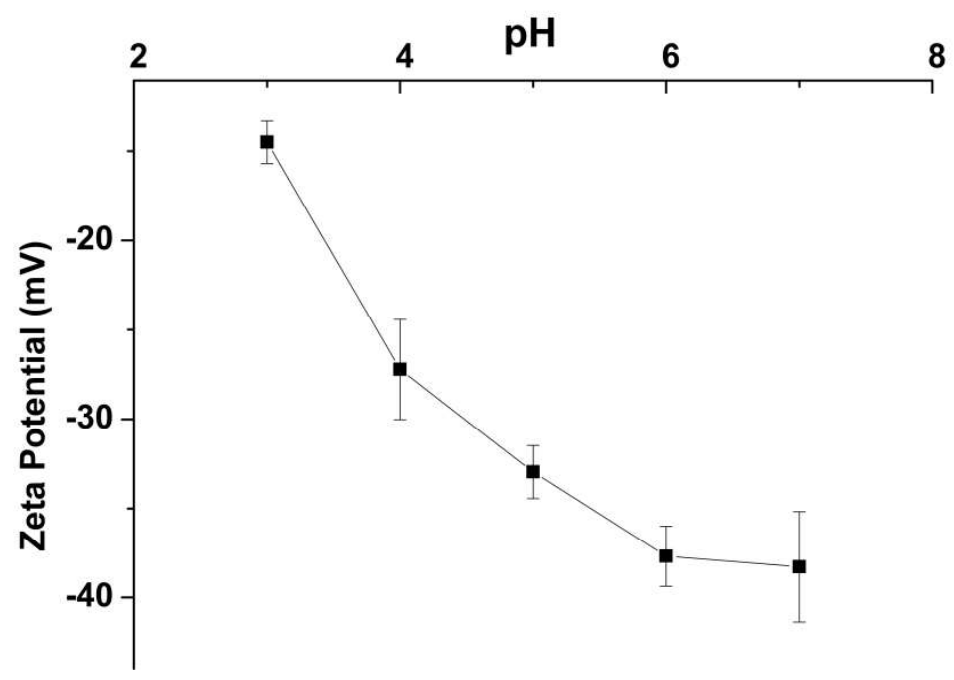

Figure 5.3.1. Zeta potential of suspensions of powdered peanut shell (PPS) at different $\mathrm{pH}$ values.

In the range of $\mathrm{pH}$ values evaluated, increasing $\mathrm{pH}$ from 3 to 6 resulted in a significant deviation on zeta-potential value, with smaller influence between $\mathrm{pH} 6$ and 7. If zeta potential values are near to zero, it is expected more interactions between particles, since there are no electrostatic repulsion between them. Similar behavior was also observed for suspensions of cellulose fibers of banana waste (Elanthikkal et al., 2010). The addition of cationic compounds, such as $\mathrm{H}^{+}$, on negatively charged products may cause aggregation in different ways. The main mechanism is the charge screening, which reduces the zeta potential magnitude and the electrostatic repulsion between molecules, such as cellulose (Alince and Robertson, 1974).

\subsubsection{Particles size distribution}

Volume particles size distribution showed a high polydispersity (span 1.886), probably due to the great amount of small size (between 3 and $12 \mu \mathrm{m}$ ) particles and some particles with larger sizes. Results showed that $10 \%$ of particles $\left(D_{1,0}\right)$ are smaller than $105.62 \mu \mathrm{m}$ while $10 \%$ of particles show larger sizes than $948.03 \mu \mathrm{m}$ $\left(D_{9,0}\right)$, reflecting the high polydispersity even though a monomodal particle size distribution of powdered peanut shell (PPS) was observed by volume and number distribution (Figure 5.3.2). 


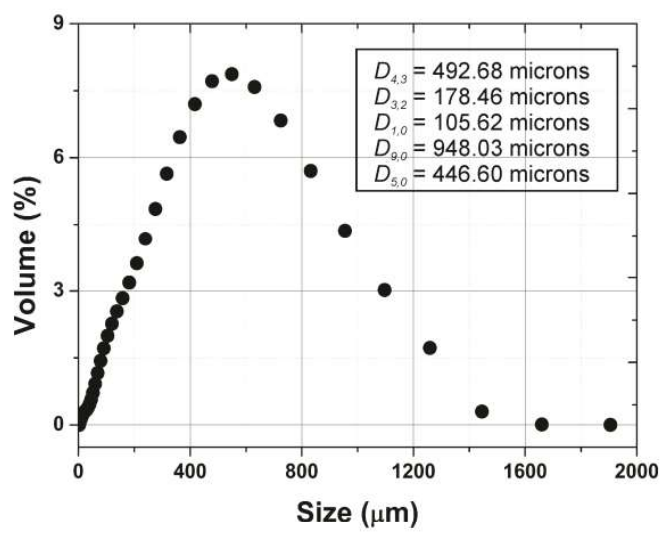

(a)

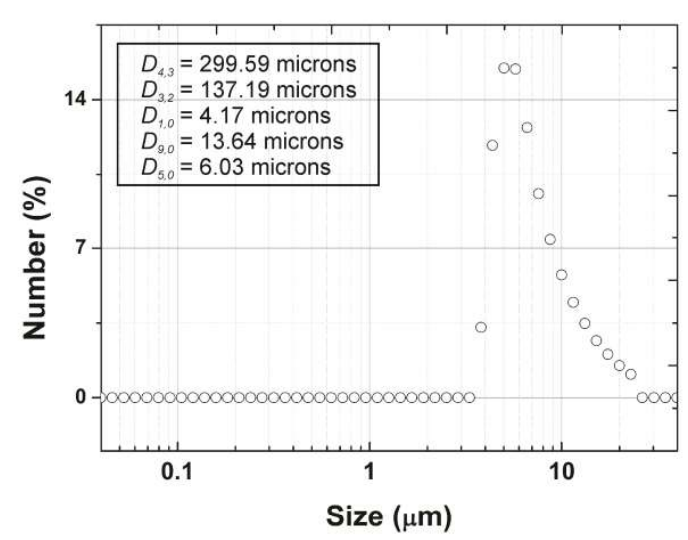

(b)

Figure 5.3.2. Particles size distribution based on (a) volume and (b) number of particles.

A significant difference between the peaks from Figures 5.3.2a and 5.3.2b can be observed. Such difference is attributed to the fact that the larger particles represent a higher volume fraction, while smaller particles $(\sim 5 \mu \mathrm{m})$ represent the higher number fraction, once a great amount of small particles is necessary to occupy the same volume as a single big particle.

The mean volume weighted diameter $\left(D_{4,3}\right)$ was $492.68 \mu \mathrm{m}$, while the surface weighted diameter $\left(D_{3,2}\right)$ was $178.46 \mu \mathrm{m}$. In the presence of high content of fine particles, $D_{3,2}$ would give lower values than $D_{4,3}$, as observed for soybean extract (Fasolin and Cunha, 2013) and the PPS evaluated in the present work. As $D_{3,2}$ is defined as the diameter of a sphere with the same volume/surface ratio (Filippa et al., 2012), fine particles seem to have volume lower than the representative sphere when compared to its surface. Since this analysis consist to verify the light scattering pattern of a specific particles volume, it is useful to compare the fraction of each size particles range present in the powder. Results indicated that the most of particles showed a diameter around $6 \mu \mathrm{m}$ (mode).

\subsubsection{Optical microcopy (OM)}

Particles were observed through images obtained by optical microscopy (Figure 5.3.3), showing particles with unlike size (high polydispersity) and irregular 
shape. The morphology was typical of cellulosic material and their average aspect ratio $\left(a_{r}\right)$ was $1.86 \pm 0.72$.

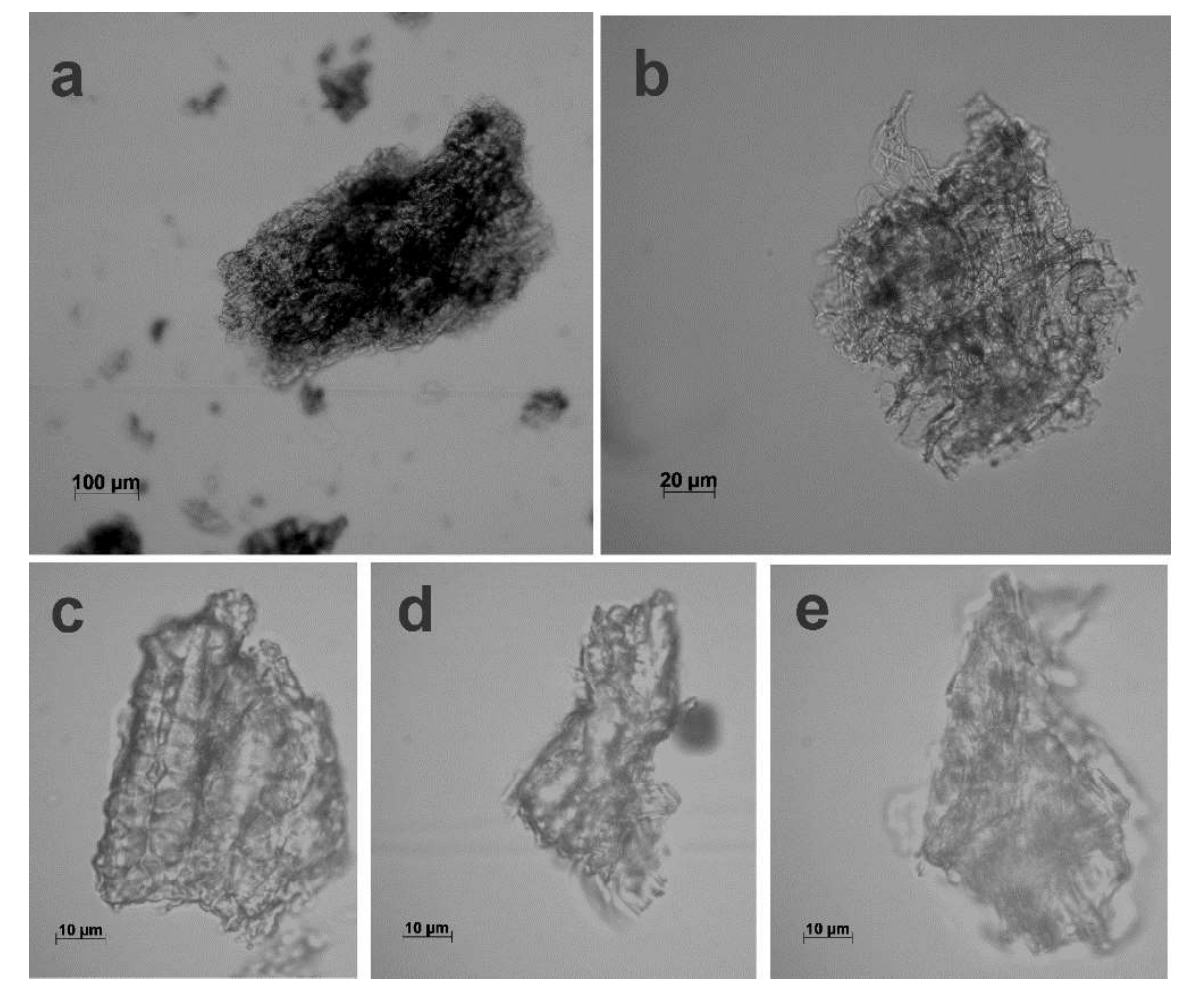

Figure 5.3.3. Optical microscopy of PPS at different magnifications: a) 10x; b) 40x and $\mathrm{c}, \mathrm{d}$ and e) 100x.

\subsubsection{Flow behavior}

Fitting values of the 3-parameter non-linear regression, Herschel-Bulkley equation, are presented in Table 5.3.3. Fitting parameters show the rheological behavior as function of concentration, $\mathrm{pH}$ and temperature.

The rheological characteristics were very well-fitted to Herschel-Bulkley equation, with $R^{2}>0.999$. Suspensions with solids concentration up to $8 \%$ showed flow behavior index close to 1 and $\tau_{0}$ close to zero, indicating Newtonian behavior as the dispersant solutions ( $0 \%$ of solids). Since flow behavior index is very close to the unit and there is no residual stress $\left(\tau_{0} \approx 0\right)$ for almost all cases, it brings the HerschelBulkley into Newton's equation. Probably, up to $8 \%$ of PPS the particles do not show significant interactions between them to induce a change in rheological behavior, predominating the dispersant properties. 
Table 5.3.3. Fitting parameters of Herschel-Bulkley equation for some suspensions.

\begin{tabular}{|c|c|c|c|c|c|c|c|c|c|c|}
\hline & \multirow{2}{*}{\multicolumn{3}{|c|}{$2 \%$}} & \multicolumn{3}{|c|}{ [biomass] (w/w) } & & & \\
\hline & & & & & \multicolumn{3}{|c|}{$8 \%$} & \multicolumn{3}{|c|}{$10 \%$} \\
\hline & & $\mathrm{pH} 3.0$ & $\mathrm{pH} 5.0$ & & H 3.0 & $\mathrm{nH} 50$ & & & $\mathrm{nH} 50$ & \\
\hline \multirow{4}{*}{$1^{\circ} \mathrm{C}$} & $T_{0}$ & & 0.0897 & & & & & & & \\
\hline & $k$ & 0.2558 & 0.2545 & 0.2558 & 3.2755 & 3.6082 & & & 5.6382 & \\
\hline & $n$ & & 1.0009 & 0.9984 & 0.9955 & 1.0016 & & & 0.8604 & \\
\hline & $R^{2}$ & 0.9999 & 0.9999 & 0.9999 & 0.9999 & 0.9999 & & 9999 & 0.9999 & 0.9999 \\
\hline \multirow{4}{*}{$10^{\circ} \mathrm{C}$} & $T_{0}$ & 0.059 & 0.0609 & 0.0650 & 0.7380 & 0.9791 & 259 & 1.7602 & 1.6998 & 1.7137 \\
\hline & $k$ & 0.1599 & 0.1589 & & 1.9965 & 1.8379 & & & 4.0592 & \\
\hline & $n$ & & 1.0001 & & 0010 & 1.0026 & & & 0.8731 & \\
\hline & $R^{2}$ & & 0.9999 & & 0.9999 & 0.9999 & & & 0.9999 & \\
\hline & $T_{0}$ & 0.042 & 0.0468 & & 0.5833 & 0.5478 & & & 1.5200 & \\
\hline & $k$ & 0.118 & 0.1177 & & 1.4708 & 1.4435 & & & 2.7384 & \\
\hline & $n$ & 0.99 & 1.0006 & & 1.0013 & 1.0010 & & & 0.8712 & \\
\hline & $R^{2}$ & 0.99 & 0.9999 & 0.9 & 0.9999 & 0.9999 & & & 0.9999 & \\
\hline \multirow{4}{*}{$30^{\circ} \mathrm{C}$} & $T_{0}$ & 0.03 & 0.0364 & & 0.5102 & 0.4762 & & & 1.0097 & \\
\hline & $k$ & & 0.09 & & 1490 & 1.17 & & & 2.4921 & \\
\hline & $n$ & & 1.0002 & & 1.0003 & 1.0013 & & & 0.8737 & \\
\hline & $R^{2}$ & & 0.9999 & & 0.9999 & 0.9999 & & & 0.9999 & \\
\hline \multirow{4}{*}{$J^{\circ} \mathrm{C}$} & $T_{0}$ & 0.0322 & 0.0272 & 2 & 0.3756 & 0.3754 & & 23 & 0.9067 & \\
\hline & $k$ & 0.0825 & 0.0836 & 0.0 & 1.0279 & 0.9997 & & & 2.0502 & \\
\hline & & & 0.998 & & 1.0013 & 1.00 & & & 0.8675 & \\
\hline & $R^{2}$ & 0.999 & 0.9999 & & 0.9999 & 0.9999 & & & 0.9999 & \\
\hline \multirow{4}{*}{$50^{\circ} \mathrm{C}$} & $T_{0}$ & 0.0249 & 0.0267 & 0.0223 & 0.2096 & 0.3502 & & 0.5401 & 0.5239 & \\
\hline & $k$ & 0.0749 & 0.0736 & 0.0 & 0.9670 & 0.8975 & & 2.0 & 2.0548 & \\
\hline & $n$ & & 1.0008 & & 0.9955 & & & & 0.8 & \\
\hline & $R^{2}$ & & 0.9999 & & 0.9999 & 0.9999 & & 0.9999 & 0.9999 & \\
\hline \multirow{4}{*}{$60^{\circ} \mathrm{C}$} & $T_{0}$ & 0.0218 & 0.0236 & 0194 & 0.3398 & 0.2371 & 978 & 0.5018 & 0.6648 & 0.4759 \\
\hline & $k$ & 0.0689 & 0.0686 & & 0.8413 & 0.8819 & & & 1.8663 & \\
\hline & $n$ & & & & & & & & & \\
\hline & $R^{2}$ & 0.9999 & 0.9999 & 0.9999 & 0.9999 & 0.9999 & 0.9999 & 0.9999 & 0.9999 & 0.999 \\
\hline
\end{tabular}

The more concentrated suspensions $(>10 \% \mathrm{w} / \mathrm{w})$ showed pseudoplasticity (minimum $n$ value of 0.85 ) and a considerable increase in initial yield stress (up to 3.54 Pa), which was also evidenced for slurries by Chen et al. (2009) and Lin et al. (2008). Considering that yield stress represents the necessary initial energy to induce the flow, at higher solids concentration, the particles are more misaligned and 
disorganized, increasing $T_{0}$ values. Although the mechanism is unknown, authors suggested that in highly concentrated suspensions, the breakdown of a three dimensional network structure along the increase of shear rate promotes the release of interstitial water reducing on the apparent viscosity, which results in shear thinning behavior (Sato, 1995; Seka and Verstraete, 2003). This effect was also verified in the different kind of suspensions such as some fruit pulps as tomato (Sharma et al., 1996) and mango (Bhattacharya, 1999), slurries of limestone (He et al., 2006), nickel (Bobicki et al., 2014) and biomass of corn stover (Viamajala et al., 2009). All of them were also characterized as shear thinning fluids with yield stress.

\subsubsection{Influence of $\mathrm{pH}$ on rheological parameters}

In addition to the particle's physical characteristics, affinity with the dispersant medium and the medium properties can hardly change the suspensions rheology (Chang and Powell, 1994). This effect could be evaluated from zeta potential values, since a more pronounced particles aggregation are likely to occur at $\mathrm{pH}$ in which neutral surface charge is observed. Thus, in order to verify the $\mathrm{pH}$ influence on rheological parameters, a Tukey test at $95 \%$ confidence interval was used between the samples with 2 and $12 \%$ of solids at different $\mathrm{pH}$ values. Means and standard deviation can be seen in Table 5.3.4.

Even though zeta potential indicated a tendency to agglomeration at more acidic $\mathrm{pH}$ values, rheological parameters did not show differences at varying $\mathrm{pH}$, confirming that $\mathrm{pH}$ solution did not affect the suspensions rheology. The absence of significant differences could be attributed to the hydrodynamic forces, which seems to be more pronounced than Brownian motion in systems with average particle size or aggregates higher than $100 \mu \mathrm{m}$ (Genovese et al., 2007), which corresponded to the major fraction of the particles (Figure 5.3.2a), and of electrostatic interactions, that would be favored by the acidic $\mathrm{pH}$. 
Table 5.3.4. Means and standard deviation of Herschel-Bulkley parameters for the runs in triplicate at 2 and $12 \%$ of solids.

\begin{tabular}{|c|c|c|c|c|c|c|c|}
\hline $\begin{array}{l}\text { Biomass } \\
(\% \mathrm{w} / \mathrm{w})\end{array}$ & $\begin{array}{l}\text { Rheological } \\
\text { Parameters }\end{array}$ & $T\left({ }^{\circ} \mathrm{C}\right)$ & $\mathrm{pH}=3$ & $\mathrm{pH}=4$ & $\mathrm{pH}=5$ & $\mathrm{pH}=6$ & $\mathrm{pH}=7$ \\
\hline \multirow{21}{*}{2} & \multirow{7}{*}{$T_{0}(\mathrm{mPa})$} & 1 & $76.80 \pm 11.06^{a}$ & $85.16 \pm 30.72^{a}$ & $84.28 \pm 4.91^{a}$ & $89.50 \pm 16.73^{a}$ & $76.06 \pm 5.48^{a}$ \\
\hline & & 10 & $67.88 \pm 9.23^{a}$ & $56.79 \pm 6.91^{\mathrm{a}}$ & $63.07 \pm 2.75^{\mathrm{a}}$ & $62.58 \pm 3.07^{a}$ & $62.11 \pm 2.62^{a}$ \\
\hline & & 20 & $45.84 \pm 4.17^{\mathrm{a}}$ & $44.01 \pm 6.18^{a}$ & $46.76 \pm 0.46^{a}$ & $45.51 \pm 1.68^{a}$ & $45.96 \pm 2.11^{\mathrm{a}}$ \\
\hline & & 30 & $37.43 \pm 2.08^{a}$ & $39.48 \pm 9.14^{a}$ & $36.58 \pm 2.82^{a}$ & $36.22 \pm 1.92^{a}$ & $37.87 \pm 1.28^{a}$ \\
\hline & & 40 & $30.92 \pm 1.22^{a}$ & $33.23 \pm 7.36^{\mathrm{a}}$ & $31.10 \pm 3.53^{\mathrm{a}}$ & $28.83 \pm 7.70^{a}$ & $30.03 \pm 2.80^{a}$ \\
\hline & & 50 & $21.67 \pm 3.60^{\mathrm{a}}$ & $27.25 \pm 4.57^{\mathrm{a}}$ & $29.71 \pm 6.45^{a}$ & $24.96 \pm 3.68^{a}$ & $23.52 \pm 1.73^{a}$ \\
\hline & & 60 & $22.74 \pm 2.13^{a}$ & $24.57 \pm 5.38^{a}$ & $22.42 \pm 1.16^{\mathrm{a}}$ & $22.48 \pm 2.39^{a}$ & $20.94 \pm 2.28^{a}$ \\
\hline & \multirow{7}{*}{$k\left(\mathrm{mPa} \cdot \mathrm{s}^{\mathrm{n}}\right)$} & 1 & $257.45 \pm 3.26^{a}$ & $257.18 \pm 6.55^{a}$ & $255.29 \pm 0.72^{a}$ & $253.12 \pm 2.36^{a}$ & $253.80 \pm 1.81^{a}$ \\
\hline & & 10 & $158.61 \pm 1.41^{a}$ & $160.72 \pm 2.24^{a}$ & $158.40 \pm 0.50^{a}$ & $158.38 \pm 0.39^{a}$ & $158.35 \pm 0.29^{a}$ \\
\hline & & 20 & $117.96 \pm 0.85^{a}$ & $118.56 \pm 1.71^{\mathrm{a}}$ & $117.74 \pm 0.14^{a}$ & $116.75 \pm 0.12^{a}$ & $16.75 \pm 0.10^{a}$ \\
\hline & & 30 & $95.77 \pm 0.07^{\mathrm{a}}$ & $89.35 \pm 1.41^{b}$ & $95.69 \pm 0.26^{a}$ & $95.67 \pm 0.18^{a}$ & $95.81 \pm 0.10^{a}$ \\
\hline & & 40 & $82.58 \pm 0.10^{a}$ & $82.29 \pm 1.09^{a}$ & $82.90 \pm 0.60^{a}$ & $83.50 \pm 1.93^{a}$ & $82.03 \pm 0.48^{a}$ \\
\hline & & 50 & $75.51 \pm 1.34^{a}$ & $73.47 \pm 0.69^{a, b}$ & $73.11 \pm 0.98^{b}$ & $73.71 \pm 0.18^{\mathrm{a}, \mathrm{b}}$ & $73.98 \pm 0.46^{\mathrm{a}, \mathrm{b}}$ \\
\hline & & 60 & $68.74 \pm 0.33^{\mathrm{a}}$ & $68.41 \pm 0.79^{\mathrm{a}}$ & $68.79 \pm 0.19^{a}$ & $68.84 \pm 0.14^{a}$ & $68.92 \pm 0.49^{a}$ \\
\hline & \multirow{7}{*}{$n(-)$} & 1 & $1.00 \pm 0.00^{a}$ & $1.00 \pm 0.00^{a}$ & $1.00 \pm 0.00^{a}$ & $1.00 \pm 0.00^{a}$ & $1.00 \pm 0.00^{a}$ \\
\hline & & 10 & $1.00 \pm 0.00^{\mathrm{a}}$ & $1.00 \pm 0.00^{\mathrm{a}}$ & $1.00 \pm 0.00^{a}$ & $1.00 \pm 0.00^{a}$ & $1.00 \pm 0.00^{\mathrm{a}}$ \\
\hline & & 20 & $1.00 \pm 0.00^{\mathrm{a}}$ & $1.00 \pm 0.00^{\mathrm{a}}$ & $1.00 \pm 0.00^{a}$ & $1.00 \pm 0.00^{\mathrm{a}}$ & $1.00 \pm 0.00^{\mathrm{a}}$ \\
\hline & & 30 & $1.00 \pm 0.00^{\mathrm{a}}$ & $1.00 \pm 0.00^{\mathrm{a}}$ & $1.00 \pm 0.00^{a}$ & $1.00 \pm 0.00^{\mathrm{a}}$ & $1.00 \pm 0.00^{a}$ \\
\hline & & 40 & $1.00 \pm 0.00^{\mathrm{a}}$ & $1.00 \pm 0.00^{\mathrm{a}}$ & $1.00 \pm 0.00^{a}$ & $1.00 \pm 0.01^{\mathrm{a}}$ & $1.00 \pm 0.00^{a}$ \\
\hline & & 50 & $1.00 \pm 0.00^{a}$ & $1.00 \pm 0.00^{a}$ & $1.00 \pm 0.00^{a}$ & $1.00 \pm 0.00^{\mathrm{a}}$ & $1.00 \pm 0.00^{a}$ \\
\hline & & 60 & $1.00 \pm 0.00^{\mathrm{a}}$ & $1.00 \pm 0.00^{\mathrm{a}}$ & $1.00 \pm 0.00^{a}$ & $1.00 \pm 0.00^{a}$ & $1.00 \pm 0.00^{a}$ \\
\hline \multirow{21}{*}{12} & \multirow{7}{*}{$T_{0}(\mathrm{mPa})$} & 1 & $3125.47 \pm 72.12^{\mathrm{a}}$ & $3140.77 \pm 61.47^{a}$ & $2895.23 \pm 582.46^{a}$ & $2931.76 \pm 598.53^{a}$ & $3026.46 \pm 208.40^{a}$ \\
\hline & & 10 & $1774.67 \pm 63.65^{\mathrm{a}}$ & $1861.19 \pm 175.73^{a}$ & $1914.41 \pm 166.73^{a}$ & $1540.47 \pm 364.99^{a}$ & $1691.52 \pm 149.52^{a}$ \\
\hline & & 20 & $1619.21 \pm 124.14^{a}$ & $1558.56 \pm 13.01^{a}$ & $1543.96 \pm 265.46^{a}$ & $1662.27 \pm 112.85^{a}$ & $1505.55 \pm 93.55^{a}$ \\
\hline & & 30 & $1032.31 \pm 60.71^{\mathrm{a}}$ & $1050.41 \pm 26.48^{a}$ & $938.79 \pm 298.07^{a}$ & $936.88 \pm 297.43^{a}$ & $1012.85 \pm 145.41^{a}$ \\
\hline & & 40 & $937.44 \pm 50.93^{a}$ & $910.38 \pm 3.40^{\mathrm{a}}$ & $972.08 \pm 55.16^{a}$ & $885.68 \pm 251.72^{a}$ & $881.98 \pm 71.66^{a}$ \\
\hline & & 50 & $563.94 \pm 31.89^{a}$ & $575.04 \pm 52.07^{\mathrm{a}}$ & $467.42 \pm 204.92^{a}$ & $648.81 \pm 94.53^{a}$ & $597.57 \pm 45.48^{a}$ \\
\hline & & 60 & $543.12 \pm 82.48^{a}$ & $494.10 \pm 3.98^{a}$ & $523.05 \pm 51.16^{a}$ & $531.52 \pm 29.46^{a}$ & $565.02 \pm 66.33^{a}$ \\
\hline & \multirow{7}{*}{$k\left(\mathrm{mPa} \cdot \mathrm{s}^{\mathrm{n}}\right)$} & 1 & $5941.65 \pm 24.84^{a}$ & $5933.67 \pm 18.84^{\mathrm{a}}$ & $6005.47 \pm 220.71^{a}$ & $6001.84 \pm 221.26^{a}$ & $5994.65 \pm 77.66^{a}$ \\
\hline & & 10 & $4242.28 \pm 16.36^{a}$ & $4225.14 \pm 36.09^{a}$ & $4194.92 \pm 25.85^{\mathrm{a}}$ & $4315.14 \pm 132.74^{a}$ & $4271.24 \pm 62.60^{a}$ \\
\hline & & 20 & $2838.21 \pm 27.71^{a}$ & $2848.99 \pm 8.86^{a}$ & $2860.49 \pm 80.65^{a}$ & $2812.53 \pm 17.39^{a}$ & $2867.97 \pm 39.40^{\mathrm{a}}$ \\
\hline & & 30 & $2597.80 \pm 23.77^{\mathrm{a}}$ & $2595.05 \pm 11.97^{a}$ & $2636.20 \pm 92.68^{a}$ & $2640.54 \pm 90.34^{a}$ & $2616.05 \pm 42.55^{\mathrm{a}}$ \\
\hline & & 40 & $2132.17 \pm 17.72^{a}$ & $2140.70 \pm 9.64^{a}$ & $2127.84 \pm 16.35^{a}$ & $2158.40 \pm 81.80^{a}$ & $2142.58 \pm 45.50^{\mathrm{a}}$ \\
\hline & & 50 & $2157.88 \pm 3.79^{a}$ & $2134.98 \pm 23.35^{a}$ & $2184.27 \pm 74.62^{\mathrm{a}}$ & $2130.89 \pm 18.51^{a}$ & $2144.49 \pm 2.11^{\mathrm{a}}$ \\
\hline & & 60 & $1957.22 \pm 16.42^{\mathrm{a}}$ & $1968.02 \pm 8.67^{a}$ & $1955.21 \pm 18.46^{a}$ & $1956.85 \pm 14.43^{a}$ & $1950.18 \pm 12.57^{a}$ \\
\hline & \multirow{7}{*}{$n(-)$} & 1 & $0.86 \pm 0.00^{a}$ & $0.86 \pm 0.00^{a}$ & $0.86 \pm 0.01^{a}$ & $0.86 \pm 0.01^{\mathrm{a}}$ & $0.86 \pm 0.00^{a}$ \\
\hline & & 10 & $0.87 \pm 0.00^{a}$ & $0.87 \pm 0.00^{a}$ & $0.87 \pm 0.00^{a}$ & $0.87 \pm 0.01^{a}$ & $0.87 \pm 0.00^{a}$ \\
\hline & & 20 & $0.87 \pm 0.00^{\mathrm{a}}$ & $0.87 \pm 0.00^{\mathrm{a}}$ & $0.87 \pm 0.01^{a}$ & $0.87 \pm 0.00^{a}$ & $0.87 \pm 0.00^{a}$ \\
\hline & & 30 & $0.87 \pm 0.00^{\mathrm{a}}$ & $0.87 \pm 0.00^{\mathrm{a}}$ & $0.87 \pm 0.01^{a}$ & $0.87 \pm 0.01^{a}$ & $0.87 \pm 0.00^{\mathrm{a}}$ \\
\hline & & 40 & $0.87 \pm 0.00^{\mathrm{a}}$ & $0.87 \pm 0.00^{a}$ & $0.87 \pm 0.00^{a}$ & $0.87 \pm 0.01^{\mathrm{a}}$ & $0.87 \pm 0.00^{a}$ \\
\hline & & 50 & $0.87 \pm 0.00^{a}$ & $0.87 \pm 0.00^{a}$ & $0.87 \pm 0.01^{a}$ & $0.87 \pm 0.00^{a}$ & $0.87 \pm 0.00^{a}$ \\
\hline & & 60 & $0.87 \pm 0.00^{a}$ & $0.87 \pm 0.00^{a}$ & $0.87 \pm 0.00^{a}$ & $0.87 \pm 0.00^{\mathrm{a}}$ & $0.87 \pm 0.00^{a}$ \\
\hline
\end{tabular}

${ }^{\mathrm{a}, \mathrm{b}}$ Letters in the same line represent no significant difference at $95 \%$ of confidence interval by Tukey test. 


\subsubsection{Solids concentration and temperature dependence}

Since $\mathrm{pH}$ did not show the affect the rheological parameters, solids concentration and temperature dependence on rheological parameters was evaluated at an average $\mathrm{pH}$ value (5.0). Apparent viscosity at a shear rate indicated for mixture process $\left(10 \mathrm{~s}^{-1}\right)$ (Steffe, 1996) was analyzed and showed a similar effect described by Mewis and Macosco (1993) (Figure 5.3.4), where an increase on suspensions' viscosity was observed as the solids concentration increased. Similar tendency was verified in other studies involving cellulosic fiber as dispersed material (Nguyen et al., 2013; Sepehr et al., 2004; Viamajala et al., 2009). An exponential model (Equation 5.3.8) was used to fit the apparent viscosity data at $10 \mathrm{~s}^{-1}$ and resulted in Equation (5.3.10).

$$
\eta_{a p p ; 10 s^{-1}}(\mathrm{~Pa} \cdot \mathrm{s})=-0.0635+5.66 \times 10^{-5} \exp \left(\frac{17346.89}{R(T+273.15)}\right) X_{S}^{1.51}\left(R^{2}=0.928\right)
$$

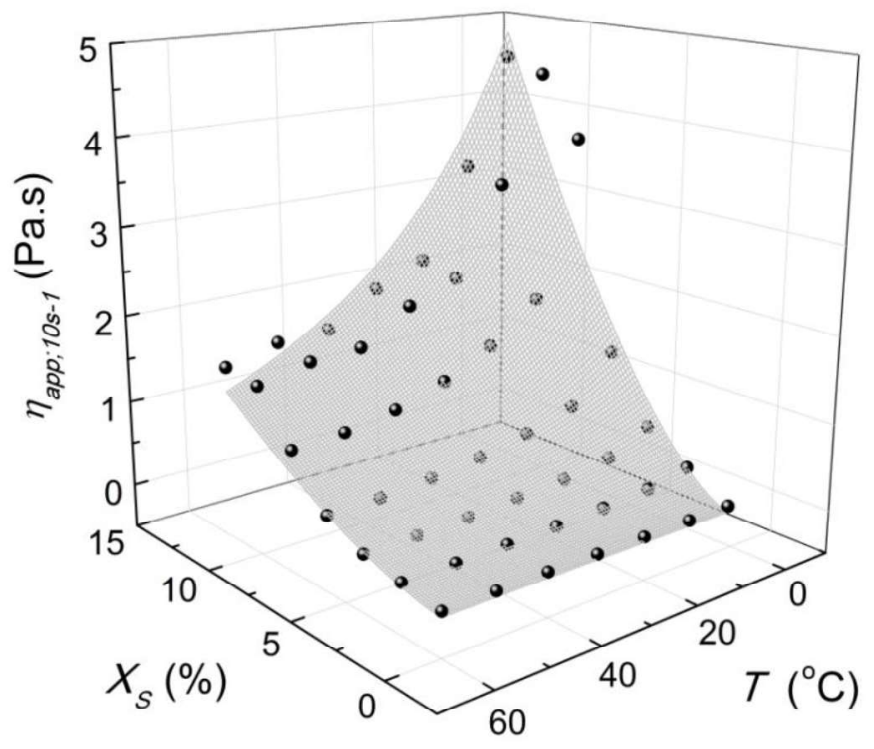

Figure 5.3.4. Apparent viscosity (at $10 \mathrm{~s}^{-1}$ ) as function of solids content (\%) and temperature $\left({ }^{\circ} \mathrm{C}\right)$.

By analysis of variance (ANOVA) at 95\% of confidence using STATISTICA 10 (StatSoft, Tulsa, USA), apparent viscosity revealed a quadratic dependence on temperature and linear dependence on solid content (all with $p_{\text {value }}<0.05$ ). 
All Herschel-Bulkley parameters were plotted as function of solids concentration and temperature (Figure 5.3.5), allowing to fit separated models for initial yield stress (Equation 5.3.11), consistency coefficient (Equation 5.3.12) and flow behavior index (Equation 5.3.13), for later use in processes design calculation. The following fitted models with the respective $R^{2}$ are:

$$
\begin{aligned}
& \tau_{0}(\mathrm{~Pa})=-0.016+2.56 \times 10^{-7} \exp \left(\frac{25126.29}{R(T+273.15)}\right) X_{S}^{2.18}\left(R^{2}=0.895\right) \\
& k\left(\mathrm{~Pa} \cdot \mathrm{s}^{n}\right)=-0.063+3.81 \times 10^{-5} \exp \left(\frac{17050.71}{R(T+273.15)}\right) X_{S}^{1.82} \quad\left(R^{2}=0.930\right) \\
& n(\text { dimensionless })=\exp \left(0.01 X_{S}-0.002 X_{S}^{2}-\frac{8.76}{R(273.15)}\right) \quad\left(R^{2}=0.820\right)
\end{aligned}
$$

Consistency coefficient and yield stress have a second degree of dependence on temperature and solids content. Higher temperature favored molecular movement, reducing the viscosity, consistency index and the yield stress. However, the suspension solids increase leads to spatial structures formation, hindering the motion and increasing the resistance to the flow (Sheng et al., 2006). The effect of temperature on flow behavior index was not evident as reported by other authors for biomass (Natarajan and Suppes, 1997) and petrochemical (Wang et al., 2012) slurries. On the other hand, the solid concentration is responsible by interfere quadratically on flow behavior index, inducing shear thinning, probably due to particle-particle interactions. Such strong solids effect was also observed by Qiu and Rao (1988) for apple purée suspension.

Evaluating the behavior of relative viscosity $\left(\eta_{S} / \eta_{d}\right)$ as function of solids concentration, up to $8 \%(\mathrm{w} / \mathrm{w})$ of solids, an exponential tendency was observed. However, at higher solids content, a significant deviation on the slope was observed for all $\mathrm{pH}$ values. Data of others $\mathrm{pH}$ is not shown, since this behavior followed the same pattern as presented in Figure 5.3.6 for pH 5.0. 
a)

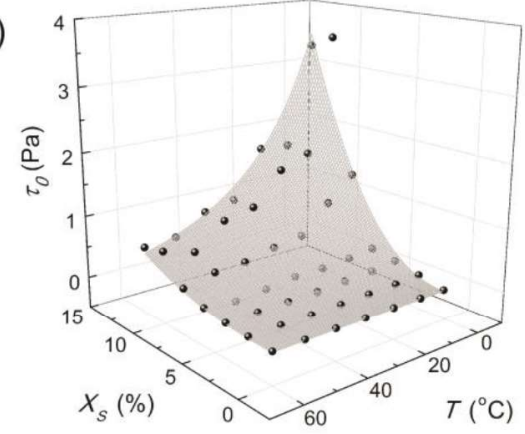

b)

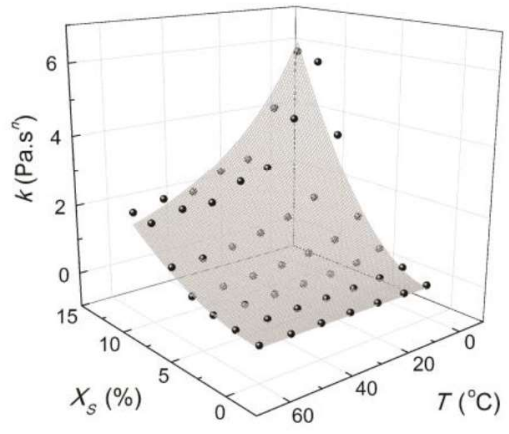

c)

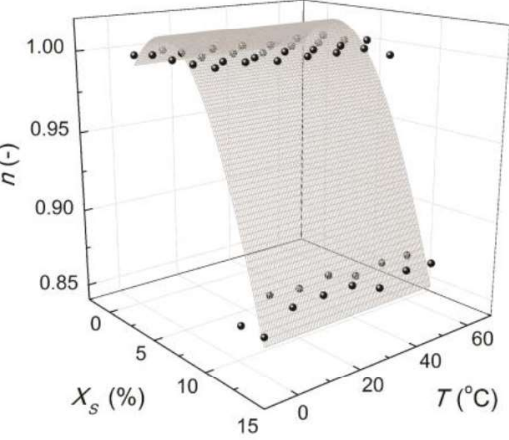

Figure 5.3.5. Initial yield stress (a), consistency coefficient (b) and flow behavior index (c) dependence on temperature $\left({ }^{\circ} \mathrm{C}\right)$ and solids content (\%) at $\mathrm{pH} 5.0$.

Even though a pronounced increase of relative viscosity was expected at higher amount of particles, a decrease on the slope of the curve was observed for solids content between 8 and $12 \%(\mathrm{w} / \mathrm{w})$. In these cases, the relative viscosity observed was hardly influenced by solids content like at lower concentrations. One theory capable to explain this deviation it is the effect described by Farris (1968). This author proposed that fine particles can act like dispersant when inserted in a suspension with larger particles, facilitating the flow of coarse particles. Even though fines were also observed at lower solids concentration, this behavior was pronounced only at higher concentrations, when there is an increase on the particle- 
particle interactions. The particles size distribution (in number of particles) reinforces this idea, once a large number of particles $(\sim 86 \%)$ showed size below $10 \mu \mathrm{m}$, while $10 \%$ showed size larger than $13.637 \mu \mathrm{m}$ (Figure 5.3.2a). By Figure 5.3.6, it can be concluded that Farris effect is pronounced when $10 \%$ of solids is reached. At this concentration $8.6 \mathrm{~g}$ of fines and $1.4 \mathrm{~g}$ of coarse are encountered in $100 \mathrm{~g}$ of suspension, stablishing the beginning of Farris effect. The fines concentration reaches similar value as reported by Farris (1968) when $10.7 \%$ of fines were added into the original suspension.

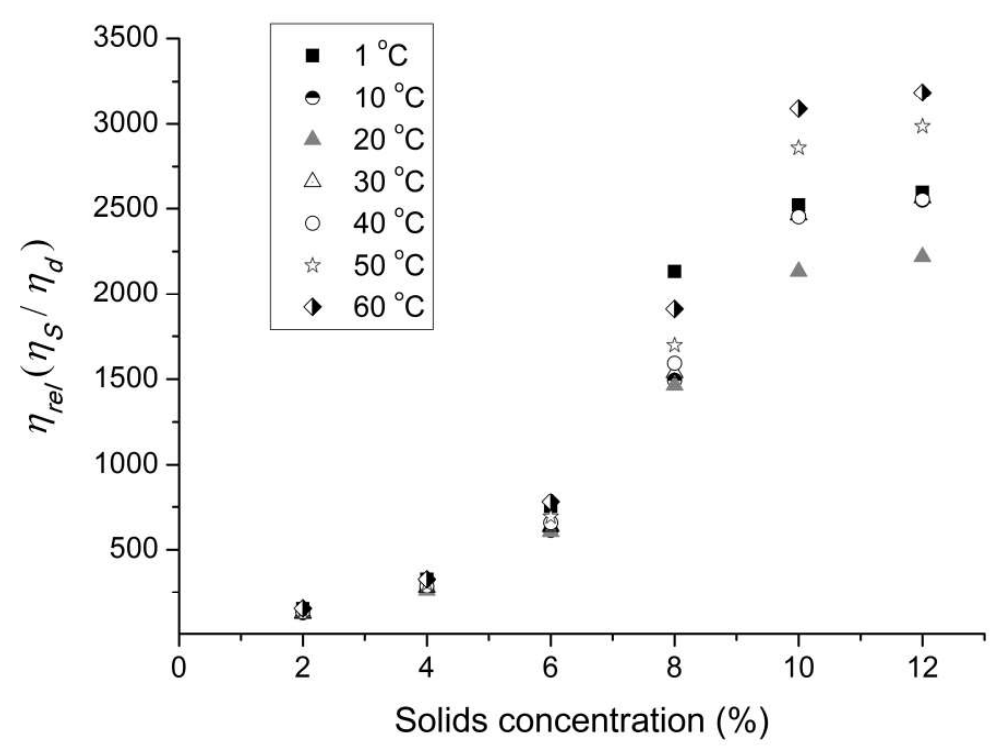

Figure 5.3.6. Relative viscosity as function of PPS concentration at $\mathrm{pH} 5.0$.

\subsubsection{Density evaluation}

As verified for rheology, the Tukey test showed no significant differences for densities at different $\mathrm{pH}$. Table 5.3.5 shows density values as function of solids concentration $(0-12 \% \mathrm{w} / \mathrm{w})$ and temperature $\left(1-60^{\circ} \mathrm{C}\right)$ at different $\mathrm{pH}$ values.

Density was negatively influenced by temperature, while a rise in solids content promoted an increase of density (Figure 5.3.7). Temperature diminishes the interactive forces between molecules, dispersing them from each other. As the solid content gets higher, density approximated to values reported by Abdullah et al. (2010) of $1250 \mathrm{~kg} / \mathrm{m}^{3}$ for biochar slurry at $20 \%$ (w/w) of solids. 
Table 5.3.5. Density of acidic PPS suspensions at different temperature $\left({ }^{\circ} \mathrm{C}\right)$ and concentration of biomass (\%).

\begin{tabular}{|c|c|c|c|c|c|c|}
\hline \multirow{2}{*}{$\begin{array}{c}\text { Biomass } \\
(\% \mathrm{w} / \mathrm{w})\end{array}$} & \multirow{2}{*}{$T\left({ }^{\circ} \mathrm{C}\right)$} & \multicolumn{5}{|c|}{ Density of peanut shells in acid solutions $\left(\mathrm{kg} / \mathrm{m}^{3}\right)$} \\
\hline & & $\mathrm{pH}=3$ & $\mathrm{pH}=4$ & $\mathrm{pH}=5$ & $\mathrm{pH}=6$ & $\mathrm{pH}=7$ \\
\hline \multirow{7}{*}{0} & 1 & $998.1 \pm 1.4^{\mathrm{a}}$ & $997.9 \pm 0.8^{a}$ & $996.6 \pm 0.6^{a}$ & $994.7 \pm 4.1^{\text {a }}$ & $993.4 \pm 0.8^{a}$ \\
\hline & 10 & $998.5 \pm 1.8^{a}$ & $997.7 \pm 0.7^{\mathrm{a}}$ & $994.2 \pm 2.1^{\mathrm{a}}$ & $994.4 \pm 4.1^{\mathrm{a}}$ & $994.2 \pm 3.4^{\mathrm{a}}$ \\
\hline & 20 & $998.1 \pm 0.9^{a}$ & $995.7 \pm 1.0^{\mathrm{a}, \mathrm{b}}$ & $995.5 \pm 1.2^{a, b}$ & $993.1 \pm 4.0^{a, b}$ & $991.9 \pm 0.8^{b}$ \\
\hline & 30 & $994.5 \pm 1.9^{a}$ & $991.3 \pm 0.6^{a}$ & $993.7 \pm 1.6^{a}$ & $993.6 \pm 2.3^{a}$ & $991.6 \pm 0.2^{a}$ \\
\hline & 40 & $993.6 \pm 0.9^{a}$ & $990.6 \pm 0.6^{b}$ & $990.3 \pm 0.6^{b}$ & $989.0 \pm 0.2^{b, c}$ & $988.5 \pm 0.7^{c}$ \\
\hline & 50 & $991.1 \pm 0.6^{a}$ & $987.0 \pm 1.7^{\mathrm{a}}$ & $987.1 \pm 1.6^{\mathrm{a}}$ & $985.3 \pm 4.0^{a}$ & $986.8 \pm 3.1^{a}$ \\
\hline & 60 & $986.0 \pm 1.0^{\mathrm{a}}$ & $982.9 \pm 3.4^{\mathrm{a}}$ & $984.7 \pm 0.7^{\mathrm{a}}$ & $983.0 \pm 0.9^{a}$ & $982.7 \pm 3.1^{\mathrm{a}}$ \\
\hline \multirow{7}{*}{2} & 1 & $990.5 \pm 3.7^{a}$ & $995.4 \pm 7.7^{a}$ & $995.4 \pm 3.4^{a}$ & $990.8 \pm 8.7^{a}$ & $986.7 \pm 9.9^{a}$ \\
\hline & 10 & $992.2 \pm 8.1^{\mathrm{a}}$ & $994.0 \pm 1.8^{a}$ & $995.0 \pm 6.3^{a}$ & $994.5 \pm 6.0^{\mathrm{a}}$ & $993.5 \pm 6.4^{\mathrm{a}}$ \\
\hline & 20 & $991.7 \pm 1.8^{a}$ & $994.3 \pm 5.1^{a}$ & $993.1 \pm 3.0^{a}$ & $992.7 \pm 6.2^{\mathrm{a}}$ & $992.2 \pm 13.7^{\mathrm{a}}$ \\
\hline & 30 & $997.6 \pm 4.1^{a}$ & $999.6 \pm 7.2^{a}$ & $987.5 \pm 2.9^{a}$ & $991.7 \pm 2.9^{a}$ & $986.9 \pm 7.1^{a}$ \\
\hline & 40 & $982.4 \pm 1.9^{a}$ & $988.8 \pm 4.6^{a}$ & $988.9 \pm 4.1^{a}$ & $987.9 \pm 8.2^{a}$ & $989.4 \pm 12.1^{a}$ \\
\hline & 50 & $984.9 \pm 5.1^{a}$ & $986.3 \pm 4.1^{\mathrm{a}}$ & $984.4 \pm 3.9^{a}$ & $977.2 \pm 6.3^{a}$ & $986.1 \pm 4.5^{a}$ \\
\hline & 60 & $975.3 \pm 4.3^{a}$ & $981.1 \pm 4.3^{a}$ & $979.7 \pm 3.9^{a}$ & $977.0 \pm 3.9^{a}$ & $981.3 \pm 4.6^{a}$ \\
\hline \multirow{7}{*}{4} & 1 & $1000.2 \pm 3.7^{a}$ & $1002.2 \pm 7.7^{a}$ & $1003.0 \pm 3.4^{a}$ & $994.0 \pm 8.8^{a}$ & $1001.5 \pm 10.1^{a}$ \\
\hline & 10 & $1002.7 \pm 8.1^{a}$ & $1003.0 \pm 1.9^{a}$ & $1001.8 \pm 6.3^{a}$ & $999.5 \pm 6.0^{a}$ & $1000.8 \pm 6.4^{a}$ \\
\hline & 20 & $1000.9 \pm 1.8^{a}$ & $1000.4 \pm 5.1^{a}$ & $996.8 \pm 3.0^{a}$ & $992.7 \pm 6.2^{a}$ & $996.3 \pm 13.7^{a}$ \\
\hline & 30 & $994.7 \pm 4.1^{a}$ & $998.6 \pm 7.2^{a}$ & $999.1 \pm 2.9^{a}$ & $998.1 \pm 3.0^{a}$ & $999.6 \pm 7.2^{a}$ \\
\hline & 40 & $994.7 \pm 1.9^{a}$ & $999.8 \pm 4.6^{a}$ & $995.8 \pm 4.1^{a}$ & $995.3 \pm 8.2^{a}$ & $997.0 \pm 12.2^{a}$ \\
\hline & 50 & $992.7 \pm 5.1^{a}$ & $985.5 \pm 4.1^{a}$ & $993.4 \pm 4.0^{a}$ & $988.5 \pm 6.4^{a}$ & $989.7 \pm 4.5^{a}$ \\
\hline & 60 & $987.1 \pm 4.3^{a}$ & $989.7 \pm 4.4^{a}$ & $989.6 \pm 3.9^{a}$ & $989.6 \pm 4.0^{a}$ & $993.3 \pm 4.6^{a}$ \\
\hline \multirow{7}{*}{6} & 1 & $1011.9 \pm 3.7^{a}$ & $1005.0 \pm 3.9^{a}$ & $1009.1 \pm 0.7^{a}$ & $1004.8 \pm 3.4^{a}$ & $1006.0 \pm 3.8^{a}$ \\
\hline & 10 & $1010.3 \pm 8.2^{a}$ & $1009.0 \pm 7.6^{a}$ & $1009.0 \pm 1.2^{a}$ & $1000.4 \pm 12.6^{a}$ & $1006.5 \pm 1.6^{a}$ \\
\hline & 20 & $1001.9 \pm 1.8^{a}$ & $1007.5 \pm 2.6^{a}$ & $1007.3 \pm 5.7^{a}$ & $999.3 \pm 7.8^{a}$ & $1005.4 \pm 4.6^{a}$ \\
\hline & 30 & $1007.9 \pm 4.1^{a}$ & $998.3 \pm 7.1^{a}$ & $1003.1 \pm 1.9^{a}$ & $1006.7 \pm 7.7^{a}$ & $1004.3 \pm 4.4^{a}$ \\
\hline & 40 & $1005.9 \pm 2.3^{a}$ & $1004.2 \pm 2.5^{a}$ & $1002.8 \pm 3.2^{a}$ & $1002.8 \pm 13.4^{a}$ & $1002.8 \pm 5.7^{a}$ \\
\hline & 50 & $1002.0 \pm 1.4^{a}$ & $992.4 \pm 6.8^{\mathrm{a}}$ & $999.5 \pm 7.0^{\mathrm{a}}$ & $992.7 \pm 6.4^{\mathrm{a}}$ & $995.4 \pm 3.6^{a}$ \\
\hline & 60 & $998.4 \pm 2.8^{a}$ & $995.6 \pm 2.6^{a}$ & $993.5 \pm 7.5^{\mathrm{a}}$ & $988.7 \pm 6.5^{a}$ & $992.0 \pm 3.2^{a}$ \\
\hline & 1 & $1019.8 \pm 4.4^{a}$ & $1018.1 \pm 5.1^{a}$ & $1005.2 \pm 17.2^{a}$ & $1017.9 \pm 2.8^{a}$ & $1016.7 \pm 5.7^{a}$ \\
\hline & 10 & $1010.8 \pm 11.9^{a}$ & $1017.4 \pm 2.0^{a}$ & $1017.1 \pm 5.7^{a}$ & $1016.7 \pm 5.4^{a}$ & $1017.1 \pm 1.7^{a}$ \\
\hline & 20 & $1017.5 \pm 5.2^{a}$ & $1010.1 \pm 7.8^{a}$ & $1016.3 \pm 5.3^{a}$ & $1009.5 \pm 5.0^{a}$ & $1015.3 \pm 0.4^{a}$ \\
\hline & 30 & $1016.3 \pm 3.7^{a}$ & $1013.9 \pm 0.9^{a}$ & $1013.8 \pm 6.9^{a}$ & $1013.6 \pm 1.6^{a}$ & $1007.6 \pm 5.0^{a}$ \\
\hline & 40 & $1012.5 \pm 11.8^{a}$ & $1011.3 \pm 4.9^{a}$ & $1010.6 \pm 1.1^{a}$ & $1011.2 \pm 0.8^{a}$ & $1010.6 \pm 0.2^{a}$ \\
\hline & 50 & $1010.1 \pm 3.1^{a}$ & $1008.7 \pm 4.3^{a}$ & $1007.2 \pm 3.3^{a}$ & $1008.1 \pm 4.2^{a}$ & $1007.9 \pm 0.9^{a}$ \\
\hline & 60 & $1006.2 \pm 1.9^{a}$ & $1003.3 \pm 7.0^{a}$ & $1003.2 \pm 2.6^{a}$ & $1004.3 \pm 8.0^{a}$ & $1003.6 \pm 1.4^{a}$ \\
\hline
\end{tabular}


Table 5.3.5. (cont) Density of acidic PPS suspensions at different temperature $\left({ }^{\circ} \mathrm{C}\right)$ and concentration of biomass (\%).

\begin{tabular}{|c|c|c|c|c|c|c|}
\hline \multirow{2}{*}{$\begin{array}{l}\text { Biomass } \\
(\% \mathrm{w} / \mathrm{w})\end{array}$} & \multirow{2}{*}{$T\left({ }^{\circ} \mathrm{C}\right)$} & \multicolumn{5}{|c|}{ Density of peanut shells in acid solutions $\left(\mathrm{kg} / \mathrm{m}^{3}\right)$} \\
\hline & & $\mathrm{pH}=3$ & $\mathrm{pH}=4$ & $\mathrm{pH}=5$ & $\mathrm{pH}=6$ & $\mathrm{pH}=7$ \\
\hline \multirow{7}{*}{10} & 1 & $1022 \pm 3.8^{a}$ & $1022.6 \pm 7.9^{a}$ & $1020.5 \pm 3.5^{a}$ & $1017.6 \pm 9.0^{a}$ & $1015.4 \pm 10.2^{a}$ \\
\hline & 10 & $1022.7 \pm 8.4^{a}$ & $1022.3 \pm 1.9^{a}$ & $1016.9 \pm 6.4^{a}$ & $1017.1 \pm 6.1^{a}$ & $1016.8 \pm 6.6^{a}$ \\
\hline & 20 & $1022.7 \pm 1.8^{a}$ & $1019.8 \pm 5.2^{a}$ & $1019.4 \pm 3.1^{a}$ & $1015.7 \pm 6.4^{\mathrm{a}}$ & $1013.8 \pm 14.0^{\mathrm{a}}$ \\
\hline & 30 & $1018.0 \pm 4.2^{a}$ & $1013.7 \pm 7.3^{a}$ & $1017.6 \pm 3.0^{a}$ & $1017.5 \pm 3.0^{a}$ & $1014.2 \pm 7.3^{a}$ \\
\hline & 40 & $1018.0 \pm 2.0^{a}$ & $1014.1 \pm 4.7^{\mathrm{a}}$ & $1013.8 \pm 4.2^{a}$ & $1011.6 \pm 8.4^{\mathrm{a}}$ & $1010.9 \pm 12.3^{a}$ \\
\hline & 50 & $1016.1 \pm 5.3^{a}$ & $1010.4 \pm 4.2^{a}$ & $1010.6 \pm 4.0^{a}$ & $1007.9 \pm 6.5^{a}$ & $1010.2 \pm 4.6^{a}$ \\
\hline & 60 & $1010.4 \pm 4.5^{\mathrm{a}}$ & $1006.3 \pm 4.5^{\mathrm{a}}$ & $1009.3 \pm 4.0^{a}$ & $1006.5 \pm 4.1^{\mathrm{a}}$ & $1006.1 \pm 4.7^{\mathrm{a}}$ \\
\hline \multirow{7}{*}{12} & 1 & $1036.5 \pm 3.6^{a}$ & $1030.7 \pm 7.9^{a}$ & $1028.6 \pm 7.7^{a}$ & $1025.6 \pm 6.2^{a}$ & $1023.4 \pm 10.3^{a}$ \\
\hline & 10 & $1031.3 \pm 8.6^{a}$ & $1030.4 \pm 1.9^{a}$ & $1024.9 \pm 8.9^{a}$ & $1025.1 \pm 6.6^{a}$ & $1024.8 \pm 6.6^{a}$ \\
\hline & 20 & $1033.1 \pm 1.3^{a}$ & $1027.8 \pm 5.3^{a}$ & $1027.4 \pm 4.0^{a}$ & $1023.6 \pm 6.4^{a}$ & $1021.7 \pm 13.6^{a}$ \\
\hline & 30 & $1030.4 \pm 1.8^{a}$ & $1021.6 \pm 7.4^{a}$ & $1025.6 \pm 7.2^{a}$ & $1025.5 \pm 8.4^{a}$ & $1022.2 \pm 6.0^{a}$ \\
\hline & 40 & $1030.2 \pm 2.3^{a}$ & $1022.1 \pm 4.7^{a}$ & $1021.8 \pm 8.2^{a}$ & $1019.6 \pm 6.2^{a}$ & $1018.8 \pm 9.1^{a}$ \\
\hline & 50 & $1025.7 \pm 4.5^{a}$ & $1018.3 \pm 4.2^{a}$ & $1018.6 \pm 4.1^{a}$ & $1015.8 \pm 6.4^{a}$ & $1018.1 \pm 4.7^{\mathrm{a}}$ \\
\hline & 60 & $1023.1 \pm 2.5^{a}$ & $1012.5 \pm 6.2^{a}$ & $1017.2 \pm 4.0^{a}$ & $1014.5 \pm 4.1^{a}$ & $1014.1 \pm 5.1^{a}$ \\
\hline
\end{tabular}

$\overline{a, b, c}$ Letters in the same line represent no significant difference at $95 \%$ of confidence interval by Tukey test.
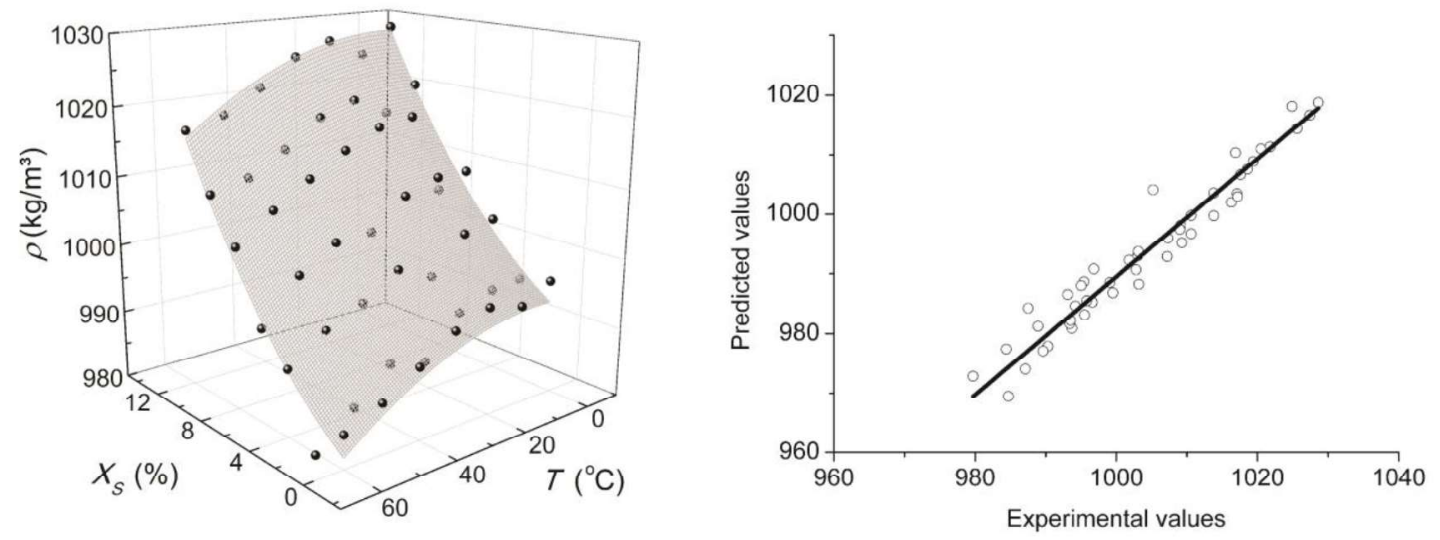

Figure 5.3.7. Fitted surface of density values at pH 5.0 (left) and predicted values from the polynomial model versus the observed ones (right).

ANOVA allowed asserting that both temperature and solids content influence quadratically the values of density, resulting in a second order polynomial model. The non-linear regression resulted in a $R^{2}=0.951$ :

$\rho\left(\mathrm{kg} / \mathrm{m}^{3}\right)=993.56+1.47 X_{S}+0.12 X_{S}^{2}+0.03 T-0.0038 T^{2}$ 
A linear regression between the experimental versus predicted data presented an angular coefficient of 0.98 , very close to the unit, which represents a good accuracy of the model.

\subsubsection{Conclusions}

The rheological properties and density of acidic suspensions of powder peanut shell were determined as function of solids concentration and temperature. A Newtonian behavior was found for suspensions up to $8 \%(w / w)$ of solids, and above this value, non-Newtonian characteristics were verified, including shear thinning and residual yield stress. In addition, the more concentrated suspensions seemed to be influenced by Farris effect, due to the large number of fine particles present in the material. At higher solids content, shear thinning was accompanied by increase in initial yield stress, consistency coefficient and density. As the $\mathrm{pH}$ did not present significant effects neither in rheological parameters nor in density, these properties could be represented solely as a function of temperature and solids concentration by the proposed models. These models are useful and will enable basis for equipment and processes designing, mainly in those involving the lignocellulose conversion into biofuels.

\subsubsection{Acknowledgment}

Authors acknowledge the São Paulo Research Foundation, FAPESP (Grants 2013/09344-4 and 2013/17497-5) for financial support.

\subsubsection{References}

Abdullah, H., Mourant, D., Li, C.-Z., Wu, H., (2010). Bioslurry as a Fuel. 3. Fuel and Rheological Properties of Bioslurry Prepared from the Bio-oil and Biochar of Mallee Biomass Fast Pyrolysis. Energy \& Fuels 24, 5669-5676.

Alince, B., Robertson, A.A., (1974). Aggregation of microcrystalline cellulose with polyethylenimine. Colloid and Polymer Science 252(11), 920-927.

AOAC, (1997). Offical methods of analysis International (16 ed). Association of Offical Analytical Chemists International, Gaithersburg. 
Araki, J., Kuga, S., (2001). Effect of Trace Electrolyte on Liquid Crystal Type of Cellulose Microcrystals. Langmuir 17(15), 4493-4496.

ASTM, (1989). Annual Book of ASTM Standards. American Society for Testing and Materials, Philadelphia.

Bhattacharya, S., (1999). Yield Stress and Time-dependent Rheological Properties of Mango Pulp. Journal of Food Science 64(6), 1029-1033.

Bobicki, E.R., Liu, Q., Xu, Z., (2014). Effect of microwave pre-treatment on ultramafic nickel ore slurry rheology. Minerals Engineering 61(0), 97-104.

Castro, A.M., Pereira-Jr, N., (2010). Production, properties and application of cellulases in the hydrolysis of agroindustrial residues. Química Nova 33(1), 181188.

Chang, C., Powell, R.L., (1994). Effect of particle size distributions on the rheology of concentrated bimodal suspensions. Journal of Rheology (1978-present) 38(1), 85-98.

Chen, L., Duan, Y., Zhao, C., Yang, L., (2009). Rheological behavior and wall slip of concentrated coal water slurry in pipe flows. Chemical Engineering and Processing: Process Intensification 48(7), 1241-1248.

Elanthikkal, S., Gopalakrishnapanicker, U., Varghese, S., Guthrie, J.T., (2010). Cellulose microfibres produced from banana plant wastes: Isolation and characterization. Carbohydrate Polymers 80(3), 852-859.

Esteghlalian, A., Hashimoto, A.G., Fenske, J.J., Penner, M.H., (1997). Modeling and optimization of the dilute-sulfuric-acid pretreatment of corn stover, poplar and switchgrass. Bioresource Technology 59(2-3), 129-136.

Farris, R.J., (1968). Prediction of the Viscosity of Multimodal Suspensions from Unimodal Viscosity Data. Transactions of The Society of Rheology (1957-1977) 12(2), 281-301.

Fasolin, L.H., Cunha, R.L., (2013). Characterisation of soy extract processed under different drying methods and extraction conditions. International Journal of Food Science \& Technology 48(3), 503-511.

Ferguson, J., Kemblowski, Z., (1991). Applied Fluid Rheology. Elsevier, New York. 
Filippa, L., Trento, A., Álvarez, A.M., (2012). Sauter mean diameter determination for the fine fraction of suspended sediments using a LISST-25X diffractometer. Measurement 45(3), 364-368.

Genovese, D.B., Lozano, J.E., Rao, M.A., (2007). The Rheology of Colloidal and Noncolloidal Food Dispersions. Journal of Food Science 72(2), R11-R20.

Godoy, O.P., Marcos-Filho, J., Câmara, G.M.S., Fonseca, H., (1982). Tecnologia da produção, Amendoim: produção, pré-processamento e transformação agroindustrial. Secretaria da Indústria, Comércio, Ciência e Tecnologia, São Paulo.

Hamelinck, C.N., Hooijdonk, G.v., Faaij, A.P.C., (2005). Ethanol from lignocellulosic biomass: techno-economic performance in short-, middle- and long-term. Biomass and Bioenergy 28(4), 384-410.

He, M., Wang, Y., Forssberg, E., (2006). Parameter studies on the rheology of limestone slurries. International Journal of Mineral Processing 78(2), 63-77.

Holdsworth, S.D., (1993). Rheological models used for the prediction of the flow properties of food products: a literature review. Food and Bioproducts Processing: Transactions of the Institution of of Chemical Engineers, Part C 71(3), 139-179.

IBGE, (2014). Levantamento Sistemático da Produção Agrícola - LSPA. Ministério do Planejamento, Orçamento e Gestão.

Lide, D.R., (1993). CRC Handbook of Chemistry and Physics (74 ed). CRC, Boca Raton.

Lin, D.-Q., Zhong, L.-N., Yao, S.-J., (2006). Zeta potential as a diagnostic tool to evaluate the biomass electrostatic adhesion during ion-exchange expanded bed application. Biotechnology and Bioengineering 95(1), 185-191.

Lin, H.-W., Chang, C.-P., Hwu, W.-H., Ger, M.-D., (2008). The rheological behaviors of screen-printing pastes. Journal of Materials Processing Technology 197(13), 284-291.

Mewis, J., Macosco, C.W., (1993). Suspension rheology, in: MACOSCO, C.W. (Ed.), Rheology: principles, measurements and applications. VCH Publishers, New York, pp. 425-474. 
Mood, S.H., Golfeshan, A.H., Tabatabaei, M., Jouzani, G.S., Najafi, G.H., Gholami, M., Ardjmand, M., (2013). Lignocellulosic biomass to bioethanol, a comprehensive review with a focus on pretreatment. Renewable and Sustainable Energy Reviews 27(0), 77-93.

Natarajan, V.P., Suppes, G.J., (1997). Rheological studies on a slurry biofuel to aid in evaluating its suitability as a fuel. Fuel 76(14-15), 1527-1535.

Nguyen, T.-C., Anne-Archard, D., Coma, V., Cameleyre, X., Lombard, E., Binet, C., Nouhen, A., To, K.A., Fillaudeau, L., (2013). In situ rheometry of concentrated cellulose fibre suspensions and relationships with enzymatic hydrolysis. Bioresource Technology 133(0), 563-572.

Quu, C.G., Rao, M.A., (1988). Role of Pulp Content and Particle Size in Yield Stress of Apple Sauce. Journal of Food Science 53(4), 1165-1170.

Rao, M.A., (1986). Rheological properties of fluid foods, in: Rao, M.A., Rizvi, S.S.H. (Eds.), Engineering Properties of Foods. Marcel Dekker Inc, New York, pp. 147.

Riedlberger, P., Weuster-Botz, D., (2012). New miniature stirred-tank bioreactors for parallel study of enzymatic biomass hydrolysis. Bioresource Technology 106(0), 138-146.

Santana, R.d.C., Sato, A.C.K., Cunha, R.L.d., (2012). Emulsions stabilized by heattreated collagen fibers. Food Hydrocolloids 26(1), 73-81.

Sato, T., (1995). Rheology of suspensions. Journal of coatings technology 67, 69-79.

Seka, M.A., Verstraete, W., (2003). Test for assessing shear sensitivity of activated sludge flocs: a feasibility study. Water Research 37(14), 3327-3334.

Sepehr, M., Carreau, P.J., Moan, M., Ausias, G., (2004). Rheological properties of short fiber model suspensions. Journal of Rheology (1978-present) 48(5), 10231048.

Sharma, S.K., LeMaguer, M., Liptay, A., Poysa, V., (1996). Effect of composition on the rheological properties of tomato thin pulp. Food Research International 29(2), 175-179. 
Sheng, G.P., Yu, H.Q., Li, X.Y., (2006). Stability of sludge flocs under shear conditions: Roles of extracellular polymeric substances (EPS). Biotechnology and Bioengineering 93(6), 1095-1102.

Steffe, J.F., (1996). Rheological Methods in Food Process Engineering (2 ed). Freeman Press, East Lansing.

Stickel, J.J., Knutsen, J.S., Liberatore, M.W., Luu, W., Bousfield, D.W., Klingenberg, D.J., Scott, C.T., Root, T.W., Ehrhardt, M.R., Monz, T.O., (2009). Rheology measurements of a biomass slurry: an inter-laboratory study. Rheologica Acta 48(9), 1005-1015.

Sun, Y., Cheng, J., (2002). Hydrolysis of lignocellulosic materials for ethanol production: a review. Bioresource Technology 83(1), 1-11.

Van Soest, P.J., (1963). Use of Detergents in the Analysis of Fibrous Feeds. II. A Rapid Method for the Determination of Fiber and Lignin. Journal of the Association of Official Agricultural Chemists 43(5), 829 - 835.

Van Soest, P.J., Wine, R.H., (1967). Use of detergents in the analysis of fibrous feeds. IV. Determination of plant cell-wall constituents. Journal of the Association Official of Analytical Chemists 50, 50-55.

Velmurugan, R., Muthukumar, K., (2011). Utilization of sugarcane bagasse for bioethanol production: Sono-assisted acid hydrolysis approach. Bioresource Technology 102(14), 7119-7123.

Viamajala, S., McMillan, J.D., Schell, D.J., Elander, R.T., (2009). Rheology of corn stover slurries at high solids concentrations - Effects of saccharification and particle size. Bioresource Technology 100(2), 925-934.

Wang, R., Liu, J., Gao, F., Zhou, J., Cen, K., (2012). The slurrying properties of slurry fuels made of petroleum coke and petrochemical sludge. Fuel Processing Technology 104(0), 57-66

Wijaya, Y.P., Putra, R.D.D., Widyaya, V.T., Ha, J.-M., Suh, D.J., Kim, C.S., (2014). Comparative study on two-step concentrated acid hydrolysis for the extraction of sugars from lignocellulosic biomass. Bioresource Technology 164(0), 221231. 
5.4. CHAPTER 4 Acoustic Fields in Suspensions Containing Cassava Bagasse 
Submitted to Ultrasonics Sonochemistry.

\section{Acoustic Fields of Acid Suspensions Containing Cassava Bagasse: Influence of Physical Properties on Acoustic Attenuation}

Tiago Carregari Polachini ${ }^{1,2}$; Antonio Mulet ${ }^{2}$; Javier Telis-Romero ${ }^{1}$ and Juan A. Cárcel ${ }^{2}$

${ }^{1}$ Food Engineering and Technology Department, São Paulo State University (Unesp), Institute of Biosciences, Humanities and Exact Sciences (Ibilce), Campus São José do Rio Preto, Cristóvão Colombo Street 2265, São José do Rio Preto, São Paulo State, 15054000, Brazil.

${ }^{2}$ Group of Analysis and Simulation of Agro-food Processes, Food Technology Department, Universitat Politècnica de València Camino de Vera, s/n, Valencia, 46071, Spain. 


\begin{abstract}
The effects produced by high-intensity ultrasound application during the acid pretreatment of biomass can enhance the later conversion into bioethanol. So, it is interesting to evaluate how residues such as cassava bagasse (CB) affects the actual acoustic field applied and, therefore, the magnitude of its effects. For this, calorimetric method was used to estimate acoustic energy and the efficiency of electric-acoustic energy conversion in acid suspensions containing different $C B$ concentration (2-10\%). Tests were carried out under different input power from 160 to $400 \mathrm{~W}$ at $1.5-5.5 \mathrm{~cm}$ of distance from the sonotrode. Thus, the experimental acoustic intensity measured varied from 12.90 to $68.57 \mathrm{~W} \cdot \mathrm{cm}^{-2}$ being the highest values registered in the lowest $C B$ content suspensions $(65.55-36.81 \%$ of conversion yield close to the sonotrode). Attenuation was also addressed during sound wave propagation being found a constant value of $0.021 \mathrm{~cm}^{-1}$. Acoustic parameters were well-fitted to polynomial models and acoustic intensity showed high correlation $\left(|r|>0.87\right.$ and $\left.p_{\text {value }} \leq 0.05\right)$ with experimental thermophysical properties of the suspensions.
\end{abstract}

Keywords: acoustic field, calorimetric method, ultrasound, attenuation, modelling. 


\subsubsection{Introduction}

The second-generation $(2 \mathrm{G})$ ethanol appears as an interesting and alternative biofuel for reducing the exploitation of non-renewable resources and for giving an eco-friendly destination to the agro-industrial residues. Its production consists of biomass pretreatment and hydrolysis, fermentation of the resulting sugars and ethanol distillation. However, pretreatment and hydrolysis of biomass are the most challenging steps that should be addressed to reduce the processing costs and make possible the bioethanol production with good effectiveness (Chen and Fu, 2016).

In order to reduce the raw matter costs, different residues from agroindustry can be employed with this purpose. Among them, cassava bagasse can be considered an interesting raw material due to its rich composition of residual starch $(>30 \%$ dry basis) and high availability in countries as Brazil $(\sim 2,000,000$ tons of wet bagasse/year) (FAO, 2019). Meanwhile, the performance of each biomass under a given process needs to be evaluated separately since their composition and structural arrangement can vary from one to another (Somerville et al., 2014). Moreover, the method used for treating these residues is of great importance for improving the technological issues linked to the biofuel production. In addition to conventional techniques, alternative and non-conventional ones such as microwave, $\mathrm{CO}_{2}$ supercritical, ozone and ultrasound application has been highlighted (Akhtar et al., 2016; Hassan et al., 2018).

Although high-intensity ultrasound (US) is a versatile technology, a special focus has been given to its potential use for enhancing biomass conversion into bioethanol (Bundhoo and Mohee, 2018; Sindhu et al., 2017; Subhedar and Gogate, 2015). The sonication of biomass provides mechanical energy in the form of sound waves, which, in liquid medium, produces a series of bubble collapses close to the solid-liquid interface. The shear forces produced by these collapses are able to break down the carbohydrate-lignin bonds, to depolymerize hemicellulose, cellulose and/or starch into sugars of low molecular chain and, consequently, to increase the surface area for further enzymatic treatment (Rehman et al., 2013). Those effects are enhanced if some catalyst, e. g. alkali and acids, are used together with sonication.

The success of each individual process assisted by US is dependent on its yield of conversion but also on its reproducibility. Well-designed treatments can be 
adequately reproduced from small to large scale. For this, it is very important to characterize the actual acoustic field produced in each specific condition being considered the calorimetric methods and the uses of hydrophones as adequate tools for this goal. The calorimetric method assumes that all acoustic energy applied is converted into heat as a consequence of the collisions between the cavitation bubbles (Margulis and Margulis, 2003). Such collisions generates pressure gradients which can be measured by hydrophone and, then both calorimetrically measured powers and acoustic pressure measurements correlated (Cárcel et al., 2007a). But, the acid solutions used in pretreatments of biomass and the higher input power could damage hydrophones and affect their sensitivity. In this sense, calorimetric method can considered to be feasible for reproduction in distinct systems with estimated standard deviation less than 10\% (Kikuchi and Uchida, 2011).

The real acoustic power transmitted to a medium is the energy responsible by the actual sonochemical effects on biomass, while the difference from the input electrical power is dispersed in form of wave reflection back to the transducer, noise, heating or weariness of the ultrasonic processor (Berlan and Mason, 1996; Löning et al., 2002). As seen as the sound waves suffer attenuation when travel across a medium, the distance between the sonotrode tip and the sample should be also taken into account for the knowledge about the distribution of acoustic energy in the reactor (Gogate and Pandit, 2000). It influences the correct positioning of the samples and the treatment homogeneity of heterogeneous media as are suspensions (Cárcel et al., 2012). Gogate (2007) highlighted the need of determining such data to understand the energy distribution from an irradiating system at a given input power.

The properties of the medium play an important role on how the ultrasound propagates through it. Thermal properties relate the capacity of the medium for absorbing energy and transferring it. On the other hand, density and viscous properties affect the transmission of vibration and can increase the resistance to the cavitation occurrence. Such properties, in turn, can vary according to conditions of temperature, biomass loading or acid concentration in the suspension.

Thus, this work aimed to characterize the acoustic field generated (acoustic power, intensity, density and yield of power conversion) in suspensions composed by 
different acid solutions and cassava bagasse concentration and relate this with the experimental physical properties of such suspensions.

\subsubsection{Materials and Methods}

\subsubsection{Samples preparation}

Dried and coarsely milled cassava (Manihot esculenta) bagasse was provided by TechnoAmido (São Pedro do Turvo, São Paulo, Brazil) from the cassava starch extraction process. The bagasse was then finely milled to obtain particle size lower than $0.147 \mathrm{~mm}$ by a Tyler sieve mesh 100. This material was chemically and physically characterized by Polachini et al. (2019b).

Phosphoric acid (85\% solution; Dinâmica, Diadema, São Paulo) was added to distilled water to obtain acid solutions in the $\mathrm{pH}$ of $3.0 ; 4.0 ; 5.0 ; 6.0$ and 7.0. Powdered cassava bagasse was suspended in these acid solutions to obtain suspensions of different concentrations $(2,4,6,8$ and $10 \% \mathrm{~g}$ of cassava bagasse per $100 \mathrm{~g}$ of suspensions) at the different $\mathrm{pH}$. The combination of these parameters supposed a total number of 25 different experimental conditions tested.

\subsubsection{Acoustic field characterization}

Acoustic parameters were determined by the calorimetric method, which consisted in the measurement of the temperature increase of the suspensions in the first $90 \mathrm{~s}$ of ultrasound application. In this period, it was assumed the system behaved in adiabatic conditions (Raso et al., 1999). Temperature records were taken using the experimental set-up shown in Figure 5.4.1. Ultrasound was applied by an ultrasonic processor UP400S (Hielscher Ultrasonics $\mathrm{GmbH}$, Germany) coupled with a titanium sonotrode of $22 \mathrm{~mm}$ in diameter (model $\mathrm{H} 40$, Hielscher Ultrasonics $\mathrm{GmbH}$, Germany), operating at $24 \mathrm{kHz}$ of frequency and maximum nominal input power of $400 \mathrm{~W}$. 


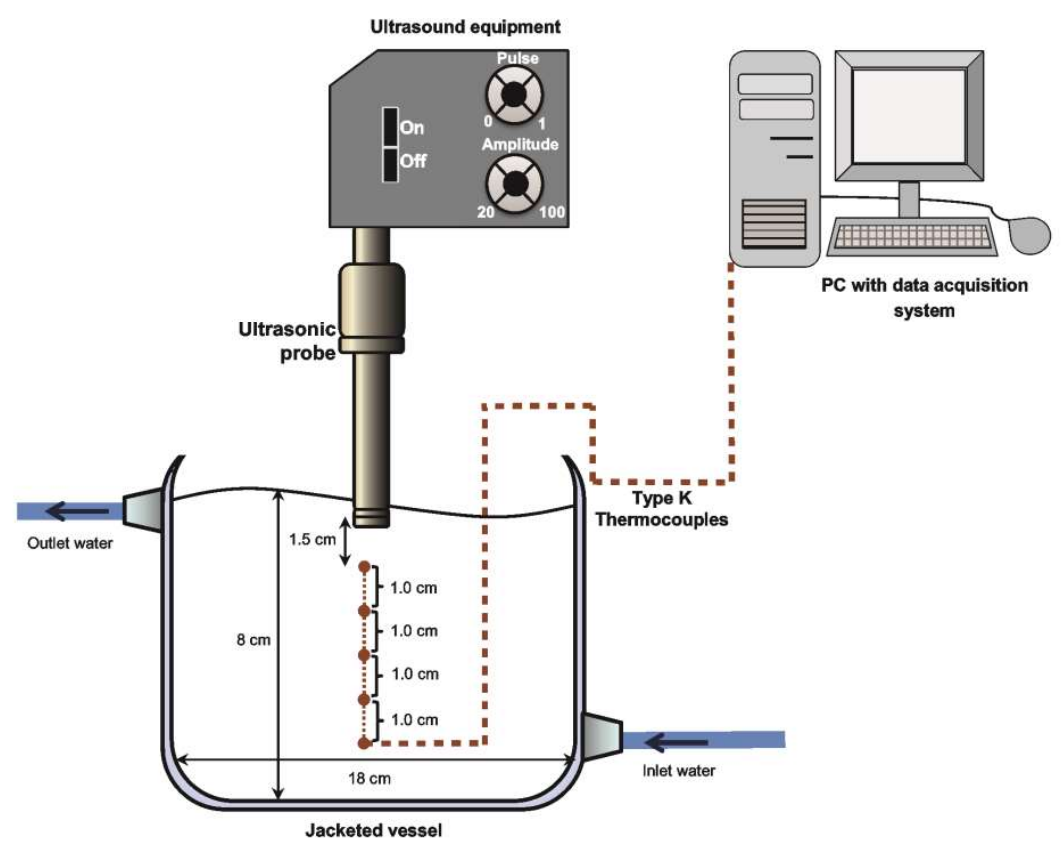

Figure 5.4.1. Set-up used for the measurements of the acoustic field produced on acid suspensions of cassava bagasse.

Each characterization was carried out with $2 \mathrm{~L}$ of untreated $\mathrm{CB}$ acid suspension which was placed in a jacketed stainless steel chamber. The initial temperature of the suspensions was maintained constant at $20{ }^{\circ} \mathrm{C}$ through a thermostatic bath (model MA-184, Marconi, Piracicaba, Brazil). Five type J thermocouples were placed at different position $(d)$ below the sonotrode: $1.5 \mathrm{~cm}, 2.5$ $\mathrm{cm}, 3.5 \mathrm{~cm}, 4.5 \mathrm{~cm}$ and $5.5 \mathrm{~cm}$, to be connected to a data acquisition system (LabView 2010, National Instruments, USA). Measurements were taken every $5 \mathrm{~s}$ over the first 90 first seconds of ultrasound application. The experiments were varied according to the percentage of the maximum nominal power applied $\left(P_{N}\right)$ : 40\% (160 W), 60\% (240 W), 80\% (320 W), 90\% (360 W) and 100\% (400 W).

Thus, the acoustic power could be calculated by the Eq. (5.4.1):

$$
P=V \rho c_{p} \frac{d T}{d t}
$$


where $P$ is the acoustic power (W), $V$ is the volume of suspensions used in each experiment $\left(\mathrm{m}^{3}\right), \rho$ is the suspension density $\left(\mathrm{kg} \cdot \mathrm{m}^{-3}\right), c_{p}$ is the specific heat of the acid suspensions $\left(\mathrm{J} \cdot \mathrm{kg}^{-1} \cdot{ }^{\circ} \mathrm{C}^{-1}\right)$ and $\mathrm{d} T / \mathrm{d} t$ the heating rate $\left({ }^{\circ} \mathrm{C} \cdot \mathrm{s}^{-1}\right)$. Density and specific heat of the suspensions were acquired from the study of Polachini et al. (2019b) and the heating heat was obtained by the linear regression between the rise of temperature over the sonication time.

Acoustic intensity $\left(I, \mathrm{~W} \cdot \mathrm{cm}^{-2}\right)$, acoustic density $\left(D ; \mathrm{W} \cdot \mathrm{mL}^{-1}\right)$ and acoustic power per mass of particles $\left(D_{p}, \mathrm{~W} \mathrm{~kg}^{-1}\right.$ of cassava bagasse) were given by the Eq. (5.4.2), Eq. (5.4.3) and Eq. (5.4.4), respectively:

$$
\begin{aligned}
& I=\frac{P}{A} \\
& D=\frac{P}{V} \\
& D_{p}=\frac{P}{V \rho w_{S}}
\end{aligned}
$$

where $A$ is the area of the transversal section of the sonotrode $\left(\mathrm{cm}^{2}\right)$ and $w_{\mathrm{S}}$ is the biomass fraction in the suspension $\left(X_{S} / 100\right)$.

\subsubsection{Attenuation factor}

Phenomena such friction, reflexion or dispersion produces de attenuation of the ultrasonic intensity. Thus, acoustic intensity could be correlated to the distance from the sonotrode by an exponential relation (Eq. (5.4.5)) as presented by Mamvura et al. (2018):

$$
I=I_{0} \exp (-2 \alpha d)
$$

where $I_{0}\left(\mathrm{~W} \cdot \mathrm{cm}^{-2}\right)$ is the pre-exponential factor, $\alpha$ is the attenuation factor $\left(\mathrm{cm}^{-1}\right)$ and $d$ is the vertical distance $(\mathrm{cm})$ from the sonotrode tip. 


\subsubsection{Statistical evaluation and mathematical modeling}

The significant effect $\left(p_{\text {value }}<0.05\right)$ among the linear and quadratic effect of the $\mathrm{pH}$ of the solution, solids concentration in the suspensions $\left(X_{S}, \% \mathrm{w} \cdot \mathrm{w}^{-1}\right)$, nominal input power $\left(P_{N}, \mathrm{~W}\right)$ and distance from the sonotrode $(d, \mathrm{~cm})$ on the $\mathrm{d} T / \mathrm{d} t$, acoustic power $P$, acoustic intensity $l$, acoustic density $D$, acoustic power per mass of particles $D_{\mathrm{p}}$ and yield of power conversion acoustic power $P(\mathrm{~W})$ was evaluated using the software STATISTICA 10.0 (StatSoft Enterprise, Tulsa, USA). Polynomial equations, based on the Equation (5.4.6), were obtained as a function of the significant parameters.

$\phi=\beta_{0}+\beta_{1} p H+\beta_{2} p H^{2}+\beta_{3} X_{S}+\beta_{4} X_{S}^{2}+\beta_{5} P_{N}+\beta_{6} P_{N}^{2}+\beta_{7} d+\beta_{8} d^{2}$

where $\phi$ is the studied variable $\left(P, I, D, D_{\mathrm{p}}\right.$ and Yield) and $\beta_{0}, \beta_{1}, \beta_{2}, \beta_{3}, \beta_{4}, \beta_{5}, \beta_{6}, \beta_{7}$, and $\beta_{8}$ are empirical parameters of the polynomial model.

Graphical plot and non-linear regressions were carried out through the software OriginPro 8.0 (OriginLab Corporation, Northampton, USA). The accuracy of the obtained models was expressed by the determination coefficient $R^{2}$ and by the root mean square error (RMSE).

\subsubsection{Correlation between acoustic and physical properties}

As it is known that acoustic properties are dependent on the physical properties of the medium, it was evaluate the correlation between acoustic intensity and physical properties of the acid suspensions containing cassava bagasse. Among the physical properties, there are apparent viscosity (Polachini et al., 2019a), density, thermal conductivity and thermal diffusivity (Polachini et al., 2019b). The agreement between acoustic intensity and a given physical property was adressed by a Pearson

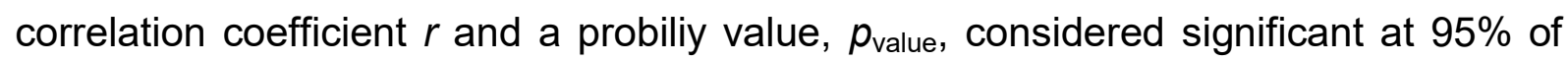
confidence. 


\section{Results and discussions}

\subsection{Acoustic characterization}

The ultrasound application over the $90 \mathrm{~s}$ of treatment resulted in a linear increase of temperature $\left(R^{2}>0.968\right)$ for all acid suspensions at the different positions of the thermocouple. The heating rate $\left({ }^{\circ} \mathrm{C} \cdot \mathrm{s}^{-1}\right)$, that is the slope of temperature evolution with the treatment time $(\mathrm{d} T / \mathrm{d} t)$ during ultrasound application, varied from 0.0063 to $0.0326{ }^{\circ} \mathrm{C} \cdot \mathrm{s}^{-1}$ according to the $\mathrm{pH}$, solids concentration, nominal input power and distance from the sonotrode in the range of studied conditions. Taking into account these experimental heating rates together with the density and specific heat of the acid suspensions reported by Polachini et al. (2019b), acoustic power was calculated for all conditions using Equation (5.4.1). These values were in the range from 49.05 to $260.64 \mathrm{~W}$. Intensity (I, Equation 5.4 .2 ), acoustic density ( $D$, Equation 5.4.3) and acoustic power per mass of particles $\left(D_{p}\right.$, Equation 5.4.4) were also estimated because they can be interesting to quantiy the ultrasound application iflluence. Thus, acoustic intensity presented values between 12.90 and $68.57 \mathrm{~W} \cdot \mathrm{cm}^{-2}$. These figures are in the range $\left(<100 \mathrm{~W} \cdot \mathrm{cm}^{-2}\right)$ recommended by Gogate and Pandit (2000), where the level of power applied does not influence negatively the acoustic intensity as a consequence of the cavitation bubble overgrowth and the subsequent decrease on the bubble wall pressure. For acoustic density, the calculed values varied from 24.53 up to $130.32 \mathrm{~kW} \cdot \mathrm{m}^{-3}$. Finally, acoustic power applied per mass of biomass treated, an interesting parameter to correlate the acoustic field with the sonochemical effects generated on the particles in the suspension, varied from 0.24 up to $6.66 \mathrm{~kW} \cdot \mathrm{kg}$ of cassava bagasse ${ }^{-1}$.

Understanding how each factor affects the acoustic property can provide important information for the correct design of different processes assisted by ultrasound. The influence of each variable $(\mathrm{pH}$, solids concentration, nominal input power and distance from the sonotrode tip) on the acoustic parameters was studied separately in the following sections:

\subsection{Influence of $\mathrm{pH}$ on acoustic intensity $(I)$}

The $\mathrm{pH}$ of the solutions did not significantly influence $\left(p_{\text {value }}>0.05\right)$ the heating rate as well as the acoustic intensity when ultrasound were applied. This could 
indicate that, in the $\mathrm{pH}$ interval between 3.0 and 7.0, the acid content of suspension do not significant influence the intensity of cavitation, in a similar way as previously observed for acid suspensions containing powdered peanut shells (Polachini et al., 2017).

This fact was observed for suspensions with different solid concentration, when different nominal input power was applied and at any position from the tip of the sonotrode (Figure 5.4.2). This no clear trend of the heating rate at different $\mathrm{pH}$ means that suspensions containing biomass can be slightly acidified in order to obtain optimal conditions for a possible enzyme actuation without alter the ultrasonic field applied.

From this point, $\mathrm{pH}$ was not taken into account for determining and modelling the influence of the solids concentration, the nominal input power applied and the distance from the sonotrode tip on the acoustic properties. Thus, the following experiments were carried out at a fixed $\mathrm{pH}$ value of 7.0.
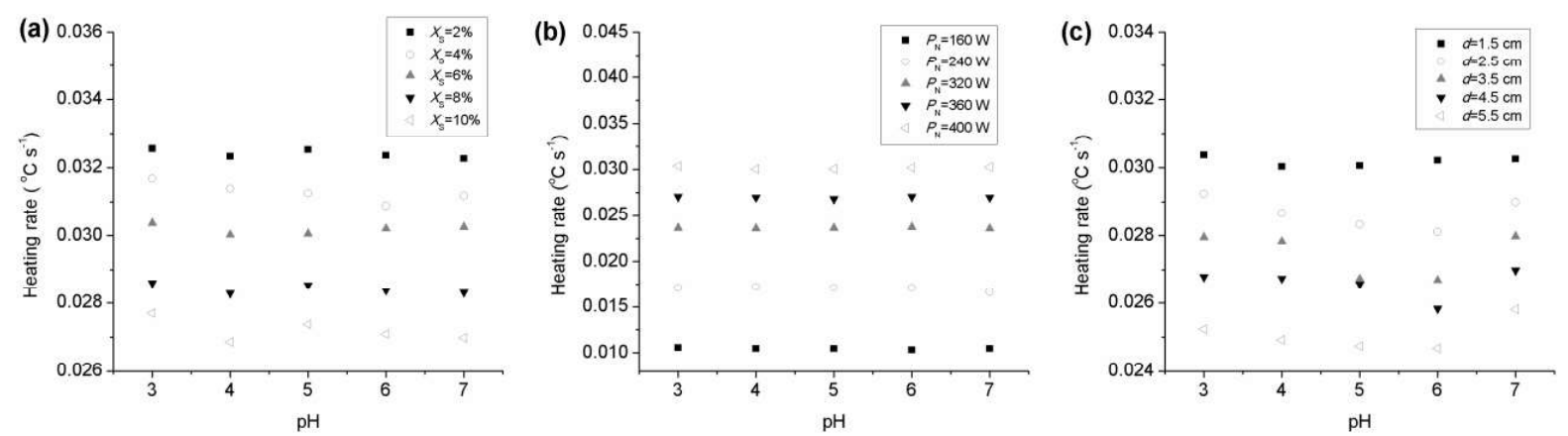

Figure 5.4.2. Acoustic intensity $I\left(\mathrm{~W} \cdot \mathrm{cm}^{-2}\right)$ as affected by $\mathrm{pH}$ at different (a) solids concentration $\left(P_{\mathrm{N}}=400 \mathrm{~W}\right.$ and $\left.d=1.5 \mathrm{~cm}\right)$, (b) nominal input power $\left(X_{\mathrm{S}}=6 \%\right.$ and $d=1.5$ $\mathrm{cm})$ and $(\mathrm{c})$ distances from the sonotrode $\left(X_{\mathrm{S}}=6 \%\right.$ and $\left.P_{\mathrm{N}}=400 \mathrm{~W}\right)$.

\subsection{Influence of nominal electrical power applied $\left(P_{N}\right)$ on acoustic intensity (I)}

The increase of the the $P_{\mathrm{N}}$ caused a significant linear increase in the heating rate, and consequently in the I ( $\left.p_{\text {value }}<0.05\right)$. This linear dependence was previously reported for different systems and for different solvents (Contamine et al., 1995; Toma et al., 2011), distilled water (Mamvura et al., 2018), municipal wastewater with suspended particles (Gibson et al., 2009) or peanut shell suspensions (Polachini et 
al., 2017). Increasing the nominal applied energy enhanced the heating rate in the suspensions. This ncrease of the acoustic intensity was observed in all the suspensions tested with different concentrations of solids and at the different points of measurement considered (Figure 5.4.3). The increase in the electrical input power could have increased the acoustic intensity by the generation of a more violent collapse between cavitation bubbles (Ferkous et al., 2015). Moreover, the differences of the slope and intercept of the curves may be attributed to the efficiency of energy conversion at different electrical power in the varied conditions (Toma et al., 2011).

(a)

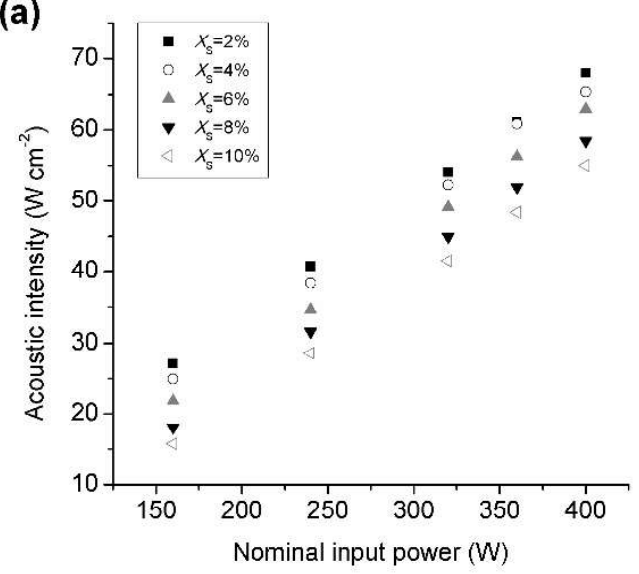

(b)

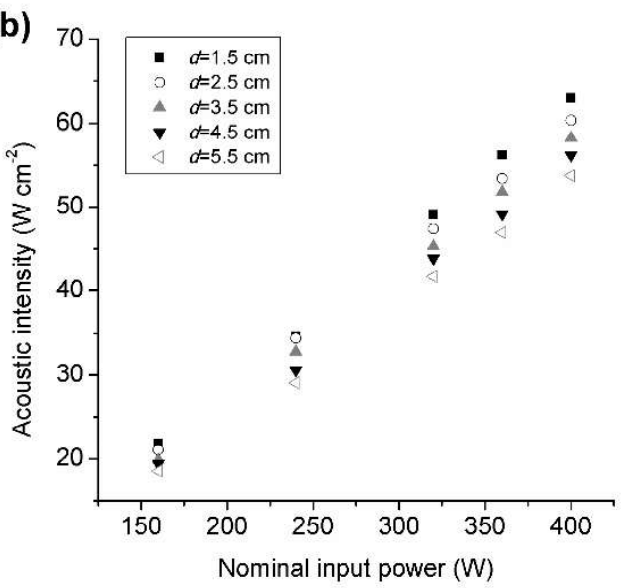

Figure 5.4.3. Acoustic intensity $I\left(\mathrm{~W} \cdot \mathrm{cm}^{-2}\right)$ as affected by the nominal input power (a) in suspensions with different solids content $(d=1.5 \mathrm{~cm})$ and $(\mathrm{b})$ at different distances from the sonotrode $\left(X_{S}=6 \%\right)$.

\subsection{Influence of solids concentration $\left(X_{S}\right)$ of suspensions on acoustic intensity (I)}

A significant linear and quadratic effect $\left(p_{\text {value }}<0.05\right)$ by the solids concentration on the heating rate was observed. The increase in the solids content resulted lower heating rates, probably due to the higher viscosity of concentrated suspensions in comparison to dilute ones (Polachini et al, 2019a). Consequently, higher acoustic intensity was observed for the more diluted suspensions at the higher amplitude of nominal input power in the closer position to the tip (Figure 5.4.4). The presence of suspended particles promotes the energy attenuation, as higher energy levels are required to overcome the molecular interaction in the decompression 
zones during sound wave propagation. The same behavior was reported in a previous study with powdered peanut shells suspended in water (Polachini et al., 2017). In addition, the reduced acoustic intensity in suspensions with higher concentrations of cassava bagasse may be also attributed to the difference between the liquid and particle impedance. As the ultrasound propagates through the medium and come across a particle, it is expected the reflectance and scattering of acoustic fields (Gupta and Feke, 1997; Saint-Michel et al., 2017).
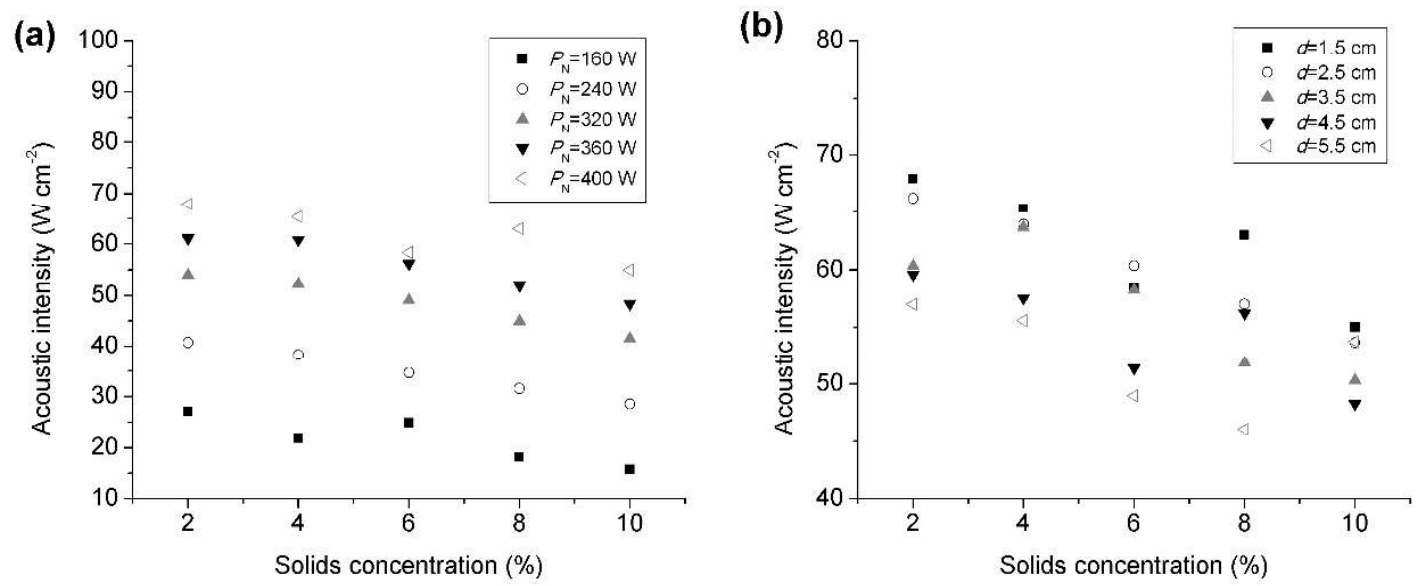

Figure 5.4.4. Acoustic intensity $I\left(\mathrm{~W} \cdot \mathrm{cm}^{-2}\right)$ as affected by solids concentration (a) under different nominal input power $(d=1.5 \mathrm{~cm})$ and $(\mathrm{b})$ at different distances from the sonotrode $\left(P_{\mathrm{N}}=400 \mathrm{~W}\right)$.

\subsection{Influence of distance from the sonotrode $(d)$ on acoustic intensity $(I)$}

The experimental measurements showed that the acoustic intensity significantly decreased when increasing the distance between the point of temperature measurement and the tip of the probe, evidencing that energy attenuation occurs through the material during sonication (Figure 5.4.5). Possible reasons for this attenuation are related to the reflection, refraction, diffraction or scattering of the wave when travelling across the suspensions. Moreover viscous interactions of the particles can also contribute to the degradation of the acoustic energy into heat (Mamvura et al., 2018;Mason and Lorimer, 2002). The acoustic intensity, $I$, can be related to the distance from the tip, $d$, by an exponential relation (Equation 5.4.5). It allows the estimation of the attenuation factor $(\alpha)$ and the pre- 
exponential term $\left(I_{0}\right)$. In this sense, I values for all suspensions under different input power levels were plotted against $d$ and fitted to Equation (5.4.5) (Figure 5.4.5). The fitting procedure resulted good accuracy $\left(R^{2}>0.8416\right.$ and $\left.R M S E<1.79\right)$, presenting close agreement of the predicted values with the observed ones (Table 5.4.1).

From the analysis of variance, the pre-exponential term $\left(I_{0}\right)$ demonstrated to be dependent on the cassava bagasse concentration and on the input power $(p<0.05)$. It tended to increase with decreasing solids concentration and increasing input power. On the other hand, attenuation factor $(\alpha)$ did not present a significant relationship with these variables. All values of acoustic intensity are supposed to be in the region of linear decrease of the exponential equation (Figure 5.4.5), leading to the absence of correlation of $\alpha$ with $X_{\mathrm{S}}$ and $P_{\mathrm{N}}$ with a constant mean attenuation value of $0.021 \mathrm{~cm}^{-1}$ for the conditions applied to the suspensions. The constant $\alpha /(\text { frequency })^{2}$, considered unique for each solution (Son et al., 2009), can be so determined as a constant value $3.64 \times 10^{-11} \mathrm{~cm}^{-1} \cdot \mathrm{s}^{2}$ for the studied suspensions. Even more, the distance of half-acoustic intensity in which acoustic intensity decreases by $50 \%$ (when $I / I_{0}=0.5$ ) would be assumed equal to approximately $7.17 \mathrm{~cm}$. This value is lower than the ones observed by Son et al. (2009) for tap water at higher frequency than $35 \mathrm{kHz}$, indicating that suspended particle of cassava bagasse could have actuated as attenuating material in contrast to pure water. Analogously, the constant $\alpha /$ (frequency $)^{2}$ was higher in this study when comparing with the previous authors, leading to the same observation.

When measuring acoustic pressure by indirect methods, Chivate and Pandit (1995) found that the zone of exponential decrease of pressure was found below 1 $\mathrm{cm}$ from the sonotrode. In other words, it is probable that acoustic intensity decreased in a constant way from $1.5 \mathrm{~cm}$ up to $5.5 \mathrm{~cm}$ away from the sonotrode because the maximum acoustic intensity decreased exponentially when too little distances close to the tip are taken. Mamvura et al. (2018) and Son et al. (2009) also reported similar linear trend when applying electrical power above $100 \mathrm{~W}$ in distilled water over higher distances. Therefore, concerning the design reactors for heterogeneous systems, calculations about the acoustic intensity could be done considering that acoustic intensity would not suffer abrupt decreases, characteristic of exponential behavior, in the region between 1.5 and $5.5 \mathrm{~cm}$. 
(a)

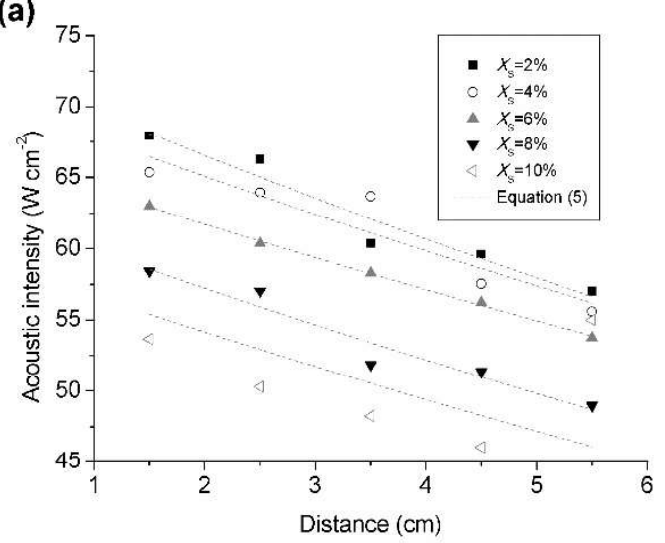

(b)

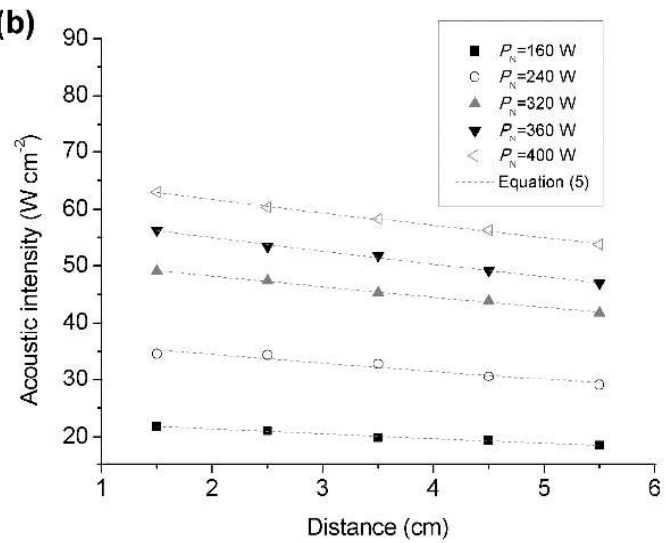

Figure 5.4.5. Acoustic intensity $I\left(\mathrm{~W} \cdot \mathrm{cm}^{-2}\right)$ as affected by the distance from the sonotrode at different (a) solids concentration $\left(P_{\mathrm{N}}=400 \mathrm{~W}\right)$ and (b) nominal input power $\left(X_{S}=6 \%\right)$; data are fitted to the Equation (5.4.5).

Table 5.4.1. Fitted values for $I_{0}$ and $\alpha$ at different input power and cassava bagasse concentrations.

\begin{tabular}{ccccccc}
\hline \multirow{2}{*}{$P(\mathrm{~W})$} & Parameters & \multicolumn{6}{c}{ Solids concentration, $X_{\mathrm{S}}(\%)$} \\
& & 2 & 4 & 6 & 8 & 10 \\
\hline \multirow{4}{*}{160} & $I_{0}\left(\mathrm{~W} \cdot \mathrm{cm}^{-2}\right)$ & 29.16 & 26.67 & 23.23 & 19.28 & 16.94 \\
& $\alpha\left(\mathrm{W} \cdot \mathrm{cm}^{-1}\right)$ & 0.0208 & 0.0228 & 0.0205 & 0.0171 & 0.0221 \\
& $R^{2}$ & 0.9435 & 0.9894 & 0.9921 & 0.9557 & 0.9152 \\
& $R M S E$ & 0.46 & 0.19 & 0.13 & 0.22 & 0.35 \\
\hline \multirow{4}{*}{240} & $I_{0}\left(\mathrm{~W} \cdot \mathrm{cm}^{-2}\right)$ & 43.66 & 40.98 & 37.85 & 33.99 & 30.55 \\
& $\alpha\left(\mathrm{W} \cdot \mathrm{cm}^{-1}\right)$ & 0.0202 & 0.0205 & 0.0229 & 0.0198 & 0.0204 \\
& $R^{2}$ & 0.9858 & 0.9599 & 0.9577 & 0.9723 & 0.9686 \\
& $R M S E$ & 0.32 & 0.52 & 0.55 & 0.34 & 0.34 \\
\hline \multirow{4}{*}{320} & $I_{0}\left(\mathrm{~W} \cdot \mathrm{cm}^{-2}\right)$ & 57.79 & 57.41 & 52.20 & 48.26 & 44.15 \\
& $\alpha\left(\mathrm{W} \cdot \mathrm{cm}^{-1}\right)$ & 0.0200 & 0.0229 & 0.0199 & 0.0207 & 0.0194 \\
& $R^{2}$ & 0.9544 & 0.8426 & 0.9977 & 0.9561 & 0.9660 \\
& $R M S E$ & 0.77 & 1.78 & 0.15 & 0.65 & 0.49 \\
\hline \multirow{4}{*}{360} & $I_{0}\left(\mathrm{~W} \cdot \mathrm{cm}^{-2}\right)$ & 65.71 & 65.43 & 60.02 & 55.83 & 52.12 \\
& $\alpha\left(\mathrm{W} \cdot \mathrm{cm}^{-1}\right)$ & 0.0230 & 0.0230 & 0.0221 & 0.0235 & 0.0227 \\
& $R^{2}$ & 0.9536 & 0.9536 & 0.9962 & 0.9679 & 0.9794 \\
& $R M S E$ & 0.99 & 0.99 & 0.24 & 0.71 & 0.51 \\
\hline \multirow{4}{*}{400} & $I_{0}\left(\mathrm{~W} \cdot \mathrm{cm}^{-2}\right)$ & 72.99 & 70.79 & 66.73 & 62.76 & 59.35 \\
& $\alpha\left(\mathrm{W} \cdot \mathrm{cm}^{-1}\right)$ & 0.0230 & 0.0210 & 0.0194 & 0.0230 & 0.0229 \\
& $R^{2}$ & 0.9634 & 0.9184 & 0.9988 & 0.9601 & 0.9906 \\
& $R M S E$ & 0.98 & 1.36 & 0.13 & 0.88 & 0.39 \\
\hline
\end{tabular}




\subsection{Conversion yield}

Yield of power conversion is useful not only from an economical point of view but also for designing appropriate ultrasonic processors to produce a given acoustic effect from specific electrical input power. In the present study with cassava bagasse suspensions, it was observed that the conversion of electrical into acoustic energy was higher as greater the input power applied and lower the solids content. Thus, the maximum yield found was $64.58 \%$ in the conditions of $X_{S}=2 \%$ and $P_{N}=400 \mathrm{~W}$ s at the closer position to the tip. Löning et al. (2002) and Polachini et al. (2017) reported close conversion yield values in similar conditions for water and peanut shell suspensions, respectively. In the same point, yield could decrease to $36.81 \%$ if the solids concentration is increased to $10 \%$ and nominal power was established at the minimum value of $160 \mathrm{~W}$. McDonnell et al. (2014) also found better conversion rates when operating ultrasound at higher nominal power, indicating that sonochemical effects are supposed to be more intense at highest nominal power. However, as can be observed in Figure 5.4.6, the increase of conversion rate was not linear. In this sense, Gibson et al. (2009) and Polachini et al. (2017) found that the efficiency of power conversion increased non-linearly with nominal power when studying biomass suspensions, approaching to a plateau level at higher $P_{\mathrm{N}}$. Cárcel et al. (2007b) also found a non-linear trend in experiments carried out with sucrose solution, emphasizing that electrical input power does not provide enough information about the actual acoustic intensity transmitted to the medium. Similarly, a non-linear increase was observed when the cassava bagasse concentration increased, reaching a plateau above approximately 8\% (Figure 5.4.6). These deviations from linearity are more noticeable both at higher nominal powers and solids concentration. It highlights that controlling of the operations conditions and reactor design can provide the required energy with the maximum efficiency of energy conversion (Mason and Lorimer, 2002; Toma et al., 2011). 

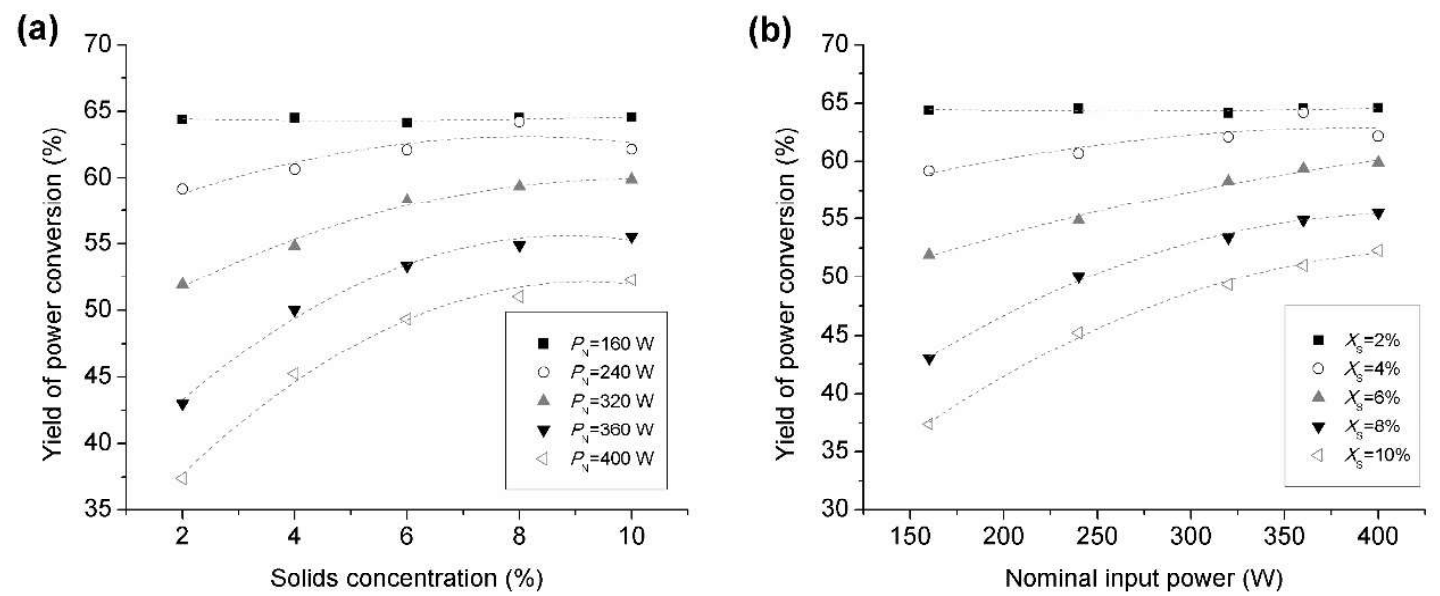

Figure 5.4.6. Yield of power conversion measured at the point of maximum cavitation $(d=1.5 \mathrm{~cm})$ as a function of (a) nominal input power and (b) solids concentration.

\subsubsection{Mathematical modelling}

Acoustic properties can be predicted by both empirical and theoretical models. The obtained values for acoustic power, intensity, density and acoustic power per mass unit of particles could be fitted with good accuracy to polynomial equations in order to provide ready-to-use information for reproducing a given condition. Table 5.4.2 shows the fitting parameters of each corresponding acoustic variable.

Table 5.4.2. Fitting parameters of the Equation (5.4.6) for heating rate $(d T / d t)$ acoustic power $(P)$, acoustic intensity $(I)$, acoustic density $(D)$, acoustic power per mass of particles $\left(D_{p}\right)$ and yield of power conversion.

\begin{tabular}{ccccccc}
\hline Parameter & $\begin{array}{c}\mathrm{d} T / \mathrm{d} t \\
\left({ }^{\circ} \mathrm{C} \cdot \mathrm{s}^{-1}\right)\end{array}$ & $P(\mathrm{~W})$ & $I\left(\mathrm{~W} \cdot \mathrm{cm}^{-2}\right)$ & $D\left(\mathrm{~kW} \cdot \mathrm{m}^{-3}\right)$ & $D_{p}\left(\mathrm{~kW} \cdot \mathrm{kg}^{-1}\right)$ & Yield $(\%)$ \\
\hline$\beta_{0}$ & $4.03 \times 10^{-3}$ & 34.85 & 9.17 & 17.42 & 5.18 & 54.32 \\
$\beta_{1}$ & - & - & - & - & - & - \\
$\beta_{2}$ & - & - & - & - & - & - \\
$\beta_{3}$ & $-4.81 \times 10^{-4}$ & -4.04 & -1.06 & -2.02 & -1.45 & -1.57 \\
$\beta_{4}$ & $-1.21 \times 10^{-5}$ & -0.13 & -0.03 & -0.06 & 0.08 & -0.04 \\
$\beta_{5}$ & $7.49 \times 10^{-5}$ & 0.59 & 0.15 & 0.29 & $6.91 \times 10^{-3}$ & 0.09 \\
$\beta_{6}$ & - & - & - & - & - & $1.19 \times 10^{-3}$ \\
$\beta_{7}$ & $-8.54 \times 10^{-4}$ & -6.75 & -1.77 & -3.37 & -0.08 & -2.24 \\
$\beta_{8}$ & - & - & - & - & - & - \\
\hline$R^{2}$ & 0.9923 & 0.9921 & 0.9921 & 0.9921 & 0.9198 & 0.9199 \\
$R M S E$ & $6.32 \times 10^{-4}$ & 4.87 & 1.28 & 2.43 & 0.45 & 2.11 \\
$E M R(\%)$ & 2.90 & 2.99 & 4.45 & 3.50 & 32.78 & 4.30 \\
\hline
\end{tabular}




\subsubsection{Correlation between acoustic and physical properties}

Physical properties of the medium are supposed to affect the cavitation degree. In this sense, acoustic intensity were correlated with experimental values of density $(\rho)$, specific heat $\left(c_{p}\right)$, thermal diffusivity $(\alpha)$, thermal conductivity $(\lambda)$ reported by Polachini et al. (2019b) and apparent viscosity observed by Polachini et al. (2019a) at fixed shear rate of $10 \mathrm{~s}^{-1}\left(\eta_{a p p, 10 s^{-1}}\right)$ at a temperature of $25^{\circ} \mathrm{C}$. Thus, all of the physical properties showed to be highly correlated with the acoustic intensity $\left(p_{\text {value }} \leq 0.05\right)$ as showed the high figures of the Pearson's correlation coefficient (Table 5.4.3). As expected, acoustic intensity was strongly influenced by $c_{p}$ and $\rho$ since these properties are included in the calculation of acoustic power from heating rate data. As Figure 5.4.7a and 5.4.7b shows, the increase of the specific heat capacity and the density of the medium led to greater values of acoustic intensity. Regarding the thermal properties, thermal diffusivity and thermal conductivity, the greater values the higher acoustic intensity observed. This fact can be attributed to a more intense cavitation in fluids with higher $\alpha$ and $\lambda$ figures (Figure 5.4.7c and 5.4.7d). On the other hand, the acoustic intensity was lower in suspensions with greater viscosity as indicated by the negative correlation coefficient found (Figure 5.4.7e). Toma et al. (2011) observed that solvents with elevated viscosity seemed to present lower acoustic power, similarly as noticed for cassava bagasse. According to Raso et al. (1999), the molecular motion is reduced in liquids with higher viscosity, i. e. more energy is required by the molecules to overcome the critical molecular distance necessary to induce the formation of cavitation bubbles. 
(a)

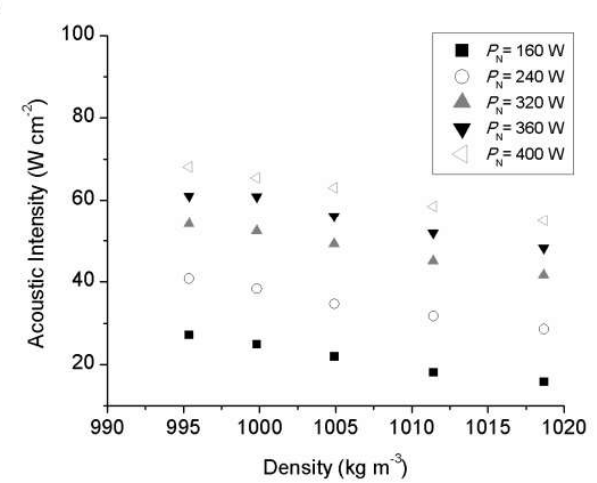

(c)

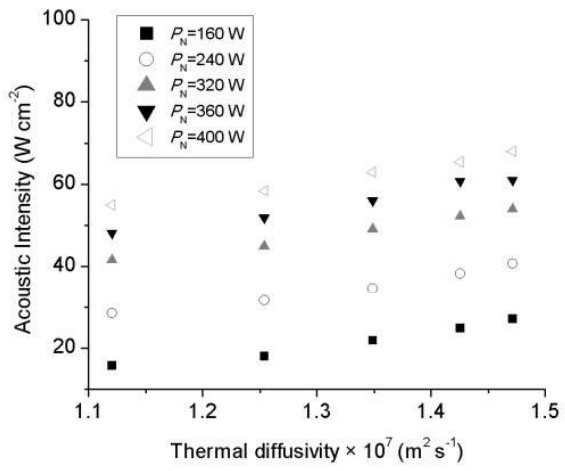

(e) (b)

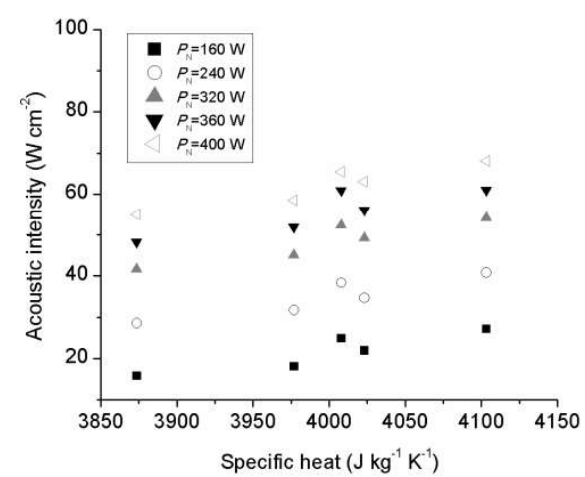

(d)

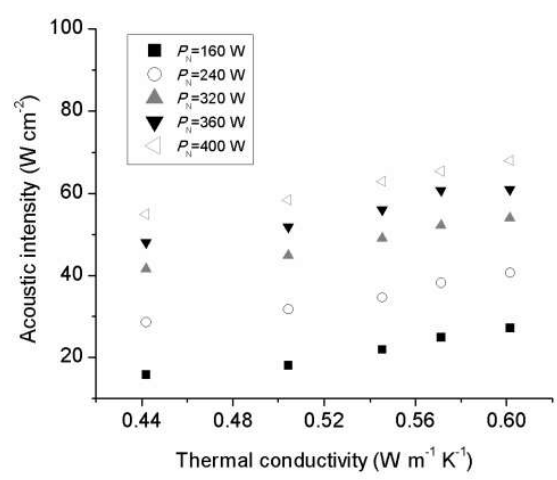

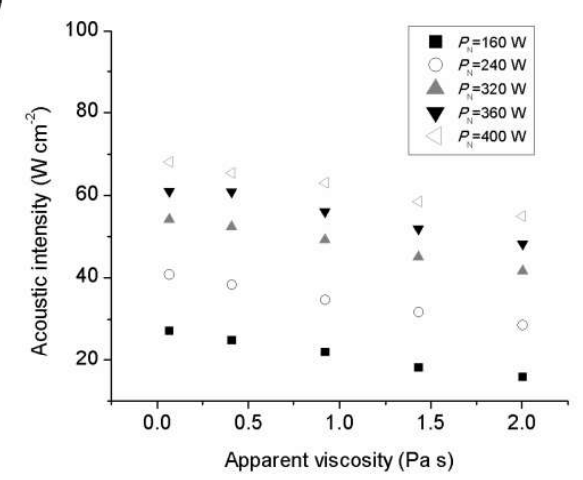

Figure 5.4.7. Acoustic intensity $(I)$ as a function of (a) density, (b) specific heat, (c) thermal diffusivity, (d) thermal conductivity and (e) apparent viscosity of the suspensions under different nominal input power $\left(P_{\mathrm{N}}\right)$. 
Table 5.4.3. Parameters of Pearson correlations between acoustic intensity and each physical property in the different nominal input power at the closest position to the sonotrode.

\begin{tabular}{ccccccc}
\hline \multirow{2}{*}{$P_{\mathrm{N}}(\mathrm{W})$ Parameter } & $\rho$ & $c_{p}$ & $\alpha$ & $\lambda$ & $\eta_{a p p, 10^{-1}}$ \\
\hline \multirow{2}{*}{160} & $r$ & -0.9940 & 0.9099 & 0.9837 & 0.9798 & -0.9965 \\
& $p_{\text {value }}$ & $5.5 \times 10^{-4}$ & $3.2 \times 10^{-2}$ & $2.5 \times 10^{-3}$ & $3.4 \times 10^{-3}$ & $2.52 \times 10^{-4}$ \\
& & & & & & \\
240 & $r$ & -0.9944 & 0.9150 & 0.9843 & 0.9811 & -0.9977 \\
& $p_{\text {value }}$ & $5.0 \times 10^{-4}$ & $2.9 \times 10^{-2}$ & $2.3 \times 10^{-3}$ & $3.1 \times 10^{-3}$ & $1.3 \times 10^{-4}$ \\
& & & & & & \\
320 & $r$ & -0.9975 & 0.9168 & 0.9939 & 0.9893 & -0.9979 \\
& $p_{\text {value }}$ & $1.5 \times 10^{-4}$ & $2.8 \times 10^{-2}$ & $5.6 \times 10^{-4}$ & $1.3 \times 10^{-3}$ & $1.1 \times 10^{-4}$ \\
& & & & & & \\
360 & $r$ & -0.9868 & 0.8774 & 0.9877 & 0.9769 & -0.9895 \\
& $p_{\text {value }}$ & $1.8 \times 10^{-3}$ & $5.0 \times 10^{-2}$ & $1.6 \times 10^{-3}$ & $4.2 \times 10^{-3}$ & $1.3 \times 10^{-3}$ \\
400 & $r$ & -0.9978 & 0.9353 & 0.9926 & 0.9916 & -0.9963 \\
& $p_{\text {value }}$ & $1.2 \times 10^{-4}$ & $2.0 \times 10^{-2}$ & $7.7 \times 10^{-4}$ & $9.3 \times 10^{-4}$ & $2.7 \times 10^{-4}$ \\
\hline
\end{tabular}

\subsubsection{Conclusions}

The application of ultrasound in acid suspensions containing cassava bagasse resulted in different heating rates, being these significantly enhanced by decreasing the solids concentration in the suspensions and increasing nominal input power. No significant influence of the $\mathrm{pH}$ of suspensions was observed. The decrease of heating rate with the distand from the sonotrode tip was used to evaluate the attenuation of the acoustic field being this constant for all the suspensions considered. Acoustic intensity, acoustic power, acoustic density and acoustic power per mass unit of particles were well-fitted to polynomial models, presenting good accuracy $\left(R^{2}>0.9198\right)$ in order to make available ready-to-use information. Additionally, acoustic intensity was well correlated with some physical properties of the cassava bagasse suspensions. In this sense, cavitation and, consequently the sonochemical effects on the biomass, could be enhanced by modifying the physical properties of a given suspensions. Although better energy efficiency and more intense cavitation can be obtained when applying higher input power in diluted 
suspension, energy and water expenses should be assessed together with the sonochemical effects to obtain an overall optimization of the process.

\subsubsection{Acknowledgments}

Authors acknowledge the INIA-ERDF (RTA2015-00060-C04-02 and RTA2015-00060-C04-03) from Spain and the São Paulo Research Foundation FAPESP (Grant 2017/06518-2) and the Coordination for the Improvement of Higher Level Personnel - CAPES (Grant 88881.132626/2016-01) from Brazil for the financial support.

\subsubsection{References}

Akhtar, N., Gupta, K., Goyal, D., Goyal, A., (2016). Recent advances in pretreatment technologies for efficient hydrolysis of lignocellulosic biomass. Environmental Progress \& Sustainable Energy 35(2), 489-511.

Berlan, J., Mason, T.J., (1996). Dosimetry for power ultrasound and sonochemistry, in: Mason, T.J. (Ed.), Advances in Sonochemistry. JAI Press Inc, Londres, pp. 1-73.

Bundhoo, Z.M.A., Mohee, R., (2018). Ultrasound-assisted biological conversion of biomass and waste materials to biofuels: A review. Ultrasonics Sonochemistry 40, 298-313.

Cárcel, J.A., Benedito, J., Bon, J., Mulet, A., (2007a). High intensity ultrasound effects on meat brining. Meat Science 76(4), 611-619.

Cárcel, J.A., Benedito, J., Rosselló, C., Mulet, A., (2007b). Influence of ultrasound intensity on mass transfer in apple immersed in a sucrose solution. Journal of Food Engineering 78(2), 472-479.

Cárcel, J.A., García-Pérez, J.V., Benedito, J., Mulet, A., (2012). Food process innovation through new technologies: Use of ultrasound. Journal of Food Engineering 110(2), 200-207.

Chen, H., Fu, X., (2016). Industrial technologies for bioethanol production from lignocellulosic biomass. Renewable and Sustainable Energy Reviews 57, 468478. 
Chivate, M.M., Pandit, A.B., (1995). Quantification of cavitation intensity in fluid bulk. Ultrasonics Sonochemistry 2(1), S19-S25.

Contamine, R.F., Wilhelm, A.M., Berlan, J., Delmas, H., (1995). Power measurement in sonochemistry. Ultrasonics Sonochemistry 2(1), S43-S47.

FAO, (2019). Official data of cassava production. Food and Agriculture Organization of the United Nations.

Ferkous, H., Hamdaoui, O., Merouani, S., (2015). Sonochemical degradation of naphthol blue black in water: Effect of operating parameters. Ultrasonics Sonochemistry $26,40-47$.

Gibson, J.H., Hon, H., Farnood, R., Droppo, I.G., Seto, P., (2009). Effects of ultrasound on suspended particles in municipal wastewater. Water Research 43(8), 2251-2259.

Gogate, P.R., (2007). Application of cavitational reactors for water disinfection: Current status and path forward. Journal of Environmental Management 85(4), 801-815.

Gogate, P.R., Pandit, A.B., (2000). Engineering design method for cavitational reactors: I. Sonochemical reactors. AIChE Journal 46(2), 372-379.

Gupta, S., Feke, D.L., (1997). Acoustically driven collection of suspended particles within porous media. Ultrasonics 35(2), 131-139.

Hassan, S.S., Williams, G.A., Jaiswal, A.K., (2018). Emerging technologies for the pretreatment of lignocellulosic biomass. Bioresource Technology 262, 310-318.

Kikuchi, T., Uchida, T., (2011). Calorimetric method for measuring high ultrasonic power using water as a heating material. Journal of Physics: Conference Series $279,012012$.

Löning, J.-M., Horst, C., Hoffmann, U., (2002). Investigations on the energy conversion in sonochemical processes. Ultrasonics Sonochemistry 9(3), 169179.

Mamvura, T.A., lyuke, S.E., Paterson, A.E., (2018). Energy changes during use of high-power ultrasound on food grade surfaces. South African Journal of Chemical Engineering 25, 62-73. 
Margulis, M.A., Margulis, I.M., (2003). Calorimetric method for measurement of acoustic power absorbed in a volume of a liquid. Ultrasonics Sonochemistry 10(6), 343-345.

Mason, T.J., Lorimer, J.P., (2002). Applied sonochemistry. Wiley-vch, Weinheim.

McDonnell, C.K., Lyng, J.G., Arimi, J.M., Allen, P., (2014). The acceleration of pork curing by power ultrasound: A pilot-scale production. Innovative Food Science \& Emerging Technologies 26(0), 191-198.

Polachini, T.C., Carvalho, G.R.d., Telis-Romero, J., (2017). Determination of acoustic fields in acidic suspensions of peanut shell during pretreatment with highintensity ultrasound. Brazilian Journal of Chemical Engineering 34, 385-394.

Polachini, T.C., Mulet, A., Cárcel, J.A., Telis-Romero, J., (2019a). Rheology of acid suspensions containing cassava bagasse: effect of biomass loading, acid content and temperature. Powder Technology.

Polachini, T.C., Mulet, A., Cárcel, J.A., Telis-Romero, J., (2019b). Thermophysical properties of dilute acid slurries of cassava bagasse as a function of biomass loading, acid concentration and temperature. Chemical Engineering Research \& Design.

Raso, J., Manas, P., Pagan, R., Sala, F.J., (1999). Influence of different factors on the output power transferred into medium by ultrasound. Ultrasonics Sonochemistry 5(4), 157-162.

Rehman, M.S.U., Kim, I., Chisti, Y., Han, J.-I., (2013). Use of ultrasound in the production of bioethanol from lignocellulosic biomass. Energy Education Science and Technology Part A: Energy Science and Research 30(2), 13911410.

Saint-Michel, B., Bodiguel, H., Meeker, S., Manneville, S., (2017). Simultaneous Concentration and Velocity Maps in Particle Suspensions under Shear from Rheo-Ultrasonic Imaging. Physical Review Applied 8(1), 014023.

Sindhu, R., Binod, P., Mathew, A.K., Abraham, A., Gnansounou, E., Ummalyma, S.B., Thomas, L., Pandey, A., (2017). Development of a novel ultrasoundassisted alkali pretreatment strategy for the production of bioethanol and xylanases from chili post harvest residue. Bioresource Technology 242, 146151. 
Somerville, C.R., Youngs, H., Szemenyei, H., Sorek, N., Yeats, T.H., (2014). The Implications of Lignocellulosic Biomass Chemical Composition for the Production of Advanced Biofuels. BioScience 64(3), 192-201.

Son, Y., Lim, M., Khim, J., (2009). Investigation of acoustic cavitation energy in a large-scale sonoreactor. Ultrasonics Sonochemistry 16(4), 552-556.

Subhedar, P.B., Gogate, P.R., (2015). Ultrasound-assisted bioethanol production from waste newspaper. Ultrasonics Sonochemistry 27, 37-45.

Toma, M., Fukutomi, S., Asakura, Y., Koda, S., (2011). A calorimetric study of energy conversion efficiency of a sonochemical reactor at $500 \mathrm{kHz}$ for organic solvents. Ultrasonics Sonochemistry 18(1), 197-208. 
5.5. CHAPTER 5 Acoustic Fields in Peanut Waste Suspensions 
Brazilian Journal of Chemical Engineering, 2017, v. 34, n. 02, p. 385-394.

\section{Determination of Acoustic Fields in Acidic Suspensions of Peanut Shell During Pretreatment With High- Intensity Ultrasound}

Tiago Carregari Polachini ${ }^{1 *}$; Gisandro Reis de Carvalho ${ }^{1}$,
and Javier Telis-Romero ${ }^{1}$

${ }^{1}$ Food Engineering and Technology Department State University of São Paulo São José do Rio Preto, São Paulo, 15054-000, Brazil. 


\begin{abstract}
The benefits of high-intensity ultrasound in diverse processes have stimulated many studies based on biomass pretreatment. In order to improve processes involving ultrasound, a calorimetric method has been widely used to measure the real power applied to a material as well as to characterized the cavitation effects. Peanut shells, a byproduct of peanut processing, were immersed in acidified aqueous solutions and submitted to an ultrasonic field. Acoustic power absorbed, acoustic intensity and power yield were obtained through specific heat determination and experimental data were modeled in different conditions. Specific heat values ranged from 3537.0 to $4190.6 \mathrm{~J} \cdot \mathrm{kg}^{-1} \cdot \mathrm{K}^{-1}$, being found the lower values in the more concentrated biomass suspensions. The acoustic power transmitted and acoustic intensity varied linearly with the applied power and quadratically with solids concentration, reaching maximum values at higher applied nominal power and for less concentrated suspensions. A power yield of $82.7 \%$ was reached for dilute suspensions at $320 \mathrm{~W}$, while $6.4 \%$ efficiency was observed for a concentrated suspension at low input energy (80 W).
\end{abstract}

Keywords: acoustic intensity, biomass pretreatment, ultrasonic hydrolysis, specific heat, power yield. 


\subsubsection{Introduction}

The increase of $\mathrm{CO}_{2}$ emissions combined with the search for nonpetroleumbased sources of energy has strengthened many studies involving lignocellulosic wastes conversion into biofuel (Alvira et al., 2010). Lignocellulosic biomass is a less expensive product and its availability in larger quantities as compared to sucrose, for example, represents a great source for the bioethanol industry (Zheng et al., 2009).

Peanut shell is a byproduct obtained from peanut processing which has a great potential to be used as lignocellulosic raw material for the second-generation ethanol industry. It has been widely used as a rotary culture for sugarcane and, considering the grain/shell ratio, represents about 90 thousand tons of biomass per year (Godoy et al., 1982; IBGE, 2014). The $38 \%$ of cellulose average content shows its capability of releasing sugars for posterior fermentation and distillation (Castro and Pereira-Jr, 2010).

Although peanut waste offers advantages, a viable cellulose treatment has been a bottleneck for bioethanol production. New technologies have been developed to enhance the process of biomass accessibility. Among them, there are processes involving supercritical fluids (Okajima and Sako, 2014), acid or alkaline treatments (Cabrera et al., 2014; Moe et al., 2012), steam explosion (Liu et al., 2013) and highintensity ultrasound (Villa-Vélez et al., 2015b).

High-intensity ultrasound, or power ultrasound, is a technology able to reduce cellulose crystallinity and release polymers and monomers of carbohydrates from lignocellulosic material. Its success is directly related to the applied power, as well as the degree of cavitation achieved (Kanthale et al., 2003). Determination of the real power applied by ultrasound is an important step to quantify the cavitation effects occasioned by the collapse of microbubbles (Kuijpers et al., 2002). This cavitation phenomenon can be influenced by many factors such as local high temperatures, electric fields and mechanical action on interfaces (Contamine et al., 1995).

The active energy is the main parameter responsible for the sonochemical reactions in sonication processes, and can be measured from the absorbed acoustical energy. On the other hand, unabsorbed energy is the energy lost during the process and should not be taken into account during cavitation measurement. Studies of the efficiency of input energy conversion into absorbed power in the liquid 
volume have been developed to evaluate the energy output in different food processes, e. g., bioactive compounds extraction and meat brining (Cárcel et al., 2007a; McDonnell et al., 2014; Pingret et al., 2012). However, studies involving biomass treatment with ultrasound are still missing in the literature. Different methods have been considered to determine the real acoustic power absorbed by the material of interest. Some of them intended to correlate physical effects by the dosage of radicals during sonication (lida et al., 2005; Trabelsi et al., 1996), by calorimetry of thermal response (Margulis and Margulis, 2003) and by acoustic pressure using hydrophones (Jenderka and Koch, 2006; Lewin, 1981; Zeqiri et al., 2006).

The calorimetric method is a highlighted practice due to its reproducibility and accuracy (Berlan and Mason, 1996; Raso et al., 1999). This method is based on the continuous recording of the temperature change according to the sonication time (Raso et al., 1999) at the beginning of ultrasound application. It assumes an adiabatic behavior of the system and then all absorbed acoustical energy is transformed into heat, although acoustic streaming may happen as a dissipation form at high power levels (Margulis and Margulis, 2003).

Many independent variables can influence the energy absorption during ultrasonic application, making it unique for each process. Among these variables, there are physical properties (specific heat, viscosity, surface pressure and vapor pressure), liquid volume and/or height, input power, sonotrode type and position, etc. (Toma et al., 2011).

These facts reinforce the need for evaluating the real power absorbed by different acidic suspensions of biomass used during ultrasonic pretreatment. Thus, this work aimed to characterize the acoustic field (acoustic power, acoustic intensity and power yield) produced in acidified suspensions of peanut shells..

\subsubsection{Materials and Methods}

\subsubsection{Raw material and sample preparation}

Cleaned and dried peanut (Arachishypogaea L.) shells were acquired from the Agro-industrial Cooperative - COPLANA (Jaboticabal, São Paulo, Brazil). Using a knife mill MA380 (Marconi, Piracicaba, Brazil), the shells were milled and separated by Tyler sieves of 12 and 150 mesh to obtain powdered peanut shells with particle 
size between 104-1397 $\mu \mathrm{m}$. This wide range of particle size was used to simulate a real situation that might be used in the second-generation ethanol industry.

For experimental measurements, acidic suspensions of powdered peanut shells (ASPPS) were prepared in weight/weight units using an analytical balance with an accuracy of $1 \times 10^{-5} \mathrm{~g}$ (model AUX220, Shimadzu, Japan), obtaining biomass concentrations of $4,6,8,10$ and $12 \%$. The acidification of the solutions was previously realized using $500 \mathrm{~mL}$ of distilled water, adding $0.05 \%(\mathrm{v} / \mathrm{v}) \mathrm{H}_{2} \mathrm{SO}_{4}$ solution and stabilizing for 3 days to obtain $\mathrm{pH}$ values of $3,4,5,6$ and 7 . Only for the specific heat measurements, the suspensions were prepared with particle size of 104 $\mu \mathrm{m}$ to avoid particle sedimentation and microsyringe obstruction. This step ensured particle scattering and sample homogeneity to carry out the thermal analysis in the differential scanning calorimeter.

\subsubsection{Specific heat measurements}

Through a differential scanning calorimeter DSC 8000 (Perkin Elmer, Shelton, USA), specific heat $\left(c_{p}\right)$ were determined by the standard ASTM method for thermally stable liquids and solids (ASTM-E1269, 2005). The analysis consists of applying a heat flow under a controlled atmosphere (nitrogen $99.5 \%$ of purity) to evaluate the heat flow and energy alterations in the material. Equipment was calibrated with indium (melting point $429.75 \mathrm{~K}, \Delta \mathrm{h}_{f}=28.45 \mathrm{~J} / \mathrm{g}$ ) under a heat flow of $10 \mathrm{~K} \cdot \mathrm{min}^{-1}$. The same thermal program was used for the baseline, reference material of a sapphire disk of $3 \mathrm{~mm}$ (Archer, 1993), and ASPPS samples of approximately $5 \mu \mathrm{L}$. They were maintained isothermal at $273.13 \mathrm{~K}$ for $4 \mathrm{~min}$, heat flow of $10 \mathrm{~K} \cdot \mathrm{min}^{-1}$ until reaching $333.13 \mathrm{~K}$ and isothermal for 4 more min. For all experimental runs, samples were placed in aluminum pans (ref 0219-0062, Perkin Elmer, EUA). The Software PYRIS 10.1 (Perkin Elmer, Shelton, USA) was used to obtain the thermal curves and to determine the specific heat from the following Equation (5.5.1):

$$
c_{P}=\frac{D_{S}}{W_{S} \theta}
$$


where $D_{S}$ is the vertical displacement between the sample and reference material curves at a given temperature $(\mathrm{mW}), W_{S}$ is the sample weight $(\mathrm{mg})$, and $\theta$ the heat flow $\left(K \cdot \mathrm{s}^{-1}\right)$.

\subsubsection{Determination of the acoustic fields}

Experimental procedures were realized in the ASPPS at biomass concentrations from 4 to $12 \%$ using an ultrasound UP400S (Hielscher Ultrasonics $\mathrm{GmbH}$, Germany). This equipment has a titanium sonotrode with diameter of $22 \mathrm{~mm}$ (model H22, Hielscher Ultrasonics $\mathrm{GmbH}$, Germany), and operates at $24 \mathrm{kHz}$ of frequency and maximum nominal input power of $400 \mathrm{~W}$. The applied input power by the transducer could be modified from 0 to $100 \%$.

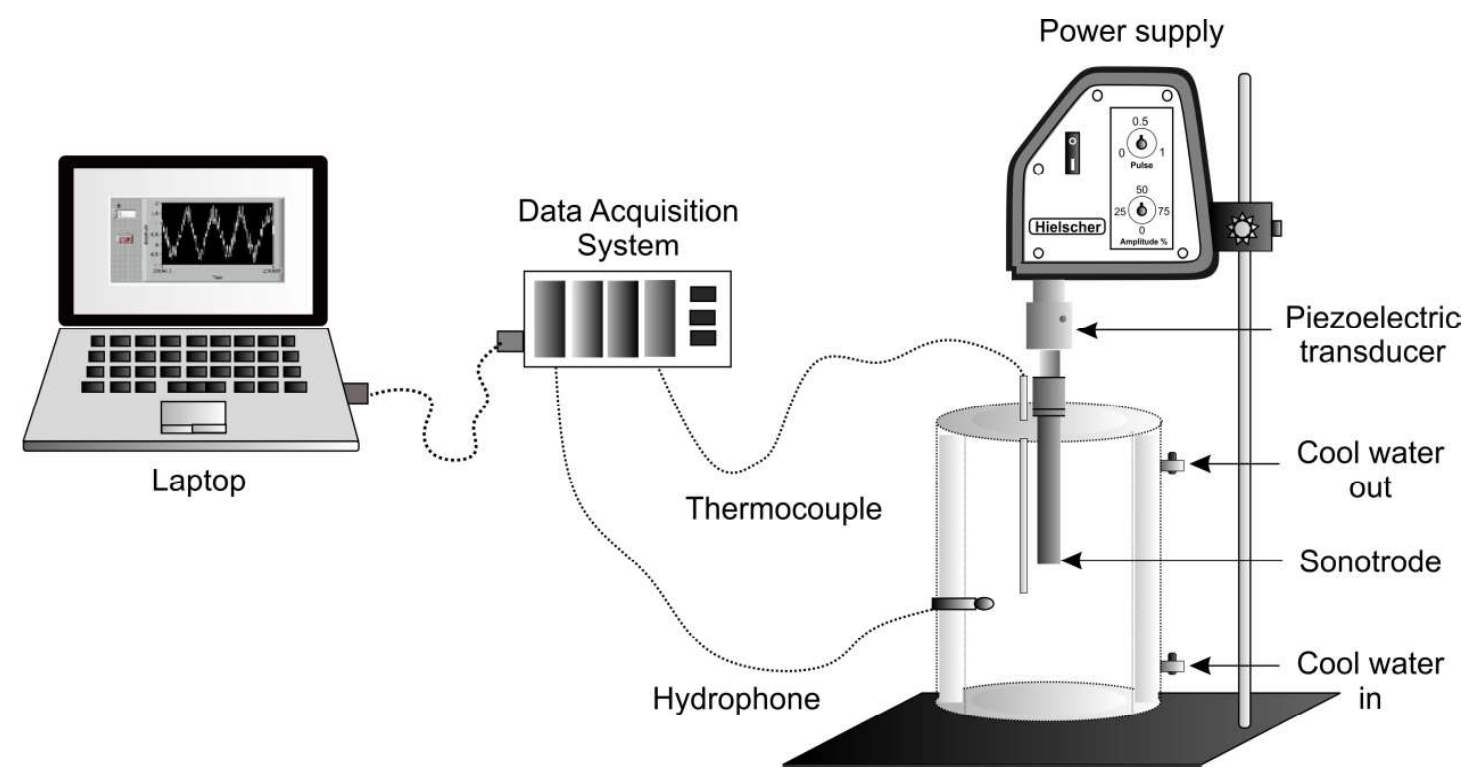

Figure 5.5.1. System used in the ultrasonic experiments for acoustic fields measurements.

Acoustic field determinations were carried out in a stainless steel chamber (with approximately $2.5 \mathrm{~kg}$ of liquid), starting at a temperature of $26 \pm 0.1{ }^{\circ} \mathrm{C}$. The calorimetric method was used in this research due to the sensitivity of the thermocouple to record the temperature in biomass solutions with minimal interference in the measurements (Moholkar et al., 2000; Raso et al., 1999). A type J thermocouple was connected to a data acquisition system (LabView 2010, National 
Instruments, USA) and placed at $2 \mathrm{~cm}$ from the sonotrode, where the maximum intensity was verified by a model TC4014 hydrophone (Teledyne Reson A/S, Slangerup, Denmark). The system, exemplified in Figure 5.5.1, recorded the temperature changes over the $225 \mathrm{~s}$ of ultrasound application.

Once the temperature gradient data were obtained, the real power absorbed by ASPPS and the acoustic intensity transferred by the sonotrode were calculated using Equations (5.5.2) and (5.5.3), respectively.

$$
\begin{aligned}
& P=m c_{p} \frac{d T}{d t} \\
& I=\frac{P}{A}
\end{aligned}
$$

In Equations (5.5.2) and (5.5.3), $P$ is the real power absorbed at a determined position of the sonotrode $(\mathrm{W}), c_{p}$ is the specific heat of ASPPS $\left(\mathrm{J} \cdot \mathrm{kg}^{-1} \cdot \mathrm{K}^{-1}\right), m$ is the mass of liquid measured for each experiment $(\mathrm{kg}), d T / d t$ is the temperature gradient along time registered by the data acquisition system $\left(\mathrm{K} \cdot \mathrm{s}^{-1}\right), I$ is the acoustic intensity $\left(\mathrm{W} \cdot \mathrm{cm}^{-2}\right)$ and $A$ is the sonotrode tip area $\left(\mathrm{cm}^{2}\right)$ (Raso et al., 1999).

\subsubsection{Statistical analysis}

Mathematical modeling was carried out using linear and non-linear models as a function of the significant variables through the software OriginPro 8.0 (OriginLab Corporation, Northampton, USA). Statistical analyses involving analysis of variance were done using the software STATISTICA 10.0 (StatSoft Enterprise, Tulsa, USA). The influence of each variable on the response, as well as the interactions between them, was evaluated with a 95\% confidence interval. Estimated effects were useful to predict an equation involving the significant terms that influenced the acoustical properties. Also, the adjusted determination coefficient $\left(R_{a d j}^{2}\right)$ and the mean relative error (MRE) were used to evaluate the goodness of fit and accuracy of the estimation, respectively. 


\subsubsection{Results and Discussion}

\subsubsection{Specific heat and mathematical modeling}

The specific heat of the suspensions was determined as a function of solids concentration $(0-12 \%)$, temperature $(274.13-333.13 \mathrm{~K})$ and $\mathrm{pH}(3-7)$, showing values in the range of 3537.0 to $4190.6 \mathrm{~J} \cdot \mathrm{kg}^{-1} \cdot \mathrm{K}^{-1}$ (Table 5.5.1). These results were similar to those reported for acidified aqueous solutions with added flower stalk biomass (Villa-Vélez et al., 2015a), where a direct relationship of $c_{p}$ with biomass concentration and temperature was observed. In fact, the $c_{p}$ of ASPPS showed a linear dependence on $\mathrm{pH}$ and temperature, while a quadratic dependence on solids concentration ( $p_{\text {value }}<0.05$ ) was observed. A linear effect of $\mathrm{pH}$ was verified for $c_{p}$, because it showed approximately constant values at the same temperature and solids content. To reinforce this idea, a Tukey test was applied among samples at different $\mathrm{pH}$ and practically none showed significant differences at the $95 \%$ level of confidence, as observed in Table 5.5.1.

Table 5.5.2 presented the fitting values of three selected models and their statistical parameters. In this modeling, $c_{p}$ was correlated with temperature and biomass concentration. The $\mathrm{pH}$ term was excluded due to no statistical significance $(p<0.05)$ was observed. Higher values of $c_{p}$ were found for less concentrated suspensions since dry biomass has a lower specific heat than water (Collazo et al., 2012). Specific heat as a function of multiple variables may be incorporated into the energy balance equation in order to predict the temperature profiles with great accuracy (Koufopanos et al., 1991). Similar equations were obtained for lignocellulosic waste materials, such as banana flower-stalk (Villa-Vélez et al., 2015a) or woods (Koufopanos et al., 1991).

In general terms, the three models showed good and simple descriptions of the experimental data as functions of all parameters studied $\left(R_{a d j}^{2}>0.967\right)$. Although all the parameters of the tested models were statistically significant, it is recommended the simplest equation that is in accordance with the analysis of variance. In this way, Equation (5.5.8) was selected among the three models to proceed with the acoustic field calculation. The agreement between the experimental and calculated values for the $c_{p}$ can be seen in Figure 5.5.2. 
Table 5.5.1. Specific heat values at different solids concentrations, temperature and $\mathrm{pH}$.

\begin{tabular}{|c|c|c|c|c|c|c|}
\hline \multirow{2}{*}{$\begin{array}{c}\text { Biomass } \\
\text { concentration } \\
(\%)\end{array}$} & \multirow[b]{2}{*}{$\mathrm{T}(\mathrm{K})$} & \multicolumn{5}{|c|}{$c_{p}\left(\mathrm{~J} \cdot \mathrm{kg}^{-1} \cdot \mathrm{K}^{-1}\right)$} \\
\hline & & $\mathrm{pH}=3$ & $\mathrm{pH}=4$ & $\mathrm{pH}=5$ & $\mathrm{pH}=6$ & $\mathrm{pH}=7$ \\
\hline \multirow[t]{7}{*}{ ( } & 274.13 & $4164.5 \pm 2.4^{a}$ & $4174.7 \pm 2.4^{a}$ & $4176.1 \pm 2.7^{a}$ & $4175.2 \pm 12.0^{a}$ & $4176.4 \pm 2.1^{a}$ \\
\hline & 283.13 & $4164.4 \pm 4.7^{\mathrm{a}}$ & $4174.4 \pm 1.3^{a}$ & $4174.7 \pm 2.9^{a}$ & $4174.8 \pm 12.0^{a}$ & $4174.8 \pm 8.5^{\mathrm{a}}$ \\
\hline & 293.13 & $4165.3 \pm 1.0^{a}$ & $4175.0 \pm 2.7^{a}$ & $4175.9 \pm 1.6^{a}$ & $4175.5 \pm 12.0^{a}$ & $4176.8 \pm 2.1^{a}$ \\
\hline & 303.13 & $4166.7 \pm 2.7^{\mathrm{a}}$ & $4177.5 \pm 1.4^{b}$ & $4179.1 \pm 3.4^{b}$ & $4177.8 \pm 6.7^{b}$ & $4178.5 \pm 0.6^{b}$ \\
\hline & 313.13 & $4170.7 \pm 2.9^{a}$ & $4180.4 \pm 1.4^{a}$ & $4181.3 \pm 2.1^{a}$ & $4181.4 \pm 0.6^{a}$ & $4181.5 \pm 2.1^{a}$ \\
\hline & 323.13 & $4174.2 \pm 1.0^{\mathrm{b}}$ & $4183.5 \pm 5.7^{\mathrm{a}, \mathrm{b}}$ & $4184.5 \pm 1.8^{a}$ & $4184.3 \pm 12.0^{a}$ & $4184.6 \pm 9.1^{\mathrm{a}}$ \\
\hline & 333.13 & $4179.9 \pm 3.4^{b}$ & $4188.6 \pm 10.7^{\mathrm{a}, \mathrm{b}}$ & $4190.0 \pm 2.0^{a}$ & $4190.6 \pm 4.4^{a}$ & $4189.7 \pm 9.1^{\mathrm{a}, \mathrm{b}}$ \\
\hline \multirow{7}{*}{4} & 274.13 & $3901.4 \pm 6.6^{a}$ & $3938.4 \pm 12.7^{a}$ & $3916.9 \pm 6.0^{a}$ & $3883.2 \pm 15.1^{a}$ & $3858.4 \pm 17.5^{a}$ \\
\hline & 283.13 & $3914.2 \pm 13.1^{a}$ & $3940.1 \pm 3.1^{a}$ & $3879.7 \pm 11.1^{a}$ & $3882.9 \pm 10.6^{a}$ & $3879.8 \pm 11.0^{a}$ \\
\hline & 293.13 & $3929.1 \pm 3.1^{a}$ & $3924.5 \pm 8.7^{\mathrm{a}}$ & $3923.8 \pm 5.3^{a}$ & $3880.5 \pm 11.1^{a}$ & $3858.8 \pm 23.4^{a}$ \\
\hline & 303.13 & $3898.6 \pm 7.3^{a}$ & $3877.6 \pm 12.7^{\mathrm{a}}$ & $3926.0 \pm 5.1^{a}$ & $3925.6 \pm 5.2^{a}$ & $3887.4 \pm 12.5^{a}$ \\
\hline & 313.13 & $3931.8 \pm 3.4^{a}$ & $3915.6 \pm 8.1^{a}$ & $3915.1 \pm 7.3^{a}$ & $3890.1 \pm 14.2^{a}$ & $3881.4 \pm 20.7^{a}$ \\
\hline & 323.13 & $3951.8 \pm 8.5^{a}$ & $3914.7 \pm 7.3^{a}$ & $3920.6 \pm 7.1^{a}$ & $3888.7 \pm 11.3^{a}$ & $3915.7 \pm 8.0^{a}$ \\
\hline & 333.13 & $3937.9 \pm 7.4^{\mathrm{a}}$ & $3919.5 \pm 7.8^{a}$ & $3957.4 \pm 6.4^{a}$ & $3925.2 \pm 7.1^{\mathrm{a}}$ & $3920.5 \pm 8.2^{a}$ \\
\hline \multirow{7}{*}{6} & 274 & $3885.5 \pm 11.0^{a}$ & $3834.4 \pm 6.6^{\mathrm{a}}$ & $3885.5 \pm 1.2^{a}$ & $3835.4 \pm 5.8^{a}$ & $3849.8 \pm 6.4^{a}$ \\
\hline & 283.13 & $3871.2 \pm 1.2^{a}$ & $3885.4 \pm 11.9^{a}$ & $3888.4 \pm 2.0^{a}$ & $3789.7 \pm 20.8^{a}$ & $3859.8 \pm 2.7^{\mathrm{a}}$ \\
\hline & 293.13 & $3788.0 \pm 12.1^{a}$ & $3881.8 \pm 4.1^{a}$ & $3882.8 \pm 9.0^{a}$ & $3790.4 \pm 13.4^{a}$ & $3860.5 \pm 7.4^{\mathrm{a}}$ \\
\hline & 303.13 & $3881.3 \pm 2.2^{a, b}$ & $3799.2 \pm 12.1^{b}$ & $3857.5 \pm 3.3^{a, b}$ & $3899.8 \pm 12.2^{a, b}$ & $3872.0 \pm 6.9^{a, b}$ \\
\hline & 313.13 & $3890.4 \pm 3.8^{a}$ & $3900.1 \pm 4.1^{\mathrm{a}}$ & $3887.2 \pm 5.0^{a}$ & $3887.7 \pm 21.3^{a}$ & $3887.3 \pm 9.0^{a}$ \\
\hline & 323.13 & $3887.9 \pm 2.2^{a}$ & $3805.5 \pm 11.8^{a}$ & $3891.3 \pm 11.0^{a}$ & $3812.0 \pm 11.2^{a}$ & $3843.8 \pm 6.0^{a}$ \\
\hline & 333.13 & $3899.0 \pm 4.6^{a}$ & $3894.7 \pm 4.1^{\mathrm{a}}$ & $3872.5 \pm 12.2^{a}$ & $3816.7 \pm 11.3^{a}$ & $3855.4 \pm 5.4^{a}$ \\
\hline \multirow{7}{*}{8} & 274.13 & $3802.6 \pm 6.7^{a}$ & $3812.4 \pm 7.9^{a}$ & $3671.4 \pm 28.0^{a}$ & $3813.5 \pm 4.4^{a}$ & $3800.0 \pm 8.6^{a}$ \\
\hline & 283.13 & $3706.5 \pm 19.0^{a}$ & $3809.3 \pm 3.2^{\mathrm{a}}$ & $3808.9 \pm 8.7^{a}$ & $3804.7 \pm 8.3^{a}$ & $3809.0 \pm 2.7^{a}$ \\
\hline & 293.13 & $3795.7 \pm 7.8^{a}$ & $3741.3 \pm 12.5^{a}$ & $3813.8 \pm 8.2^{a}$ & $3737.5 \pm 8.4^{a}$ & $3803.3 \pm 0.7^{a}$ \\
\hline & 303.13 & $3804.7 \pm 5.8^{a}$ & $3807.1 \pm 1.4^{a}$ & $3808.1 \pm 10.6^{a}$ & $3807.1 \pm 2.6^{a}$ & $3739.2 \pm 8.3^{a}$ \\
\hline & 313.13 & $3793.9 \pm 17.9^{a}$ & $3809.8 \pm 7.6^{a}$ & $3804.3 \pm 1.7^{\mathrm{a}}$ & $3812.0 \pm 1.3^{a}$ & $3804.6 \pm 0.3^{a}$ \\
\hline & 323.13 & $3808.4 \pm 4.7^{a}$ & $3822.2 \pm 6.5^{a}$ & $3808.2 \pm 5.1^{a}$ & $3817.7 \pm 6.5^{\mathrm{a}}$ & $3815.7 \pm 1.4^{a}$ \\
\hline & 333.13 & $3815.9 \pm 3.0^{a}$ & $3811.9 \pm 10.9^{a}$ & $3812.8 \pm 4.0^{a}$ & $3826.5 \pm 12.4^{a}$ & $3818.1 \pm 2.2^{a}$ \\
\hline \multirow{7}{*}{10} & 274.13 & $3657.0 \pm 6.1^{\mathrm{a}}$ & $3692.2 \pm 11.9^{a}$ & $3672.2 \pm 5.6^{a}$ & $3640.6 \pm 14.2^{a}$ & $3617.4 \pm 16.4^{a}$ \\
\hline & 283.13 & $3669.0 \pm 12.2^{a}$ & $3693.8 \pm 2.9^{a}$ & $3637.3 \pm 10.4^{a}$ & $3640.3 \pm 10.0^{a}$ & $3637.4 \pm 10.3^{a}$ \\
\hline & 293.13 & $3682.9 \pm 2.9^{a}$ & $3679.3 \pm 8.1^{a}$ & $3678.7 \pm 5.0^{a}$ & $3638.1 \pm 10.4^{a}$ & $3617.7 \pm 21.9^{a}$ \\
\hline & 303.13 & $3654.4 \pm 6.8^{a}$ & $3635.3 \pm 11.9^{a}$ & $3680.7 \pm 4.8^{a}$ & $3680.4 \pm 4.9^{a}$ & $3644.6 \pm 11.8^{a}$ \\
\hline & 313.13 & $3685.5 \pm 3.2^{a}$ & $3670.9 \pm 7.6^{a}$ & $3670.5 \pm 6.9^{a}$ & $3647.1 \pm 13.4^{a}$ & $3638.9 \pm 19.4^{a}$ \\
\hline & 323.13 & $3704.3 \pm 8.0^{a}$ & $3670.0 \pm 6.9^{a}$ & $3675.7 \pm 6.6^{a}$ & $3645.7 \pm 10.6^{a}$ & $3671.1 \pm 7.5^{\mathrm{a}}$ \\
\hline & 333.13 & $3691.3 \pm 7.0^{a}$ & $3674.5 \pm 7.3^{a}$ & $3710.1 \pm 6.0^{a}$ & $3680.0 \pm 6.7^{a}$ & $3675.6 \pm 7.7^{\mathrm{a}}$ \\
\hline \multirow{7}{*}{12} & 274.13 & $3642.9 \pm 5.3^{a}$ & $3610.2 \pm 11.6^{a}$ & $3590.6 \pm 11.6^{a}$ & $3559.7 \pm 9.8^{a}$ & $3537.0 \pm 16.0^{a}$ \\
\hline & 283.13 & $3593.2 \pm 12.1^{a}$ & $3611.8 \pm 2.9^{a}$ & $3556.5 \pm 13.7^{\mathrm{a}}$ & $3559.4 \pm 10.3^{a}$ & $3556.6 \pm 10.1^{a}$ \\
\hline & 293.13 & $3625.3 \pm 1.8^{a}$ & $3597.5 \pm 8.0^{a}$ & $3597.0 \pm 6.2^{a}$ & $3557.3 \pm 10.0^{a}$ & $3537.3 \pm 20.8^{a}$ \\
\hline & 303.13 & $3619.3 \pm 2.5^{a}$ & $3554.5 \pm 11.6^{a}$ & $3599.0 \pm 10.8^{a}$ & $3598.6 \pm 12.0^{a}$ & $3563.6 \pm 9.5^{\mathrm{a}}$ \\
\hline & 313.13 & $3647.5 \pm 3.6^{a}$ & $3589.3 \pm 7.4^{\mathrm{a}}$ & $3589.0 \pm 12.3^{a}$ & $3566.1 \pm 9.9^{a}$ & $3558.1 \pm 14.2^{a}$ \\
\hline & 323.13 & $3639.1 \pm 6.5^{a}$ & $3588.5 \pm 6.7^{\mathrm{a}}$ & $3594.0 \pm 6.5^{\mathrm{a}}$ & $3564.7 \pm 10.2^{a}$ & $3589.5 \pm 7.5^{\mathrm{a}}$ \\
\hline & 333.13 & $3659.7 \pm 3.8^{a}$ & $3573.9 \pm 9.9^{b}$ & $3627.7 \pm 5.9^{a, b}$ & $3598.2 \pm 6.5^{a, b}$ & $3593.9 \pm 8.0^{a, b}$ \\
\hline
\end{tabular}

$\overline{a, b}$ Same letters in the same line represent no significant difference at the $95 \%$ level of confidence by a Tukey test. 
Table 5.5.2. Fitting parameters of different models for the specific heat $\left(\mathrm{J} \cdot \mathrm{kg} \cdot \mathrm{K}^{-1}\right)$.

\begin{tabular}{|c|c|c|c|c|}
\hline Equation & Model & Parameters & $R_{a d j}^{2}$ & MRE (\%) \\
\hline$(5.5 .6)$ & $c_{P}=\alpha_{1}+a_{2} X$ & $\begin{array}{l}\alpha_{1}=4149.3\left(\mathrm{~J} \cdot \mathrm{kg}^{-1} \cdot \mathrm{K}^{-1}\right) \\
\alpha_{2}=-47.42\left(\mathrm{~J} \cdot \mathrm{kg}^{-1} \cdot \mathrm{K}^{-1}\right)\end{array}$ & 0.959 & 0.85 \\
\hline$(5.5 .7)$ & $c_{P}=\alpha_{1}+a_{2} X+a_{3} T$ & $\begin{array}{l}\alpha_{1}=4125.1\left(\mathrm{~J} \cdot \mathrm{kg}^{-1} \cdot \mathrm{K}^{-1}\right) \\
\alpha_{2}=-47.42\left(\mathrm{~J} \cdot \mathrm{kg}^{-1} \cdot \mathrm{K}^{-1}\right) \\
\alpha_{3}=0.07\left(\mathrm{~J} \cdot \mathrm{kg}^{-1} \cdot \mathrm{K}^{-1}\right)\end{array}$ & 0.959 & 0.85 \\
\hline$(5.5 .8)$ & $c_{P}=\alpha_{1}+a_{2} X^{M}+a_{3} T$ & $\begin{array}{l}\alpha_{1}=4149.8\left(\mathrm{~J} \cdot \mathrm{kg}^{-1} \cdot \mathrm{K}^{-1}\right) \\
\alpha_{2}=-75.73\left(\mathrm{~J} \cdot \mathrm{kg}^{-1} \cdot \mathrm{K}^{-1}\right) \\
\alpha_{3}=0.07 \mathrm{~J} \cdot \mathrm{kg}^{-1} \cdot \mathrm{K}^{-2} \\
M=0.82\end{array}$ & 0.967 & 0.74 \\
\hline
\end{tabular}

$\alpha_{1}, \alpha_{2}, \alpha_{3}$ and $M$ are parameters of the models, $T$ is the absolute temperature $(\mathrm{K}), X$ is the biomass concentration (\%) and $c_{p}$ is the specific heat $\left(\mathrm{J} \cdot \mathrm{kg}^{-1} \cdot \mathrm{K}^{-1}\right)$.

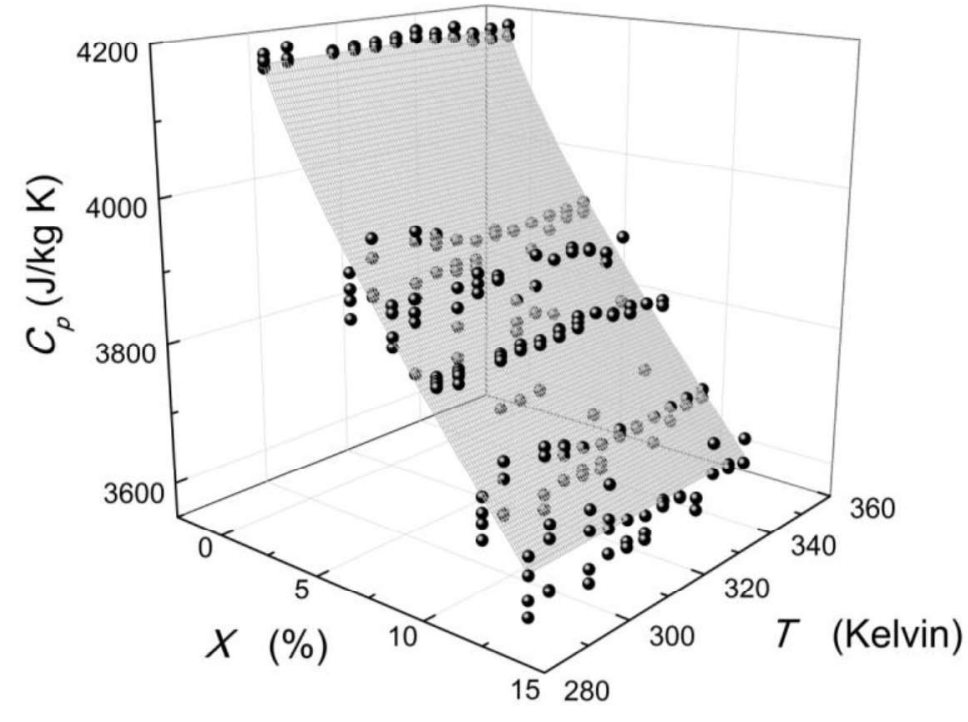

Figure 5.5.2. Representation of the specific heat values fitted to Equation (5.5.8).

\subsection{Acoustic field characterization}

The temperature gradient versus time during the first moments of the ultrasound application followed a linear tendency being $d T / d t$ the slope. This heating rate decreased as the solid concentrations increased (Figure 5.5.3). On the contrary, at a fixed biomass concentration, the temperature variation $(d T / d t)$ increased when higher input powers were applied. No effect related to different $\mathrm{pH}$ was observed, 
and could not be distinguished as observed for specific heat. Toma et al. (2011) and Cárcel et al. (2007b) also recorded a linear increase of temperature for different solvents (both at 500 and $20 \mathrm{kHz}$ of frequency) and for sucrose solutions, respectively.

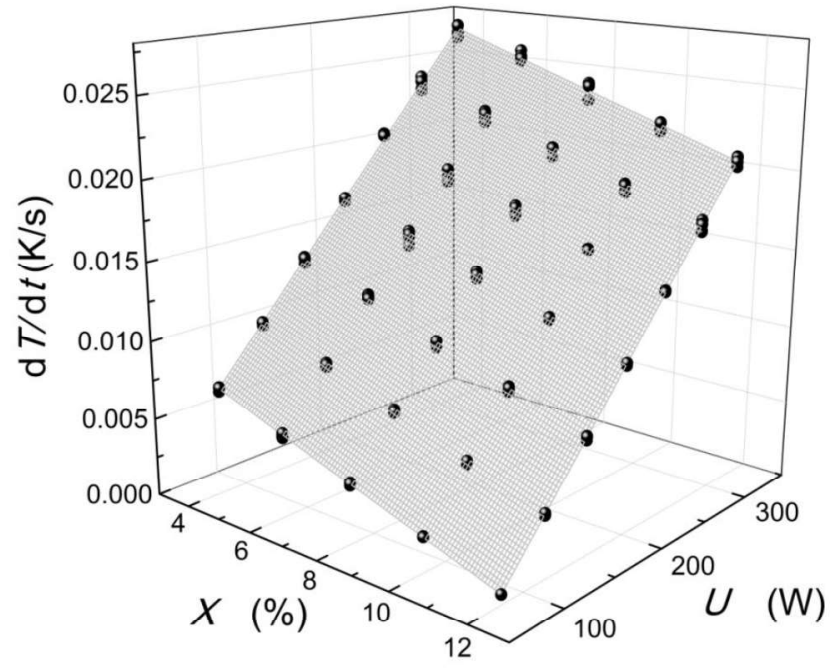

Figure 5.5.3. Temperature gradient with time as a function of the biomass concentration $(X, \%)$ and nominal power output of ultrasound $(U, W)$ for all $p H$ values.

Using $d T / d t$ values calculated by linear regressions, the real power transmitted $(P)$ and the acoustic intensity $(I)$ as a function of the nominal power applied $(U)$ from 80 to $320 \mathrm{~W}$, biomass concentration $(X)$ from 4 to $12 \%$ and $\mathrm{pH}$ from 3 to 7 were determined by Equations (5.5.2) and (5.5.3). The results are shown in Figure 5.5.4. 
(a)

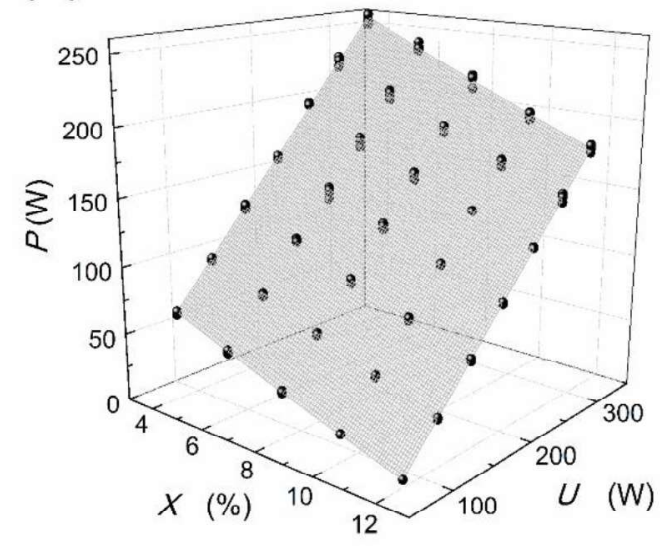

(b)

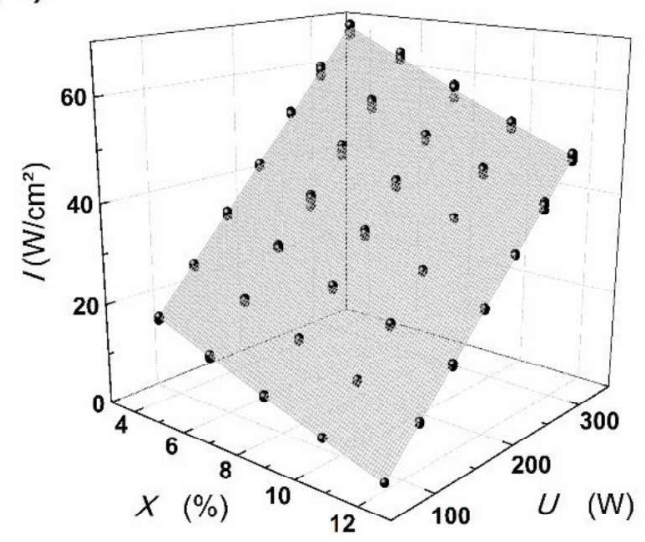

Figure 5.5.4. (a) Power transmitted $(P)$ and (b) acoustic intensity $(I)$ as a function of nominal power applied $(U)$ and biomass concentration $(X)$. Properties were determined at a distance of $2 \mathrm{~cm}$ from the sonotrode.

As shows in Figure 5.5.4a, the measured power transmitted increased when greater was the nominal power applied. The increase of biomass concentration produced a decrease in the power absorbed, in a similar trend that the specific heat behavior. The values of acoustic power observed ranged from 5.12 to $260.2 \mathrm{~W}$, while acoustic intensity was in the interval of 1.35 and $68.45 \mathrm{~W} \cdot \mathrm{cm}^{-2}$, (Figure $5.5 .4 \mathrm{~b}$ ). A non-linear equation was fitted based on the significant parameters, and acoustic power $(P)$ and acoustic intensity $(I)$ could be expressed using the coefficients shown in Table 5.5.3.

Table 5.5.3. Fitting results and statistical validation of acoustic power $(P)$ and acoustic intensity $(I)$ by ASPPS.

\begin{tabular}{ccccccccc}
\hline & \multicolumn{9}{c}{$P(\mathrm{~W})$} & & \multicolumn{4}{c}{$I\left(\mathrm{~W} \cdot \mathrm{cm}^{-2}\right)$} \\
Parameters & Coefficient & $p_{\text {value }}$ & $R_{a d j}^{2}$ & MRE (\%) & Coefficient & $p_{\text {value }}$ & $R_{a d j}^{2}$ & MRE (\%) \\
\hline Intercept & 32.96 & - & & & 8.67 & - & & \\
$U$ & 0.84 & $<0.001$ & & & 0.22 & $<0.001$ & & \\
$X$ & -8.25 & $<0.001$ & 0.999 & 2.090 & -2.17 & $<0.001$ & 0.999 & 2.090 \\
$X^{2}$ & 0.09 & $<0.001$ & & & 0.02 & $<0.001$ & & \\
$U \times X$ & -0.01 & $<0.001$ & & & -0.002 & $<0.001$ & & \\
\hline
\end{tabular}

$U$ is the nominal power applied (W), $X$ is the biomass concentration (\%) and $p_{\text {value }}$ is the probability of the factor $F(I C=95 \%)$.

Results from the analysis of variance showed that the acoustic power transmitted had a quadratic dependence on the solids concentration of suspensions 
$\left(p_{\text {value }}<0.001\right)$ and linear dependence on the nominal power applied $\left(p_{\text {value }}<0.001\right)$, with a linear interaction between them. In a previous study, the acoustic powers were linearly correlated with input power. Such correlations were specific for frequencies of $24 \mathrm{kHz}$ and the agreement between predicted and further experimental measurements can be useful for checking the correct functioning of the ultrasonic device (Contamine et al., 1995).

The linear effect of $\mathrm{pH}$ on the acoustic power applied resulted $p_{\text {value }}$ close to 0.05 , indicating a weak effect when compared to the other variables. Acoustic power at different $\mathrm{pH}$ levels had a mean deviation of $4 \%$ between values, demonstrating that the acoustic power is practically constant over the $\mathrm{pH}$ range. This fact allowed us to exclude the $\mathrm{pH}$ effect and consider only biomass concentration and input power in the modeling.

\subsubsection{Efficiency of the ultrasound power transmitted}

As known, not all nominal electric power applied is transferred as acoustic energy to the system. The determination of the power yield $(100 * P / U)$ makes it necessary to evaluate how much energy is losing in each specific process. These losses generally occur during electrical conversion into mechanical energy, where noise and thermal energy could be dissipated to the environment.

The maximum yield (82.7\%) was observed for less concentrated suspensions, which is in accord with the values obtained by Toma et al. (2011) for water. This high yield could be achieved by the fact that sonotrode systems are more efficient in the application of high intensity ultrasonic fields than the ultrasonic baths (Kimura et al., 1996; Wu et al., 2001). In addition, it must be highlighted that for the temperature measurements, the thermocouple was positioned in the maximum cavitation point ( 2 $\mathrm{cm}$ from the sonotrode).

However, in the case of suspensions with the higher content of biomass tested ( $12 \%$ of peanut shells) and under the lower nominal applied power $(80 \mathrm{~W})$, the percentage of energy lost reached to $93.6 \%$. The low yield achived could be attributed to the viscous character of biomass which offered a significant mechanical resistance to the vibration of the sonotrode and, making that, only small amounts of electrical energy were transformed into acoustic power. 


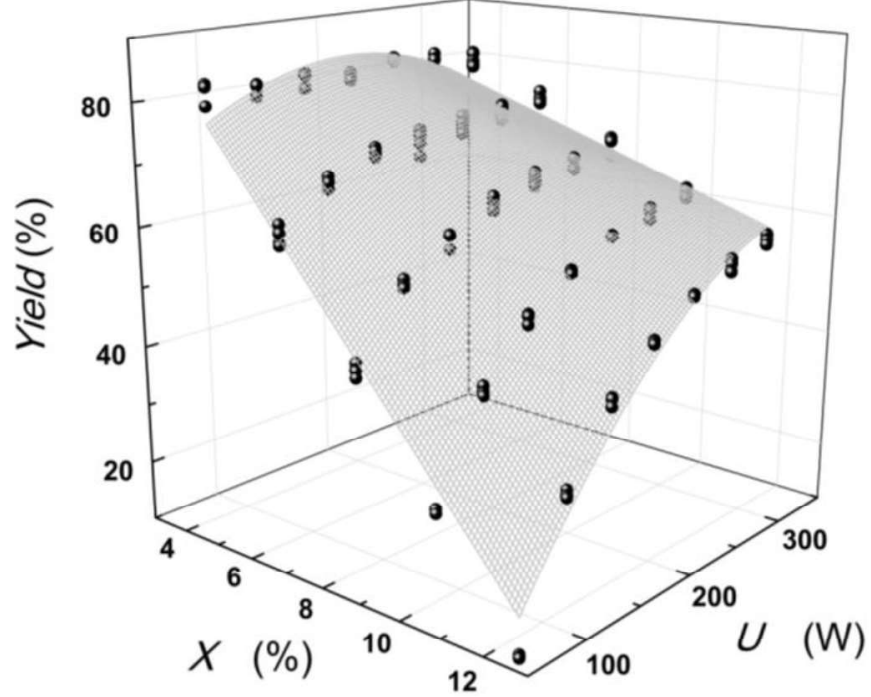

Figure 5.5.5. Power yield as a function of biomass concentration $(X)$ and nominal applied power (W).

Table 5.5.4. Statistical and fitting parameters to represent the power yield (\%).

\begin{tabular}{ccccc}
\hline & \multicolumn{5}{c}{ Power yield (\%) } \\
Parameters & Coefficient & $p_{\text {value }}$ & $R_{a d j}^{2}$ & MRE (\%) \\
\hline Intercept & 102.15 & - & & \\
$U$ & 0.12 & $<0.001$ & & \\
$U^{2}$ & $-5.40 \times 10^{-4}$ & $<0.001^{8}$ & 0.977 & 6.410 \\
$X$ & -9.86 & $<0.001$ & & \\
$U \times X$ & 0.024 & $<0.001$ & & \\
\hline
\end{tabular}

$U$ is the nominal applied power (W), $X$ is the biomass concentration (\%) and $p_{\text {value }}$ is the probability of the factor $F(I C=95 \%)$.

Power yield data were plotted as a function of nominal applied power and solids concentration, as shown in Figure 5.5.5, and fitted to a non-linear equation. The coefficients and statistical values of each significant variable found are presented in Table 5.5.4. Similarly, a non-linear relationship was found by Cárcel et al. (2007b) when comparing the electrical energy supplied with the ultrasonic intensity. The need to stablish a relation between these variables is emphasized by Sivakumar and Pandit (2001), which confirms that the electrical input of an ultrasonic generator does not supply enough information about the ultrasonic power that promotes chemical transformations. 
Although these results provide significant information regarding the acoustic fields at a local position, the procedures involved in this research can be adapted and applied to identify $P$ and $I$ for different positions from the sonotrode, mapping the acoustic power at all chamber points. Therefore, studies regarding the geometry of the acoustic system and the capacity of ultrasound processing of biomass suspensions on a large scale are essential for an efficient application.

\subsubsection{Conclusions}

This study reported data of the acoustic fields produced by ultrasound application to acidified aqueous solutions of peanut waste. In order to evaluate the acoustic properties, the specific heat was determined and modeled as a function of solids concentration and absolute temperature, while the $\mathrm{pH}$ did not present significant effects. Acoustic power and intensity data were calculated and fitted according to the significant process variablesUltrasound application was demonstrated to be more efficient at low concentration and higher input power, showing a maximum power yield value of $82.7 \%$. These conditions could maximize the hydrolysis and biomass pretreatment during sonication.

Finally, the determination of the maximum acoustic field is an important step for designing and building acoustic processor systems. Data about acoustic fields in biomass suspensions make possible the development of sonication processes involving the bioconversion of renewable sources into second-generation ethanol.

\subsubsection{Acknowledgements}

The authors acknowledge the financial support by the Sao Paulo Research Foundation - FAPESP (Grants number 2013/09344-4 and 2013/17497-5).

\subsubsection{References}

Alvira, P., Tomás-Pejó, E., Ballesteros, M., Negro, M.J., (2010). Pretreatment technologies for an efficient bioethanol production process based on enzymatic hydrolysis: A review. Bioresource Technology 101(13), 4851-4861.

Archer, D.G., (1993). Thermodynamic Properties of Synthetic Sapphire (a-Al2O3), Standard Reference Material 720 and the Effect of Temperature-Scale 
Differences on Thermodynamic Properties. Journal of Physical and Chemical Reference Data 22(6), 1441-1453.

ASTM-E1269, (2005). Standart test method for determining specific heat capacity by differentail scanning calorimetry. ASTM Internacional, West Conshohocken.

Berlan, J., Mason, T.J., (1996). Dosimetry for power ultrasound and sonochemistry, in: Mason, T.J. (Ed.), Advances in Sonochemistry. JAI Press Inc, Londres, pp. 1-73.

Cabrera, E., Muñoz, M.J., Martín, R., Caro, I., Curbelo, C., Díaz, A.B., (2014). Alkaline and alkaline peroxide pretreatments at mild temperature to enhance enzymatic hydrolysis of rice hulls and straw. Bioresource Technology 167(0), 17.

Cárcel, J.A., Benedito, J., Bon, J., Mulet, A., (2007a). High intensity ultrasound effects on meat brining. Meat Science 76(4), 611-619.

Cárcel, J.A., Benedito, J., Rosselló, C., Mulet, A., (2007b). Influence of ultrasound intensity on mass transfer in apple immersed in a sucrose solution. Journal of Food Engineering 78(2), 472-479.

Castro, A.M., Pereira-Jr, N., (2010). Production, properties and application of cellulases in the hydrolysis of agroindustrial residues. Química Nova 33(1), 181188.

Collazo, J., Pazó, J.A., Granada, E., Saavedra, Á., Eguía, P., (2012). Determination of the specific heat of biomass materials and the combustion energy of coke by DSC analysis. Energy 45, 746-752.

Contamine, R.F., Wilhelm, A.M., Berlan, J., Delmas, H., (1995). Power measurement in sonochemistry. Ultrasonics Sonochemistry 2(1), S43-S47.

Godoy, O.P., Marcos-Filho, J., Câmara, G.M.S., Fonseca, H., (1982). Tecnologia da produção, Amendoim: produção, pré-processamento e transformação agroindustrial. Secretaria da Indústria, Comércio, Ciência e Tecnologia, São Paulo.

IBGE, (2019). Levantamento Sistemático da Produção Agrícola - LSPA. Ministério do Planejamento, Orçamento e Gestão.

lida, Y., Yasui, K., Tuziuti, T., Sivakumar, M., (2005). Sonochemistry and its dosimetry. Microchemical Journal 80(2), 159-164. 
Jenderka, K.V., Koch, C., (2006). Investigation of spatial distribution of sound field parameters in ultrasound cleaning baths under the influence of cavitation. Ultrasonics 44(0), 401-406.

Kanthale, P.M., Gogate, P.R., Pandit, A.B., Wilhelm, A.M., (2003). Mapping of an ultrasonic horn: link primary and secondary effects of ultrasound. Ultrasonics Sonochemistry 10(6), 331-335.

Kimura, T., Sakamoto, T., Leveque, J.M., Sohmiya, H., Fujita, M., Ikeda, S., Ando, T., (1996). Standardization of ultrasonic power for sonochemical reaction. Ultrasonics Sonochemistry 3(3), S157-S161.

Koufopanos, C.A., Papayannakos, N., Maschio, G., Lucchesi, A., (1991). Modelling of the pyrolysis of biomass particles. Studies on kinetics, thermal and heat transfer effects. The Canadian Journal of Chemical Engineering 69(4), 907-915.

Kuijpers, M.W.A., Kemmere, M.F., Keurentjes, J.T.F., (2002). Calorimetric study of the energy efficiency for ultrasound-induced radical formation. Ultrasonics 40(18), 675-678.

Lewin, P.A., (1981). Miniature piezoelectric polymer ultrasonic hydrophone probes. Ultrasonics 19(5), 213-216.

Liu, Z.H., Qin, L., Pang, F., Jin, M.J., Li, B.Z., Kang, Y., Dale, B.E., Yuan, Y.J., (2013). Effects of biomass particle size on steam explosion pretreatment performance for improving the enzyme digestibility of corn stover. Industrial Crops and Products 44(0), 176-184.

Margulis, M.A., Margulis, I.M., (2003). Calorimetric method for measurement of acoustic power absorbed in a volume of a liquid. Ultrasonics Sonochemistry 10(6), 343-345.

McDonnell, C.K., Lyng, J.G., Arimi, J.M., Allen, P., (2014). The acceleration of pork curing by power ultrasound: A pilot-scale production. Innovative Food Science \& Emerging Technologies 26(0), 191-198.

Moe, S.T., Janga, K.K., Hertzberg, T., Hägg, M.B., Øyaas, K., Dyrset, N., (2012). Saccharification of Lignocellulosic Biomass for Biofuel and Biorefinery Applications - A Renaissance for the Concentrated Acid Hydrolysis? Energy Procedia 20(0), 50-58. 
Moholkar, V.S., Sable, S.P., Pandit, A.B., (2000). Mapping the cavitation intensity in an ultrasonic bath using the acoustic emission. AIChE Journal 46(4), 684-694.

Okajima, I., Sako, T., (2014). Energy conversion of biomass with supercritical and subcritical water using large-scale plants. Journal of Bioscience and Bioengineering 117(1), 1-9.

Pingret, D., Fabiano-Tixier, A.S., Bourvellec, C.L., Renard, C.M.G.C., Chemat, F., (2012). Lab and pilot-scale ultrasound-assisted water extraction of polyphenols from apple pomace. Journal of Food Engineering 111(1), 73-81.

Raso, J., Manas, P., Pagan, R., Sala, F.J., (1999). Influence of different factors on the output power transferred into medium by ultrasound. Ultrasonics Sonochemistry 5(4), 157-162.

Sivakumar, M., Pandit, A.B., (2001). Ultrasound enhanced degradation of Rhodamine B: optimization with power density. Ultrasonics Sonochemistry 8(3), 233-240.

Toma, M., Fukutomi, S., Asakura, Y., Koda, S., (2011). A calorimetric study of energy conversion efficiency of a sonochemical reactor at $500 \mathrm{kHz}$ for organic solvents. Ultrasonics Sonochemistry 18(1), 197-208.

Trabelsi, F., Ait-lyazidi, H., Berlan, J., Fabre, P.L., Delmas, H., Wilhelm, A.M., (1996). Electrochemical determination of the active zones in a high-frequency ultrasonic reactor. Ultrasonics Sonochemistry 3(2), S125-S130.

Villa-Vélez, H.A., Váquiro, H.A., Lopes-Filho, J.F., Telis, V.R.N., Telis-Romero, J., (2015a). Study of the specific heat capacity of biomass from banana waste for application in the second-generation ethanol industry. Environmental Progress and Sustainable Energy.

Villa-Vélez, H.A., Váquiro, H.A., Telis-Romero, J., (2015b). The effect of powerultrasound on the pretreatment of acidified aqueous solutions of banana flowerstalk: Structural, chemical and statistical analysis. Industrial Crops and Products 66(0), 52-61.

Wu, J., Lin, L., Chau, F., (2001). Ultrasound-assisted extraction of ginseng saponins from ginseng roots and cultured ginseng cells. Ultrasonics Sonochemistry 8(4), 347-352. 
Zeqiri, B., Hodnett, M., Carroll, A.J., (2006). Studies of a novel sensor for assessing the spatial distribution of cavitation activity within ultrasonic cleaning vessels. Ultrasonics 44(1), 73-82.

Zheng, Y., Pan, Z., Zhang, R., (2009). Overview of biomass pretreatment for cellulosic ethanol production. International Journal of Agricultural and Biological Engineering 2(3), 51-67. 
5.6. CHAPTER 6 Kinetics of Sugar Release From Artichoke Waste 
Submitted to Chemical Engineering and Processing: Process Intensification.

Influence of High-Intensity Ultrasound Application in the Kinetics of Sugar Release From Acid Suspensions of Artichoke (Cynara scolymus) Biomass

Tiago Carregari Polachini ${ }^{1,2}$; Antonio Mulet ${ }^{2}$; Javier Telis-Romero ${ }^{1}$ and Juan A. Cárcel ${ }^{2}$

${ }^{1}$ Food Engineering and Technology Department, São Paulo State University (Unesp), Institute of Biosciences, Humanities and Exact Sciences (Ibilce), Campus São José do Rio Preto, Cristóvão Colombo Street 2265, São José do Rio Preto, São Paulo State, 15054000, Brazil.

${ }^{2}$ Group of Analysis and Simulation of Agro-food Processes, Food Technology Department, Universitat Politècnica de Valéncia Camino de Vera, s/n, Valencia, 46071, Spain. 


\begin{abstract}
The study of the sugar release kinetics is an essential previous step for developing new technologies to be applied in the bioethanol industry. For this, kinetics of reducing and total sugar release (extraction/hydrolysis) from artichoke waste were obtained in different conditions to evaluate separately the solubility of free sugars from raw matter and the hydrolysis of larger chain molecules. Thus experimens of extraction with water (WE), hydrolysis (HY) in acid solutions and a conventional industrial hydrolysis which combines dissolution and hydrolysis effects (IHY) were carried out. All treatments were studied with (US) and without (AG) ultrasound application. In WE experiments, US application accelerated the sugar dissolution compared to AG experiments while HY experiments was the opposite. The decrease in the biomass concentration in the suspensions increased the US effects. In IHY experiments, US was also able to enhance the final yield of sugars. The rheological changes of the suspensions during treatments can explain the different magnitude of ultrasound effects. The acoustic field characterization and viscosity measured of the acid suspensions were in accordance with these results.
\end{abstract}

Keywords: hydrolysis, pretreatment, modeling, phosphoric acid, fermentable sugar. 


\subsubsection{Introduction}

The environmental concerns about the use of fossil combustibles have boosted researches to explore the use of emerging technologies for improving the conversion of alternative renewable resources into biofuels. Most of these resources are biomass from agro-industrial processes and residues from agriculture. Their utilization as raw material for bioethanol production can aggregate value to the byproduct, reduce the costs regarding waste storage and disposal and provide sustainable alternative to fossil fuels. Moreover, it can contribute to reduce the use of crops, which can be used for food production, e.g. corn, as biofuels sources.

Biomass structures are rich in cellulose and hemicellulose, polymers of pentose and hexose. Their large molecular chains can be broken down and converted by fermentation into bioethanol and other feedstock chemicals. In this sense, the residues from artichoke (Cynara scolymus) processing are an interesting raw material to be studied for bioethanol production. The artichoke production reaches approximately 900,000 tons per year regarding only the main producer countries: Italy, Egypt, Spain and Argentina (FAO, 2017). Artichoke is rich in antioxidant compounds and has many health beneficial effects (Martínez-Esplá et al., 2017). The industrial processing of the artichoke involves the separation of outer bracts, stem and tip from pieces in order to obtain the artichoke heart, which is the edible fraction. This means that, more than $50 \%$ of the raw matter which arrives to the industrial process becomes waste, leading to a biomass generation higher than 500,000 tons per year. This by-product is rich in cellulose, hemicellulose, fructosans and pectic polysaccharides that can be converted into fermentable sugars (Femenia et al., 1998).

The pretreatment of lignocellulose is one of the main challenging steps addressed to second generation ethanol production. At this stage, the carbohydrate polymers of cellulose and hemicellulose are prepared to be converted into short chain carbohydrates and, even, into monomers molecules. In addition to partial hydrolysis, pretreatments can also affect the arrangement and accessibility of cellulose fibers and, consequently, enhance further processing (Karimi and Taherzadeh, 2016; Kassaye et al., 2017; Loow et al., 2016; Villa-Vélez et al., 2015). The magnitude of each effect is dependent on some variables, e. g. treatment 
temperature, type and concentration of catalyst, reaction time or the application of alternative technologies. The different pretreatments includes conventional methods such as the acid and alkaline hydrolysis under mechanical agitation (AG), the steam explosion and oxidative treatments, and emerging technics as microwaves, ozone, irradiation by gamma rays, supercritical $\mathrm{CO}_{2}$ or ultrasound application (Taherzadeh and Karimi, 2008). In this sense, high-intensity ultrasound (US) has demonstrated to be an efficient tool for intensifying the treatment of biomass in combination to conventional processes (Borah et al., 2016; Luo et al., 2014; Luzzi et al., 2017; Yunus et al., 2010). The application of US in the presence of dilute acid is a highlighted alternative of primary pretreatment for enhancing sugar production under mild conditions regarding temperature or acid concentration (Werle et al., 2013). Moreover, it can promote the cellulose and hemicellulose retrieval in the solid fraction, reduction on further enzyme loadings during enzymatic hydrolysis, higher accessibility of solid fraction to microorganisms and others (Loow et al., 2016).

However, little information has been reported about the kinetics of ultrasoundassisted sugar release in diluted acid medium in comparison with, e. g. conventional agitation (Bensah and Mensah, 2013). The quantification of the process variable effects can provide useful information about efficiency of sugar release (Lenihan et al., 2010).

Thus, the aim of this work was to evaluate the kinetics of reducing and total sugar release from artichoke waste (AW) by conventional agitation (AG) in acid solution and evaluate the influence of the ultrasound application (US). The effect of biomass concentration on hydrolysis was also addressed.

\subsubsection{Materials and Methods}

\subsubsection{Sample preparation}

Fresh artichokes (Cynara scolymus) were bought in a local market of Valencia, Spain. The outer bracts, one of the main by-products generated during artichoke processing, were manually removed, cleaned and introduced at $60^{\circ} \mathrm{C}$ in a convective oven until reaching constant weight. The dried product was then milled and sieved to obtain a powder of artichoke by-product (AW) with particle size smaller than $1 \mathrm{~mm}$. Moreover, the moisture content of dried samples were determined by 
drying the samples in a vacuum oven at $70{ }^{\circ} \mathrm{C}$ until constant weight $(24 \mathrm{~h}$ approximately). The obtained average moisture content was $4.92 \% \pm 0.04 \%$ (w.b.). Then, the AW was packed in polypropylene bags for later use.

\subsubsection{Experimental plan}

The experimental plan included three sets of experiments, summarized in Table 5.6.1. In the first one, it was studied the extraction of soluble sugars of AW with water (WE); in the second, the hydrolysis process in acid solution (HY) after the WE process; and finally, the third set consisted on the simultaneous study of the previous both processes (WE and HY), that is the study of the direct treatment of AW in acid solution (IHY). This last was applied to simulate an industrial like process of hydrolysis of artichoke by-product. Each condition considered was tested, at least, by triplicate using $150 \mathrm{~g}$ of suspension for each experiment.

Table 5.6.1. Conditions of the total set of experiments.

\begin{tabular}{|c|c|c|c|c|c|}
\hline Set & Code & $\begin{array}{c}\text { AW } \\
\text { concetration } \\
\left(\% \mathrm{w} \cdot \mathrm{w}^{-1}\right)\end{array}$ & $\begin{array}{c}{\left[\mathrm{H}_{3} \mathrm{PO}_{4}\right]} \\
\text { concentration } \\
\left(\% \mathrm{w} \cdot \mathrm{w}^{-1}\right)\end{array}$ & $\begin{array}{l}\text { Previous agitation } \\
\text { in aqueous } \\
\text { medium (2h) }\end{array}$ & $\begin{array}{l}\text { Technology } \\
\text { applied }\end{array}$ \\
\hline \multirow{2}{*}{$\begin{array}{l}\text { Extraction } \\
\text { with water } \\
\text { (WE) }\end{array}$} & B5AG0 & 5 & 0 & No & Agitation \\
\hline & B5US0 & 5 & 0 & No & Ultrasound \\
\hline $\begin{array}{l}\text { Hydrolysis } \\
(\mathrm{HY})\end{array}$ & $\begin{array}{c}\text { B5AG10-A } \\
\text { B5US10-A } \\
\text { B2.5AG10-A } \\
\text { B2.5US10-A }\end{array}$ & $\begin{array}{c}5 \\
5 \\
2.5 \\
2.5 \\
\end{array}$ & $\begin{array}{l}10 \\
10 \\
10 \\
10 \\
\end{array}$ & $\begin{array}{l}\text { Yes } \\
\text { Yes } \\
\text { Yes } \\
\text { Yes } \\
\end{array}$ & $\begin{array}{l}\text { Agitation } \\
\text { Ultrasound } \\
\text { Agitation } \\
\text { Ultrasound }\end{array}$ \\
\hline \multirow{2}{*}{$\begin{array}{c}\text { Industrial } \\
\text { hydrolysis } \\
\text { (IHY) }\end{array}$} & B5AG10 & 5 & 10 & No & Agitation \\
\hline & B5US10 & 5 & 10 & No & Ultrasound \\
\hline
\end{tabular}

The conventional conditions for hydrolysis include the application of high temperatures and strong and corrosive acids. However, because the goal of this study was to enhance the process with the application of ultrasound at mild conditions, it was employed an acid concentration of $10 \% \mathrm{w} \cdot \mathrm{w}^{-1}$ of metaphosphoric acid (GPR Rectapur; VWR Chemicals, Lutterworth, UK) and a temperature of $50^{\circ} \mathrm{C}$, similarly as applied for other authors (Ramón et al., 2015; Werle et al., 2013). To control this temperature, all the experiments were carried out in a jacketed vessel circulating a tempered liquid through the jacket from a thermostatic bath (Frigedor, 
J.P. Selecta, Barcelona, Spain). Next, the experimental conditions of each set of experiments are described in detail.

\subsection{Extraction of soluble sugars with water (WE)}

Initially, aqueous suspensions (distilled water) containing $5 \%\left(w \cdot w^{-1}\right)$ of AW were maintained at $50{ }^{\circ} \mathrm{C}$ in order to determine the total amount of free sugars that can be directly extracted by solubilization with water. These experiments were carried out with agitation of the suspension (B5AG0) or with ultrasound application (B5US0).

\subsection{Hydrolysis in acid suspensions (HY)}

This set of experiments consists on a previous phase where the soluble sugar were extracted in a similar way than WE experiments $\left(2.5\right.$ or $5 \% \mathrm{w} \cdot \mathrm{w}^{-1}$ aqueous suspensions continuously agitated at $50{ }^{\circ} \mathrm{C}$ ) for $120 \mathrm{~min}$ (time to reach the equilibrium). After that, a hydrolysis in acid medium was carried out by adding phosphoric acid at the suspension until reach a concentration of $10 \%\left(w \cdot w^{-1}\right)$. The conditions were maintained for $60 \mathrm{~min}$ at $50{ }^{\circ} \mathrm{C}$ under conventional agitation (B2.5AG10-A, B5AG10-A) or with ultrasound application (B2.5US10-A, B5US10-A). The goal of this set of experiments was to differentiate the effects of solubilization of free sugars from the actual hydrolysis in acid medium.

\subsection{Simulation of an industrial hydrolysis (IHY) process.}

Finally, to assess a more realistic approach to an industrial process, a set of experiments were carried out including in one simultaneuos step the sugar solubilization and actual hydrolysis. Experiments B5AG10 and B5US10 consisted on submitting directly $A W$ to the treatment in a $\left(5 \% \mathrm{w} \cdot \mathrm{w}^{-1}\right)$ suspension of phosphoric acid $\mathrm{p}\left(10 \% \mathrm{w} \cdot \mathrm{w}^{-1}\right)$ at $50{ }^{\circ} \mathrm{C}$ for $60 \mathrm{~min}$ under conventional agitation or ultrasound application, respectively (Table 5.6.1).

\subsubsection{High-intensity ultrasound (US) system}

The experimental set-up used to carry out ultrasound application experiments is showed in Figure 5.6.1. An ultrasonic probe type system (UP400S, Dr. Hielscher 
$\mathrm{GmbH}$, Teltow, Germany) provided with a probe of $2.2 \mathrm{~cm}$ diameter of the emitter surface was used to generate a high intensity ultrasonic field. The ultrasonic probe was immersed $1 \mathrm{~cm}$ into the different suspensions and the maximum electrical nominal power $(400 \mathrm{~W})$ was applied in pulses $(0.6 \mathrm{~s}$ on followed by $0.4 \mathrm{~s}$ off) thus avoiding the system overheating.

As stated before, during the experiments, the suspensions temperature was maintained constant at $50 \pm 2{ }^{\circ} \mathrm{C}$. For this, a thermocouple $\mathrm{K}$ type immersed in the suspension was connected to a process controller (E5CK, Omron, Hoofddorp, Netherlands). This controller drove a peristaltic pump (302 S, Watson-Marlow, Postfach, Germany) to recirculate a glycol solution ( $30 \%$ glycol) at $-10{ }^{\circ} \mathrm{C}$, from a refrigerated bath (Frigedor, J.P. Selecta, Barcelona, Spain), through the jacketed vessel.

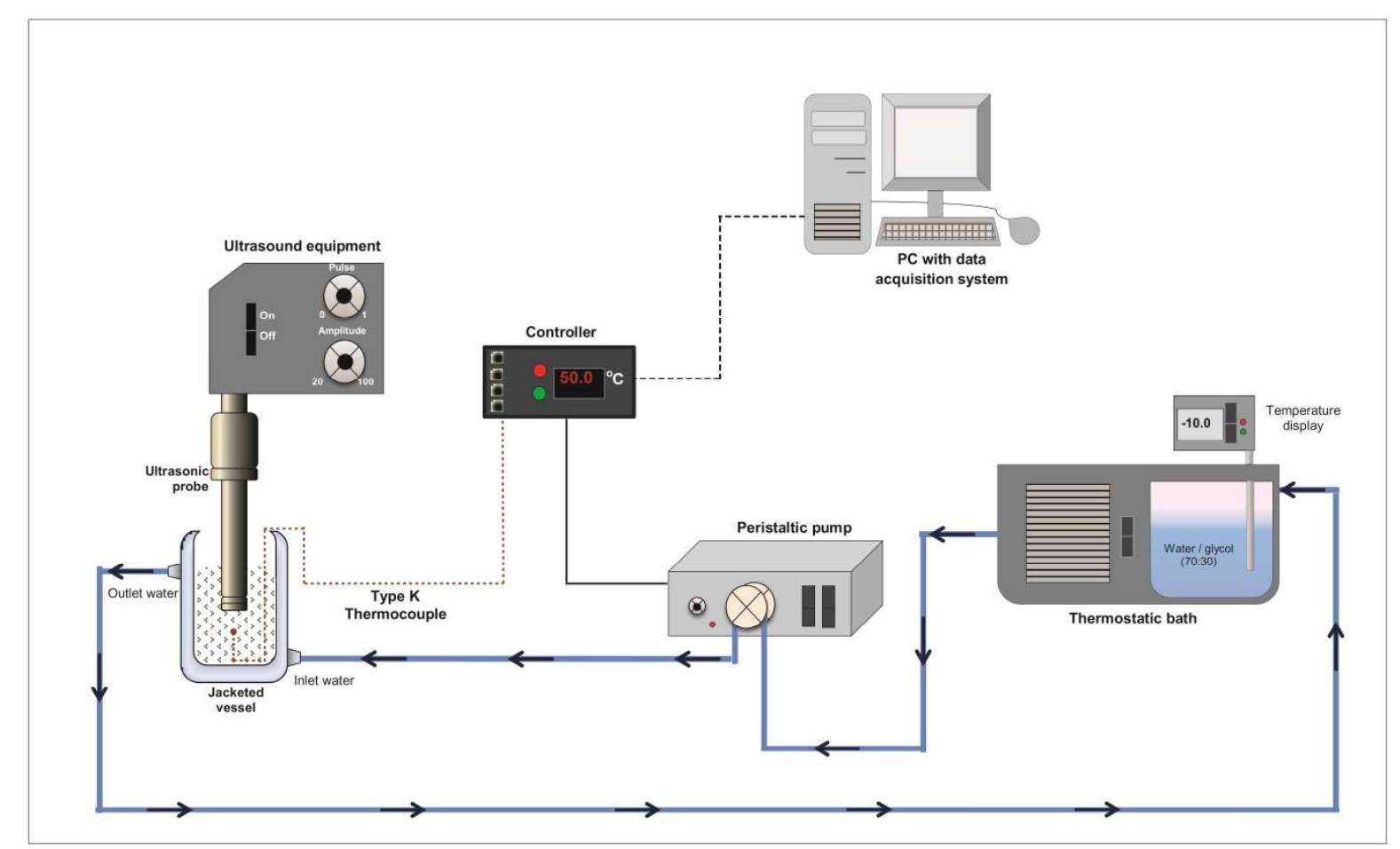

Figure 5.6.1. Scheme of the set-up used in ultrasound-assisted experiments.

\subsubsection{Conventional agitation (AG) system}

Experiments under conventional agitation (AG) were carried out in a similar set-up showed in Figure 5.6.1 but changing the ultrasonic probe by an agitator (Heidolph RZR1; Heidolph Instruments GMBH \& Co., Schwabach, Germany). A 
detail of the agitator and different shape factors $\left(F_{1}, F_{2}, F_{3}, F_{4}\right.$ and $\left.F_{5}\right)$ calculated to characterize the agitation are shown in Figure 5.6.2. The agitator consisted on a rectangular impeller, inclined in $45^{\circ}$. Suspensions were stirred at $1000 \mathrm{rpm}$.

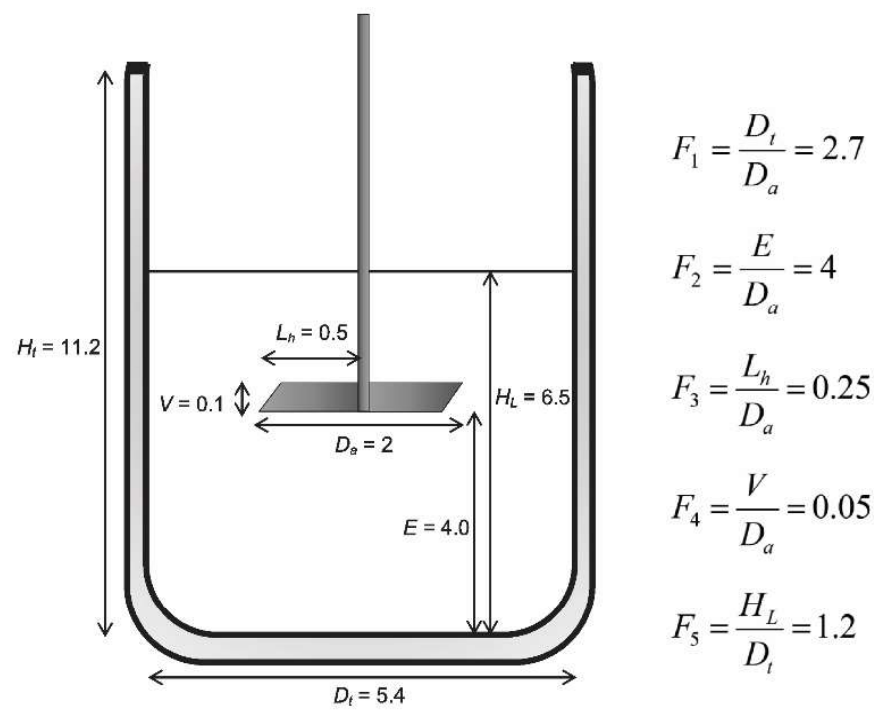

Figure 5.6.2. Geometrical characteristics (distances showed in $\mathrm{cm}$ ) of the agitation system with the corresponding shape factors.

\subsubsection{Sugar determination}

Aliquots of approximately $3 \mathrm{~mL}$ were taken from the suspensions at preset times. In the case of acid suspensions, the aliquots were immediately neutralized with $\mathrm{NaOH} 2.5 \mathrm{M}$. After that, all samples were centrifuged at $8000 \mathrm{rpm}$ during $10 \mathrm{~min}$ at $5{ }^{\circ} \mathrm{C}$ and filtered with PTFE micro filters $(0.45 \mu \mathrm{m}, 25 \mathrm{~mm}$ diameter; LabBox, Barcelona, Spain) to proceed to sugar determinations.

Determination of reducing sugars $\left(S_{R}\right)$ was made using DNS method, similarly as used by Kassaye et al. (2017). This is a fast and practical method for determining reducing sugars, which is based on the reduction, in alkaline medium, of the acid 3,5dinitrosalicylic in the presence of reducing sugars. The acid 3-amino-5-nitrosalicylic is produced from this reaction in the same stoichiometric proportion, presenting stability and orange-red color. For this, $200 \mu \mathrm{L}$ of neutralized and properly diluted aliquots were mixed to $200 \mu \mathrm{L}$ of DNS solution to be, then, boiled for 5 minutes. After cooled, $1.6 \mathrm{~mL}$ of distilled water was added to the orange-red solution. The absorbance was measured at $540 \mathrm{~nm}$ wavelength using a spectrophotometer (Helios Gamma, 
Thermo Spectronic, Cambridge, UK). Analyses were done in triplicate. Results were expressed as $\mathrm{kg}$ of reducing sugar (glucose equivalent) per $100 \mathrm{~kg}$ of dried matter using a previously determined standard curve of anhydrous glucose.

To measure the total amount of hydrolysable sugars $\left(S_{T}\right)$ present in the samples, the aliquots were submitted to a previous hydrolysis as done by Ramón et al. (2015). Neutralized aliquots were hydrolyzed using $\mathrm{HCl} 2 \mathrm{M}$ under boiling for 30 min to be cooled and neutralized with $\mathrm{NaOH} 2.5 \mathrm{M}$. Then, hydrolyzed samples proceeded to the DNS method and the amount of total fermentable sugar was also expressed as $\mathrm{kg}$ of glucose equivalent per $100 \mathrm{~kg}$ of AW dried matter ( $\mathrm{kg}$ gl-eq·100 $\mathrm{kg} \mathrm{AW}^{-1}$ d.b.).

\subsubsection{Mathematical modeling}

The kinetics of sugar release during the treatments was described mathematically by an adaptation of Naik model (1989), given by Eq. (5.6.1), considering in this case the relative sugar release $(Y)$ :

$$
Y=\frac{Y_{\infty} t}{(B+t)}
$$

Being $Y$ calculated by Eq. (5.6.2):

$$
Y=\frac{\left([S]-[S]_{t=0}\right)}{[S]_{l=0}}
$$

Where $[S]$ is the sugar production at time $t\left(\mathrm{~kg} \mathrm{gl-eq} \cdot 100 \mathrm{~kg} \mathrm{AW}^{-1} \mathrm{~d} . \mathrm{b}.\right) ;[S]_{t=0}$ the initial sugar content (kg gl-eq.100 kg AW-1 d.b.); $t$ is the treatment time (min), $Y_{\infty}$ is the relative difference of sugar production at equilibrium and $B(\mathrm{~min})$ is the time needed to reach half of $Y_{\infty}$.

In order to determine the goodness of the fitting of the experimental data, it was used the adjusted determination coefficient $\left(R_{a d j}^{2}\right)$ and the root-mean-square error (RMSE) given by the Eq. (5.6.3) and Eq. (5.6.4), respectively: 
$R_{a d j}^{2}=1-\frac{n-1}{n-(k+1)}\left(1-R^{2}\right)$

$R M S E=\sqrt{\frac{\sum_{n=1}^{n}\left(y_{p}-y_{\exp }\right)^{2}}{n}}$

where $n$ is the number of observations, $k$ is the number of parameters in the model (excluding the constant), $R^{2}$ is the determination coefficient, $y_{p}$ is the predicted value and $y_{\exp }$ is the experimental value.

\subsubsection{Viscosity evolution over the acid hydrolysis}

The viscosity of acid suspensions was measured before and after the treatment, under agitation or under sonication, to quantify possible changes induced by the process. For this, it was used a rotational rheometer AR-G2 (TA Instruments, USA) coupled with the Starch Pasting Cell geometry (gap $5500 \mu \mathrm{m}$ ) in order to avoid particles sedimentation. Approximately $28 \mathrm{~mL}$ of each sample was inserted in the equipment to perform measurements in triplicate of the shear stresses for the range of shear rate from 1 up to $265 \mathrm{~s}^{-1}$. A thermostatic bath included in the equipment maintained constant the temperature at $50{ }^{\circ} \mathrm{C}$, simulating the same conditions employed during the acid hydrolysis. Results were exported by the data acquisition system Universal Analysis 2000 version 4.7 (TA Instruments, USA).

\subsubsection{Acoustic field characterization}

Acoustic power was determined to characterize the ultrasound application on the acid hydrolysis of AW. The experimental measurements were performed in the same experimental set-up used for hydrolysis experiments with a calorimetric method. Specifically, the temperature of the suspension containing biomass (5 or $\left.2.5 \% \mathrm{w} \cdot \mathrm{w}^{-1}\right)$, phosphoric acid $\left(10 \% \mathrm{w} \cdot \mathrm{w}^{-1}\right)$ and water was measured every second for the first $60 \mathrm{~s}$ of ultrasound application. These measurements were carried out with the help of a type $\mathrm{K}$ thermocouple placed at $2 \mathrm{~cm}$ of from the tip of the ultrasonic probe and connected to a PC through a process controller (E5CK, Omron Spain, Spain). There, a software (LabVIEW Run-Time Engine 7.0, National Instruments, 
USA) allowed the recording of the temperature every second. Acoustic power applied was determined using Eq. (5.6.5) (Raso et al., 1999):

$$
P=m c_{p} \frac{d T}{d t}
$$

where $P$ is the acoustic power (W), $m$ is the acid solution mixture mass $(\mathrm{kg}), c_{p}$ is the specific heat capacity of the acid solution $\left(4064.8 \mathrm{~J} \cdot \mathrm{kg}^{-1} \cdot{ }^{\circ} \mathrm{C}^{-1}\right.$, determined by differential scanning calorimetry) and $\mathrm{d} T / \mathrm{d} t$ is the heating rate $\left({ }^{\circ} \mathrm{C} \cdot \mathrm{s}^{-1}\right)$. The rise in temperature was recorded in triplicate for each condition tested, before and after hydrolysis experiments. Thus, the influence on ultrasonic power applied of changes produced in the acid solution mixture during treatment could be studied.

Acoustic density $\left(D ; \mathrm{kW} \cdot \mathrm{kg}^{-1}\right.$ of $\left.\mathrm{AW}\right)$ was given by the relation between the acoustic power and the particles loading in the treated volume.

\subsubsection{Results and discussions}

\subsubsection{Extraction of soluble sugars with water}

Total and reducing sugar extraction kinetics with water in a conventional agitation system (B5AG0 experiments) from artichoke waste (AW) were performed over 2 hours. This time was enough to reach at the equilibrium and to obtain the total amount of sugar that can be dissolved. As can be observed in Figure 5.6.3, after 60 min of extraction, both curves reached an asymptotic value of $5.78(\mathrm{~kg} \mathrm{gl}-\mathrm{eq} \cdot 100 \mathrm{~kg}$ $A W^{-1}$ d.b.) for reducing sugar and 8.29 (kg gl-eq.100 kg AW-1 d.b.) for total sugar. 


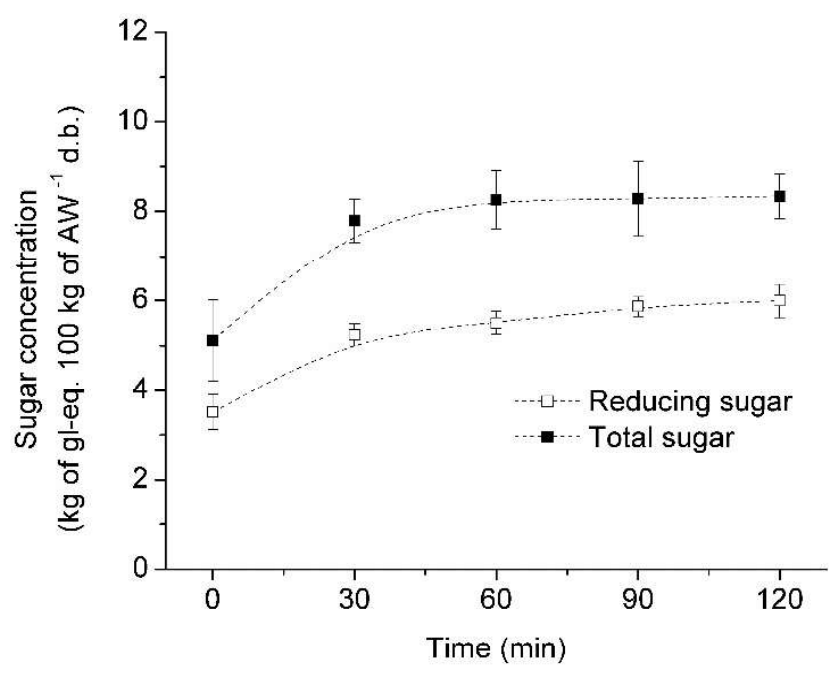

Figure 5.6.3. Extraction kinetics with water of reducing and total sugar release from AW. Experiments carried out with conventional agitation (B5AG0).

Due to this, experiments carried out with ultrasound application (B5US0) were only carried out for $60 \mathrm{~min}$. In fact, these experiments showed a faster and greater dissolution of soluble sugar when compared to experiments carried out only with agitation (B5AG0) as can be observed in Figure 5.6.4. Although the differences were not significant between both kinds of experiments, probably due to the high natural variability, US application seemed not only to increase the extraction kinetics but also the relative sugar release. In these treatment conditions (non-acid aqueous suspensions at moderate temperature), no hydrolysis occurred. Therefore, the mechanical effects of US application can be related to the improvement of the mass transfer, leading to a faster dissolution (Chemat et al., 2017). US could facilitate the sugar dissolution by enhancing the contact between the liquid and the solid by the solvent penetration into areas where conventional agitation is not efficient (Zhu et al., 2017). Some authors stated that aqueous treatment with US has more effects on physical structure, such as biomass accessibility and cellulose crystallinity, than on the chemical reaction (Yunus et al., 2010). Thus, the B5US0 experiments attained faster the equilibrium of dissolution than B5AG0 experiments, being US more efficient for extracting soluble sugars already existent in biomass. 

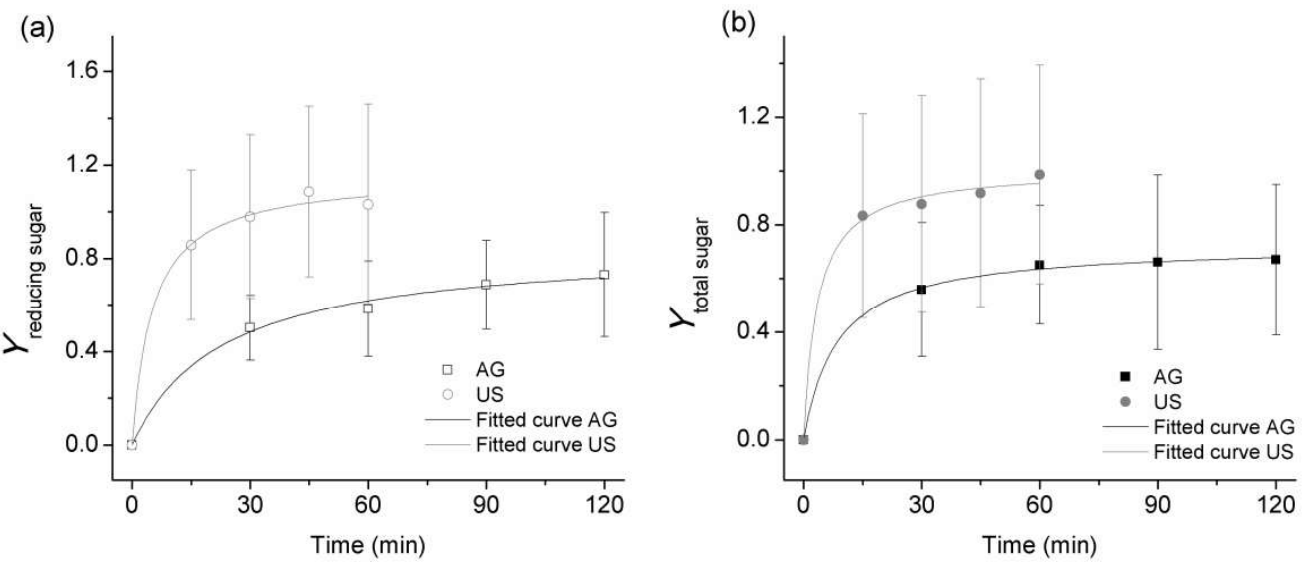

Figure 5.6.4. Kinetics of (a) reducing sugar and (b) total sugar release fitted to Naik model for the experiments B5AG0 and B5US0.

\subsubsection{Hydrolysis in acid suspensions}

Taking into account the results showed in the previous section and in order to differentiate the hydrolysis treatment from the sugar dissolution process, hydrolysis experiments of AW previously treated in water were carried out. For this, after treating $\mathrm{AW}$ in agitated aqueous suspensions for $120 \mathrm{~min}$ to assure a total dissolution of soluble sugars, it was added phosphoric acid to reach $10 \%\left(w \cdot w^{-1}\right)$ of acid in the dispersant. These final suspensions were submitted to hydrolysis under mechanical agitation or US irradiation.

\subsection{Hydrolysis kinetics}

Figure 5.6.5 shows the kinetics of both reducing and total sugar relative release from $\mathrm{HY}$ experiments of $5 \%\left(w \cdot w^{-1}\right)$ AW suspensions carried out with (B5US10-A) and without (B5AG10-A) ultrasound application. As can be observed, no significant differences $(p<0.05)$ in the relative release of total sugars obtained with ultrasound application and with suspension agitation were found. On the contrary, the release of reducing sugar was greater for conventionally agitated experiments when compared to US-assisted ones. These results can be attributed to the changes in the viscosity of the suspensions produced by the previous soluble sugar extraction with water. Thus, after this stage, suspensions showed a paste-like appearance, probably as a consequence of particles swelling. This fact could increase their volume and decrease the amount of free dispersant. In these conditions, the conventional 
mechanical agitation seemed to be more efficient to enhance the rate of hydrolysis. According to Loow et al. (2016), mechanical agitation generally promotes adequate heating and contact acid-biomass to recover fermentable sugars. On the contrary, a viscous behavior of the suspensions can prevent the effects of ultrasound to be significant. Thus, viscous forces between particles can make difficult the transmission of mechanical vibration and high cohesive forces between molecules can make that the energy necessary to overcome is greater that the provided. In this case, it is very difficult that cavitation takes place and the micro-agitation phenomena could be quite limited. As a consequence, the ultrasound effects on acid hydrolysis at the intensity applied was limited.

Despite the differences on the hydrolysis rate, both conventional agitation and ultrasound application contributed for hydrolyzing the fermentable matter over the treatment time. These results indicate the possibility of using dilute acid solutions to produce a continuous sugar amount without sugar decomposition. Lenihan et al. (2010) also found similar results as the hydrolysis was carried out in mild concentrations of acid. Moreover, it must be highlighted that the curves of sugar productions at these conditions did not attained an asymptotic behavior at the time tested. Thus, at the end of $60 \mathrm{~min}$, it was observed a total sugar production of 12.16 $\mathrm{kg}$ per $100 \mathrm{~kg}$ of dried AW while the reducing sugar content reached $11.29 \mathrm{~kg}$ per $100 \mathrm{~kg}$ of dried AW. Karimi et al. (2006) encourage the employment of two-stages hydrolysis or enzymatic hydrolysis if the main objective is to obtain greater amounts of total sugars. When analyzing the hydrolysis of rice straw, the same authors noticed that the first stage has higher effect on xylan depolymerization while significant amounts of glucose was observed after the second stage as a consequence of cellulose digestion. 

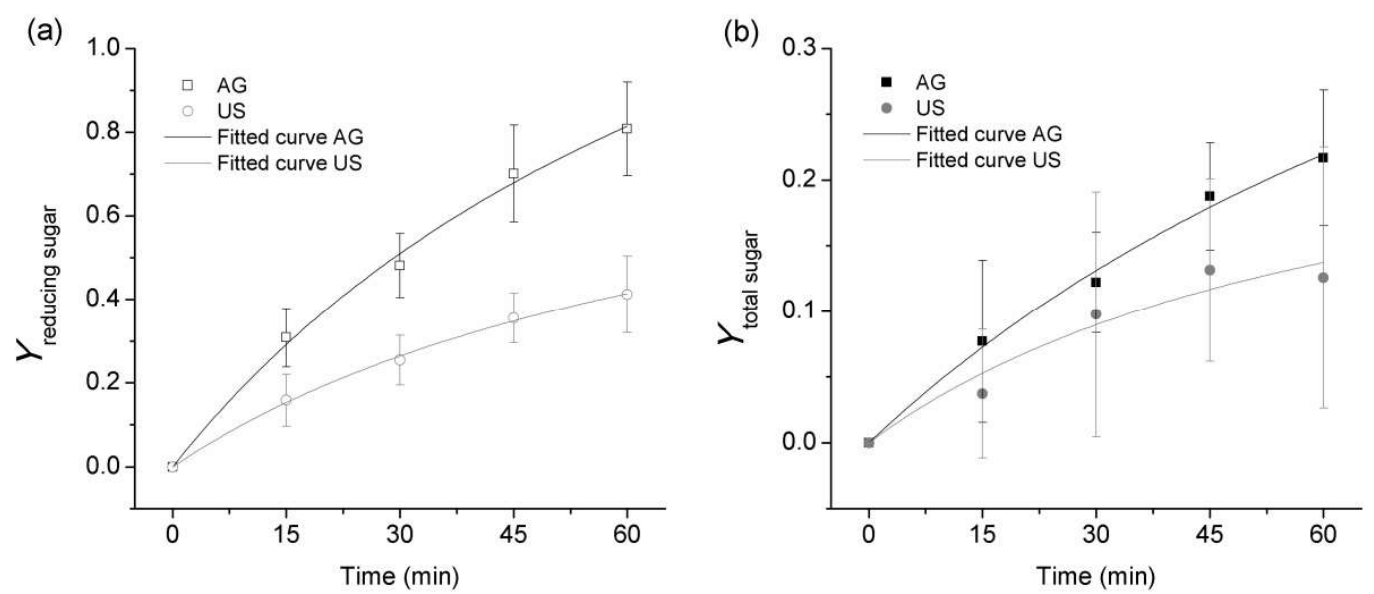

Figure 5.6.5. Kinetics of (a) reducing sugar and (b) total sugar release fitted to Naik model for the experiments B5AG10-A and B5US10-A.

\subsection{Influence of artichoke waste (AW) concentration in $\mathrm{HY}$ treatments}

The effect of the biomass content in the HY treatments was also studied. For this purpose, a new set of experiments considering $2.5 \%\left(w \cdot w^{-1}\right) A W$ content on the suspensions were carried out (B2.5AG10-A and B2.5US10-A experiments). On the contrary than the $5 \%\left(w \cdot w^{-1}\right) A W$ experiments (Figure 5.6.5a), no differences were found between experiments carried out with agitation and with ultrasound application in $2.5 \%\left(w^{-1} \cdot w^{-1}\right)$ AW experiments. In fact, as can be observed in Figure 5.6.6a, US and $A G$ both kinetics overlapped. Regarding the appearance, the $2.5 \%\left(\mathrm{w} \cdot \mathrm{w}^{-1}\right)$ of AW suspensions seemed to be less viscous than the $5 \%\left(w \cdot w^{-1}\right)$ of AW suspensions, qualitatively. This fact agreed with the explanation of the negative influence of suspensions viscosity on ultrasound effects. Thus, in the US treatments the reduction of the biomass concentration from $5 \%\left(\mathrm{w} \cdot \mathrm{w}^{-1}\right)$ to $2.5 \%\left(\mathrm{w} \cdot \mathrm{w}^{-1}\right)$ resulted in the increase of relative reducing sugar release from $40 \%$ up to $80 \%$ after $60 \mathrm{~min}$ of treatment. This value reached the same value that the achieved by $A G$ experiments.

On the other hand, the relative sugar release in $A G$ experiments was quite similar for the two AW concentrations of suspensions tested (B5AG10-A and B2.5AG10-A experiments). Higher concentrations have to be tested to determine the maximum concentration to be used in these kinds of treatments in order to process higher amounts of biomass with the minimum chemicals and water expenses. 
The HY experiments also showed that after $60 \mathrm{~min}$ of treatments, the hydrolysis was far from reaching the equilibrium (Figure 5.6.5 and 5.6.6). This fact is particularly evident in the case of total sugars release, mainly in the $2.5 \%\left(\mathrm{w} \cdot \mathrm{w}^{-1}\right) \mathrm{AW}$ suspensions where only a linear trend was observed. In this case, it must be highlighted the increase in the acid-biomass ratio (from 1.9 in the $5 \%\left(w \cdot w^{-1}\right)$ of AW suspensions to 3.9 in the $2.5 \%$ ( $\left.w \cdot w^{-1}\right)$ of AW suspensions) that can produce a more intense contact between acid and biomass. Moreover, the less qualitative viscosity of these suspensions can favor the appearance of significant effects of ultrasound (Figure 5.6.6b). Thus, after $60 \mathrm{~min}$ of treatment, the relative total sugar release of B2.5US10-A experiments was $87 \%$ higher than B2.5AG10-A experiments. The application of acoustic fields in these conditions could promote enough microjets toward the crystalline cellulose, besides erosion in the solid material by the shockwave of cavitation bubbles (Alvira et al., 2010). According to Luo et al. (2014), it can lead to pre-fractionation of raw material, opening of crystalline structure of cellulose and intensification of mass transfer process to release more fermentable sugars over the treatment when compared to AG experiments.

(a)

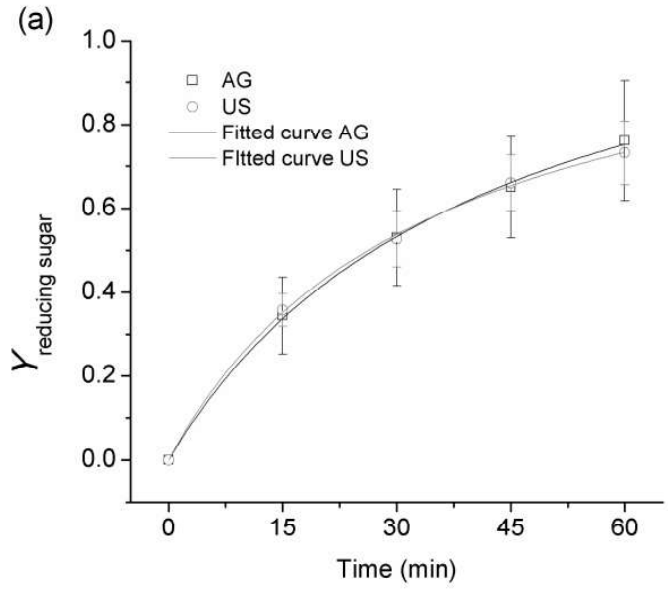

(b)

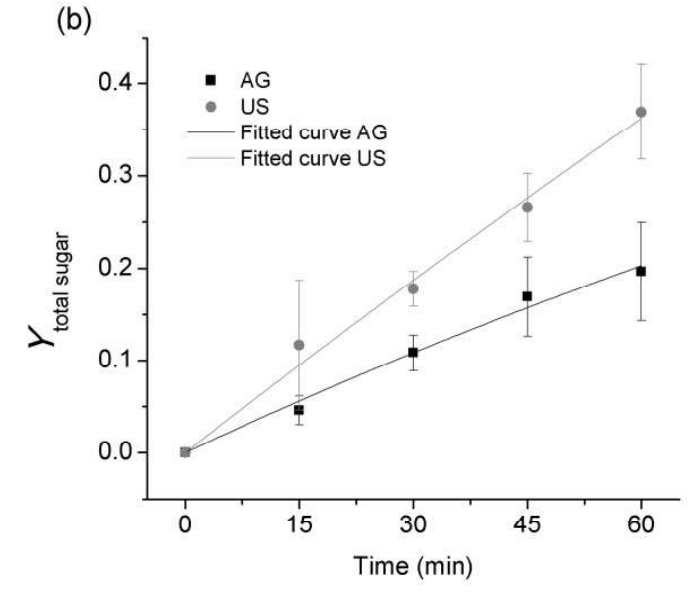

Figure 5.6.6. Kinetics of (a) reducing sugar and (b) total sugar release fitted to Naik model for the experiments B2.5AG10-A and B2.5US10-A.

\subsubsection{Industrial approach application}

An industrial approach application should obtain the greatest sugar release in the minimum time as possible, independently if the sugar release is due to dilution of 
present sugars or hydrolysis. For this reason, a new set of experiments considering this fact were carried out (B5AG10 and B5US10), in which the biomass was directly suspended in acid medium to be treated.

The results (Figure 5.6.7) showed that acid suspensions directly treated with US (B5US10 experiments) produced a relative reducing sugar and total sugar 213\% and $175 \%$ significantly higher than the obtained with agitation of suspensions (B5AG10 experiments). The less qualitative viscosity at the beginning of the treatments can favor the mechanical effects of ultrasound not only by producing an intense microstirring in the suspension but also providing the energy needed to produce cavitation. Yunus et al. (2010) related the US application to the enhancement of acid penetration in order to convert cellulose and hemicellulose into fermentable sugars of low molecular weight. In addition to hydrolysis, there is an important combined effect of acid and ultrasound on the extraction of pectin of plant tissue cells (Grassino et al., 2016). The presence of pectin in the acid solution makes easier its depolymerization, leading to higher rates of reducing sugar production when compared to total sugars. At the same time the US-assisted treatments allow to recover carbohydrates and hydrolyzes lignocellulose, modifications in the biomass surface can be obtained for improving its accessibility to enzymes and microorganisms for further additional stages (Bensah and Mensah, 2013).
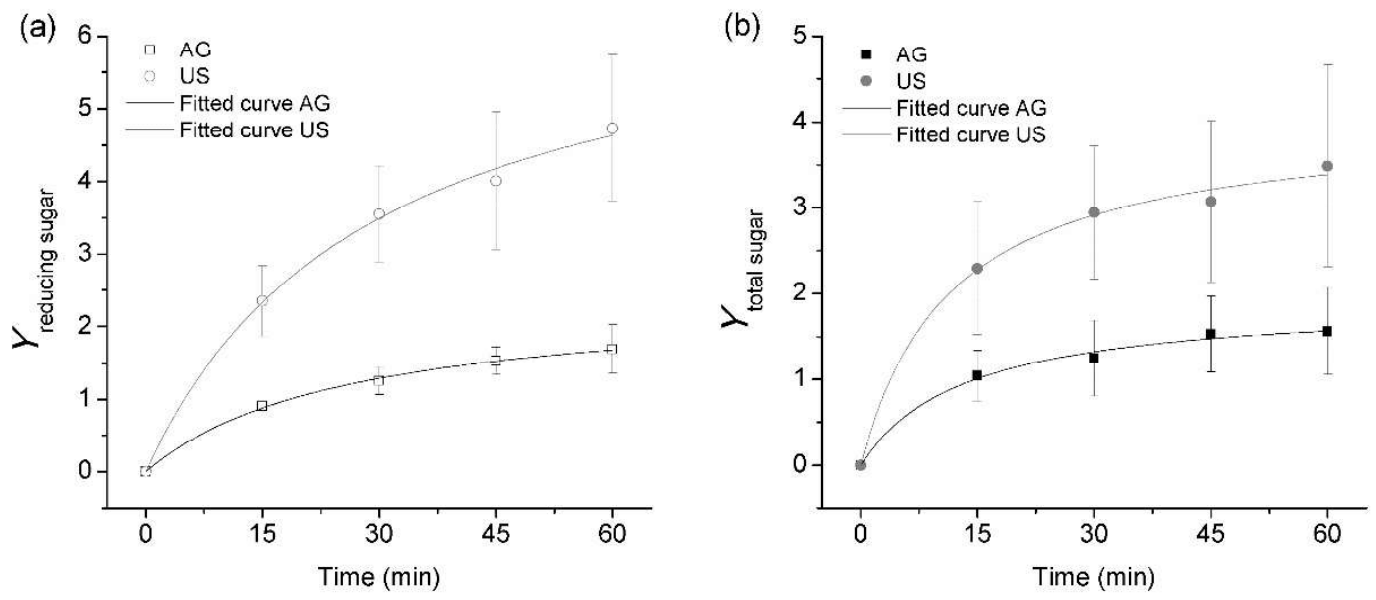

Figure 5.6.7. Kinetics of (a) reducing sugar and (b) total sugar release fitted to Naik model for the experiments B5AG10 and B5US10. 


\subsubsection{Mathematical modeling}

Mean experimental data of relative sugar release were fitted to the Naik model for the different experiments to quantify the differences among the tested treatments. The fitting parameters of each condition are shown in Table 5.6.2.

On the whole, the Naik model fitted adequately the experimental data as shown by the high values of determination coefficient $\left(R_{a d j}^{2}\right)$, greater than 0.93 in all cases, and the low figure of root-mean-square error (RMSE), lower than 0.093. Moreover, the calculated curves with the model followed the same trend than those of the experimental data in all the conditions studied (Figure 5.6.4, Figure 5.6.5, Figure 5.6.6 and Figure 5.6.7). According to Gaméz et al. (2004), representative kinetics equations are useful for economical estimations in the conversion industry.

Table 5.6.2. Kinetics parameters of adapted Naik model for the different treatments tested: extraction of soluble sugars with water (WE); hydrolysis in acid suspensions $(\mathrm{HY})$ and simulation of industrial hydrolysis (IHY).

\begin{tabular}{|c|c|c|c|c|c|c|c|c|}
\hline & \multicolumn{2}{|c|}{ EW } & \multicolumn{4}{|c|}{ HY } & \multicolumn{2}{|c|}{$(\mathrm{IHY})$} \\
\hline & B5AG0 & B5US0 & $\begin{array}{c}\text { B5AG10- } \\
\text { A }\end{array}$ & $\begin{array}{c}\text { B5US10- } \\
\text { A }\end{array}$ & $\begin{array}{c}\mathrm{B} 2.5 \mathrm{AG} 10- \\
\mathrm{A}\end{array}$ & $\begin{array}{c}\text { B2.5US10- } \\
\text { A }\end{array}$ & B5AG10 & B5US10 \\
\hline & & & \multicolumn{6}{|c|}{ Reducing sugars } \\
\hline$Y_{\infty}$ & 0.854 & 1.157 & 2.019 & 0.958 & 1.274 & 1.148 & 2.411 & 6.900 \\
\hline$B$ & 22.870 & 5.154 & 88.735 & 78.856 & 41.686 & 33.986 & 26.162 & 29.274 \\
\hline$R_{a d j}^{2}$ & 0.994 & 0.994 & 0.995 & 0.998 & 0.999 & 0.999 & 0.999 & 0.996 \\
\hline \multirow[t]{2}{*}{ RMSE } & 0.010 & 0.027 & 0.018 & 0.006 & 0.007 & 0.006 & 0.012 & 0.093 \\
\hline & & & \multicolumn{6}{|c|}{ Total sugars } \\
\hline$Y_{\infty}$ & 0.726 & 1.009 & 0.673 & 0.294 & 1.579 & 5.911 & 1.918 & 4.040 \\
\hline$B$ & 8.516 & 3.461 & 123.863 & 68.343 & 406.882 & 918.091 & 13.495 & 11.556 \\
\hline$R_{a d j}^{2}$ & 0.999 & 0.995 & 0.992 & 0.934 & 0.986 & 0.988 & 0.992 & 0.995 \\
\hline RMSE & 0.008 & 0.022 & 0.006 & 0.012 & 0.008 & 0.012 & 0.044 & 0.078 \\
\hline
\end{tabular}

Regarding the WE set of experiments, $B$ parameter was $80 \%$, for reducing sugars, and $60 \%$, for total sugars, lower in the US-assisted experiments than in AG ones. On the other hand, the estimated sugar release at equilibrium $\left(Y_{\infty}\right)$ was greater in US experiments than in AG for both reducing (35\%) and total sugars $(39 \%)$ 
extraction. These parameters indicate that the application of US was a more efficient to dissolve the soluble sugars presents in artichoke waste than AG.

Regarding the hydrolysis of $5 \%\left(w \cdot w^{-1}\right)$ AW suspensions (HY experiments), the higher values for the release of total and reducing sugar at equilibrium $\left(Y_{\infty}\right)$ was observed for $A G$ experiments (B5AG10-A) instead US treatments (B5US10-A). It means that acid hydrolysis under $A G$ was more efficient for converting fermentable matter into reducing sugar in concentrated suspensions. Regarding $B$ parameter, the lower values obtained in US experiments compared with $A G$ ones seemed to indicate a faster process. However, because this parameter represents the time needed to release half of sugar at equilibrium $\left(Y_{\infty}\right)$ and this parameter was lower for US experiments, it is not possible to extract a clear difference between AG and US application.

The decrease on AW concentration from $5 \%\left(w \cdot w^{-1}\right)$ to $2.5 \%\left(w \cdot w^{-1}\right)$ resulted in very similar kinetics parameters, $B$ and $Y_{\infty}$, for reducing sugar release of B2.5AG10$A$ and B2.5US10-A. On the contrary, in the case of total sugar release, the values obtained in US experiments were higher than the obtained under AG. The high values of $B$ found for total sugars release indicated that the equilibrium was far from being reached in these conditions.

Finally, in IHY experiments, the application of US increased both the total and the reducing sugar release in the equilibrium being this value $110 \%$ and $186 \%$ higher, than AG experiments, respectively. Regarding the $B$ parameter, it was quite similar in both cases.

\subsubsection{Viscosity of the acid suspensions}

The differences between the influence of US application in WE and HY experiments, as state before can be attributed to the influence of changes in the apparent viscosity of suspensions during HY process. Thus, the qualitative increase of apparent viscosity could make difficult ultrasound transmission and, therefore, its effects. Hou et al. (2016) stated that hydrolysis produces changes on the rheological properties of acid suspensions. Thus, the viscosity of suspensions before and after HY treatment was measured to quantify these changes. 
In the studied conditions, the resulting rheograms showed absence of yield stress and linear dependence of the shear stress $(\mathrm{mPa})$ on the shear rate $\left(\mathrm{s}^{-1}\right)$. Thus, Newton model could be fitted to the experimental data to provide the Newtonian viscosity values ( $\mathrm{mPa} \cdot \mathrm{s}$ ) of the suspensions. As can be observed in Table 5.6.3, the HY treatment produced an increase of suspensions viscosity. The viscosity of $5 \%$ AW suspensions (B5AG10-A) was $53 \%$ higher after HY treatments while $70 \%$ for $2.5 \%$ ones (B2.5AG10-A). The application of US during treatments caused higher increase in the viscosity when compared to the treatments with AG (Table 5.6.3). Thus, in B5US10-A the viscosity increase was a $360 \%$ at the end of the HY treatment and $326 \%$ in the case of B2.5US10-A.

These results were in accordance to Koppram et al. (2014), who stated that rheological properties of treated suspensions containing biomass depends on the type of raw material and the pretreatment conditions. Probably, the US application was more efficient in retrieving hemicellulose and lignin to the liquid phase than AG. It may have increased the viscosity of the dispersant with the same degree of particle-particle interactions as the initial suspensions, leading to an increased flow resistance of the resulting acid suspension.

Table 5.6.3. Viscosity of the AW acid suspensions before and after HY treatments carried out with agitation (AG) or with ultrasound (US) application.

\begin{tabular}{|c|c|c|}
\hline \multirow{2}{*}{ Experiment } & \multicolumn{2}{|c|}{ Viscosity (mPa's) } \\
\hline & Before & After \\
\hline $\begin{array}{l}\text { B5US10-A } \\
\text { B5AG10-A }\end{array}$ & $180.1 \pm 0.1^{d}$ & $\begin{array}{l}834.2 \pm 0.4^{\mathrm{a}} \\
276.9 \pm 0.1^{\mathrm{c}}\end{array}$ \\
\hline $\begin{array}{l}\text { B2.5US10-A } \\
\text { B2.5AG10-A }\end{array}$ & $83.3 \pm 0.1^{f}$ & $\begin{array}{r}355.9 \pm 0.2^{b} \\
142.83 \pm 0.01^{\mathrm{e}}\end{array}$ \\
\hline
\end{tabular}

\subsubsection{Characterization for the acoustic fields}

As stated in previous papers, the magnitude of ultrasound effects depends on the acoustic energy that is effectively applied (Chemat et al., 2017; GonzálezCenteno et al., 2015). In this sense, the sonication of suspension leads to difficulties 
compared to the processing of liquids. The presence of heterogeneous systems influences cavitation activity and transport phenomena (Gogate et al., 2011). The combination of the suspensions properties and sonication parameters can affect the intensity of diverse chemical and mechanical effects (Mason and Cordemans, 1996). Therefore, every modification of viscous properties of suspensions can also influence the transmission of the acoustic energy and, then, the magnitude of ultrasound effects.

In this way, the actual power applied in the acid suspensions was determined by using a calorimetric method. Because the significant change of the viscosity observed during the acid hydrolysis of suspensions, the ultrasonic power measurements were carried out before process and after 1 hour of HY treatment. It must be highlighted that all the conditions tested were carried out in triplicate.

The results (Table 5.6.4) indicated that the acoustic density were greater in the diluted suspensions than in the concentrated ones. Thus, the acoustic density measured in the $5 \%\left(w \cdot w^{-1}\right)$ of AW suspensions was a $43 \%$ lower than the measured in the $2.5 \%\left(w \cdot w^{-1}\right)$ or AW suspensions. This means that with the same input power applied, the sonochemical effects generated in suspensions with lower solids content were more intense compared to those induced in the higher concentrated suspensions. This was in agreement with the sugar release results from HY experiments, where the influence of US application was greater enhanced in the $2.5 \%\left(w \cdot w^{-1}\right)$ AW suspensions compared to $5 \%\left(w \cdot w^{-1}\right)$ ones. Higher concentrations of lignocellulosic biomass in suspensions generally caused an increase on the apparent viscosity when compared to diluted suspensions, probably as a consequence of the particle-particle interactions (Polachini et al., 2016). Therefore, in order to obtain similar sonochemical effects in concentrated solutions, it will be necessary to apply more energy, not only to overcome the frictional forces but also to supply more energy per unit of mass.

The significant differences on the acoustic energy at the beginning and at the end of both processes indicated also the changes occurred in the suspension during the process. Specifically, the acoustic density decreased $34 \%$ in the case of $5 \%$ $\left(w \cdot w^{-1}\right)$ of AW suspensions and $49 \%$ in the case of $2.5 \%\left(w \cdot w^{-1}\right)$ of AW suspensions after $60 \mathrm{~min}$ of $\mathrm{HY}$ treatments. In addition to the particles swelling, the intensified 
action of acid by US could hydrolyze more easily hemicellulose than cellulose, and the linkages between xylan and lignin (Harmsen et al., 2010; Zu et al., 2014). It may have provoked the release of lignin fragments and the consequent increase observed in the medium viscosity (Table 5.6.3), raising difficulties to ultrasound propagation. Moreover, acid treatment can affect the particles surface and consequently modified how they interact to each other to form agglomerates during longer holding time (Zhu et al., 2016). These phenomena could be higher in the $2.5 \%\left(w \cdot w^{-1}\right)$ of AW suspensions than in the $5 \%\left(w \cdot w^{-1}\right)$ of AW ones due to an initial better transmission of acoustic energy that enhanced ultrasound effects, leading to a higher reduction of acoustic density after $60 \mathrm{~min}$ of treatment in the first case.

Table 5.6.4. Acoustic density measured in 5 and $2.5 \%\left(w \cdot w^{-1}\right)$ AW suspensions before and after $1 \mathrm{~h}$ of $\mathrm{HY}$ treatment.

\begin{tabular}{|c|c|c|}
\hline \multirow[t]{2}{*}{ Experiment } & \multicolumn{2}{|c|}{$\begin{array}{c}\text { Acoustic density } \\
\left(\mathrm{kW} \cdot \mathrm{kg}^{-1} \text { of dried } \mathrm{AB}\right)\end{array}$} \\
\hline & Before & After $1 \mathrm{~h} \mathrm{HY}$ treatment \\
\hline B5US10-A & $21.1 \pm 0.1^{b}$ & $14 \pm 2^{d}$ \\
\hline B2.5US10-A & $37.0 \pm 0.5^{\mathrm{a}}$ & $19 \pm 1^{\mathrm{c}}$ \\
\hline
\end{tabular}

\subsubsection{Conclusions}

The processes of sugar release from artichoke waste by dissolution in water or by hydrolysis in acid suspensions were studied. In the first case, ultrasound application enhanced the kinetics of soluble sugar release when compared to conventional agitation extraction. Regarding the hydrolysis in acid suspensions, the effectiveness of ultrasound applications was higher in the lowest artichoke waste concentration suspensions tested $\left(2.5 \%\right.$ of $\left.A W w \cdot w^{-1}\right)$. The greater viscosity of the highest concentration suspensions ( $5 \%$ of $\left.A W w \cdot w^{-1}\right)$ tested could limit the ultrasound effects. Actual acoustic field measurements agree with this fact, being the acoustic density obtained in $5 \%\left(w \cdot w^{-1}\right)$ of AW suspensions lower than that measured in $2.5 \%$ $\left(w \cdot w^{-1}\right)$ ones. In addition, changes on the rheological properties of the suspensions over the acid hydrolysis could be linked to the decrease on the acoustic density at the end of the processes. 
Simulating a practical approach in which biomass particles are directly treated in acid medium, ultrasound-assisted experiments provided sugar release equilibrium values higher than that obtained in experiments carried out with conventional agitation. In addition to the enhancement on sugar release from biomass, ultrasound could provide secondary effects on the structure of lignocellulose that can worth of investigation in further enzymatic and/or fermentative processes involved in bioethanol production.

\subsubsection{Acknowledgments}

Authors acknowledge the INIA-ERDF (RTA2015-00060-C04-02) from Spain, the São Paulo Research Foundation - FAPESP (Grant 2017/06518-2) and the Coordination for the Improvement of Higher Level Personnel - CAPES (Grant 88881.132626/2016-01) from Brazil for the financial support.

\subsubsection{References}

Alvira, P., Tomás-Pejó, E., Ballesteros, M., Negro, M.J., (2010). Pretreatment technologies for an efficient bioethanol production process based on enzymatic hydrolysis: A review. Bioresource Technology 101(13), 4851-4861.

Bensah, E.C., Mensah, M., (2013). Chemical Pretreatment Methods for the Production of Cellulosic Ethanol: Technologies and Innovations. International Journal of Chemical Engineering 2013, 21.

Borah, A.J., Agarwal, M., Poudyal, M., Goyal, A., Moholkar, V.S., (2016). Mechanistic investigation in ultrasound induced enhancement of enzymatic hydrolysis of invasive biomass species. Bioresource Technology 213, 342-349.

Chemat, F., Rombaut, N., Sicaire, A.-G., Meullemiestre, A., Fabiano-Tixier, A.-S., Abert-Vian, M., (2017). Ultrasound assisted extraction of food and natural products. Mechanisms, techniques, combinations, protocols and applications. A review. Ultrasonics Sonochemistry 34, 540-560.

FAO, (2017). Official data of artichoke production. Food and Agriculture Organization of the United Nations.

Femenia, A., Robertson, J.A., Waldron, K.W., Selvendran, R.R., (1998). Cauliflower (Brassica oleracea L), globe artichoke (Cynara scolymus) and chicory witloof 
(Cichorium intybus) processing by-products as sources of dietary fibre. Journal of the Science of Food and Agriculture 77(4), 511-518.

Gámez, S., Ramírez, J.A., Garrote, G., Vázquez, M., (2004). Manufacture of Fermentable Sugar Solutions from Sugar Cane Bagasse Hydrolyzed with Phosphoric Acid at Atmospheric Pressure. Journal of Agricultural and Food Chemistry 52(13), 4172-4177.

Gogate, P.R., Sutkar, V.S., Pandit, A.B., (2011). Sonochemical reactors: Important design and scale up considerations with a special emphasis on heterogeneous systems. Chemical Engineering Journal 166(3), 1066-1082.

González-Centeno, M.R., Comas-Serra, F., Femenia, A., Rosselló, C., Simal, S., (2015). Effect of power ultrasound application on aqueous extraction of phenolic compounds and antioxidant capacity from grape pomace (Vitis vinifera L.): Experimental kinetics and modeling. Ultrasonics Sonochemistry 22, 506-514.

Grassino, A.N., Brnčić, M., Vikić-Topić, D., Roca, S., Dent, M., Brnčić, S.R., (2016). Ultrasound assisted extraction and characterization of pectin from tomato waste. Food Chemistry 198, 93-100.

Harmsen, P.F.H., Huijgen, W., Bermudez, L., Bakker, R., (2010). Literature review of physical and chemical pretreatment processes for lignocellulosic biomass. Wageningen UR Food \& Biobased Research, Wageningen.

Hou, W., Zhang, L., Zhang, J., Bao, J., (2016). Rheology evolution and CFD modeling of lignocellulose biomass during extremely high solids content pretreatment. Biochemical Engineering Journal 105, 412-419.

Karimi, K., Kheradmandinia, S., Taherzadeh, M.J., (2006). Conversion of rice straw to sugars by dilute-acid hydrolysis. Biomass and Bioenergy 30(3), 247-253.

Karimi, K., Taherzadeh, M.J., (2016). A critical review of analytical methods in pretreatment of lignocelluloses: Composition, imaging, and crystallinity. Bioresource Technology 200, 1008-1018.

Kassaye, S., Pant, K.K., Jain, S., (2017). Hydrolysis of cellulosic bamboo biomass into reducing sugars via a combined alkaline solution and ionic liquid pretreament steps. Renewable Energy 104, 177-184. 
Koppram, R., Tomás-Pejó, E., Xiros, C., Olsson, L., (2014). Lignocellulosic ethanol production at high-gravity: challenges and perspectives. Trends in Biotechnology 32(1), 46-53.

Lenihan, P., Orozco, A., O'Neill, E., Ahmad, M.N.M., Rooney, D.W., Walker, G.M., (2010). Dilute acid hydrolysis of lignocellulosic biomass. Chemical Engineering Journal 156(2), 395-403.

Loow, Y.-L., Wu, T.Y., Jahim, J.M., Mohammad, A.W., Teoh, W.H., (2016). Typical conversion of lignocellulosic biomass into reducing sugars using dilute acid hydrolysis and alkaline pretreatment. Cellulose 23(3), 1491-1520.

Luo, J., Fang, Z., Smith-Jr, R.L., (2014). Ultrasound-enhanced conversion of biomass to biofuels. Progress in Energy and Combustion Science 41, 56-93.

Luzzi, S.C., Artifon, W., Piovesan, B., Tozetto, E., Mulinari, J., Kuhn, G.O., Mazutti, M.A., Priamo, W.L., Mossi, A.J., Silva, M.F., Golunski, S.M., Treichel, H., Bender, J.P., (2017). Pretreatment of lignocellulosic biomass using ultrasound aiming at obtaining fermentable sugar. Biocatalysis and Biotransformation 35(3), 161-167.

Martínez-Esplá, A., García-Pastor, M.E., Zapata, P.J., Guillén, F., Serrano, M., Valero, D., Gironés-Vilaplana, A., (2017). Preharvest application of oxalic acid improves quality and phytochemical content of artichoke (Cynara scolymus L.) at harvest and during storage. Food Chemistry 230, 343-349.

Mason, T.J., Cordemans, E.D., (1996). Ultrasonic intensification of chemical processing and related operations: A review. Chemical Engineering Research \& Design 74(A5), 511-516.

Naik, S.N., Lentz, H., Maheshwari, R.C., (1989). Extraction of perfumes and flavours from plant materials with liquid carbon dioxide under liquid-vapor equilibrium conditions. Fluid Phase Equilibria 49, 115-126.

Polachini, T.C., Sato, A.C.K., Cunha, R.L., Telis-Romero, J., (2016). Density and rheology of acid suspensions of peanut waste in different conditions: An engineering basis for bioethanol production. Powder Technology 294, 168-176.

Ramón, A.P., Taschetto, L., Lunelli, F., Mezadri, E.T., Souza, M., Foletto, E.L., Jahn, S.L., Kuhn, R.C., Mazutti, M.A., (2015). Ultrasound-assisted acid and enzymatic 
hydrolysis of yam (Dioscorea sp.) for the production of fermentable sugars. Biocatalysis and Agricultural Biotechnology 4(1), 98-102.

Raso, J., Manas, P., Pagan, R., Sala, F.J., (1999). Influence of different factors on the output power transferred into medium by ultrasound. Ultrasonics Sonochemistry 5(4), 157-162.

Taherzadeh, M., Karimi, K., (2008). Pretreatment of Lignocellulosic Wastes to Improve Ethanol and Biogas Production: A Review. International Journal of Molecular Sciences 9(9), 1621-1651.

Villa-Vélez, H.A., Váquiro, H.A., Telis-Romero, J., (2015). The effect of powerultrasound on the pretreatment of acidified aqueous solutions of banana flowerstalk: Structural, chemical and statistical analysis. Industrial Crops and Products 66(0), 52-61.

Werle, L.B., Garcia, J.C., Kuhn, R.C., Schwaab, M., Foletto, E.L., Cancelier, A., Jahn, S.L., Mazutti, M.A., (2013). Ultrasound-assisted acid hydrolysis of palm leaves (Roystonea oleracea) for production of fermentable sugars. Industrial Crops and Products 45(0), 128-132.

Yunus, R., Salleh, S.F., Abdullah, N., Biak, D.R.A., (2010). Effect of ultrasonic pretreatment on low temperature acid hydrolysis of oil palm empty fruit bunch. Bioresource Technology 101(24), 9792-9796.

Zhu, Z., Guan, Q., Koubaa, M., Barba, F.J., Roohinejad, S., Cravotto, G., Yang, X., Li, S., He, J., (2017). HPLC-DAD-ESI-MS2 analytical profile of extracts obtained from purple sweet potato after green ultrasound-assisted extraction. Food Chemistry 215, 391-400.

Zhu, Z., Rezende, C.A., Simister, R., McQueen-Mason, S.J., Macquarrie, D.J., Polikarpov, I., Gomez, L.D., (2016). Efficient sugar production from sugarcane bagasse by microwave assisted acid and alkali pretreatment. Biomass and Bioenergy 93, 269-278.

Zu, S., Li, W.-z., Zhang, M., Li, Z., Wang, Z., Jameel, H., Chang, H.-m., (2014). Pretreatment of corn stover for sugar production using dilute hydrochloric acid followed by lime. Bioresource Technology 152, 364-370. 
5.7. CHAPTER 7

Kinetics of Sugar Release From Cassava Bagasse 


\section{A Comparison Between Conventional Agitation and Ultrasound Application on the Acid Hydrolysis of Cassava (Manihot esculenta) Bagasse}

Tiago Carregari Polachini ${ }^{1,2}$; Antonio Mulet ${ }^{2}$; Isabel Hernando ${ }^{3}$, Javier Telis-Romero ${ }^{1}$ and Juan A. Cárcel ${ }^{2}$

${ }^{1}$ Food Engineering and Technology Department, São Paulo State University (Unesp), Institute of Biosciences, Humanities and Exact Sciences (Ibilce), Campus São José do Rio Preto, Cristóvão Colombo Street 2265, São José do Rio Preto, São Paulo State, 15054-000, Brazil.

${ }^{2}$ Group of Analysis and Simulation of Agro-food Processes Food Technology Department, Universitat Politècnica de València Camino de Vera, s/n, Valencia, 46071, Spain.

${ }^{3}$ Group of Microstructure and Food Chemistry Food Technology Department, Universitat Politècnica de València Camino de Vera, s/n, Valencia, 46071, Spain. 


\begin{abstract}
Acid hydrolysis of cassava bagasse (CB), an interesting starch-based byproduct, with the assistance of high-intensity ultrasound (US) or mechanical agitation (AG) was evaluated. The kinetics of reducing and total sugar release were mathematically modeled to quantify the influence of process variables. Microscopic analyses (visible, fluorescence and polarized light) were carried out to identify changes produced by treatments in the matrix. Moreover, the acoustic field was characterized and the results correlated with the apparent viscosity of the different suspensions studied. Both $A G$ and $U S$ treatments showed to be effective for hydrolyzing $\mathrm{CB}$. In addition, when compared to AG, US experiments reached before the equilibrium of reducing sugar release and obtained slight higher values of total sugars released. Data were fitted to the Naik model with good accuracy. Higher loss of birefringence of the starch granules and degradation of lignocellulosic matter was also observed in starch granules from US-assisted hydrolysis. Acoustic power was reduced at the end of hydrolysis, probably due to the increases in the apparent viscosity of the resulting suspensions.
\end{abstract}

Keywords: bioethanol, hydrolysis kinetics, reducing sugar, total sugar, birefringence. 


\subsubsection{Introduction}

Ethanol has been considered one of the most suitable secondary biofuels to replace fossil fuels (Nigam and Singh, 2011). It can be produced through the fermentation of the sugars that compose the carbohydrates of some food industry residues such as those generated from the processing of sugarcane, corn or potato. In this sense, cassava (Manihot esculenta) bagasse represents an abundant source of agro-industrial waste in Brazil. The development and design of alternative treatments to this waste has become a must. Its residual starch content can range from 35 to $85 \% \mathrm{db}$ as a consequence of the low yield of the cassava starch extraction process (Pandey et al., 2000). Moreover, this byproduct also includes a higher content of fiber (10-65\% d.b).

The release of sugars of low molecular weight from this material is dependent on adequate pretreatments and hydrolysis. So, studies about alternative and ecofriendly process have become worth of investigation (Kassaye et al., 2017). The pretreatment step, commonly carried out by chemical or physical methods or a combination of them, is responsible for breaking and exposing the structure of lignocellulose and starch granules, making them more accessible to enzymes and chemicals (Cinelli et al., 2015; Li et al., 2010). An efficient pretreatment can provoke simultaneous alterations on both structure and chemical linkages, leading to a partial hydrolysis.

Among the chemical methods, alkaline treatments are aimed at solubilizing the lignin and increasing cellulose digestibility (Alvira et al., 2010). On the other hand, the use of acids, as phosphoric acid, has demonstrated their effectiveness on modifying the structure of both lignocellulose and starch granules at lower cost (Fontana et al., 2001; Ramón et al., 2015; Sun and Cheng, 2002; Werle et al., 2013). Although it can be used in concentrated solutions, dilute acids are preferred in this kind of pretreatments to avoid equipment corrosion and make easier the acid recovery.

During the acid pretreatment, biomass suspensions can be stirred by conventional agitation at controlled temperature to make easy the acid transfer to the internal matrix. On the other hand, alternative physical methods can be applied to enhance the effects of the acid solution on biomass and to allow the use of mild conditions of temperature and catalyst concentration. High-intensity (or power) 
ultrasound has appeared as an interesting non-conventional technology to this end (Rehman et al., 2013). The sonochemical effects are linked to certain mechanisms produced when ultrasound travels across a medium with enough energy: cavitation, micro-agitation or heating. Cavitation occurs in liquid media by the collapse of the cavitation bubbles, creating molecular displacement throughout the successive zones of high and low pressure. The intensity of the collapse is able to cause the erosion of polymeric materials by micro-jets formation and enhance the mass transfer between liquid and solid media (Mason and Cordemans, 1996). Ultrasound can also promote the micro-agitation inside the particles and the acoustic streaming at interfaces (Mason and Lorimer, 2002). Moreover, heating is a consequence of the resistance forces against acoustic vibration. This effect is useful for measuring the real acoustic power applied and for determining the proportion of acoustic energy transferred to the medium, being this an important information for reproducing similar conditions and scale-up the process (Polachini et al., 2017).

Therefore, the main goal of this paper was the study of the ultrasonically assisted acid treatment of cassava bagasse under mild conditions of temperature and phosphoric acid concentration to evaluate their influence on the kinetics of sugar release and structural effects.

\subsubsection{Materials and Methods}

\subsubsection{Samples preparation}

In this study, it was used the residue from the cassava (Manihot esculenta C.) starch extraction process. Thus, the wet bagasse was dried at $55^{\circ} \mathrm{C}$ for $48 \mathrm{~h}$. The resulting powder was sieved to obtain samples with particle size lower than $1 \mathrm{~mm}$. This material presented a moisture content of $4.18 \pm 0.22 \%$ (w. b.), determined in triplicate in a vacuum oven at $60{ }^{\circ} \mathrm{C}$ until constant weight (about 24h). Chemical composition of the dried matter was characterized in a previous study (Polachini et al. 2019).

\subsubsection{Experimental plan}

The experimental plan included two sets of experiments. In the first one, it was studied the dissolution of free sugars present in cassava bagasse. In the second one, 
an analysis of the acid hydrolysis treatment was carried out. In this last case, mild conditions were tested in order to avoid the use of corrosive acids and temperatures that might cause the suspensions gelatinization, raising difficulties on mass transfer. For this, the temperature of test was maintained at $50^{\circ} \mathrm{C}$, below the gelatinization temperature of cassava starch (Monroy et al., 2018). All of the experiments as well as the different chemical determinations were performed in triplicate.

\subsection{Sugar dissolution experiments (SD)}

For this set of experiments, $5 \%$ cassava bagasse suspensions in distilled water ( $\mathrm{g}$ of dried cassava bagasse per $100 \mathrm{~g}$ of suspension) were prepared. After that, the suspensions ( $150 \mathrm{~g}$ each one) were subjected to conventional agitation for 5 $\mathrm{h}$ at $50^{\circ} \mathrm{C}$ in order to determine the amounts of total and reducing sugar in the cassava bagasse that were directly soluble (experiments B5AG0). At preset times, samples were extracted and total and reducing sugar determinations were carried to achieve the kinetics of the process.

\subsection{Acid hydrolysis experiments $(\mathrm{AH})$}

These experiments were carried out in two steps. Firstly, 5\% (g of cassava bagasse per $100 \mathrm{~g}$ of suspension) cassava bagasse aqueous suspensions were agitated for $4 \mathrm{~h}$ at $50^{\circ} \mathrm{C}$ in a similar way that described for SD experiments. This time was enough to ensure the total dissolution of the present free soluble sugars. After that, metaphosphoric acid (GPR Rectapur; VWR Chemicals, Lutterworth, UK) was added to the aqueous suspensions to obtain an acid concentration in the suspensions of $10 \%$ (g of acid per $100 \mathrm{~g}$ of solution). These acid suspensions (150 g by sample) were maintained under conventional agitation (B5AG10-A experiments) or high-intensity ultrasound application (B5US10-A experiments). Samples were extracted at preset times and total and reducing sugar determinations were performed.

\subsubsection{Conventional agitation (AG) system}

Acid treatments under conventional agitation were performed in a jacketed vessel using an agitator (Heidolph RZR1; Heidolph Instruments GMBH \& Co., 
Schwabach, Germany). This equipment was adjusted to work at $1000 \mathrm{rpm}$ in order to achive an intense stirring in the suspensions. The suspensions were maintained at $50{ }^{\circ} \mathrm{C}$ during the treatments by introducing the reaction vessel in a thermostatic bath (Frigedor, J.P. Selecta, Barcelona, Spain). Figure 5.7.1 shows some shape parameters $\left(F_{1}, F_{2}, F_{3}, F_{4}\right.$ and $\left.F_{5}\right)$ that characterize the agitation of the suspension induced by the system.

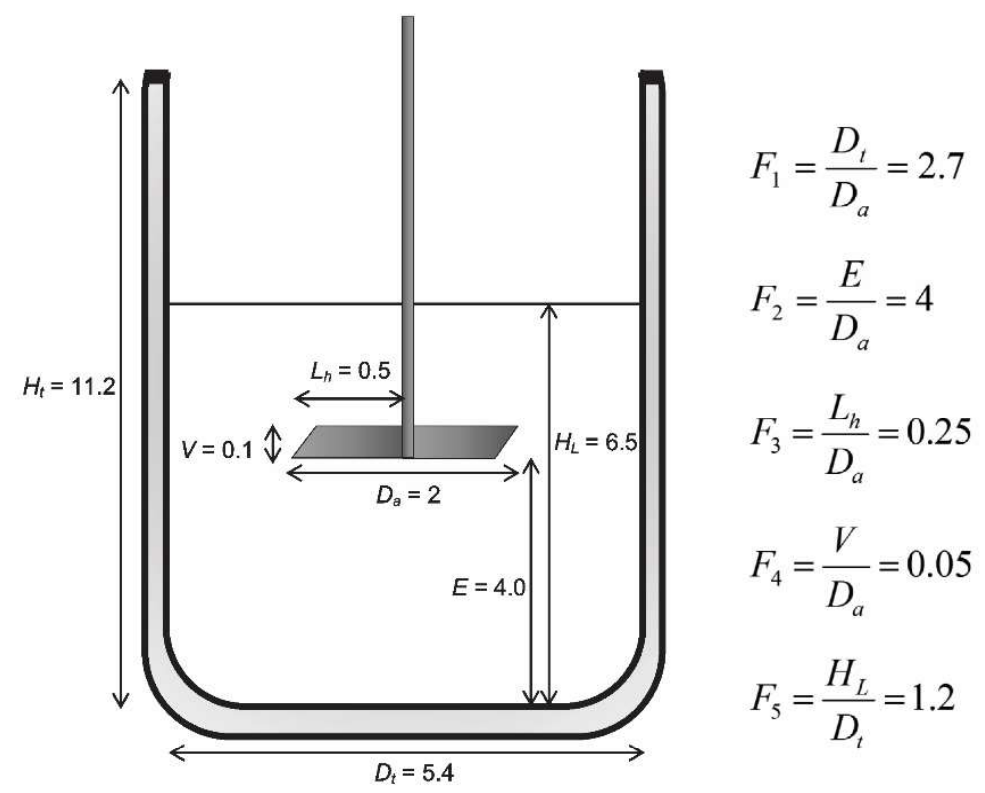

Figure 5.7.1. Set-up used in the experiments under conventional agitation.

\subsubsection{High-intensity ultrasound (US) system}

A scheme of the experimental set-up used in the ultrasound-assisted hydrolysis experiments is presented in Figure 5.7.2. The equipment consisted on an ultrasonic probe-type system (UP400S, Dr. Hielscher, Teltow, Germany) provided with a $22 \mathrm{~mm}$ diameter emitter surface probe (irradiation surface of $3.8 \mathrm{~cm}^{2}$ ). The probe was immersed $1 \mathrm{~cm}$ into the acid suspensions, which were placed in a jacketed vessel. The tests were carried out at the maximum electrical power input of the system $(400 \mathrm{~W})$ in pulsed way ( $0.6 \mathrm{~s}$ on $-0.4 \mathrm{~s}$ off). The temperature was maintained constant $\left(50 \pm 2{ }^{\circ} \mathrm{C}\right)$ during the experiments to avoid the suspensions overheating. For this, the temperature of the suspensions was recorded with a $\mathrm{K}$ type thermocouple placed $2 \mathrm{~cm}$ below the probe. The thermocouple was connected to a 
process controller (E5CK, Omron, Hoofddorp, Netherlands) which drove a peristaltic pump (302 S, Watson-Marlow, Postfach, Germany) to recirculate a $30 \%$ glycol solution at $-10{ }^{\circ} \mathrm{C}$ from a refrigerated bath (Frigedor, J.P. Selecta, Barcelona, Spain) through the jacketed recipient containing the suspensions (Figure 5.7.2).

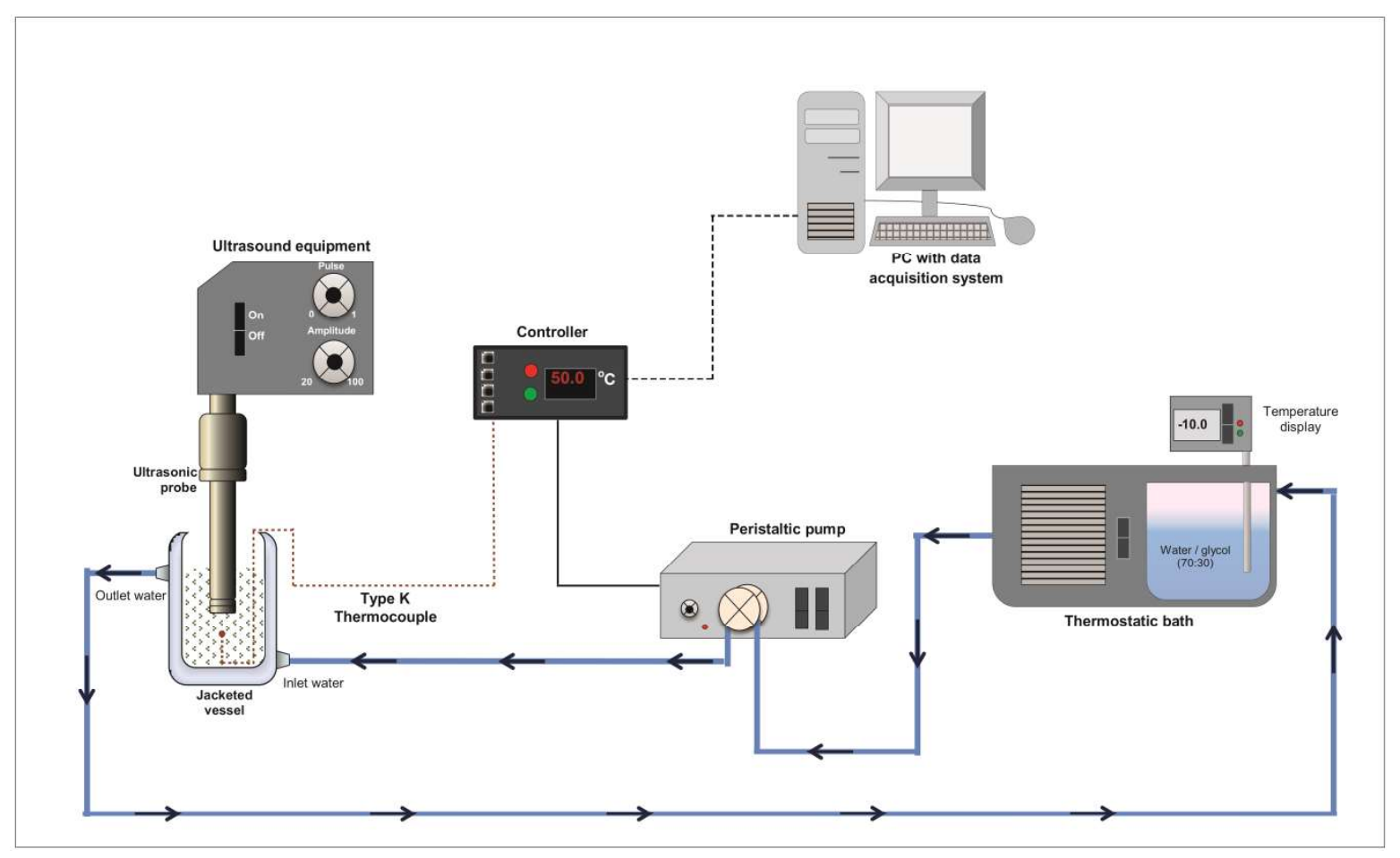

Figure 5.7.2. Scheme of the set-up used in the ultrasound-assisted hydrolysis.

\subsubsection{Sugar determination}

Aliquots of approximately $3 \mathrm{~mL}$ were taken every $60 \mathrm{~min}$ in the case of B5AG0 experiments $(0,60,120,180,240$ and $300 \mathrm{~min})$, and every $15 \mathrm{~min}$ in B5AG10 and B5US10 experiments $(0 ; 15 ; 30 ; 45$ and $60 \mathrm{~min})$. The acid aliquots were neutralized with $\mathrm{NaOH} 2.5 \mathrm{M}$ to be then centrifuged and filtered in PTFE micro filters $(0.45 \mu \mathrm{m}$, $25 \mathrm{~mm}$ diameter; LabBox, Barcelona, Spain). The supernatant was used for different sugar content measurement. Thus, the determination of reducing sugars $\left(S_{R}\right)$ was done in triplicate using DNS method, similarly as proposed by Kassaye et al (2017). This is a rapid and practical method, which is based on the reduction, in alkaline medium, of the acid 3,5-dinitrosalicylic. The absorbance of the resulting compound was measured at wavelength of $540 \mathrm{~nm}$ and the reducing sugars content was quantified by using a standard curve of anhydrous glucose, previously determined. 
Data were expressed as $\mathrm{g}$ of reducing sugar (glucose equivalent) per $100 \mathrm{~g}$ of dried cassava bagasse.

The total amount of hydrolysable sugars $\left(S_{T}\right)$ was determined by the same method but including a previous hydrolysis step (Werle et al., 2013). Thus, samples were introduced in a $\mathrm{HCl} 2 \mathrm{M}$ solution and maintained under boiling for $30 \mathrm{~min}$. After that, they were cooled and neutralized with $\mathrm{NaOH} 2.5 \mathrm{M}$. Then, hydrolyzed samples proceeded to the DNS method to determine the total amount of fermentable sugar (glucose equivalent) per $100 \mathrm{~g}$ of dried cassava bagasse.

The values obtained by both methods were used to calculate the relative sugar release $Y$ (Equation 5.7.1):

$$
Y=\frac{\left([S]_{t}-[S]_{t=0}\right)}{[S]_{t=0}}
$$

Where $[S]_{t}$ represents the sugar released at time $t$ and $[S]_{t=0}$ the sugar released just at the beginning of the experiment.

\subsubsection{Microscopic analysis}

The morphology of the raw cassava bagasse and the product obtained after the hydrolysis treatements were microscopically analyzed. For this, it was used an optical microscope Nikon Eclipse E80i (Nikon, Tokyo, Japan). To evaluate any possible alterations on fibrous particles, images were acquired by light field after diluting samples in distilled water in the 1:5 ratio. Untreated and treated samples were placed on the glass slide and stained with toluidine blue $(0.1 \%)$ to be observed through the 10x objective lens. Non-stained samples were observed through the $20 \mathrm{x}$ objective lens by light field, fluorescence and polarized light microscopy. This permits to observe possible alterations on the starch granules structures and on their birefringency. All images were captured and stored by NIS-Elements F software (Version 4.0, Nikon, Tokyo, Japan). 


\subsubsection{Mathematical modeling}

The Naik model (Naik et al., 1989), given by Equation (5.7.2), was used to fit the kinetics of sugar release assuming it behaves as an extraction process:

$$
Y=\frac{Y_{\infty} t}{(B+t)}
$$

where $t$ is the treatment time $(\mathrm{min}), Y_{\infty}$ is the relative difference of sugar production at equilibrium and $B$ is the time needed $(\mathrm{min})$ to reach half of $Y_{\infty}$. The goodness of the fitting procedure was evaluated by the adjusted determination coefficient $\left(R_{a d j}^{2}\right)$ and the root-mean-square error (RMSE) given by the Equation (5.7.3) and (5.7.4), respectively.

$$
\begin{gathered}
R_{a d j}^{2}=1-\frac{n-1}{n-(k+1)}\left(1-R^{2}\right) \\
R M S E=\sqrt{\frac{\sum_{n=1}^{n}\left(y_{p}-y_{\exp }\right)^{2}}{n}}
\end{gathered}
$$

where $n$ is the number of observations, $k$ is the number of parameters in the model (excluding the constant), $R^{2}$ is the determination coefficient, $y_{p}$ is the predicted value and $y_{\exp }$ is the experimental value.

\subsubsection{Apparent viscosity}

The apparent viscosity of the suspensions before and after the acid hydrolyses was measured under steady-state flow in a rotational rheometer AR-G2 (TA Instruments, USA) coupled with the Starch Pasting Cell (SPC) geometry to avoid particles sedimentation. Shear stress was obtained in an interval of shear rate between 1 and $265.5 \mathrm{~s}^{-1}$, maintaining the temperature at $50{ }^{\circ} \mathrm{C}$ through the thermostatic bath of the own equipment. Flow curves were analyzed to determine the apparent viscosity over the range of shear rate. 


\subsubsection{Acoustic field characterization}

A calorimetric method was employed to characterize the actual acoustic power applied in each case. For this, the temperature increase in the first $60 \mathrm{~s}$ of ultrasound application (Raso et al., 1999) was recorded with a K type thermocouple placed into the suspensions $2 \mathrm{~cm}$ below the probe and connected to a data acquisition system (LabVIEW Run-Time Engine 7.0, National Instruments, USA). The measurements were performed in triplicate and were carried out before and after $60 \mathrm{~min}$ of hydrolysis treatment with the aim of detecting any influence of the treatment in the actual ultrasonic power applied. The temperature records were taken using the same experimental set-up used for the US assisted hydrolysis experiments. So, the acoustic power applied could be calculated by the Equation (5.7.5):

$P=m c_{p} \frac{d T}{d t}$

where $P$ is the acoustic power (W), $m$ is the mass of the suspension $(\mathrm{kg}), c_{p}$ is the specific heat capacity of the acid solution $\left(4064.8 \mathrm{~J}^{\mathrm{kgg}}{ }^{-1} \cdot{ }^{\circ} \mathrm{C}^{-1}\right.$, determined by differential scanning calorimetry) and $d T / d t$ the heating rate $\left({ }^{\circ} \mathrm{C} \cdot \mathrm{s}^{-1}\right)$. Acoustic intensity $\left(I, \mathrm{~W} \cdot \mathrm{cm}^{-2}\right)$ was calculated by considering the acoustic power per area of the emitter surface; the acoustic density per treated volume $\left(D ; \mathrm{W} \cdot \mathrm{mL}^{-1}\right)$ and the acoustic load per the treated mass of particles $\left(\mathrm{W} \cdot \mathrm{g}^{-1}\right.$ of dried biomass).

\subsubsection{Results and discussions}

\subsubsection{Sugars dissolution}

The SD experiments allowed quantifying the kinetics of reducing and total free sugar release in aqueous medium. The results showed significant amounts of free sugars remaining in cassava bagasse that is explained because the main goal of cassava industrialization is the extraction of starch. These compounds are easily fermentable to produce bioethanol. As expected, the amount of total sugars presented higher values than the observed for reducing sugars. Regarding the kinetics, the maximum total sugars content was achieved after 2 hours of treatement (Figure 5.7.3). On the contrary, the reducing sugars needed 4 hours to achieve an 
asymptotic behavior. Therefore, 4 hours of agitation was considered to be adequate to attain the equilibrium of dissolution for both. After this period, cassava bagasse released $3.30 \pm 0.26 \mathrm{~g}$ of reducing sugar per $100 \mathrm{~g}$ of dried $\mathrm{CB}$ and $4.87 \pm 0.04 \mathrm{~g}$ of total sugar per $100 \mathrm{~g}$ of dried $\mathrm{CB}$, which correspond to a relative release of $2.78 \pm$ 0.43 and $0.39 \pm 0.13$, respectively (Figure 5.7.3).

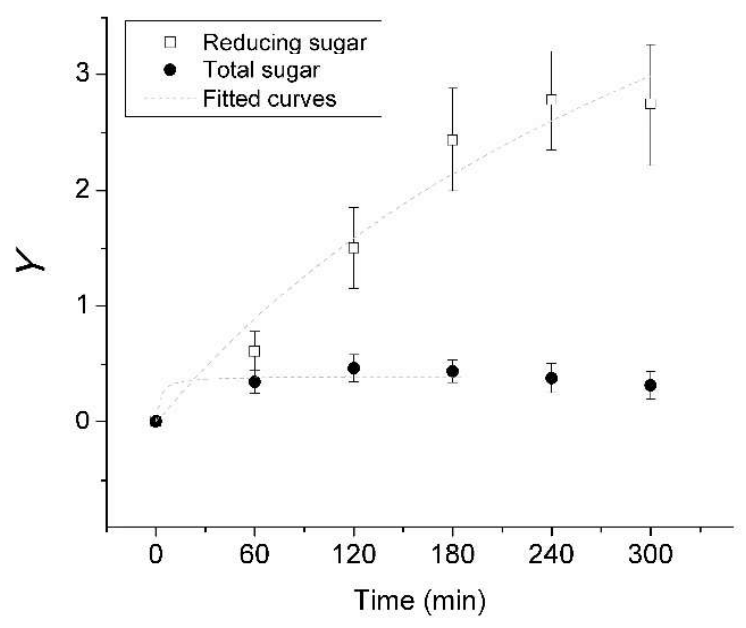

Figure 5.7.3. Relative release of total and reducing sugar concentration over the agitation of cassava bagasse in aqueous medium.

\subsubsection{Acid hydrolysis}

The results obtained in SD experiments showed that there was an important amount of soluble sugars, total and reducing, in $\mathrm{CB}$. For this reason, for $\mathrm{AH}$ experiments, the $\mathrm{CB}$ was previously treated for 4 hour in a water suspensions. Thus, soluble sugars were extracted from the $\mathrm{CB}$ matrix previously to the acid treatment and, then, it was possible to quantify the actual effect of acid treatment on the CB. The experimental kinetics of the relative production of reducing and total sugars during $\mathrm{AH}$ experiments carried out under agitation $(A G)$ or with ultrasound application (US) are shown in Figure 5.7.4. 
(a)

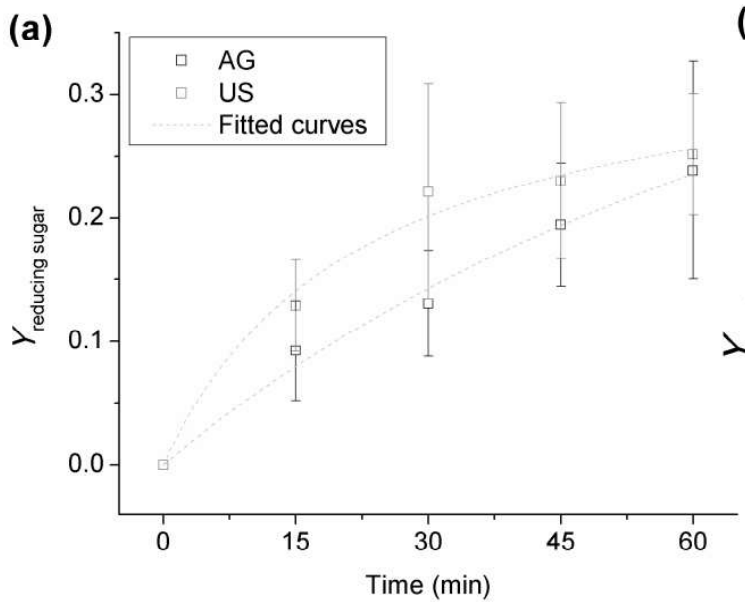

(b)

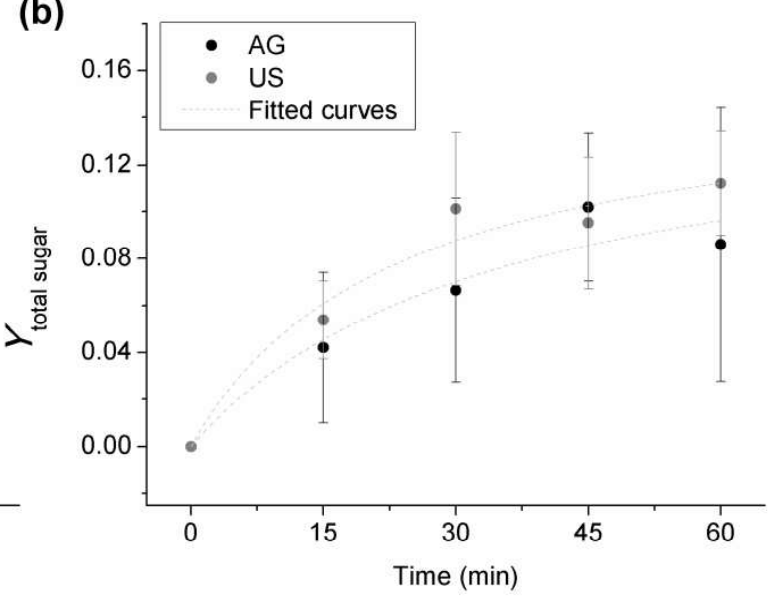

Figure 5.7.4. Relative production of (a) reducing and (b) total sugars during the acid hydrolysis of cassava bagasse (CB) assisted by conventional agitation (CA) or by ultrasound application (US).

Thus the $\mathrm{AH}$ treatment demonstrated to be relatively efficient for hydrolyzing cassava bagasse, with continuous release of reducing sugar and total sugar over the time tested. Phosphoric acid acts on the $\alpha-1,6$ bonds when hydrolyzing starch-based feedstock (Lenihan et al., 2010), debranching and opening the starch structure.

The experimental kinetics showed that for reducing sugar, the process was slightly faster in the case of US-assisted experiments (B5US10-A) compared to conventional agitation (B5AG10-A). In addition to the current hydrolysis and possible secondary effects on biomass structure, Li et al. (2018) found that pretreatment of ultrasound was able to enhance the liquefaction and saccharification of starch-based materials. The enhancement of hydrolysis by US could be attributed to the disruption of rigid hydrophobic protein matrix and amylose-lipid complex surrounding the granules (Shewale and Pandit, 2009). However, the relative release of reducing sugars in US-assisted (B5US10-A) and conventionally agitated experiments (B5AG10-A) reached similar values after $60 \mathrm{~min}$ of hydrolysis, around $25 \%$ of the initial reducing sugar content in both processes.

In the case of total sugar release after 60 min of treatment, a $30 \%$ higher yield was observed in B5US10-A experiments (11.2\%) compared to B5AG10-A (8.6\%) ones. On the contrary, after hydrolyzing yam with $5 \%$ phosphoric acid at $50{ }^{\circ} \mathrm{C}$ during 300 min, Ramón et al. (2015) found 14\% higher release of fermentable matter in 
experiments carried out in an ultrasonic bath when compared to non-ultrasonically assisted experiments. These values are lower than the ones found for reducing sugars. This fact it can be expected because the hydrolysis of the total sugar in solution into reducing sugar occurs faster than the hydrolysis of the fermentable matter trapped in the cassava bagasse structure into soluble total sugars. The differences observed between US and AG treatments were not significant likely due to the variability in the sugar content of the raw matter. The post-harvest physiological deterioration of the cassava roots occurs rapidly within $24 \mathrm{~h}$, which can impair the homogeneity of the resulting samples (Lin and Tanaka, 2006; Oirschot et al., 2000).

\subsubsection{Mathematical modeling}

The Naik model was fitted to the kinetics of sugar release by dissolution in aqueous medium (SD experiments) and by acid hydrolysis ( $\mathrm{AH}$ experiments). The fitting parameters for reducing and total sugars are showed in Table 5.7.1. A good agreement between experimental and calculated with the model data were found being the $R_{a d j}^{2}$ higher than 0.8715 and the root-mean-square error (RMSE) lower than 0.2074 .

Table 5.7.1. Fitting parameters of Naik model for the different treatments.

\begin{tabular}{ccccccc}
\hline & \multicolumn{3}{c}{ Reducing sugar } & \multicolumn{3}{c}{ Total sugars } \\
\cline { 2 - 7 } & B5AG0 & B5AG10-A & B5US10-A & B5AG0 & B5AG10-A & B5US10-A \\
\hline$Y_{\infty}$ & 7.2051 & 0.6780 & 0.3520 & 0.4009 & 0.1556 & 0.1525 \\
$B$ & 424.2585 & 112.4069 & 22.4413 & 2.0547 & 23.2993 & 35.1955 \\
$R_{a d j}^{2}$ & 0.9533 & 0.9879 & 0.9819 & 0.8715 & 0.9551 & 0.9171 \\
RMSE & 0.2074 & 0.0008 & 0.0109 & 0.0498 & 0.0076 & 0.0089 \\
\hline
\end{tabular}

Regarding the parameters identified for the acid hydrolysis experiments, the higher yield $\left(Y_{\infty}\right)$ of reducing sugar release found in the experiments carried with agitation of suspensions (B5AG10-A) indicated that the yield achieved with this kind of treatment could be higher than US treatments (B5US10-A) if the process time was 
prolonged. In contrast, US application could reach the equilibrium firstly as showed the lower $B$ value found in US experiments (B5US10-A) compared to AG experiments (B5AG10-A), which is very interesting from an indusrial point of view. Regarding the fitting parameters identified for total sugar, they presented similar values between US and AG experiments.

\subsubsection{Apparent viscosity}

After hydrolysis experiments, the supensions showed a paste-like aspect. During the treatments, some compounds could pass from the biomass structure to the solution. Thus, the solubilization of these compounds can be responsible by the increase of the apparent viscosity of the suspensions. The faster equilibrium attained in US-assisted hydrolysis could also be linked to a reduction on the actual acoustic power over the treatment produced by this increase on the apparent viscosity of the suspension. To confirm this hypothesis, rheological measurements were carried out to quantify the apparent viscosity before and after the acid treatment under agitation or under ultrasound application (Table 5.7.2). Flow curves indicated that apparent viscosity was practically constant over the shear rate $\left(R_{a d j}^{2}>0.9986\right)$, characterizing a Newtonian behavior in the studied conditions.

The measurements carried out indicated that suspensions hydrolyzed in the presence of ultrasound resulted in higher values of viscosity when compared to the suspensions mechanically agitated. This indicated that changes on the cassava bagasse structure occurred more intensely in US-assisted treatments. Yang et al. (2019) reported that ultrasound can increase the surface roughness of the starch granules, which leads to higher friction and consequently to an increase on the viscous properties of the suspensions.

In this sense, it is important to state that hydrolysis assisted by US needs an adequate mixing fo the suspensions to supply homogenous treatment to the biomass particles over a certain period of process being this mixing energy provided by acoustic agitation. The characterization of the evolution of the apparent viscosity over the hydrolysis is useful, not only to the release of compounds of interest, but to carry out a correct design of the unit operation and the equipment. As the material become more viscous, higher demands of energy are required to promote the same agitation 
degree that would be provided to less viscous fluids. Additionally, the viscosity of the medium can prevent cavitation to occur. Therefore, higher energy demand should be taken into account in the process design if similar cavitation degree is required over the process.

Table 5.7.2. Apparent viscosity for the acid suspensions before and after acid hydrolysis.

\begin{tabular}{ccc}
\hline Experiment & \multicolumn{2}{c}{ Apparent viscosity (mPa.s) } \\
& Before Hydrolysis & After Hydrolysis \\
\hline B5AG10-A & $1177 \pm 9^{c}$ & $1341 \pm 10^{\mathrm{b}}$ \\
B5US10-A & & $1746 \pm 3^{\mathrm{a}}$ \\
\hline
\end{tabular}

Means and standard deviation followed by the same lowercase letters represent no significant difference among the measurements by the Fisher test at $95 \%$ of confidence.

\subsubsection{Acoustic field's characterization}

The sonochemical effects of ultrasound are related to the real acoustic power transmitted to the medium. In order to characterize this energy, acoustic parameters were determined by the linear increase of temperature over the initial periods of ultrasound application.

Table 5.7.3. Acoustic parameters obtained from the acoustic fields' determinations.

Acoustic parameters

B5US10-A experiment

\begin{tabular}{ccc} 
& Before & After \\
\hline Acoustic power $(\mathrm{W})$ & $148.202 \pm 2.070^{\mathrm{a}}$ & $77.129 \pm 19.499^{\mathrm{b}}$ \\
Acoustic intensity $\left(\mathrm{W} \cdot \mathrm{cm}^{-2}\right)$ & $38.987 \pm 0.544^{\mathrm{a}}$ & $20.290 \pm 5.130^{\mathrm{b}}$ \\
Acoustic density $\left(\mathrm{W} \cdot \mathrm{mL}^{-1}\right)$ & $0.988 \pm 0.011^{\mathrm{a}}$ & $0.514 \pm 0.130^{\mathrm{b}}$ \\
Acoustic load & $20.586 \pm 0.235^{\mathrm{a}}$ & $10.714 \pm 2.709^{\mathrm{b}}$ \\
$\left(\mathrm{W} \cdot \mathrm{g}^{-1}\right.$ of dried cassava bagasse $)$ &
\end{tabular}

Means and standard deviation followed by the same lowercase letters in the same line represent no significant difference among the measurements by the Fisher test at $95 \%$ of confidence.

Table 5.7.3 summarizes the acoustic parameters obtained by the ultrasoundassisted hydrolysis before and after $60 \mathrm{~min}$ of the acid treatment. For all studied parameters, higher values were found before the treatment when compared to those found after. During the acid hydrolysis, fermentable matter is leached from the grains 
and from the lignocellulose. These compounds could be dispersed in the liquid medium without some alterations on the biomass structure contributing to the increase in the apparent viscosity (Table 5.7.2) and to the observed paste-like aspect of the suspensions. The increase in the flow resistance reflects a higher interaction between molecules and a higher difficulty for promoting adequate cavitation (Mason and Lorimer, 2002; Toma et al., 2011). The lower is the cavitation activity, the lower the erosion on the liquid-solid interface. Thus, extending the sonication time over the $60 \mathrm{~min}$ in this system could decrease the efficiency of energy transfer, causing the equipment and sonotrode wear. Montalbo-Lomboy et al. (2010) also stated that longer sonication periods can turn the process more onerous without big difference on the release of fermentable matter.

\subsubsection{Microscopic analyses}

\subsection{Effects on the fibrous matter}

Morphology of cassava bagasse was qualitatively assessed by different techniques of optical microscopy. Firstly, an analysis of the general structure of raw cassava bagasse was done in order to compare with the treated samples. Figure 5.7.5 presented the light micrographs of both raw material and partially hydrolyzed cassava bagasse, with agitation and with ultrasound application. The staining technique with toluidine blue had metachromatic properties on different samples. Shades of blue or green indicates the presence of phenolic compounds such as lignin (Santos et al., 2011). It could be strongly observed in the bigger fibers that they are mainly composed by cellulose and hemicellulose involved by lignin. These blue/green structures showed apparently more integrity in the untreated cassava bagasse than in treated ones, which could be related to the lower viscosity observed for the untreated suspensions. Moreover, in US-treated samples, fibrous structure seemed to have undergone by a shearing process in which the surface became less irregular when compared to untreated sampes or AG treated samples. Small pieces of fibrous matter could be also observed in the bagasse hydrolyzed by US, indicating that ultrasound could have an effect on biomass fragmentation. In fact, it could be responsible for the higher increase in the viscosity of the suspensions treated with US. 
Despite the bluish structures, it could be seen regions with purple coloration. Santos et al. (2011) related this shades of purple with primary structures of wall cells as cellulose, hemicellulose and pectin. In the raw sample, these regions appeared dispersed around the fibrous particles, probably as a consequence of the milling process. This empurpled material was not noticed in the bagasse hydrolyzed under agitation with the same concentration as it occurs in raw material, which gives an indicative that free cellulose and hemicellulose could be hydrolyzed by the acid. On the other hand, bagasse hydrolyzed in the presence of ultrasound exhibited higher concentration of empurpled materials dispersed in the sample. As the yield of sugar release was similar to conventional agitated samples, it is possible to infer that ultrasound was able, not only to hydrolyze the free polysaccharide, but also to retrieve part of the fermentable matter from the lignocellulose structure.

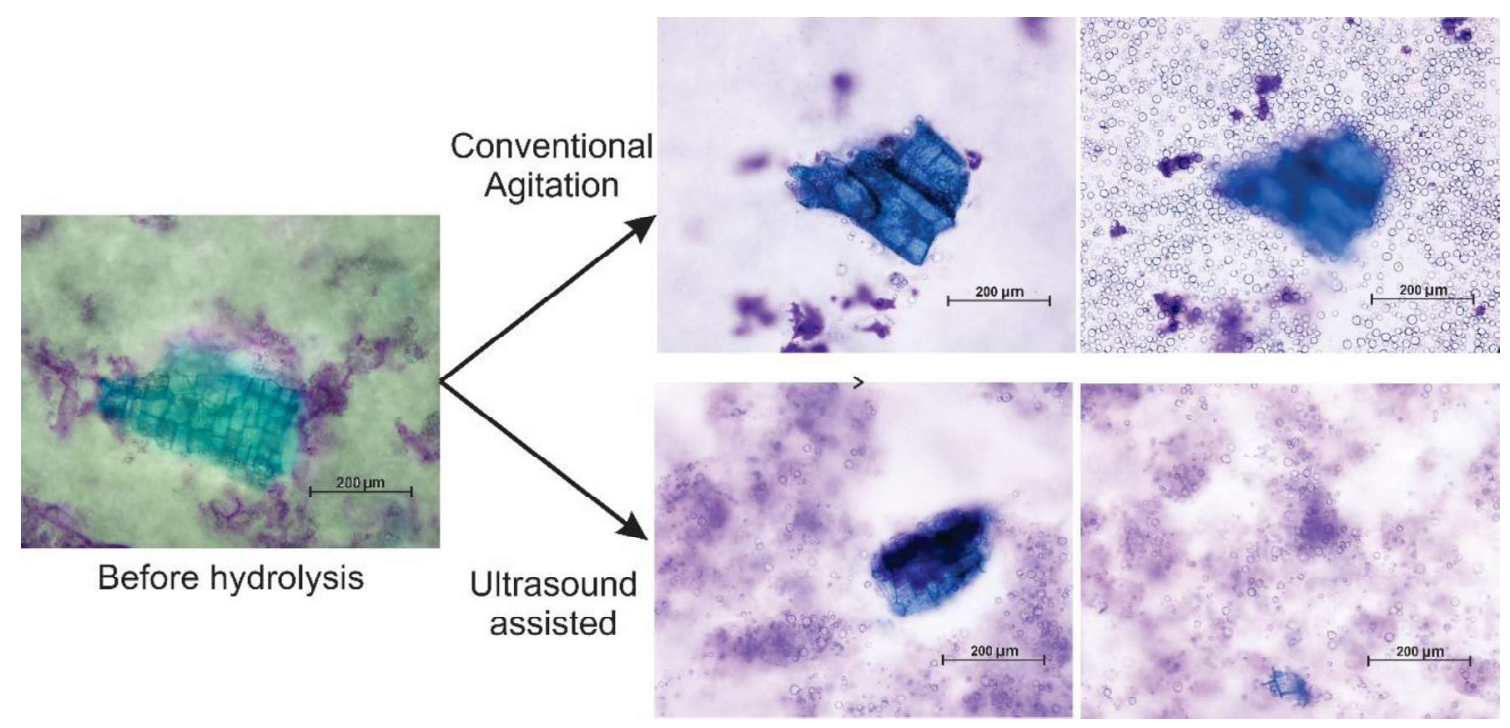

Figure 5.7.5. Light field micrographs of cassava bagasse (stained with toluidine blue $0.1 \%$ ) before and after acid treatment under conventional agitation or assisted by high-intensity ultrasound.

\subsection{Effects on the starch granules}

A high concentration of starch granules could be observed around and entangled into the fibrous matter (Figure 5.7.5), reflecting the potential source of fermentable matter by cassava bagasse. It reinforces the need to evaluate the effects of both processes on the structure of starch granules. 
In the following Figure 5.7.6, there are images obtained by light, fluorescence and polarized light microscopy of the starch granules before and after acid treatments at 20x of magnitude. Starch granules in raw cassava bagasse presented regular surface with typical morphology of cassava starch: oval, truncated and rounded (Zhu, 2015). In this sample, none significant alteration could be evidenced. The subsequent application of fluorescence and polarized light showed the birefringence properties of starch granules. A strong birefringence was noticed by the high light intensity of the Maltese cross in the grains, even after the 4 hours of previous agitation in aqueous medium.

When cassava bagasse was subjected to acid hydrolysis under conventional agitation, alterations on the light microscopy were not significantly detectable. On the other hand, a reduction on the granules birefringence could be observed as indicated by white arrows. It can be stated that agitation could promote adequate contact of phosphoric acid to the bagasse to affect the crystalline structure of the starch granules.

The application of ultrasound during the acid treatment resulted in a more clear degradation on the starch granules, observed through light microscopy analysis. The effects of acids seemed to be intensified by the ultrasound application, which is in accordance to the kinetics data of sugar release. The granules appeared with some cracks and non-regular surface, which was not observed in the raw bagasse neither in the hydrolyzed samples under mechanical agitation. Monroy et al. (2018) reported that the effects of ultrasound on the cassava starch are more pronounced on the surface roughness than on the shape itself. The authors attributed these alterations to the collapse of cavitation bubbles, which cause enough high pressure gradient and intense shear forces in the surrounding area to depolymerize amylose and amylopectin as the process is extended. This degradation generates micro channels into the granules, which is useful for enhancing digestibility by glucoamylase, for example (Wu et al., 2011).

Analogously, as the interaction between enzyme and starch was reported to be enhanced by US, the same mechanism could be applied to phosphoric acid in solution. The presence of micro-pores in the granule may be responsible by intensifying acid penetration and by promoting structural disorganization. Sujka and 
Jamroz (2013) also observed depolymerization of different starches with consequent changes on morphology and swelling properties by the increase of water absorption after ultrasonic treatment.

\section{Before Hydrolysis}
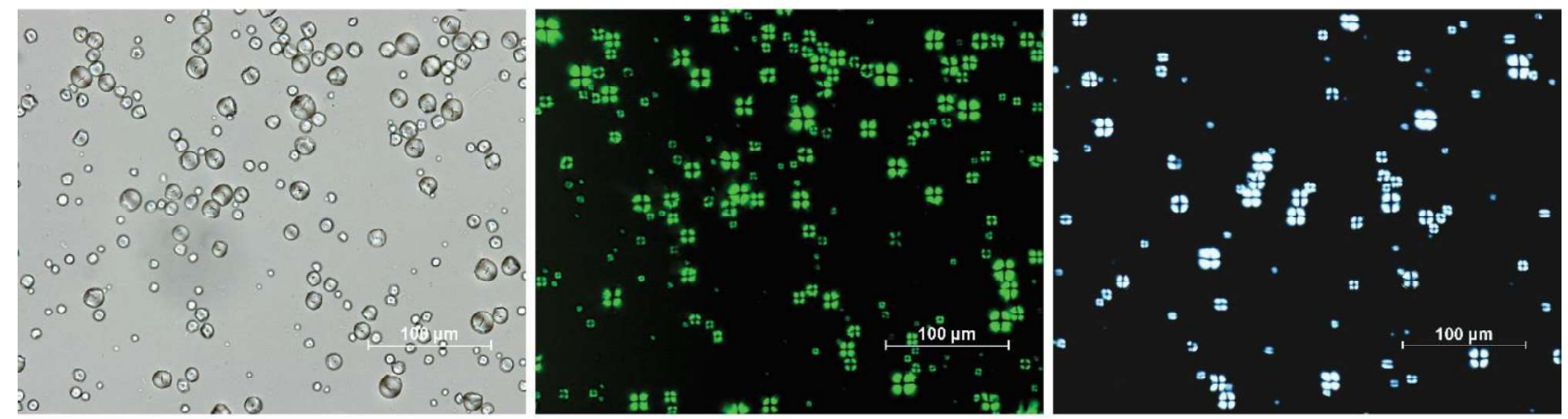

\section{Conventional Agitation}
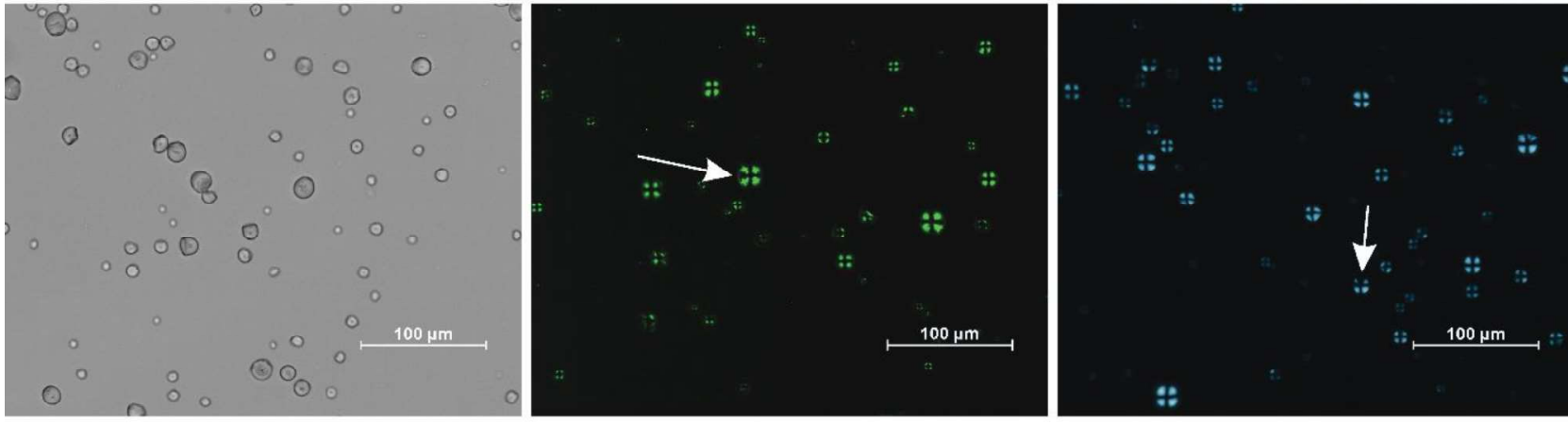

\section{Ultrasound-assisted}
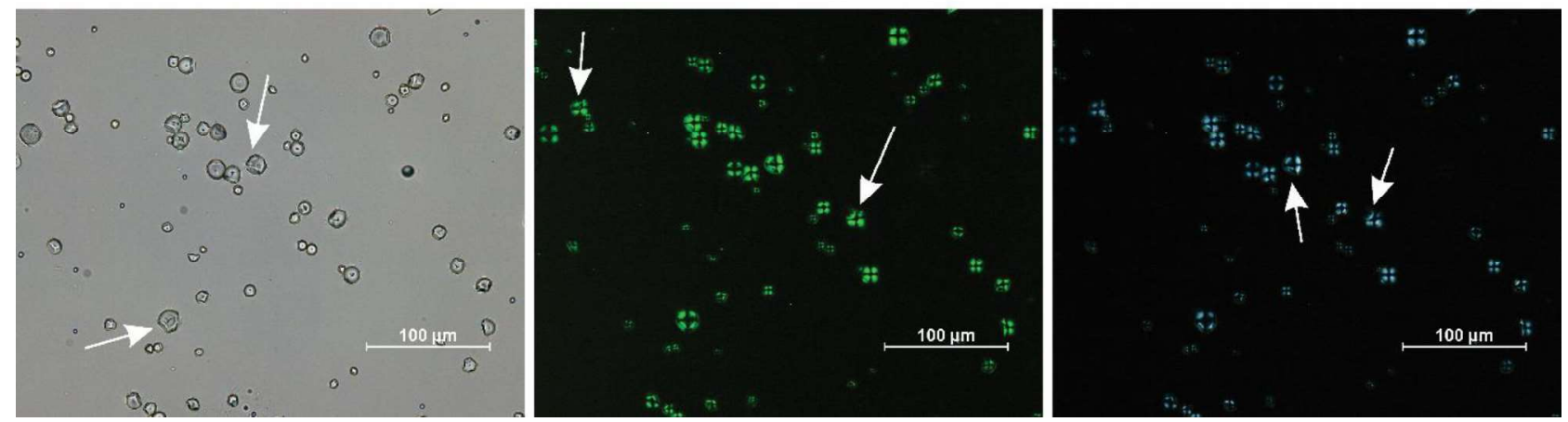

Figure 5.7.6. Visible (left), fluorescence (middle) and polarized light (right) micrographs at $20 x$ of magnitude of cassava bagasse before and after acid treatments under conventional agitation or by high-intensity ultrasound. 
These alterations are reinforced by higher decrease in the birefringence degree of US-treated bagasse when compared to the conventionally agitated ones, observed in fluorescence and polarized light microscopies. According to Muñoz et al. (2015), the granules swelling is preceded by a rapid loss of birefringence and tends to continue even after the complete loss of birefringence. The Maltese cross presented a gradual decreased from the hilium towards the surface as a consequence of the acid solution absorption by the granules. It is a result of the higher loss of radial organization of amylose and amylopectin chains (Colonna and Buleon, 2010). Tao et al. (2018) accompanied the loss of birefringence by polarized light microscopy as the granules are gelatinized.

These findings are in accordance to the observations made in the stained fibrous matters and to the kinetics data of sugar release, which demonstrated a higher effect of ultrasound on hydrolyzing solid particles when compared to agitation. The degradation of the starch surface by cavitation indicates that there is a significant release of carbohydrates from the granules and a better accessibility to chemical and enzymes in further additional steps of bioethanol production could be acquired.

\subsubsection{Conclusions}

The ultrasound application enhanced the hydrolysis of cassava bagasse in the presence of phosphoric acid. Naik model fitted adequately the experimental kinetics of sugar release. Hydrolysis assisted by ultrasound reached the equilibrium before than experiments carried out with agitation. The decrease on the acoustic power produced by the increase of viscosity during treatment could reduce the ultrasound effects at the end of the process. The conventional agitation and US application provided good interaction between the catalyst and biomass, reducing the birefringence of the starch granules in both process. In addition, US provided slight change on the fibrous matter and higher disorganization of the crystalline structure of the starch granules.

Therefore, ultrasound technology represents an alternative for treating biomass in order to alter the structure and release fermentable matter. It may also account for a reduction in the processing time and chemicals usage in further steps involved in the bioethanol production. 


\subsubsection{Acknowledgments}

Authors acknowledge the INIA-ERDF (RTA2015-00060-C04-02 and RTA2015-00060-C04-03) from Spain and the São Paulo Research Foundation FAPESP (Grant 2017/06518-2) and the Coordination for the Improvement of Higher Level Personnel - CAPES (Grant 88881.132626/2016-01) from Brazil for the financial support.

\subsubsection{References}

Alvira, P., Tomás-Pejó, E., Ballesteros, M., Negro, M.J., (2010). Pretreatment technologies for an efficient bioethanol production process based on enzymatic hydrolysis: A review. Bioresource Technology 101(13), 4851-4861.

Cinelli, B.A., Castilho, L.R., Freire, D.M.G., Castro, A.M., (2015). A brief review on the emerging technology of ethanol production by cold hydrolysis of raw starch. Fuel 150, 721-729.

Colonna, P., Buleon, A., (2010). Thermal transitions of starches, in: Bertolini, A. (Ed.), Starches, characterization, properties and applications. Taylor \& Francis Group, Boca Raton, pp. 71-102.

Fontana, J.D., Passos, M., Baron, M., Mendes, S.V., Ramos, L.P., (2001). Cassava Starch Maltodextrinization/Monomerization through Thermopressurized Aqueous Phosphoric Acid Hydrolysis, in: Davison, B.H., McMillan, J., Finkelstein, M. (Eds.), Twenty-Second Symposium on Biotechnology for Fuels and Chemicals. Humana Press, Totowa, NJ, pp. 469-478.

Kassaye, S., Pant, K.K., Jain, S., (2017). Hydrolysis of cellulosic bamboo biomass into reducing sugars via a combined alkaline solution and ionic liquid pretreament steps. Renewable Energy 104, 177-184.

Lenihan, P., Orozco, A., O'Neill, E., Ahmad, M.N.M., Rooney, D.W., Walker, G.M., (2010). Dilute acid hydrolysis of lignocellulosic biomass. Chemical Engineering Journal 156(2), 395-403.

Li, M.-F., Fan, Y.-M., Xu, F., Sun, R.-C., Zhang, X.-L., (2010). Cold sodium hydroxide/urea based pretreatment of bamboo for bioethanol production: 
Characterization of the cellulose rich fraction. Industrial Crops and Products 32(3), 551-559.

Li, M., Li, J., Zhu, C., (2018). Effect of ultrasound pretreatment on enzymolysis and physicochemical properties of corn starch. International Journal of Biological Macromolecules 111, 848-856.

Lin, Y., Tanaka, S., (2006). Ethanol fermentation from biomass resources: current state and prospects. Applied Microbiology and Biotechnology 69(6), 627-642.

Mason, T.J., Cordemans, E.D., (1996). Ultrasonic intensification of chemical processing and related operations: A review. Chemical Engineering Research \& Design 74(A5), 511-516.

Mason, T.J., Lorimer, J.P., (2002). Applied sonochemistry. Wiley-vch, Weinheim.

Monroy, Y., Rivero, S., García, M.A., (2018). Microstructural and techno-functional properties of cassava starch modified by ultrasound. Ultrasonics Sonochemistry 42, 795-804.

Montalbo-Lomboy, M., Johnson, L., Khanal, S.K., van Leeuwen, J., Grewell, D., (2010). Sonication of sugary-2 corn: A potential pretreatment to enhance sugar release. Bioresource Technology 101(1), 351-358.

Muñoz, L.A., Pedreschi, F., Leiva, A., Aguilera, J.M., (2015). Loss of birefringence and swelling behavior in native starch granules: Microstructural and thermal properties. Journal of Food Engineering 152, 65-71.

Naik, S.N., Lentz, H., Maheshwari, R.C., (1989). Extraction of perfumes and flavours from plant materials with liquid carbon dioxide under liquid-vapor equilibrium conditions. Fluid Phase Equilibria 49, 115-126.

Nigam, P.S., Singh, A., (2011). Production of liquid biofuels from renewable resources. Progress in Energy and Combustion Science 37(1), 52-68.

Oirschot, Q.E.A., O'Brien, G.M., Dufour, D., El-Sharkawy, M.A., Mesa, E., (2000). The effect of pre-harvest pruning of cassava upon root deterioration and quality characteristics. Journal of the Science of Food and Agriculture 80(13), 18661873.

Pandey, A., Soccol, C.R., Nigam, P., Soccol, V.T., Vandenberghe, L.P.S., Mohan, R., (2000). Biotechnological potential of agro-industrial residues. II: cassava bagasse. Bioresource Technology 74(1), 81-87. 
Polachini, T.C., Carvalho, G.R., Telis-Romero, J., (2017). Determination of acoustic fields in acidic suspensions of peanut shell during pretreatment with highintensity ultrasound. Brazilian Journal of Chemical Engineering 34(2), 385-394.

Polachini, T.C., Mulet, A., Cárcel, J.A., Telis-Romero, J., (2019). Thermophysical properties of dilute acid slurries of cassava bagasse as a function of biomass loading, acid concentration and temperature. Chemical Engineering Research \& Design.

Ramón, A.P., Taschetto, L., Lunelli, F., Mezadri, E.T., Souza, M., Foletto, E.L., Jahn, S.L., Kuhn, R.C., Mazutti, M.A., (2015). Ultrasound-assisted acid and enzymatic hydrolysis of yam (Dioscorea sp.) for the production of fermentable sugars. Biocatalysis and Agricultural Biotechnology 4(1), 98-102.

Raso, J., Manas, P., Pagan, R., Sala, F.J., (1999). Influence of different factors on the output power transferred into medium by ultrasound. Ultrasonics Sonochemistry 5(4), 157-162.

Rehman, M.S.U., Kim, I., Chisti, Y., Han, J.-I., (2013). Use of ultrasound in the production of bioethanol from lignocellulosic biomass. Energy Education Science and Technology Part A: Energy Science and Research 30(2), 13911410.

Santos, A.L.F., Kawase, K.Y.F., Coelho, G.L.V., (2011). Enzymatic saccharification of lignocellulosic materials after treatment with supercritical carbon dioxide. The Journal of Supercritical Fluids 56(3), 277-282.

Shewale, S.D., Pandit, A.B., (2009). Enzymatic production of glucose from different qualities of grain sorghum and application of ultrasound to enhance the yield. Carbohydrate Research 344(1), 52-60.

Sujka, M., Jamroz, J., (2013). Ultrasound-treated starch: SEM and TEM imaging, and functional behaviour. Food Hydrocolloids 31(2), 413-419.

Sun, Y., Cheng, J., (2002). Hydrolysis of lignocellulosic materials for ethanol production: a review. Bioresource Technology 83(1), 1-11.

Tao, J., Huang, J., Yu, L., Li, Z., Liu, H., Yuan, B., Zeng, D., (2018). A new methodology combining microscopy observation with Artificial Neural Networks for the study of starch gelatinization. Food Hydrocolloids 74, 151-158. 
Toma, M., Fukutomi, S., Asakura, Y., Koda, S., (2011). A calorimetric study of energy conversion efficiency of a sonochemical reactor at $500 \mathrm{kHz}$ for organic solvents. Ultrasonics Sonochemistry 18(1), 197-208.

Werle, L.B., Garcia, J.C., Kuhn, R.C., Schwaab, M., Foletto, E.L., Cancelier, A., Jahn, S.L., Mazutti, M.A., (2013). Ultrasound-assisted acid hydrolysis of palm leaves (Roystonea oleracea) for production of fermentable sugars. Industrial Crops and Products 45(0), 128-132.

Wu, Y., Du, X., Ge, H., Lv, Z., (2011). Preparation of microporous starch by glucoamylase and ultrasound. Starch - Stärke 63(4), 217-225.

Yang, Q.-Y., Lu, X.-X., Chen, Y.-Z., Luo, Z.-G., Xiao, Z.-G., (2019). Fine structure, crystalline and physicochemical properties of waxy corn starch treated by ultrasound irradiation. Ultrasonics Sonochemistry 51, 350-358.

Zhu, F., (2015). Composition, structure, physicochemical properties, and modifications of cassava starch. Carbohydrate Polymers 122, 456-480. 
6. General discussion 
The use of agroindustrial waste as raw material to produce bioethanol requires the pretreatment, being the power ultrasound application an interesting way to enhance the process. The literature review made showed that, the medium as well as the system operation conditions can affect the kinetics of sugar release during ultrasound-assisted pretreatments of biomass. In fact, the physical properties of the medium can influence the ultrasound propagation conditioning the magnitude of its effects, e. g. cavitation (Dolatowski et al., 2007). Therefore, the determination of thermophysical parameters of the medium of pretreatment can be very useful for predicting and simulating phenomena and processing conditions (Juliano et al., 2011).

Because of that, the present doctoral thesis was firstly focused on determining the physical properties of different acid suspensions to be used in the biomass conversion processes and find correlation not only with the acoustic fields generated but also with the resulting sonochemical effects. Thus, the first approach of this study was to evaluate how the thermophysical properties and, especially the rheological ones, are affected by biomass concentration changes in the suspension, acid concentration and operating temperature.

Concerning data about thermal properties of cassava bagasse acid suspensions, the higher values for thermal diffusivity $(\alpha)$ and for thermal conductivity $(\lambda)$ were observed at higher temperatures in the tested suspensions with lower solids and phosphoric acid concentration. In these conditions, it was also found the higher values of specific heat capacity. Materials with high values of $\alpha$ and $\lambda$ have the ability for diffusing heat changes with higher velocity (Daugaard et al., 2018), leading to a more homogeneous heat transfer. The higher specific heat capacity $\left(c_{p}\right)$, the greater the capacity for retaining temperature. Therefore, the heat transfer during the pretreatment was supposed to occur more efficiently in diluted suspensions which are also able to storage larger amounts of acoustic energy before increasing the temperature (higher $c_{p}$ ) when compared to concentrated suspensions. These conditions must be taken into accout in processes assisted by ultrasound because the heat absorption can produce a not always desirable temperature rise. The temperature control in sonoreactors is essential and contributes for reducing energy losses and increasing process efficiency (Nguyen et al., 2017). As thermal properties 
have a direct effect on the heating rate provoked by ultrasound cavitation during pretreatment, their determination make possible the estimation of the actual acoustic power applied by using calorimetric methods as well as the correct design of heat transfer processes.

Another group of physical properties that can affect the pretreatment are those related with the reology of suspensions. In these sense, a study of the rheological behavior was carried out for acid suspensions containing two industrial by-products, powdered peanut shells and cassava bagasse. Rheological parameters determination is necessary not only for measuring the degree of molecular interaction but also for the correct design of the unit operations and equipment. The magnitude of the cohesive forces that keep molecules close to each other reflects the cavitating potential during sonication (Mason and Lorimer, 2002). Thus, the fluids with high viscosity values had higher cohesive forces between moleules that exert greater the resistance for creating cavities during the decompression zones making difficult cavitation take place (Behrend et al., 2000; Briggs et al., 1947; Chemat et al., 2017).

The viscosity in heterogeneous systems, which is the case of biomass suspensions, may be attributed to the characteristics of the dispersant as well as of the dispersed phase (Bernaerts et al., 2017). Concerning the dispersed phase, biomass can vary according to the chemical composition, morphology and particle size. Thus, the comparison between peanut wastes and cassava bagasse suspensions showed that cassava bagasse suspensions had higher difficulty to flow as showed the higher yield stresses and consistency index from Herschel-Bulkley model. Similar degree of shear-thinning (flow index behavior $\approx 0.85$ ) was found for suspensions with $10 \%$ of cassava bagasse and $12 \%$ peanut shell suspensions. In other words, it was found similar flow resistance in peanut shell suspensions with higher solids loading than cassava bagasse suspensions with lower content of solids.

Among the studied parameters, the main differences linked to the different types of biomass can be attributed to the chemical composition and to the mean particle size, since the aspect ratio was quite similar. Peanut shells are lignocellulosic material while the cassava bagasse is mainly composed by starch granules and this difference may affect compressibility and frictional forces between the matrices structure (Klingenberg et al., 2017). Powdered peanut shells presented mean particle 
size higher $\left(D_{4,3} \approx 492.7 \mu \mathrm{m}\right)$ when compared to cassava bagasse $\left(D_{4,3} \approx 175.5 \mu \mathrm{m}\right)$. By comparing the properties of the two kind of biomass as dispersed phase, Hou et al. (2016) also reported higher apparent viscosities for suspensions containing smaller particles in comparison with suspensions constituted by bigger particles. It may be attributed to the increased specific surface area of thinner particles (Roh et al., 1995).

As regard the acid content in the suspensions, the increase of the concentration (up to $10 \% \mathrm{w} \cdot \mathrm{w}^{-1}$ ) produced a significant increase of the apparent viscosity. In different levels, this fact could affect the way by how particles interact among each other to raise resistance to flow which was observed in our study by zeta potential (Polachini et al., 2016) and agree with other reported results (Liu et al., 2016; Zhu et al., 2018). However, it can be negligible depending on the hydrodynamic forces applied during the flow.

As cited previously, this whole set of physical properties can affect how the ultrasounic waves propagate through the medium and determine not only if cavitation can occur but also the intensity of its effects (Hosny et al., 1996). In fact, the results of acoustic fields characterization in differents biomass suspension carried out from calorimetric method reinforced the statement that not all electrical input energy is converted into acoustic power. In Chapter 4 and 5 it is showed that the acoustic power and intensity and so, the efficiency by converting energy into acoustic power, were improved in the more diluted supensions and when high input power were applied. The yield of power conversion seemed to be higher for peanut shells ( $82.5 \%)$ when compared to cassava bagasse ( $60.6 \%)$ for the similar conditions. It is probably related to the different rheological characteristics of these two kind of suspensions and consequently to the particle size and chemical composition of the biomass. Thus, cassava bagasse suspensions had higher apparent viscosities when compared to the peanut shells suspension, the required molecular displacement for the cavitation to occur is impaired. Moreover, the presence of materials with different properties (e. g., suspensions containg dispersed solids with different sizes) can affect how the ultrasound propagates and sound waves scattering may occur (Povey and McClements, 1988; Yin et al., 2004).

The energy required to reach the same acoustic intensity was significantly higher in concentrated suspensions than in the diluted ones. Although equivalent 
punctual heating rates could be obtained, concentrated suspensions tend to present low efficiency in heat transport (Abdulrahman, 2015). It makes difficult the acoustic effects and heat transfer to the material placed away from the sonotrode tip, overheating the sample in contact with the sonotrode and leads to a heterogenous application of ultrasound treatment. Analogously, the cooling of concentrated suspensions, necessary to control process temperature, becomes an aditional challenge.

The analysis of the acoustic intensity for cassava bagasse suspensions in different positions away from the sonotrode permitted to quantify the attenuation of the acoustic waves through the suspensions. Although ultrasonic waves are attenuated according to the medium properties (Majumdar et al., 1998), variations in the range of studied $\mathrm{pH}$ of the aqueous solution, input power and solids concentration were not enough to promote significant changes in the attenuation factor. Thus, a constant attenuation coefficient of $0.021 \mathrm{~cm}^{-1}$ was observed in the studied range of variables. On the other hand, acoustic intensity demonstrated high correlation $(|r|>0.87)$ with previous data of density, specific heat, thermal diffusivity, thermal conductivity and apparent viscosity of suspensions showed in Chapter 1 and Chapter 2. Thus, a more intense cavitation was observed when decreasing the density and the apparent viscosity and increasing the specific heat, the thermal diffusivity and the thermal conductivity.

Finally, the kinetics of reducing and total sugar release was evaluated using artichoke wastes and cassava bagasse as examples of biomass. Kinetics analysis represents an interesting and complementary tool for identifying optimal conditions and permits the comparison of different technologies (Tizazu and Moholkar, 2018). For this, sugar dissolution in aqueous medium and the actual acid hydrolysis were differentiated testing in both cases the use of conventional agitation or ultrasound application. The results showed that sugar dissolution of artichoke waste in aqueous medium can be significantly accelerated by ultrasound application, but attaining the same values of equilibrium as obtained for conventional agitation. Mechanical agitation was efficient for promoting the contact substrate-catalyst during acid hydrolysis of suspensions with $5 \% \mathrm{w} \cdot \mathrm{w}^{-1}$ of artichoke biomass, leading to both total and reducing sugar release. Aguilar et al. (2002) related that sugars from diluted acid 
hydrolysis of lignocellulosic biomass are more attributed to hemicellulose digestion instead of cellulose.

On the other hand, the reduction in the biomass concentration below $2.5 \%$ $\mathrm{w} \cdot \mathrm{w}^{-1}$ improved the effects of ultrasound. Thus, the same levels of sugar realease were found in these conditions than in experiments carried out with conventional agitation. However, the application of ultrasound likely produced a more intense structural degradation as shown the changes on rheological measurements observed. These measurements of the suspensions hydrolyzed with ultrasound application indicated that structural modifications occurred more intensily on the biomass when compared to agitation, which may have promoted the release of carbohydrates of low molecular chain to the bulk phase.

The direct treatment of artichoke by-product into acid solutions also demonstrated the higher efficiency of ultrasound application for releasing both reducing and total sugars. Tizazu et al. (2018) reported that xylans from hemicellulose dissolves faster in acid medium and are quickly hydrolyzed, promoting a synergistic effect for sugar release. Changes in the acoustic fields and rheological behavior obtained showed the need to address these facts when developing ultrasound-assisted pretreatments with constant acoustic intensity application over the process.

Regarding the kinetics of sugar release from cassava bagasse, the actual acid hydrolysis of cassava bagasse produced similar yields when comparing conventional agitation and ultrasound with a slight higher efficiency of this last. However, the relative sugar release was higher for artichoke biomass when compared to cassava bagasse. One reason could be the higher viscosity of the cassava bagasse suspensions. Thus, during the ultrasound-assisted acid hydrolysis, a slight higher acoustic density were found in artichoke waste suspensions than in cassava bagasse ones. The analysis of the microstructure of untreated and treated samples showed that ultrasound had higher effect on hydrolyzing starch granules and causing erosion in the fibrous matters than conventional agitation. Monroy et al. (2018) reported the effects of sonication on the structural and functional properties of cassava starch. It was similarly evidenced by the microscopies and the loss of birefringence of the starch granules. Such results demonstrated that ultrasound is not able to completely 
change the whole structure of starch granules but it can increase its permeability for further applications (Huang et al., 2007). Rheological parameters changes over the different treatment as well as the acoustic fields determination were useful to contrast the alterations occurred in the material over the pretreatments, being all of them in close aggrement 
7. General conclusions 
The main conclusions extracted by this doctoral thesis are presented in seven different sections according to the different approaches addressed:

\subsection{Thermophysical properties of cassava bagasse suspensions}

- Density of acid suspensions containing cassava bagasse increased when greater was the solids concentration of suspensions, the higher the acid content and the lower the temperature $(p<0.05)$;

- Specific heat, thermal diffusivity and thermal conductivity values decreased as the solids load of suspensions and the phosphoric acid concentration in the solution increased and temperature decreased $(p<0.05)$;

- Empirical models could be well-fitted to the experimental values $\left(R^{2}>0.92\right.$ and $\left.M R E<1.75 \%\right)$;

\subsection{Rheological behavior of cassava bagasse suspensions}

- Cassava bagasse presented $49 \%$ of residual starch corresponding $43 \%$ to cellulose and hemicellulose fractions;

- Acid suspensions with less than $6 \%$ of cassava bagasse showed Newtonian characteristics while concentrations above $6 \%$ resulted in noticeable yield stress up to $3.22 \mathrm{~Pa}$ and shear-thinnning behavior $(0.85<n<1)$;

- Yield stress, consistency coefficient and apparent viscosity increased by increasing the concentration of cassava bagasse, acid content in solution and decreasing temperature;

- Flox behavior index decreased as the biomass and phosphoric acid content increase without significant effect of temperature;

- Experimental rheological parameters were fitted to polynomial models and correlated with temperature by an Arrhenius-type equation;

- Suspensions with up to $10 \%$ of suspended solids concentration, $10 \%$ of phosphoric acid in solution and temperature between 5 and $45^{\circ} \mathrm{C}$ 
presented to be a medium with fluid-like properties, suitable for being sonicated;

\subsection{Rheological behavior of peanut shells suspensions}

- Peanut shells were chemically ( $41.7 \%$ cellulose; $37.5 \%$ hemicellulose and $16.8 \%$ lignin in dry basis) and physically characterized (morphology and particle size);

- Suspensions with less than $8 \%$ of suspended solids presented Newtonian behavior while, above this value, suspensions presented shear-thinning behavior and significant values of yield stress;

- $\mathrm{pH}$ influenced the zeta potential of powdered peanut shells but did not influenced rheological parameters in the studied range of shear rate;

- Flow resistance (consistency index and apparent viscosity) and shearthinning behavior increased for concentrated suspensions at lower temperatures;

- Farris effect was observed due to the large number o thinner particles, decreasing the relative viscosity above $10 \%$ of solids;

\subsection{Acoustic fields in cassava bagasse suspensions}

- Measured heating rate in the first period of sonication, acoustic power, acoustic intensity and acoustic density increased by decreasing solids concentration and increasing nominal input power. No influence of the $\mathrm{pH}$ of the dispersant on acoustic parameters was found;

- Yield of power conversions reached a maximum value of $65.5 \%$ for diluted suspensions $\left(2 \% \mathrm{w} \cdot \mathrm{w}^{-1}\right)$ at higher input power $(400 \mathrm{~W})$ and a minimum value of $36.8 \%$ for the most concentrated suspensions $(10 \%$ $\left.\mathbf{w} \cdot \mathbf{w}^{-1}\right)$ under the lowest level of power applied (160 W);

- Acoustic parameters were fitted to empirical equations to provide readyto-use models with good accuracy $\left(R^{2}>0.92\right)$;

- Ultrasound attenuation was characterized by the attenuation coefficient, being constant at $0.021 \mathrm{~cm}^{-1}$ for the different suspensions studied; 
- High correlation coefficient was observed between acoustic intensity and physical properties, increasing the acoustic intensity when the thermal properties (specific heat, thermal diffusivity and thermal conductivity) increased and the density and viscosity decreased;

\subsection{Acoustic fields in peanut shells suspensions}

- Specific heat of acid suspensions containing powdered peanut shells was determined, presenting higher values as the solids concentration decreased and temperature increased. No significant effect of $\mathrm{pH}$ of the aqueous solutions was found;

- Acoustic power and acoustic intensity were determined, being the higher values found for the more diluted suspensions and the higher input power applied;

- Yield of power conversions also varied, reaching the higher values of $82.7 \%$ for the most diluted suspensions $\left(2 \% \mathrm{w} \cdot \mathrm{w}^{-1}\right)$ at the higher input power $(400 \mathrm{~W})$ against $7.4 \%$ in the opposite conditions $\left(12 \% \mathrm{~W} \cdot \mathrm{w}^{-1}\right.$ and $80 \mathrm{~W}$ of input power applied);

- Polynominal models were fitted to experimental data as functions of the significant variables $\left(\mathrm{R}^{2} \mathrm{adj}=0.98\right.$ and $\left.\mathrm{MRE}=6.4 \%\right)$;

\subsection{Kinetics of sugar release from artichoke waste}

- The aqueous dissolution of free sugars and the sugar release due to actual acid hydrolysis were well differentiated and quantified;

- Ultrasound accelerated the sugar dissolution from artichoke waste but reaching the same equilibrium yield that found by conventional agitation of suspensions;

- Conventional agitation was efficient for hydrolyzing of artichoke waste in acid medium of suspensions with a $5 \%$ of artichoke waste. Regarding ultrasound application, its effects were more intense when the biomass content of supensions were reduced from $5 \%$ to $2.5 \%$; 
- Ultrasound showed to be more efficient to sugar release than conventional agitation in a one step process with direct immersion of biomass in acid medium process;

- Apparent viscosity of the acid suspensions increased during treatments, being higher the increase for ultrasound-assisted hydrolysis than for mechanically-agitated ones;

- Acoustic density decreased over the hydrolysis, probably as a consequence of the viscosity increase of the suspensions. Moreover, the viscosity also decreased when the biomass content in the suspensions decreased from $5 \%$ to $2.5 \%$ allowing the ultrasonic treatment to be more effectiveness ;

- Kinetics of sugar release were fitted to the Naik model with good accuracy;

\subsection{Kinetics of sugar release from cassava bagasse}

- Both conventional agitation and ultrasound were adequate to hydrolyze cassava bagasse in acid medium, releasing reducing and total sugar;

- Ultrasound application during treatments showed slight higher effect on the relative sugar release when compared to conventional mechanical agitation;

- Ultrasound produced more intense structural modifications in the fibrous matters as well as in the starch granules than conventional agitation as showed the microstructural analysis;

- Acoustic intensity was reduced almost by a half at the end of the acid hydrolysis when compared to the beginning of the process. This reduction can be linked with the increase of viscosity of the suspensions during treatement, which was higher in the ultrasoundassited hydrolysis compared with the convetional agitated process;

- Naik model fitted adequately the experimental values of reducing and total sugar release, presenting a close agreement between predicted and experimental data; 
As a general conclusion of this work, it can be stated that ultrasound can be considered an interesting technology for the pretreating of the residues from agroindustrial sector in acid medium. Its effect can enhance the hydrolysis of biomass. Moreover, it can contribute to alter biomass microstructure, making easier the further steps involved in the bioethanol production. In addition, the sonochemical effects can be enhanced by modifying the physical properties of the acid suspensions as well as the sonicating parameters. 
8. Recommendations 
Based on the results obtained by this doctoral research, it is strongly recommended to deepen in the study of the sonochemical effects in biomass pretreatment processes. Among the different approaches that are suggested to cover the ultrasound effects in the whole process of biomass conversion, there are:

- An energetic/economic analysis in order to evaluate if the energy expenses by the use of ultrasound significantly shorten the processing or contributes to a significant chemicals reduction during the biomass saccharification, fermentation and distillation;

- Study the pretreatment assisted by ultrasound using different catalyst as other acids, alkalis, enzymes and oxidizing agentes as well as the physical properties of the suspensions constituted of these compounds;

- A chemical study about the ultrasound selectivity when acting on the biomass structure as well as about the specific compounds released over the pretreatments;

- Determining the influence of ultrasound effects produced by changes in the overall pressure as well as in the vapour pressure of the acid suspensions;

- Deepening the characterization of the effect of treating biomass with different composition, particle size and morphology on the acoustic fields and yields of sugar release when using ultrasound;

- The design of a scaled-up process assisted by ultrasound in order to treat larger volume of suspensions; 
9. Scientific contributions 


\subsection{Research papers}

Polachini, T. C.; Mulet, A.; Hernando,I.; Telis-Romero, J.; Cárcel, J. A. (2019) A Comparison Between Conventional Agitation and Ultrasound Application on the Acid Hydrolysis of Cassava (Manihot esculenta) Bagasse. Submitted to Bioresource Technology.

Polachini, T. C.; Mulet, A.; Telis-Romero, J.; Cárcel, J. A. (2019) Influence of highintensity ultrasound application in the kinetics of sugar release from acid suspensions of artichoke (Cynara scolymus) biomass. Submitted to Chemical Engineering and Processing: Process Intensification.

Polachini, T. C.; Mulet, A.; Telis-Romero, J.; Cárcel, J. A. (2019) Acoustic Fields of Acid Suspensions Containing Cassava Bagasse: Influence of Physical Properties on Acoustic Attenuation. Submitted to Ultrasonics Sonochemistry.

Polachini, T. C.; Mulet, A.; Cárcel, J. A.; Telis-Romero, J. (2019) Rheology of acid suspensions containing cassava bagasse: effect of biomass loading, acid content and temperature. Powder Technology, v. 354, p. 271-280.

Polachini, T. C.; Mulet, A.; Cárcel, J. A.; Telis-Romero, J. (2019) Thermophysical properties of dilute acid slurries of cassava bagasse as a function of biomass loading, acid concentration and temperature. Submitted to Chemical Engineering Research \& Design.

Polachini, T. C.; Carvalho, G. R.; Telis-Romero, J. (2017). Determination of acoustic fields in acidic suspensions of peanut shell during pretreatment with highintensity ultrasound. Brazilian Journal of Chemical Engineering, v. 34, p. 385394.

Polachini, T. C.; Sato, A. C. K.; Cunha, R. L.; Telis-Romero, J. (2016). Density and rheology of acid suspensions of peanut waste in different conditions: an engineering basis for bioethanol production. Powder Technology, v. 294, p. 168-176.

Polachini, T. C.; Betiol, L. F. L.; Lopes-Filho, J. F.; Telis-Romero, J. (2016). Water adsorption isotherms and thermodynamic properties of cassava bagasse. Thermochimica Acta, v. 632, p. 79-85. 


\subsection{Conference papers}

Polachini, T. C.; Martins, M. J. N.; Rodrigues, W. G.; Telis-Romero, J.; Cárcel, J. A.; Mulet, A. (2018). Campos acústicos em suspensões ácidas de resíduos de mandioca durante o pré-tratamento com ultrassom de alta intensidade. In: XXII Congresso Brasileiro de Engenharia Química, 2018, São Paulo. Blucher Chemical Engineering Proceedings,. p. 717.

Polachini, T. C.; Mulet, A.; Cárcel, J. A.; Telis-Romero, J.. (2018). Caracterização física e química de bagaço de mandioca de diferentes granulometrias. In: VI Simpósio de Engenharia e Ciência de Alimentos, 2018, São José do Rio Preto. VI Simpósio de Engenharia e Ciência de Alimentos. Campinas: Galoá Proceedings, v. 1. p. 1-7.

Polachini, T. C.; Mulet, A.; Telis-Romero, J. (2017). Specific heat of acid suspensions of cassava bagasse: a necessary tool for designing heat transfer in bioethanol industry. In: BBEST - Brazilian BioEnergy Science and Technology Conference: Designing a Sustainable Bioeconomy, 2017, Campos do Jordão. Proceedings of the Brazilian BioEnergy Science and Technology Conference 2017 (BBEST 2017). Campos do Jordão: BBEST, p. 81-81.

Polachini, T. C.; Mulet, A.; Telis-Romero, J. (2017). Rheological behaviour of different suspensions of cassava bagasse as affected by the phosphoric acid concentration in aqueous dispersant. In: 31st EFFoST International Conference, 2017, Sitges. 31st EFFoST International Conference, p. 66-66.

Polachini, T. C.; Mulet, A.; Telis-Romero, J. (2017). Thermal diffusivity of acid suspensions of powdered cassava bagasse at different conditions. In: 31st EFFoST International Conference, 2017, Sitges. 31st EFFoST International Conference, p. 69-69.

Polachini, T. C.; Mulet, A.; Telis-Romero, J. (2016). Avaliação estrutural de cascas de amendoim tratadas com ultrassom de alta intensidade. In: XXI Congresso Brasileiro de Engenharia Química, 2016, Fortaleza. Anais do Congresso Brasileiro de Engenharia Química, p. 1-8.

Polachini, T. C.; Mulet, A.; Telis-Romero, J. (2016). Efeito das condições de processo na hidrólise de cascas de amendoim utilizando ultrassom de alta 
intensidade. In: XXI Congresso Brasileiro de Engenharia Química, 2016, Fortaleza. Anais do Congresso Brasileiro de Engenharia Química, p. 1-8.

Polachini, T. C.; Telis-Romero, J.; Mulet, A. (2016). Reologia de suspensões aquosas de bagaço de mandioca em pó: efeito da temperatura, concentração de sólidos e tamanho de partícula. In: Congresso Brasileiro de Ciência e Tecnologia de Alimentos, 2016, Gramado. Anais do Congresso Brasileiro de Ciência e Tecnologia de Alimentos. Porto Alegre: SBCTA Regional, p. 1-6.

Polachini, T. C.; Carvalho, G. R.; Telis-Romero, J. (2015). Using the calorimetric method to determine the real power absorbed by acidified suspensions of lignocellulosic wastes treated with high-intensity ultrasound. In: $X$ Congreso Iberoamericano de Ingenieria de Alimentos, 2015, Montevidéu. INNOVA 2015 X CIBIA. Montevidéu: Laboratorio Tecnologico del Uruguay. v. 1. p. 154-154.

Polachini, T. C.; Carvalho, G. R.; Telis-Romero, J. (2015). Resíduos de fecularias Secagem do bagaço de mandioca em camada fina. In: $X$ Congreso Iberoamericano de Ingenieria de Alimentos, 2015, Montevidéu. INNOVA 2015 X CIBIA. Montevidéu: Laboratorio Tecnologico del Uruguay. v. 1. p. 163-163. 
10. References 
Abdulrahman, M.W., (2015). Experimental studies of direct contact heat transfer in a slurry bubble column at high gas temperature of a helium-water-alumina system. Applied Thermal Engineering 91, 515-524.

ABICAB, (2019). Estatísticas - Amendoim. Associação Brasileira da Indústria de Chocolates, Cacau, Amendoim, Balas e Derivados, São Paulo.

Agbor, V.B., Cicek, N., Sparling, R., Berlin, A., Levin, D.B., (2011). Biomass pretreatment: Fundamentals toward application. Biotechnology Advances 29(6), 675-685.

Aguilar, R., Ramírez, J.A., Garrote, G., Vázquez, M., (2002). Kinetic study of the acid hydrolysis of sugar cane bagasse. Journal of Food Engineering 55(4), 309-318.

Aimin, T., Hongwei, Z., Gang, C., Guohui, X., Wenzhi, L., (2005). Influence of ultrasound treatment on accessibility and regioselective oxidation reactivity of cellulose. Ultrasonics Sonochemistry 12(6), 467-472.

Alinia, R., Zabihi, S., Esmaeilzadeh, F., Kalajahi, J.F., (2010). Pretreatment of wheat straw by supercritical $\mathrm{CO} 2$ and its enzymatic hydrolysis for sugar production. Biosystems Engineering 107(1), 61-66.

Alvira, P., Tomás-Pejó, E., Ballesteros, M., Negro, M.J., (2010). Pretreatment technologies for an efficient bioethanol production process based on enzymatic hydrolysis: A review. Bioresource Technology 101(13), 4851-4861.

Amami, E., Khezami, W., Mezrigui, S., Badwaik, L.S., Bejar, A.K., Perez, C.T., Kechaou, N., (2017). Effect of ultrasound-assisted osmotic dehydration pretreatment on the convective drying of strawberry. Ultrasonics Sonochemistry 36, 286-300.

Anike, F.N., Yusuf, M., Isikhuemhen, O.S., (2016). Co-substrating of peanut shells with cornstalks enhances biodegradation by Pleurotus ostreatus. Journal of Bioremediation and Biodegradation 7(1), 1-7.

Azmir, J., Zaidul, I.S.M., Rahman, M.M., Sharif, K.M., Mohamed, A., Sahena, F., Jahurul, M.H.A., Ghafoor, K., Norulaini, N.A.N., Omar, A.K.M., (2013). Techniques for extraction of bioactive compounds from plant materials: $A$ review. Journal of Food Engineering 117(4), 426-436. 
Bacovsky, D., Ludwiczek, N., Ognissanto, M., Wörgetter, M., (2013). Status of advanced biofuels demonstration facilities in 2012: A report to IEA Bioenergy Task 39. IEA Bioenergy Task 39, pp. 1-209.

Balat, M., (2011). Production of bioethanol from lignocellulosic materials via the biochemical pathway: A review. Energy Conversion and Management 52(2), 858-875.

Behrend, O., Ax, K., Schubert, H., (2000). Influence of continuous phase viscosity on emulsification by ultrasound. Ultrasonics Sonochemistry 7(2), 77-85.

Benedito, J., Carcel, J.A., Gonzalez, R., Mulet, A., (2002a). Application of low intensity ultrasonics to cheese manufacturing processes. Ultrasonics $40(1-8)$, 19-23.

Benedito, J., Carcel, J.A., Rossello, C., Mulet, A., (2001). Composition assessment of raw meat mixtures using ultrasonics. Meat Science 57(4), 365-370.

Benedito, J., Mulet, A., Velasco, J., Dobarganes, M.C., (2002b). Ultrasonic Assessment of Oil Quality during Frying. Journal of Agricultural and Food Chemistry 50(16), 4531-4536.

Berlan, J., Mason, T.J., (1996). Dosimetry for power ultrasound and sonochemistry, in: Mason, T.J. (Ed.), Advances in Sonochemistry. JAI Press Inc, Londres, pp. 1-73.

Bermúdez-Aguirre, D., Mobbs, T., Barbosa-Cánovas, G., (2011). Ultrasound Applications in Food Processing, in: Feng, H., Barbosa-Canovas, G., Weiss, J. (Eds.), Ultrasound Technologies for Food and Bioprocessing. Springer New York, pp. 65-105.

Bernaerts, T.M.M., Panozzo, A., Doumen, V., Foubert, I., Gheysen, L., Goiris, K., Moldenaers, P., Hendrickx, M.E., Van Loey, A.M., (2017). Microalgal biomass as a (multi)functional ingredient in food products: Rheological properties of microalgal suspensions as affected by mechanical and thermal processing. Algal Research 25, 452-463.

Beux, M.R., Soccol, C.R., Marin, B., Tonial, T., Roussos, S., (1997). Cultivation of Lentinula edodes on mixture of cassava bagasse and sugarcane bagasse, in: Roussos, S., Lonsane, B.K., Raimbault, M., Viniegra-Gonzalez, G. (Eds.), 
Advances in Solid State Fermentation. Springer Netherlands, Dordrecht, pp. 501-513.

Bobleter, O., (1994). Hydrothermal degradation of polymers derived from plants. Progress in Polymer Science 19(5), 797-841.

Bochek, A.M., (2003). Effect of Hydrogen Bonding on Cellulose Solubility in Aqueous and Nonaqueous Solvents. Russian Journal of Applied Chemistry 76(11), 17111719.

Boistier-Marquis, E., Lagsir-Oulahal, N., Callard, M., (1999). Applications des ultrasons de puissance en industries alimentaires. Industries alimentaires et agricoles 116(3), 23-31.

Briggs, H.B., Johnson, J.B., Mason, W.P., (1947). Properties of Liquids at High Sound Pressure. The Journal of the Acoustical Society of America 19(4), 664677.

Camara, V.C., Laux, D., (2010). Moisture content in honey determination with a shear ultrasonic reflectometer. Journal of Food Engineering 96(1), 93-96.

Cárcel, J.A., Benedito, J., Bon, J., Mulet, A., (2007a). High intensity ultrasound effects on meat brining. Meat Science 76(4), 611-619.

Cárcel, J.A., Benedito, J., Rosselló, C., Mulet, A., (2007b). Influence of ultrasound intensity on mass transfer in apple immersed in a sucrose solution. Journal of Food Engineering 78(2), 472-479.

Cárcel, J.A.C., (2003). Influencia de los ultrasonidos de potencia en procesos de transferencia de materia, Departamento de Tecnología de Alimentos. Universidad Politécnica de Valencia, Valencia, p. 318.

Carlin, B., (1972). Ultrasónica. Urmo, Bilbao.

Carta, F.S., Soccol, C.R., Ramos, L.P., Fontana, J.D., (1999). Production of fumaric acid by fermentation of enzymatic hydrolysates derived from cassava bagasse. Bioresource Technology 68(1), 23-28.

Carvalheiro, F., Duarte, L.C., Girio, F.M., (2008). Hemicellulose biorefineries: a review on biomass pretreatments. Journal of Scientific \& Industrial Research 67(11), 849-864. 
Castro, A.M., Pereira-Jr, N., (2010). Production, properties and application of cellulases in the hydrolysis of agroindustrial residues. Química Nova 33(1), 181188.

Chandra, R.P., Bura, R., Mabee, W.E., Berlin, A., Pan, X., Saddler, J.N., (2007). Substrate Pretreatment: The Key to Effective Enzymatic Hydrolysis of Lignocellulosics?, in: Olsson, L. (Ed.), Biofuels. Springer Berlin Heidelberg, Berlin, Heidelberg, pp. 67-93.

Chang, V.S., Burr, B., Holtzapple, M.T., (1997). Lime pretreatment of switchgrass. Applied Biochemistry and Biotechnology 63(1), 3.

Chemat, F., Rombaut, N., Sicaire, A.-G., Meullemiestre, A., Fabiano-Tixier, A.-S., Abert-Vian, M., (2017). Ultrasound assisted extraction of food and natural products. Mechanisms, techniques, combinations, protocols and applications. A review. Ultrasonics Sonochemistry 34, 540-560.

Chen, W., Yu, H., Liu, Y., Chen, P., Zhang, M., Hai, Y., (2011). Individualization of cellulose nanofibers from wood using high-intensity ultrasonication combined with chemical pretreatments. Carbohydrate Polymers 83(4), 1804-1811.

Chisti, Y., (2003). Sonobioreactors: using ultrasound for enhanced microbial productivity. Trends in Biotechnology 21(2), 89-93.

Cho, B.K., Irudayaraj, J.M.K., (2003). A Noncontact Ultrasound Approach for Mechanical Property Determination of Cheeses. Journal of Food Science 68(7), 2243-2247.

Coupland, J.N., (2004). Low intensity ultrasound. Food Research International 37(6), 537-543.

Dadi, A., Schall, C., Varanasi, S., (2007). Mitigation of cellulose recalcitrance to enzymatic hydrolysis by ionic liquid pretreatment. Appl Biochem Biotechnol 136140.

Dahunsi, S.O., Oranusi, S., Efeovbokhan, V.E., (2017). Optimization of pretreatment, process performance, mass and energy balance in the anaerobic digestion of Arachis hypogaea (Peanut) hull. Energy Conversion and Management 139, 260-275. 
Daugaard, T.J., Dalluge, D.L., Brown, R.C., Wright, M.M., (2018). Effect of thermophysical properties of heat carriers on performance of a laboratory-scale auger pyrolyzer. Fuel Processing Technology 176, 182-189.

Demirbas, A., (2008). Comparison of transesterification methods for production of biodiesel from vegetable oils and fats. Energy Conversion and Management 49(1), 125-130.

Dolatowski, Z.J., Stadnik, J., Stasiak, D., (2007). Applications of ultrasound in food technology. Acta Scientiarum Polonorum 6(3), 89-99.

Duque, A., Manzanares, P., Ballesteros, I., Ballesteros, M., (2016). Steam explosion as lignocellulosic biomass pretreatment, in: Mussato, S.I. (Ed.), Biomass Fractionation Technologies for a Lignocellulosic Feedstock Based Biorefinery. Elsevier Inc., Waltham, pp. 349-368.

Easson, M.W., Condon, B., Dien, B.S., Iten, L., Slopek, R., Yoshioka-Tarver, M., Lambert, A., Smith, J., (2011). The Application of Ultrasound in the Enzymatic Hydrolysis of Switchgrass. Applied Biochemistry and Biotechnology 165(5), 1322-1331.

Ebringerová, A., Hromádková, Z., (2002). Effect of ultrasound on the extractibility of corn bran hemicelluloses. Ultrasonics Sonochemistry 9(4), 225-229.

Elvira, L., Sampedro, L., Montero de Espinosa, F., Matesanz, J., Gómez-Ullate, Y., Resa, P., Echevarría, F.J., Iglesias, J.R., (2006). Eight-channel ultrasonic device for non-invasive quality evaluation in packed milk. Ultrasonics 45(1-4), 92-99.

Escaramboni, B., Núñez, E.G.F., Carvalho, A.F.A., Neto, P.O., (2018). Ethanol biosynthesis by fast hydrolysis of cassava bagasse using fungal amylases produced in optimized conditions. Industrial Crops and Products 112, 368-377.

Escobar, J.C., Lora, E.S., Venturini, O.J., Yáñez, E.E., Castillo, E.F., Almazan, O., (2009). Biofuels: Environment, technology and food security. Renewable and Sustainable Energy Reviews 13(6-7), 1275-1287.

Falco, B., Incerti, G., Amato, M., Lanzotti, V., (2015). Artichoke: botanical, agronomical, phytochemical, and pharmacological overview. Phytochemistry Reviews 14(6), 993-1018. 
FAO, (2017). Official data of artichoke production. Food and Agriculture Organization of the United Nations.

FAO, (2019). Official data of cassava production. Food and Agriculture Organization of the United Nations.

Fara, L., Stanescu, C., Cincu, C., Racovitza, A., Fara, S., Moraru, A.G., (2012). High efficient bio-ethanol production method to offer competitive alternative spark ignition engine fuelling, in: Mendez-Vilas, A. (Ed.), Fuelling the future: advances in science and technologies for energy generation, transmission and storage. BrownWalker Press, Boca Raton, pp. 52-57.

Femenia, A., Robertson, J.A., Waldron, K.W., Selvendran, R.R., (1998). Cauliflower (Brassica oleracea L), globe artichoke (Cynara scolymus) and chicory witloof (Cichorium intybus) processing by-products as sources of dietary fibre. Journal of the Science of Food and Agriculture 77(4), 511-518.

Fiorda, F.A., Soares-Jr, M.S., da Silva, F.A., Grosmann, M.V.E., Souto, L.R.F., (2013a). Microestructure, texture and colour of gluten-free pasta made with amaranth flour, cassava starch and cassava bagasse. LWT - Food Science and Technology 54(1), 132-138.

Fiorda, F.A., Soares-Jr, M.S.S., Silva, F.A., Souto, L.R.F., Grossmann, M.V.E., (2013b). Farinha de bagaço de mandioca: aproveitamento de subproduto e comparação com fécula de mandioca. Pesquisa Agropecuária Tropical 43(4), 408-416.

Fontana, J.D., Passos, M., Baron, M., Mendes, S.V., Ramos, L.P., (2001). Cassava Starch Maltodextrinization/Monomerization through Thermopressurized Aqueous Phosphoric Acid Hydrolysis, in: Davison, B.H., McMillan, J., Finkelstein, M. (Eds.), Twenty-Second Symposium on Biotechnology for Fuels and Chemicals. Humana Press, Totowa, NJ, pp. 469-478.

Gabhane, J., William, S.P.M.P., Vaidya, A.N., Mahapatra, K., Chakrabarti, T., (2011). Influence of heating source on the efficacy of lignocellulosic pretreatment - A cellulosic ethanol perspective. Biomass and Bioenergy 35(1), 96-102.

Gadhe, J.B., Gupta, R.B., Elder, T., (2006). Surface modification of lignocellulosic fibers using high-frequency ultrasound. Cellulose 13(1), 9. 
Gaikwad, S.G., Pandit, A.B., (2008). Ultrasound emulsification: Effect of ultrasonic and physicochemical properties on dispersed phase volume and droplet size. Ultrasonics Sonochemistry 15(4), 554-563.

Gallego-Juárez, J.A., (1999). Some applications of air-borne power ultrasound to food processing, in: Povey, M.J.W., Mason, T.J. (Eds.), Ultrasound in Food Processing. Chapman \& Hall, Londres, pp. 127-143.

Gámez, S., González-Cabriales, J.J., Ramírez, J.A., Garrote, G., Vázquez, M., (2006). Study of the hydrolysis of sugar cane bagasse using phosphoric acid. Journal of Food Engineering 74(1), 78-88.

Gámez, S., Ramírez, J.A., Garrote, G., Vázquez, M., (2004). Manufacture of Fermentable Sugar Solutions from Sugar Cane Bagasse Hydrolyzed with Phosphoric Acid at Atmospheric Pressure. Journal of Agricultural and Food Chemistry 52(13), 4172-4177.

Gan, T.H., Pallav, P., Hutchins, D.A., (2006). Non-contact ultrasonic quality measurements of food products. Journal of Food Engineering 77(2), 239-247.

García-Cubero, M.T., González-Benito, G., Indacoechea, I., Coca, M., Bolado, S., (2009). Effect of ozonolysis pretreatment on enzymatic digestibility of wheat and rye straw. Bioresource Technology 100(4), 1608-1613.

García-Pérez, J.V., Ozuna, C., Ortuño, C., Cárcel, J.A., Mulet, A., (2011). Modeling Ultrasonically Assisted Convective Drying of Eggplant. Drying Technology 29(13), 1499-1509.

García, A., Alriols, M.G., Labidi, J., (2012). Evaluation of the effect of ultrasound on organosolv black liquor from olive tree pruning residues. Bioresource Technology 108, 155-161.

García, A., Alriols, M.G., Llano-Ponte, R., Labidi, J., (2011). Ultrasound-assisted fractionation of the lignocellulosic material. Bioresource Technology 102(10), 6326-6330.

Gavahian, M., Chen, Y.-M., Khaneghah, A.M., Barba, F.J., Yang, B.B., (2018). Inpack sonication technique for edible emulsions: Understanding the impact of acacia gum and lecithin emulsifiers and ultrasound homogenization on salad dressing emulsions stability. Food Hydrocolloids 83, 79-87. 
Germec, M., Tarhan, K., Yatmaz, E., Tetik, N., Karhan, M., Demirci, A., Turhan, I., (2016). Ultrasound-assisted dilute acid hydrolysis of tea processing waste for production of fermentable sugar. Biotechnology Progress 32(2), 393-403.

Gírio, F.M., Fonseca, C., Carvalheiro, F., Duarte, L.C., Marques, S., Bogel-Łukasik, R., (2010). Hemicelluloses for fuel ethanol: A review. Bioresource Technology 101(13), 4775-4800.

Godoy, O.P., Marcos-Filho, J., Câmara, G.M.S., Fonseca, H., (1982). Tecnologia da produção, Amendoim: produção, pré-processamento e transformação agroindustrial. Secretaria da Indústria, Comércio, Ciência e Tecnologia, São Paulo.

Gogate, P.R., Pandit, A.B., (2008). Application of Cavitational reactors for cell disruption for recovery of intracellular enzymes. Journal of Chemical Technology \& Biotechnology 83(8), 1083-1093.

Gogate, P.R., Sutkar, V.S., Pandit, A.B., (2011). Sonochemical reactors: Important design and scale up considerations with a special emphasis on heterogeneous systems. Chemical Engineering Journal 166(3), 1066-1082.

Gogate, P.R., Wilhelm, A.M., Pandit, A.B., (2003). Some aspects of the design of sonochemical reactors. Ultrasonics Sonochemistry 10(6), 325-330.

Gonçalves, A., R., Schuchardt, U., (2002). Hydrogenolysis of lignins: Influence of the pretreatment using microwave and ultrasound irradiations. Applied Biochemistry and Biotechnology 98-100(1-9), 1211-1219.

Goshadrou, A., Karimi, K., Taherzadeh, M.J., (2011). Bioethanol production from sweet sorghum bagasse by Mucor hiemalis. Industrial Crops and Products 34(1), 1219-1225.

Gullison, R.E., Frumhoff, P.C., Canadell, J.G., Field, C.B., Nepstad, D.C., Hayhoe, K., Avissar, R., Curran, L.M., Friedlingstein, P., Jones, C.D., (2007). Tropical forests and climate policy. Science 316, 985-986.

Harmsen, P.F.H., Huijgen, W., Bermudez, L., Bakker, R., (2010). Literature review of physical and chemical pretreatment processes for lignocellulosic biomass. Wageningen UR Food \& Biobased Research, Wageningen. 
Hodnett, M., Zeqiri, B., (1997). A strategy for the development and standardisation of measurement methods for high power/cavitating ultrasonic fields: review of high power field measurement techniques. Ultrasonics Sonochemistry 4(4), 273-288.

Hosny, D.M., Hudgens, D., Cox, T. (1996). Cavitation Correlation to Fluid Media Properties In Proceedings of the Conference Name|, Conference Location|.

Hou, W., Zhang, L., Zhang, J., Bao, J., (2016). Rheology evolution and CFD modeling of lignocellulose biomass during extremely high solids content pretreatment. Biochemical Engineering Journal 105, 412-419.

Hu, Z., Wen, Z., (2008). Enhancing enzymatic digestibility of switchgrass by microwave-assisted alkali pretreatment. Biochemical Engineering Journal 38(3), 369-378.

Huang, Wei, X., Zhou, S., Liu, M., Tu, Y., Li, A., Chen, P., Wang, Y., Zhang, X., Tai, H., Peng, L., Xia, T., (2015). Steam explosion distinctively enhances biomass enzymatic saccharification of cotton stalks by largely reducing cellulose polymerization degree in $G$. barbadense and $G$. hirsutum. Bioresource Technology 181, 224-230.

Huang, G., Chen, S., Dai, C., Sun, L., Sun, W., Tang, Y., Xiong, F., He, R., Ma, H., (2017). Effects of ultrasound on microbial growth and enzyme activity. Ultrasonics Sonochemistry 37, 144-149.

Huang, Q., Li, L., Fu, X., (2007). Ultrasound Effects on the Structure and Chemical Reactivity of Cornstarch Granules. Starch - Stärke 59(8), 371-378.

Huang, R., Su, R., Qi, W., He, Z., (2011). Bioconversion of Lignocellulose into Bioethanol: Process Intensification and Mechanism Research. BioEnergy Research 4(4), 225-245.

IBGE, (2019). Levantamento Sistemático da Produção Agrícola - LSPA. Ministério do Planejamento, Orçamento e Gestão.

Imai, M., Ikari, K., Suzuki, I., (2004). High-performance hydrolysis of cellulose using mixed cellulase species and ultrasonication pretreatment. Biochemical Engineering Journal 17(2), 79-83.

Iskalieva, A., Yimmou, B.M., Gogate, P.R., Horvath, M., Horvath, P.G., Csoka, L., (2012). Cavitation assisted delignification of wheat straw: A review. Ultrasonics Sonochemistry 19(5), 984-993. 
John, R.P., Nampoothiri, K.M., Pandey, A., (2006). Simultaneous saccharification and fermentation of cassava bagasse for $\mathrm{I}-(+)$-lactic acid production using Lactobacilli. Applied Biochemistry and Biotechnology 134(3), 263-272.

Juliano, P., Trujillo, F.J., Barbosa-Cánovas, G.V., Knoerzer, K., (2011). The Need for Thermophysical Properties in Simulating Emerging Food Processing Technologies, in: Knoerzer, K., Juliano, P., Roupas, P., Versteeg, C. (Eds.), Innovative food processing technologies: advances in multiphysics simulation. Wiley-Blackwell, pp. 26-38.

Karki, B., Lamsal, B.P., Jung, S., van Leeuwen, J., Pometto lii, A.L., Grewell, D., Khanal, S.K., (2010). Enhancing protein and sugar release from defatted soy flakes using ultrasound technology. Journal of Food Engineering 96(2), 270278.

Karki, B., Maurer, D., Jung, S., (2011). Efficiency of pretreatments for optimal enzymatic saccharification of soybean fiber. Bioresource Technology 102(11), 6522-6528.

Kenney, K.L., Smith, W.A., Gresham, G.L., Westover, T.L., (2013). Understanding biomass feedstock variability. Biofuels 4(1), 111-127.

Khanal, S.K., Montalbo, M., van Leeuwen, J., Srinivasan, G., Grewell, D., (2007). Ultrasound enhanced glucose release from corn in ethanol plants. Biotechnology and Bioengineering 98(5), 978-985.

Kim, S., Holtzapple, M.T., (2006). Delignification kinetics of corn stover in lime pretreatment. Bioresource Technology 97(5), 778-785.

Klingenberg, D.J., Root, T.W., Burlawar, S., Scott, C.T., Bourne, K.J., Gleisner, R., Houtman, C., Subramaniam, V., (2017). Rheometry of coarse biomass at high temperature and pressure. Biomass and Bioenergy 99, 69-78.

Kobayashi, T., Chai, X., Fujii, N., (1999). Ultrasound enhanced cross-flow membrane filtration. Separation and Purification Technology 17(1), 31-40.

Krause, D., Schöck, T., Hussein, M.A., Becker, T., (2011). Ultrasonic characterization of aqueous solutions with varying sugar and ethanol content using multivariate regression methods. Journal of Chemometrics 25(4), 216-223. 
Kumar, P., Barrett, D.M., Delwiche, M.J., Stroeve, P., (2009). Methods for Pretreatment of Lignocellulosic Biomass for Efficient Hydrolysis and Biofuel Production. Industrial \& Engineering Chemistry Research 48(8), 3713-3729.

Kuttruff, H., (1988). Physik und Technik des Ultraschalls. S. Hirzel Verlag, Stuttgart. Lenihan, P., Orozco, A., O'Neill, E., Ahmad, M.N.M., Rooney, D.W., Walker, G.M., (2010). Dilute acid hydrolysis of lignocellulosic biomass. Chemical Engineering Journal 156(2), 395-403.

Li, M.-F., Fan, Y.-M., Xu, F., Sun, R.-C., Zhang, X.-L., (2010). Cold sodium hydroxide/urea based pretreatment of bamboo for bioethanol production: Characterization of the cellulose rich fraction. Industrial Crops and Products 32(3), 551-559.

Li, M.-F., Sun, S.-N., Xu, F., Sun, R.-C., (2012). Ultrasound-enhanced extraction of lignin from bamboo (Neosinocalamus affinis): Characterization of the ethanolsoluble fractions. Ultrasonics Sonochemistry 19(2), 243-249.

Liang, H., (1993). Modelling of ultrasound assisted and osmotically induced diffusion in plant tissue. Purdue University, Lafayette, IN.

Liu, P., Zhu, M., Zhang, Z., Leong, Y.-K., Zhang, Y., Zhang, D., (2016). An experimental study of rheological properties and stability characteristics of biochar-glycerol-water slurry fuels. Fuel Processing Technology 153, 37-42.

Lu, C., Zhao, J., Yang, S.-T., Wei, D., (2012). Fed-batch fermentation for n-butanol production from cassava bagasse hydrolysate in a fibrous bed bioreactor with continuous gas stripping. Bioresource Technology 104, 380-387.

Majumdar, S., Kumar, P.S., Pandit, A.B., (1998). Effect of liquid-phase properties on ultrasound intensity and cavitational activity. Ultrasonics Sonochemistry 5(3), 113-118.

Mansfield, S.D., Mooney, C., Saddler, J.N., (1999). Substrate and Enzyme Characteristics that Limit Cellulose Hydrolysis. Biotechnology Progress 15(5), 804-816.

Marangopoulos, I.P., Martin, C.J., Hutchison, J.M.S., (1995). Measurement of field distributions in ultrasonic cleaning baths: implications for cleaning efficiency. Physics in Medicine and Biology 40(11), 1897. 
Margulis, M.A., Margulis, I.M., (2003). Calorimetric method for measurement of acoustic power absorbed in a volume of a liquid. Ultrasonics Sonochemistry 10(6), 343-345.

Margulis, M.A., Maximenko, N.A., (1991). The influence of ultrasound on oscillating reacctions. Appendix: Measurement of ultrasound absorbed power (Calorimetric method), in: Mason, T.J. (Ed.), Advances in Sonochemistry. JAI Press Inc, Londres, pp. 253-291.

Martínez, M.L., Sánchez, S., Bravo, V., (2012). Production of xylitol and ethanol by Hansenula polymorpha from hydrolysates of sunflower stalks with phosphoric acid. Industrial Crops and Products 40(0), 160-166.

Mason, T.J., (1999). Power ultrasound in food processing. The way forward., in: Povey, M.J.W., Mason, T.J. (Eds.), Ultrasound in Food Processing. Chapman \& Hall, Londres, pp. 105-126.

Mason, T.J., Cordemans, E.D., (1996). Ultrasonic intensification of chemical processing and related operations: A review. Chemical Engineering Research \& Design 74(A5), 511-516.

Mason, T.J., Lorimer, J.P., (2002). Applied sonochemistry. Wiley-vch, Weinheim.

McClements, D.J., Gunasekaran, S., (1997). Ultrasonic characterization of foods and drinks: Principles, methods, and applications. Critical Reviews in Food Science and Nutrition 37(1), 1-46.

McMillan, J.D., (1994). Pretreatment of lignocellulosic biomass, in: Himmel, M.E., Baker, J.O., Overend, R.P. (Eds.), Enzymatic conversion of biomass for fuels production. American Chemical Society, Washingtion, D. C., pp. 292-324.

Monroy, Y., Rivero, S., García, M.A., (2018). Microstructural and techno-functional properties of cassava starch modified by ultrasound. Ultrasonics Sonochemistry $42,795-804$.

Montalbo-Lomboy, M., Johnson, L., Khanal, S.K., van Leeuwen, J., Grewell, D., (2010). Sonication of sugary-2 corn: A potential pretreatment to enhance sugar release. Bioresource Technology 101(1), 351-358.

Mood, S.H., Golfeshan, A.H., Tabatabaei, M., Jouzani, G.S., Najafi, G.H., Gholami, M., Ardjmand, M., (2013). Lignocellulosic biomass to bioethanol, a 
comprehensive review with a focus on pretreatment. Renewable and Sustainable Energy Reviews 27(0), 77-93.

Mosier, N., Wyman, C., Dale, B., Elander, R., Lee, Y.Y., Holtzapple, M., Ladisch, M., (2005). Features of promising technologies for pretreatment of lignocellulosic biomass. Bioresource Technology 96(6), 673-686.

Nguyen, D.D., Yoon, Y.S., Nguyen, N.D., Bach, Q.V., Bui, X.T., Chang, S.W., Le, H.S., Guo, W., Ngo, H.H., (2017). Enhanced efficiency for better wastewater sludge hydrolysis conversion through ultrasonic hydrolytic pretreatment. Journal of the Taiwan Institute of Chemical Engineers 71, 244-252.

Nigam, P.S., Singh, A., (2011). Production of liquid biofuels from renewable resources. Progress in Energy and Combustion Science 37(1), 52-68.

Nikolić, S., Mojović, L., Rakin, M., Pejin, D., Pejin, J., (2010). Ultrasound-assisted production of bioethanol by simultaneous saccharification and fermentation of corn meal. Food Chemistry 122(1), 216-222.

Ninomiya, K., Kamide, K., Takahashi, K., Shimizu, N., (2012). Enhanced enzymatic saccharification of kenaf powder after ultrasonic pretreatment in ionic liquids at room temperature. Bioresource Technology 103(1), 259-265.

Nisamaneenate, J., Atong, D., Sornkade, P., Sricharoenchaikul, V., (2015). Fuel gas production from peanut shell waste using a modular downdraft gasifier with the thermal integrated unit. Renewable Energy 79, 45-50.

Nitayavardhana, S., Shrestha, P., Rasmussen, M.L., Lamsal, B.P., van Leeuwen, J., Khanal, S.K., (2010). Ultrasound improved ethanol fermentation from cassava chips in cassava-based ethanol plants. Bioresource Technology 101(8), 27412747.

Palmqvist, E., Hahn-Hägerdal, B., (2000). Fermentation of lignocellulosic hydrolysates. I: inhibition and detoxification. Bioresource Technology 74(1), 1724.

Pandey, A., (2009). Handbook of plant-based biofuels. CRC Press, Boca Raton, FL. Pandey, A., Soccol, C.R., Nigam, P., Soccol, V.T., Vandenberghe, L.P.S., Mohan, R., (2000). Biotechnological potential of agro-industrial residues. II: cassava bagasse. Bioresource Technology 74(1), 81-87. 
Pasquini, D., Teixeira, E.M., Curvelo, A.A.S., Belgacem, M.N., Dufresne, A., (2010). Extraction of cellulose whiskers from cassava bagasse and their applications as reinforcing agent in natural rubber. Industrial Crops and Products 32(3), 486490.

Patero, T., Augusto, P.E.D., (2015). Ultrasound (US) enhances the hydration of sorghum (Sorghum bicolor) grains. Ultrasonics Sonochemistry 23, 11-15.

Polachini, T.C., Carvalho, G.R., Telis-Romero, J., (2017). Determination of acoustic fields in acidic suspensions of peanut shell during pretreatment with highintensity ultrasound. Brazilian Journal of Chemical Engineering 34(2), 385-394.

Polachini, T.C., Sato, A.C.K., Cunha, R.L., Telis-Romero, J., (2016). Density and rheology of acid suspensions of peanut waste in different conditions: An engineering basis for bioethanol production. Powder Technology 294, 168-176.

Povey, M.J.W., (1997). Ultrasonic techniques for fluids characterization. Academic Press, San Diego.

Povey, M.J.W., McClements, D.J., (1988). Ultrasonics in food engineering. Part I: Introduction and experimental methods. Journal of Food Engineering 8(4), 217245.

Prado, F.C., Vandenberghe, L.P.S., Woiciechowski, A.L., Rodrígues-León, J.A., Soccol, C.R., (2005). Citric acid production by solid-state fermentation on a semi-pilot scale using different percentages of treated cassava bagasse. Brazilian Journal of Chemical Engineering 22, 547-555.

Raso, J., Manas, P., Pagan, R., Sala, F.J., (1999). Influence of different factors on the output power transferred into medium by ultrasound. Ultrasonics Sonochemistry 5(4), 157-162.

Recuero, M., (1995). Ingeniería acústica. Paraninfo, Madrid.

Reddy, N., Yang, Y., (2005). Biofibers from agricultural byproducts for industrial applications. Trends in Biotechnology 23(1), 22-27.

Rehman, M.S.U., Kim, I., Chisti, Y., Han, J.-I., (2013). Use of ultrasound in the production of bioethanol from lignocellulosic biomass. Energy Education Science and Technology Part A: Energy Science and Research 30(2), 13911410. 
Roh, N.-S., Shin, D.-H., Kim, D.-C., Kim, J.-D., (1995). Rheological behaviour of coalwater mixtures. 1. Effects of coal type, loading and particle size. Fuel 74(8), 1220-1225.

Romero, I., Moya, M., Sánchez, S., Ruiz, E., Castro, E., Bravo, V., (2007). Ethanolic fermentation of phosphoric acid hydrolysates from olive tree pruning. Industrial Crops and Products 25(2), 160-168.

Saha, B.C., Cotta, M.A., (2006). Ethanol Production from Alkaline Peroxide Pretreated Enzymatically Saccharified Wheat Straw. Biotechnology Progress 22(2), 449-453.

Salem, M.B., Affes, H., Ksouda, K., Dhouibi, R., Sahnoun, Z., Hammami, S., Zeghal, K.M., (2015). Pharmacological Studies of Artichoke Leaf Extract and Their Health Benefits. Plant Foods for Human Nutrition 70(4), 441-453.

Schacht, C., Zetzl, C., Brunner, G., (2008). From plant materials to ethanol by means of supercritical fluid technology. The Journal of Supercritical Fluids 46(3), 299321.

Schell, D.J., Harwood, C., (1994). Milling of lignocellulosic biomass. Applied Biochemistry and Biotechnology 45(1), 159-168.

Servant, G., Laborde, J.L., Hita, A., Caltagirone, J.P., Gérard, A., (2003). On the interaction between ultrasound waves and bubble clouds in mono- and dualfrequency sonoreactors. Ultrasonics Sonochemistry 10(6), 347-355.

Shewale, S.D., Pandit, A.B., (2009). Enzymatic production of glucose from different qualities of grain sorghum and application of ultrasound to enhance the yield. Carbohydrate Research 344(1), 52-60.

Singh, A., Pant, D., Korres, N.E., Nizami, A.-S., Prasad, S., Murphy, J.D., (2010). Key issues in life cycle assessment of ethanol production from lignocellulosic biomass: Challenges and perspectives. Bioresource Technology 101(13), 50035012.

Singh, N., Singh, J., Kaur, L., Singh Sodhi, N., Singh Gill, B., (2003). Morphological, thermal and rheological properties of starches from different botanical sources. Food Chemistry 81(2), 219-231. 
Sulaiman, A.Z., Ajit, A., Yunus, R.M., Chisti, Y., (2011). Ultrasound-assisted fermentation enhances bioethanol productivity. Biochemical Engineering Journal 54(3), 141-150.

Sun, R.-C., Tomkinson, J., (2002). Comparative study of lignins isolated by alkali and ultrasound-assisted alkali extractions from wheat straw. Ultrasonics Sonochemistry 9(2), 85-93.

Sun, R.C., Sun, X.F., Ma, X.H., (2002). Effect of ultrasound on the structural and physiochemical properties of organosolv soluble hemicelluloses from wheat straw. Ultrasonics Sonochemistry 9(2), 95-101.

Sun, Y., Cheng, J., (2002). Hydrolysis of lignocellulosic materials for ethanol production: a review. Bioresource Technology 83(1), 1-11.

Sun, Y., Cheng, J.J., (2005). Dilute acid pretreatment of rye straw and bermudagrass for ethanol production. Bioresource Technology 96(14), 1599-1606.

Tadesse, H., Luque, R., (2011). Advances on biomass pretreatment using ionic liquids: An overview. Energy \& Environmental Science 4, 3913-3929.

Taherzadeh, M., Karimi, K., (2008). Pretreatment of Lignocellulosic Wastes to Improve Ethanol and Biogas Production: A Review. International Journal of Molecular Sciences 9(9), 1621-1651.

Taiz, L., Zeiger, E., (2006). Fisiologia Vegetal (3 ed). Artmed, Porto Alegre.

Teixeira, E.M., Pasquini, D., Curvelo, A.A.S., Corradini, E., Belgacem, M.N., Dufresne, A., (2009). Cassava bagasse cellulose nanofibrils reinforced thermoplastic cassava starch. Carbohydrate Polymers 78(3), 422-431.

Tian, Y., Xu, Z., Zheng, B., Lo, Y.M., (2013). Optimization of ultrasonic-assisted extraction of pomegranate (Punica granatum L.) seed oil. Ultrasonics Sonochemistry 20(1), 202-208.

Tizazu, B.Z., Moholkar, V.S., (2018). Kinetic and thermodynamic analysis of dilute acid hydrolysis of sugarcane bagasse. Bioresource Technology 250, 197-203.

Tye, Y.Y., Lee, K.T., Abdullah, W.N.W., Leh, C.P., (2016). The world availability of non-wood lignocellulosic biomass for the production of cellulosic ethanol and potential pretreatments for the enhancement of enzymatic saccharification. Renewable and Sustainable Energy Reviews 60, 155-172. 
Velmurugan, R., Muthukumar, K., (2011). Utilization of sugarcane bagasse for bioethanol production: Sono-assisted acid hydrolysis approach. Bioresource Technology 102(14), 7119-7123.

Velmurugan, R., Muthukumar, K., (2012). Ultrasound-assisted alkaline pretreatment of sugarcane bagasse for fermentable sugar production: Optimization through response surface methodology. Bioresource Technology 112, 293-299.

Vidal, P.F., Molinier, J., (1988). Ozonolysis of lignin - Improvement of in vitro digestibility of poplar sawdust. Biomass 16(1), 1-17.

Villa-Vélez, H.A., Váquiro, H.A., Telis-Romero, J., (2015). The effect of powerultrasound on the pretreatment of acidified aqueous solutions of banana flowerstalk: Structural, chemical and statistical analysis. Industrial Crops and Products 66(0), 52-61.

Wingren, A., Galbe, M., Zacchi, G., (2003). Techno-Economic Evaluation of Producing Ethanol from Softwood: Comparison of SSF and SHF and Identification of Bottlenecks. Biotechnology Progress 19(4), 1109-1117.

Woiciechowski, A.L., Soccol, C.R., Rocha, S.N., Pandey, A., (2004). Xanthan gum production from cassava bagasse hydrolysate with Xanthomonas campestris using alternative sources of nitrogen. Applied Biochemistry and Biotechnology 118(1), 305-312.

Wyman, C.E., Dale, B.E., Elander, R.T., Holtzapple, M., Ladisch, M.R., Lee, Y.Y., (2005). Coordinated development of leading biomass pretreatment technologies. Bioresource Technology 96(18), 1959-1966.

Yang, F., Li, L., Li, Q., Tan, W., Liu, W., Xian, M., (2010). Enhancement of enzymatic in situ saccharification of cellulose in aqueous-ionic liquid media by ultrasonic intensification. Carbohydrate Polymers 81(2), 311-316.

Yang, W., Ajapur, V.K., Krishnamurthy, K., Feng, H., Yang, R., Rababah, T.M., (2009). Expedited extraction of xylan from corncob by power ultrasound. International Journal of Agricultural and Biological Engineering 2(4), 76-83.

Yin, X., Han, P., Lu, X., Wang, Y., (2004). A review on the dewaterability of biosludge and ultrasound pretreatment. Ultrasonics Sonochemistry 11(6), 337-348. 
Yu, J., Zhang, J., He, J., Liu, Z., Yu, Z., (2009). Combinations of mild physical or chemical pretreatment with biological pretreatment for enzymatic hydrolysis of rice hull. Bioresource Technology 100(2), 903-908.

Yunus, R., Salleh, S.F., Abdullah, N., Biak, D.R.A., (2010). Effect of ultrasonic pretreatment on low temperature acid hydrolysis of oil palm empty fruit bunch. Bioresource Technology 101(24), 9792-9796.

Zhang, M., Xie, L., Yin, Z., Khanal, S.K., Zhou, Q., (2016). Biorefinery approach for cassava-based industrial wastes: Current status and opportunities. Bioresource Technology 215, 50-62.

Zhang, Y.Q., Fu, E.H., Liang, J.H., (2008). Effect of Ultrasonic Waves on the Saccharification Processes of Lignocellulose. Chemical Engineering \& Technology 31(10), 1510-1515.

Zhao, X., Cheng, K., Liu, D., (2009). Organosolv pretreatment of lignocellulosic biomass for enzymatic hydrolysis. Applied Microbiology and Biotechnology 82(5), 815.

Zheng, Y., Lin, H.-M., Wen, J., Cao, N., Yu, X., Tsao, G.T., (1995). Supercritical carbon dioxide explosion as a pretreatment for cellulose hydrolysis. Biotechnology Letters 17(8), 845-850.

Zhu, J.Y., Wang, G.S., Pan, X.J., Gleisner, R., (2009). Specific surface to evaluate the efficiencies of milling and pretreatment of wood for enzymatic saccharification. Chemical Engineering Science 64(3), 474-485.

Zhu, M., Zhang, Z., Liu, P., Zhang, D., (2018). Rheological Properties and Ignition and Combustion Characteristics of Biochar-Algae-Water Slurry Fuels. Journal of Energy Resources Technology 140(6), 062203-062203-062206.

Zhu, S., Wu, Y., Yu, Z., Liao, J., Zhang, Y., (2005). Pretreatment by microwave/alkali of rice straw and its enzymic hydrolysis. Process Biochemistry 40(9), 30823086.

Zhu, S., Wu, Y., Yu, Z., Wang, C., Yu, F., Jin, S., Ding, Y., Chi, R., Liao, J., Zhang, Y., (2006). Comparison of Three Microwave/Chemical Pretreatment Processes for Enzymatic Hydrolysis of Rice Straw. Biosystems Engineering 93(3), 279283. 